\author{
Universidade de São Paulo \\ Faculdade de Filosofia, Letras e Ciências Humanas \\ Departamento de Lingüística \\ Programa de Pós-Graduação em Semiótica e Lingüística Geral
}

\title{
Performance de Crianças Falantes do Português Brasileiro no \\ Test of Early Language Development (TELD-3)
}

ELISABETE GIUSTI

Orientadora: Profa. Dra. Débora Maria Befi-Lopes

São Paulo 


\author{
Universidade de São Paulo \\ Faculdade de Filosofia, Letras e Ciências Humanas \\ Departamento de Lingüística \\ Programa de Pós-Graduação em Semiótica e Lingüística Geral
}

\title{
Performance de Crianças Falantes do Português Brasileiro no Test of Early Language Development (TELD-3)
}

\section{ELISABETE GIUSTI}

Tese apresentada ao Programa de Pós-
Graduação em Lingüística, Área de
Concentração em Semiótica e Lingüística
Geral, do Departamento de Lingüística da
Faculdade de Filosofia, Letras e Ciências
Humanas da Universidade de São Paulo,
para obtenção do Título de Doutor em
Lingüística.

Orientadora: Prof. Dra. Débora Maria Befi-Lopes

São Paulo 
Esta Tese, em sua forma, foi elaborada de acordo com: Diretrizes para apresentação de dissertações e teses da USP: documento eletrônico e impresso/ Vânia M. B. de Oliveira Funaro, coord. ...[et al.].-- São Paulo: SIBi - USP, 2004. 110 p. -- (Cadernos de Estudos; 9). 


\section{AGRADECIMENTOS}

Após a conclusão deste trabalho, não poderia deixar de agradecer a todos que de alguma forma contribuíram para sua execução:

À Professora Dra. Débora Maria Befi-Lopes - por ter me aceitado como orientanda e por todos os ensinamentos passados durante este processo. Pela paciência e por ter acreditado no meu potencial para a realização deste trabalho. Obrigada por ter me ajudado a concretizar um grande sonho.

Aos meus pais Yolanda e Octávio - pelo imenso amor e pelos constantes ensinamentos que sempre me passam. Obrigada pelo apoio de sempre.

À minha irmã Regina - pelo seu grande exemplo de determinação e por me ensinar que com dedicação e competência, podemos transformar nossos sonhos em realidade. Obrigada por sempre estar ao meu lado.

Ao Egeu - meu namorado e grande companheiro. Obrigada por compartilhar comigo todos os dias, os ensinamentos que a vida nos propõe, em todos os sentidos. Obrigada pela paciência e por compreender o significado deste trabalho na minha vida.

À Professora Dra. Claúdia Regina Furquim de Andrade - minha admiração e meu agradecimento pela sua competência e pela sua busca constante em transformar e estabelecer a Fonoaudiologia como Ciência, pelo seu forte exemplo de sabedoria e desprendimento.

À Professora Dra. Suelly Limongi - pelas importantes contribuições no exame de qualificação e por dispôr de seus conhecimentos, de forma competente e compreensivel. Pela segurança e pelo apoio que me passou durante o exame de qualificação. 
Aos professores do Curso de Fonoaudiologia da Unesp - Campus de Marília pela formação profissional que me propuseram. Em especial, à Profa. Dra. Celia Giachetti, por ter me ensinado de forma tão competente e por ter me ajudado a desenvolver o "raciocínio diagnóstico".

À amiga Noemi Takiuchi - pela ajuda, pela força que sempre me deu, desde que ingressei na USP e por ter passado seu conhecimento e sua experiência, de uma forma tão competente, todas às vezes que precisei.

Às minhas grandes amigas - Lidiane e Paula pela eterna amizade, por compartilharem dos meus sonhos e por estarem sempre ao meu lado, nos momentos que precisei.

Às minhas amigas do LIF - Amália, Karina, Marina e Juliana por participarem e compartilharem deste processo;

Ao Presidente e aos Diretores da APAE - Limeira por terem compreendido a importância da realização deste trabalho, cedendo-me o tempo exigido para sua conclusão.

Ao Centro de Estatística Aplicada da Universidade de São Paulo, em especial, às Professoras Doutoras Denise Botter e Mônica Carneiro Sandoval e aos alunos Fernando, Paulo e Cristina pela análise estatística deste trabalho;

Aos Autores do TELD-3 - Professores Doutores Wayne Hresko, D. Kim Reid e Donald D. Hammill e à Editora PRO-ED por terem autorizado a utilização deste Teste para as finalidades desta pesquisa.

Às diretoras, coordenadoras e professoras do Centro Infantil "Murilo Lemos" e da Escola Municipal de Educação Infantil e Fundamental "Preparando para o Futuro", em especial, às crianças e pais voluntários - pela disponibilidade e por terem concedido a autorização para a participação nesta pesquisa. 
Ao Departamento de Fisioterapia, Fonoaudiologia e Terapia Ocupacional da Faculdade de Medicina e ao Departamento de Lingüística da Faculdade de Filosofia, Letras e Ciências Humanas da USP que consentiram a realização deste trabalho;

À Valéria Arcari Muhi, que tão prontamente, aceitou realizar a revisão de Língua Portuguesa desta Tese;

A Deus, pelas maravilhosas oportunidades que me foram dadas e por colocar em minha vida, pessoas tão especiais e amadas, que me deram todo o apoio e suporte para que pudesse chegar até aqui. 
"Um profissional competente utilizará os testes de forma apropriada, com profissionalismo e respeito pela ética, dando a devida atenção às necessidades e direitos de todas as partes envolvidas no processo de avaliação, às razões que determinaram a aplicação dos testes e ao contexto alargado em que a avaliação tem lugar" 
GIUSTI, Elisabete. Perfomance de crianças falantes do Português Brasileiro no Test of Early Language Development - (TELD-3). 2007. 181f. Tese (Doutorado em Semiótica e Lingüística Geral) - Faculdade de Filosofia, Letras e Ciências Humanas da Universidade de São Paulo, São Paulo.

\section{RESUMO}

Diversos procedimentos são indicados para avaliar 0 desenvolvimento da linguagem na infância. Apesar da diversidade encontrada, pesquisadores da área são unânimes em afirmar a necessidade de usar testes formais e objetivos. No Brasil, faltam testes para esta finalidade. $O$ objetivo geral desta Tese foi verificar a performance de crianças típicas falantes do Português Brasileiro no Test of Early Language Development - 3 (TELD-3, de Hresko, Reid e Hammill, 1999). Participaram deste estudo 120 crianças, com faixa etária entre 2:00 anos a 7:11 anos, sendo 20 sujeitos por faixa etária (10 do sexo masculino e 10 do sexo feminino). Esta tese foi dividida em três estudos. No Estudo I foi apresentada a tradução do TELD-3 para o Português Brasileiro e os resultados obtidos indicaram que os procedimentos adotados na tradução do teste mantiveram sua equivalência com a versão original, indicando que não houve mudanças significativas no conteúdo e formato do teste, aspecto importante em pesquisas deste tipo. No Estudo II foi analisada a performance dos sujeitos típicos falantes do Português Brasileiro no teste. Os resultados indicaram que a performance foi compatível com a média esperada para todas as faixas etárias, exceto para o grupo de sujeitos de $5 \mathrm{e}$ 6 anos, no subteste expressivo da forma $B$, que foram classificados como "abaixo da média". Além disso, observou-se que as formas $A$ e $B$ do teste não foram equivalentes para todas as faixas etárias e houve um aumento nos valores dos escores brutos com o aumento da idade cronológica.

No Estudo III foi realizada uma análise comparativa entre a performance dos sujeitos falantes do Português (Brasil) e os sujeitos falantes do Inglês (EUA) no referido Teste. Os resultados indicaram que a performance dos dois grupos de sujeitos foi equivalente para a idade até $4: 11$ anos. Os sujeitos de 5, 6 e 7 anos, falantes do Português obtiveram pontuação mais alta no subteste receptivo da Forma $A$ do teste e o no subteste expressivo da Forma B, os sujeitos de 5 e 6 anos obtiveram pontuação mais baixa do que os sujeitos falantes do Inglês. 
Como conclusão, os resultados dos estudos apresentados, parecem indicar que a versão traduzida para o Português Brasileiro do TELD-3 mostrou-se sensível para caracterizar a performance de linguagem da população estudada. Futuras pesquisas relacionadas à sensibilidade e especificidade do teste são necessárias.

Palavras-chave: Fonoaudiologia; Tradução (Processo); Testes de Linguagem; Linguagem Infantil; Avaliação; 
GIUSTI, Elisabete. Performance of Brazilian Portuguese-speaking children in the Test of Early Language Development - (TELD-3). 2007. 181f. Thesis (Doctorate in Semiotics and General Linguistics) - Faculty of Humanities of the University of São Paulo, São Paulo.

\section{ABSTRACT}

Many procedures are indicated to assess language development during childhood. Besides the diversity found, researchers of the area are unanimous in affirming the need to use formal and objective tests. In Brazil, there's a lack of tests with this proposal. The main objective of this thesis was to verify the performance of typical Brazilian Portuguese-speaking children at the Test of Early Language Development-3 (TELD-3, Hresko, Reid and Hammill, 1999). Participated in this study 120 children, with ages between 2:0 and 7:11 years, distributed in age groups of 20 subjects each (10 male and 10 female). The thesis was divided in three studies. In Study I the Brazilian Portuguese translation of the TELD-3 was presented and the results obtained showed that the adopted procedures during the translation of the aforementioned test kept its equivalence with the original version, indicating no significant changes in content and format of the test, an important aspect for researches of this type. In Study II the performance of typical Brazilian Portuguesespeaking subjects on the test was analyzed. Results showed that the performance was compatible with the expected mean in all age groups, except for the five- and six-year-old subjects on the expressive subtest of the Form $B$, that were classified as "below mean". Besides, it was observed that the Forms A and B of the test were not equivalent among all age groups and there was an increase in the rough score values with the increase of chronological age. In Study III it was carried out a comparative analysis between the performances of English-speaking (USA) and Portuguese-speaking (Brazil) subjects in the aforementioned test. Results indicated that the groups had equivalent performances until the age of 4:11 years. Five-, sixand seven-year-old Portuguese-speaking subjects had higher scores on the receptive subtest of the Form $A$ and on the expressive subtest of the Form $B$, and five- and six-year-olds had lower general scores than English-speaking subjects. As a conclusion, the results of the presented studies, taken together, seem to indicate that the Brazilian Portuguese version of the TELD-3 is sensitive to characterize the 
language performance of the studied population. Further researches are necessary regarding the sensitivity and specificity of the test.

Keywords: Speech, Language and Hearing Sciences; Translating; Language Tests; Child Language; Evaluation; 


\section{SUMÁRIO}

\section{RESUMO}

\section{ABSTRACT}

ÍNDICE DE ANEXOS

ÍNDICE DE GRÁFICOS

INDICE DE QUADROS

INDICE DE TABELAS

APRESENTAÇÃO

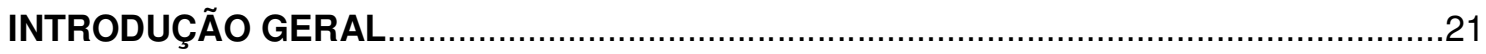

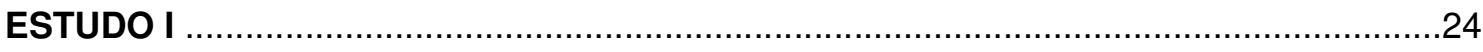

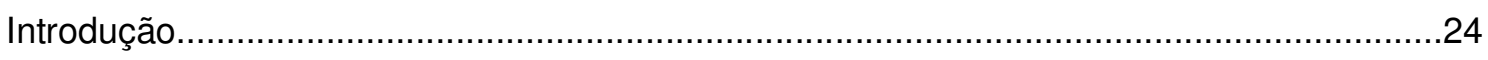

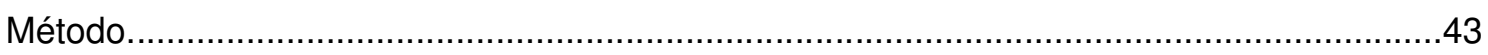

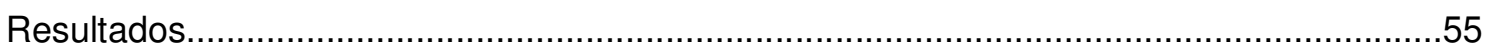

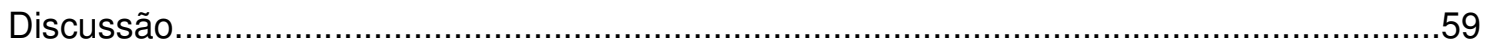

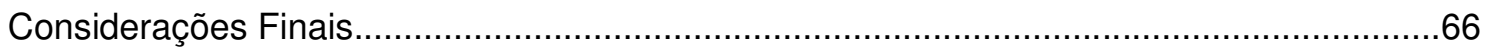

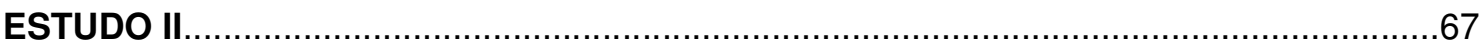

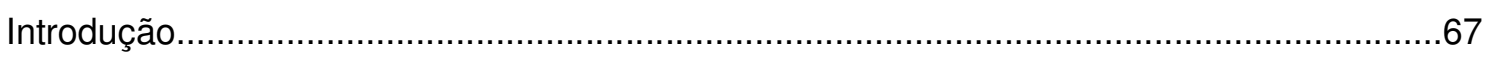

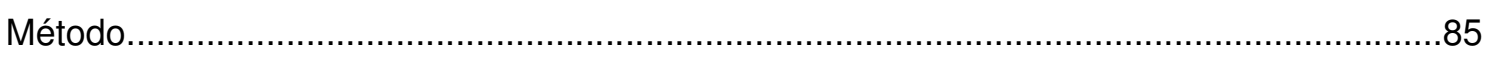

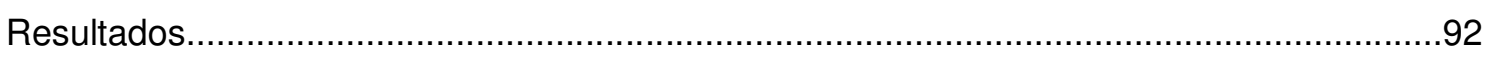

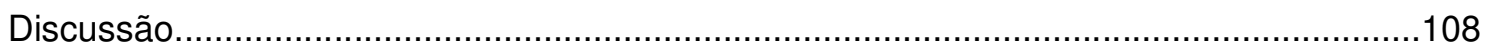

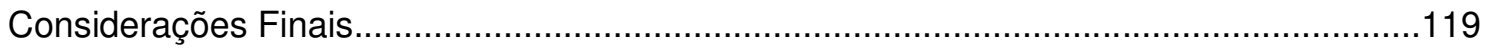

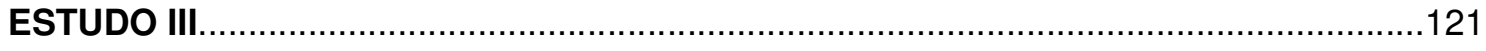

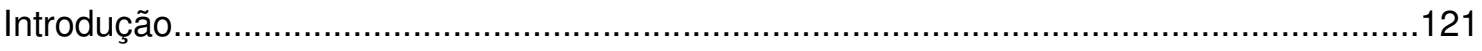

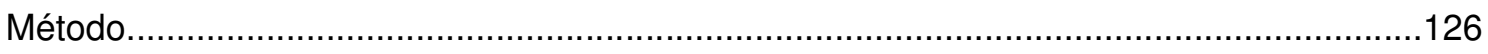

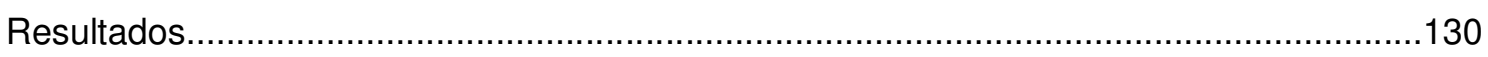

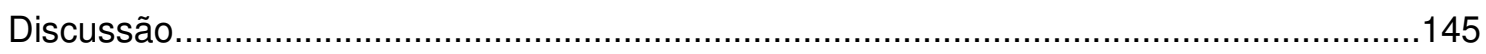

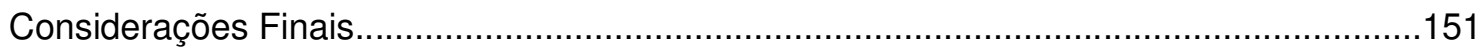

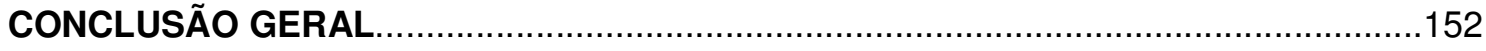

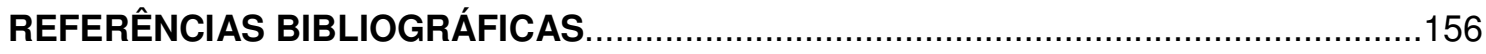

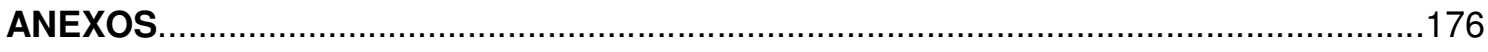




\section{ÍNDICE DE ANEXOS}

ANEXO A - Parecer da Comissão de Ética.......................................................175

ANEXO B - Autorização do Autor para Utilização do Teste...................................176

ANEXO C - Autorização da Editora para Utilização do Teste...............................177

ANEXO D - Protocolo de Resposta - Forma A ……......................................178

ANEXO E - Protocolo de Resposta - Forma B ............................................179

ANEXO F - Termo de Consentimento Livre e Esclarecido....................................180

ANEXO G - Análise Estatística - Análise de Regressão.....................................181 


\section{ÍNDICE DE GRÁFICOS}

\section{Estudo II}

Gráfico 01: Dispersão de Escore Bruto Receptivo X Idade com a curva de referência americana

Gráfico 02: Dispersão de Escore Bruto Expressivo $X$ Idade com a curva de referência americana. 101

Gráfico 03: Distribuição Percentual da Variável Classificação do Quociente Receptivo para as Formas A e B do teste. 102

Gráfico 04: Distribuição Percentual da Variável Classificação do Quociente Expressivo para as Formas A e B do teste. 103

Gráfico 05: Distribuição Percentual da Variável Classificação do Quociente de Linguagem Falada para as Formas A e B do teste. .104

Gráfico 06: Curva de Referência para o Escore Bruto Receptivo na Forma A.......105

Gráfico 07: Curva de Referência para o Escore Bruto Receptivo na Forma B.......106

Gráfico 08: Curva de Referência para o Escore Bruto Expressivo na Forma A.....107

Gráfico 09: Curva de Referência para o Escore Bruto Expressivo na Forma B....108 


\section{Estudo III}

Gráfico 01: Dispersão do Escore Bruto Receptivo X Idade com a curva de referência americana.

Gráfico 02: Dispersão do Escore Bruto Expressivo $X$ Idade com a curva de referência americana.

Gráfico 03: Curva de regressão ajustada com intervalo de 95\% para média do Escore Bruto Receptivo na Forma A e curva de referência americana 134

Gráfico 04: Curva de regressão ajustada com intervalo de 95\% para média do Escore Bruto Receptivo na Forma B e curva de referência americana 135

Gráfico 05: Curva de regressão ajustada com intervalo de 95\% para média do Escore Bruto Expressivo na Forma A e curva de referência americana. 136

Gráfico 06: Curva de regressão ajustada com intervalo de 95\% para média do Escore Bruto Expressivo na Forma B e curva de referência americana 137

Gráfico 07: Dispersão Idade X Idade Equivalente Receptiva com a reta de referência americana. 138

Gráfico 08: Dispersão Idade $X$ Idade Equivalente Expressiva com a reta de referência americana. 139 


\section{INDICE DE QUADROS}

\section{Estudo I}

Quadro 01: Relação dos Subtestes do TELD-3 com outros testes de

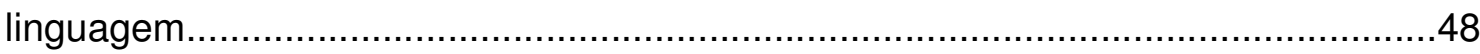

Quadro 02: Itens para Início do teste.................................................................

Quadro 03: Classificação dos Quocientes....................................................52

\section{Estudo II}

Quadro 01: Classificação dos Quocientes.................................................90

\section{Estudo III}

Quadro 01: Média dos Valores do Escore Bruto Receptivo por Faixa Etária..........131

Quadro 02: Média dos Valores do Escore Bruto Expressivo por Faixa Etária........133

Quadro 03: Distribuição da Classificação Geral obtida pelos sujeitos no Teste.....140

Quadro 04: Itens com indice de $70 \%$ ou mais de Erros - Forma A......................141

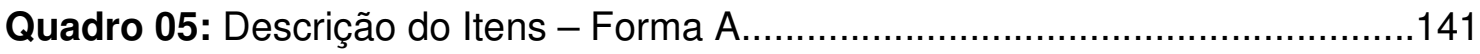

Quadro 06: Itens com indice de $70 \%$ ou mais de Erros - Forma A......................142

Quadro 07: Descrição dos Itens - Forma B...........................................143 


\section{INDICE DE TABELAS}

\section{Estudo II}

Tabela 01: Medidas descritivas para a Variável Escore Bruto na Faixa Etária 2 anos.

Tabela 02: Medidas descritivas para a Variável Quociente na Faixa Etária 2 anos.

Tabela 03: Medidas descritivas para a Variável Escore Bruto na Faixa Etária 3 anos.

Tabela 04: Medidas descritivas para a Variável Quociente na Faixa Etária 3 anos..94

Tabela 05: Medidas descritivas para a Variável Escore Bruto na Faixa Etária 4 anos.

Tabela 06: Medidas descritivas para a Variável Quociente na Faixa Etária 4 anos..94

Tabela 07: Medidas descritivas para a Variável Escore Bruto na Faixa Etária 5 anos

Tabela 08: Medidas descritivas para a Variável Quociente na Faixa Etária 5 anos..95

Tabela 09: Medidas descritivas para a Variável Escore Bruto na Faixa Etária 6 anos.

Tabela 10: Medidas descritivas para a Variável Quociente na Faixa Etária 6 anos..95

Tabela 11: Medidas descritivas para a Variável Escore Bruto na Faixa Etária 7 anos.

Tabela 12: Medidas descritivas para a Variável Quociente na Faixa Etária 7 anos..96

Tabela 13: Níveis descritivos dos testes para verificar igualdade entre as formas $A$ e $\mathrm{B}$ 
ESTUDO I - Tradução do Test of Early Language Development (TELD-3) para o Português Brasileiro 


\section{I - Introdução}

\section{1 - Avaliação da Linguagem Infantil}

Avaliar é o processo de coletar informações válidas e confiáveis, integrandoas e interpretando-as para fazer um julgamento ou tomar uma decisão. Para garantir a eficácia de uma avaliação cinco princípios são importantes: a avaliação deve ser minuciosa, é importante usar uma variedade de procedimentos para obter as informações necessárias (como história clinica, testes formais e informais, observações em situações naturais, etc), ser válida, ser confiável e deve ser elaborada especificamente para cada cliente (Shipley e McAfee, 2004).

Miller (1986) destaca que apesar da natureza ambígua da tarefa de avaliar a linguagem, tal tarefa deve ser vista com decisão, buscando sempre o melhor procedimento possível para avaliar as condutas lingüísticas infantis.

Reed (1994) e Befi-Lopes (2003), destacam que o processo de avaliação e diagnóstico é o primeiro passo para a intervenção com crianças com Alterações de Linguagem. As informações obtidas neste processo devem ser usadas para definição da necessidade, ou não, de intervenção e também para fornecer direções para o tratamento.

É possível listar alguns objetivos do processo de avaliação e diagnóstico com crianças com suspeita de alterações de linguagem (Bloom e Lahey, 1978; Lahey, 1990; Boone e Plante, 1994, Plante e Vance, 1994; Reed, 1994; Merrel e Plante, 1997; Hresko, Reid e Hammill, 1999; Paul, 2001; Befi-Lopes, 2003, Shipley e McAfee, 2004):

1.) Determinar se a criança apresenta, ou não, alguma alteração de linguagem:

Anterior ao processo de avaliação de linguagem, por meio do qual se procura estabelecer a natureza da alteração, as habilidades alteradas e o processo de intervenção indicado, existe o processo de identificação, que tem a finalidade de confirmar ou não a hipótese de alteração levantada por alguém que acompanha o 
desenvolvimento da criança, podendo ser os pais, professores, médicos ou cuidadores (Lahey, 1990).

Alguns autores destacam que o processo de identificação da alteração é caracterizado por controvérsias relacionadas a alguns fatores como: os conceitos de linguagem e de desordem de linguagem não são muito bem estabelecidos, devido à variação individual no desenvolvimento da linguagem, dificultando o estabelecimento de um padrão e também devido à grande heterogeneidade que caracteriza a população que apresenta alteração (Lahey, 1990; Boone e Plante, 1994; Reed, 1994; Watkins, 1994).

Os procedimentos de identificação devem envolver a exploração da performance da criança em uma variedade de tarefas de linguagem em situações diversas, em contextos diferentes. Os relatos dos pais e/ou cuidadores também são instrumentos importantes para identificar a presença ou ausência de uma alteração. O levantamento de predições para uma possível alteração é igualmente importante. Alguns fatores de risco podem ser considerados: possíveis déficits nas habilidades de socialização, intenção comunicativa reduzida, características do balbucio (diminuído ou com predomínio de vogais), inabilidade em usar gestos simbólicos, dificuldades fonológicas, predominando sílabas com menos complexidade e poucas consoantes em seu repertório (Reed, 1994).

2.) Identificar a causa do problema. Refere-se à discussão sobre a etiologia. Informações sobre o histórico da criança, obtida com os responsáveis e/ou cuidadores, relatos de outros profissionais, associados às informações obtidas durante a avaliação, são formas de atingir este objetivo. Em algumas situações, é possível identificar os fatores mantenedores e que estão contribuindo para a dificuldade, ao invés de uma causa correlata e estes fatores são importantes para o processo de intervenção, na medida que se torna possível a realização de condutas e orientações que podem contribuir para o processo de reabilitação.

3.) Identificar as áreas que estão deficitárias. Determinar os parâmetros de linguagem que podem estar deficientes na criança e o modo - compreensão e/ou produção, no qual os déficits ocorrem. Testagens padronizadas e não padronizadas 
e a observação da performance da criança em todos os parâmetros de linguagem ajudam a atingir este objetivo. A identificação de áreas específicas que apresentam déficits deve auxiliar no direcionamento das condutas terapêuticas.

4.) Descrever as regularidades no comportamento de linguagem da criança. Este objetivo pode ser atingido por meio de informações descritivas, de cada uma das habilidades lingüísticas da criança. Esta descrição pode conter parâmetros presentes e ausentes e isto pode auxiliar na efetividade do plano terapêutico.

5.) Decidir o que pode ser recomendado à criança. É a etapa do processo que tem a finalidade de decidir se a criança necessita ou não de intervenção. Decidir se a criança pode ou não se beneficiar da intervenção. Se sim, cabe decidir que forma, direta ou indireta, decidir qual o melhor local para atendimento e levantar a necessidade de encaminhamentos a outros profissionais. Este último objetivo, deriva dos quatro anteriores.

A avaliação de crianças com suspeita de alteração no desenvolvimento da linguagem deve determinar os parâmetros de linguagem que podem estar deficientes, ou seja, há a necessidade de discriminar as habilidades receptivas e expressivas e quais os componentes lingüísticos alterados, para que o diagnóstico possa ser melhor definido (Watkins, 1994; Plante e Vance, 1994; Rice, 1997; TagerFlusberg e Cooper, 1999; Paul, 2001; Befi-Lopes, 2002, 2003).

Para que os objetivos do processo de avaliação e diagnóstico possam ser atingidos é necessária a utilização de instrumentos e procedimentos adequados para a verificação dos padrões de linguagem da criança em questão. Estes instrumentos devem atender às reais condições de faixa etária e possibilidade de linguagem, bem como devem propiciar o melhor acesso ao potencial lingüístico da criança (Befi-Lopes, 2002). 


\section{2 - Uso de instrumentos formais para avaliar a linguagem infantil}

$\mathrm{Na}$ literatura existe referência quanto aos procedimentos usuais utilizados na avaliação do desenvolvimento da linguagem infantil. Estes procedimentos variam de acordo com a literatura consultada, alguns autores referem que esta avaliação deve ser feita em situações naturais, com amostras espontâneas de fala, outros em situações formais, outros sugerem o uso de protocolos específicos. No entanto, embora haja essa diversidade de procedimentos, a orientação quanto ao uso de testes formais e objetivos para avaliar a linguagem em crianças é unânime entre os autores (Bloom e Lahey, 1978; Stark e Tallal, 1981; Bishop, 1992; Reed, 1994; Watkins e DeThorne, 2000, Paul, 2001; Correa, Freitas e Lima, 2003; Andrade et al, 2004; Scheuer, 2006).

Os autores afirmam que para avaliar a linguagem infantil há a necessidade de utilizar vários testes e que a identificação das alterações deve ser realizada por meio de um sistema padronizado. O diagnóstico de possíveis alterações no desenvolvimento da linguagem deve identificar aspectos comprometidos e para isso existe a indicação de testes padronizados (Stark e Tallal, 1981; McCauley e Swisher, 1984; Lahey, 1990; Watkins, 1994; Watkins et al, 1995; Rice , 1997; Hresko, Reid e Hammill, 1999; Law, 2001; Befi-Lopes, 2002, Correa, Freitas e Lima, 2003; Castro-Rebolledo et al, 2004; Andrade e Juste, 2005; Broggio, 2005).

Os testes devem investigar habilidades receptivas e expressivas da linguagem, devem promover informações normativas que possibilitem comparações entre as diferentes idades e com a normalidade. Além disso, devem indicar as habilidades e dificuldades das crianças testadas e serem administrados em um período curto de tempo, de modo a evitar fadiga da criança ou do examinador (Hresko, Reid e Hammill, 1999). Os mesmos autores acrescentam que os testes além de indicarem as habilidades e dificuldades da criança, também podem ser usados como parâmetro de evolução durante o processo de reabilitação e também podem ser utilizados como instrumentos de pesquisas científicas. 
Os instrumentos utilizados para avaliar a linguagem infantil devem relacionar o desempenho das habilidades de linguagem da criança às teorias existentes e aos modelos descritivos do conhecimento lingüístico infantil, o que é fundamental para a precisão diagnóstica (Stark e Tallal, 1981; Lahey, 1990; Watkins, 1994; Watkins et al, 1995; Rice, 1997).

Para Stark e Tallal (1981), os sistemas de diagnóstico incluem, geralmente, a avaliação do vocabulário, da sintaxe e da narrativa como os aspectos primários da avaliação. A fonologia deve ser analisada para distinção entre as desordens puramente fonológicas e as alterações mais amplas de linguagem. A pragmática também é incluída por alguns autores, mas outros a descartam pela dificuldade metodológica de análise. As autoras referem que para a seleção de crianças que preenchem os critérios diagnósticos para o Distúrbio Específico de Linguagem, por exemplo, é necessário o uso de diferentes testes que avaliem as habilidades receptivas e expressivas de linguagem.

Boone e Plante (1994), referem que nos Estados Unidos, profissionais da área de Fonoaudiologia dispõem de um amplo conjunto de testes e medidas formais para testar as habilidades de linguagem. Quando um teste é selecionado para compôr uma bateria de avaliação, alguns pontos devem ser considerados: o primeiro é qual aspecto da linguagem o teste examina, pois algumas medidas são específicas e examinam apenas um aspecto, como por exemplo o Peabody Picture Vocabulary Test, que verifica apenas o vocabulário ou por exemplo o Token Test for Children que examina a capacidade da criança de seguir instruções verbais de complexidade lingüística crescente. O fonoaudiólogo deve selecionar uma combinação de medidas adequadas para investigar, de forma efetiva, as suspeitas de dificuldades da criança.

A afirmação de Boone e Plante (1994) de que nos Estados Unidos existe um amplo conjunto de testes para avaliar a linguagem infantil, pode ser confirmada quando consultado o Directory os Speech-Language Pathology Assessment Instruments (Edição 2006), da American Speech-Language-Hearing Association (ASHA). Neste diretório consta uma relação de todos os instrumentos de avaliação disponíveis para avaliação da fala e linguagem no país. 
Bloom e Lahey, 1978; Boone e Plante, 1994; Paul, 2001; Shipley e McAfee, 2004; descrevem alguns tipos de instrumentos formais de avaliação:

1.) uso de procedimentos de screening ou de triagem;

2.) testes que avaliem 0 desenvolvimento precoce de linguagem (testes de identificação precoce);

3.) testes que avaliem aspectos ou componentes lingüísticos específicos.

Os procedimentos de screening são geralmente superficiais e são designados para atender a um grande número de crianças em um período curto de tempo. Os autores alertam quanto à necessidade de se ater aos resultados falsos positivos. Para determinar se a criança apresenta ou não alguma alteração é necessário identificar se o que a criança está demonstrando em termos de comportamentos de linguagem, desviam daqueles comportamentos observados em crianças com desenvolvimento típico (Reed, 1994).

As medidas de triagem são testes geralmente curtos e que verificam uma variedade de habilidades de linguagem, com o propósito de identificar crianças que apresentam problemas. Comercialmente, nos Estados Unidos, existem vários testes com esta finalidade, dentre os quais podemos citar: CELF-3 Screening Test, Kindergarten Language Screening Test, Denver Development Screening Test II, etc (Boone e Plante, 1994; Law, 2001; Shipley e McAfee, 2004).

Os testes que visam identificação precoce são indicados para crianças que estão em processo de desenvolvimento e investigam aspectos mais genéricos deste desenvolvimento e não se atém às habilidades mais específicas ou secundárias de linguagem. Estes testes ajudam identificar aquelas crianças que necessitam dar continuidade ao processo avaliativo, ou seja, discriminam crianças típicas daquelas com suspeita de alterações. Dentre os testes voltados para esta finalidade podemos citar: Early Language Milestone Scale, Test of Early Language Development (TELD), etc (Boone e Plante, 1994; Shipley e McAfee, 2004). 
Law (2001) refere que há dois tipos principais de testes de identificação precoce: os testes multifásicos, que têm por objetivo avaliar todos os aspectos do desenvolvimento da criança ao longo dos seus primeiros anos de vida e os testes monofásicos, que são aqueles cujo alvo é o comportamento específico - nesse caso, fala e/ou linguagem.

Os testes que examinam aspectos específicos da linguagem, como por exemplo, o Test of Examining Expressive Morphology que examina aspectos relacionados à morfologia, o Test of Word Finding que avalia os aspectos semânticos, entre outros, são alguns dos vários testes disponíveis, comercialmente, nos Estados Unidos.

A maioria dos estudos utilizam testes formais para a avaliação da linguagem, ainda que não exista uma prova que inclua uma avaliação completa e que englobe a diversidade dos aspectos envolvidos (Castro-Rebolledo et al, 2004).

Capovilla e Capovilla (1997) referem que o Atraso no Desenvolvimento da Linguagem é um problema comum em pré-escolares e correlaciona-se com distúrbios posteriores de aprendizagem e ressaltam, que no Brasil, faltam instrumentos padronizados para identificar precocemente este quadro. Os autores realizaram um estudo, no qual forneceram a tradução e adaptação brasileira para o Peabody Picture Vocabulary Test (PPVT, Dunn e Dunn, 1981) e para o Language Developmental Survey (LDS, Rescorla, 1989). O PPVT é uma prova de vocabulário receptivo e avalia a compreensão do vocabulário e a LDS é uma prova de vocabulário expressivo que avalia o vocabulário em termos de palavras que a criança emite, segundo o relato da mãe. Para os autores, é necessário desenvolver e validar instrumentos para identificar precocemente possíveis atrasos de linguagem em crianças já a partir dos dois anos de idade (Capovilla e Capovilla, 1997).

Befi-Lopes (1997) em sua pesquisa de doutorado, verificou a competência e o desempenho lexicais em crianças entre 4:0 e 6:6 anos, a partir de situação de interação com livro infantil. Para dar seqüência ao estudo, Befi-Lopes, 2002, ampliou as faixas etárias estudadas para 2:0 e 3:0 anos. Após análise estatística, foi elaborada uma prova específica para a avaliação do vocabulário infantil com nove 
campos conceituais (vestuário, alimentos, animais, meios de transporte, móveis e utensílios, profissões, locais, formas e cores, brinquedos e instrumentos musicais). Esta prova compõe o teste ABFW - Teste de Linguagem Infantil (Andrade et al, 2004).

Befi-Lopes e Galea (2000) realizaram um estudo com o objetivo de verificar o desempenho lexical, em crianças com Alteração no Desenvolvimento da Linguagem, de 2:8 a 6:5 anos. Os resultados encontrados indicaram que as crianças com alteração nomeiaram com menos freqüência as palavras-alvo do que aquelas em desenvolvimento normal. O estudo mostrou que a verificação do vocabulário deve fazer parte da avaliação do desenvolvimento da linguagem. As autoras ressaltam que a maior parte dos testes para avaliação de linguagem, inclui prova para avaliar o vocabulário e estes podem ser uma grande ferramenta para identificar o atraso ou o distúrbio na aquisição de linguagem. E ressaltam ainda que no Brasil, faltam provas específicas para avaliar o vocabulário.

Andrade et al, 2004, desenvolveram um teste, ABFW Teste de Linguagem Infantil, destinado à avaliação das áreas de fonologia, vocabulário, fluência e pragmática, indicado para crianças de 2 a 12 anos. É um teste inédito no Brasil, inteiramente direcionado ao Português falado no Brasil. Para as autoras, o princípio do referido Teste é que a obtenção de dados objetivos representa um aspecto fundamental para a precisão diagnóstica das desordens da linguagem. Além disso, a utilização de dados objetivos na investigação inicial e nas reavaliações subseqüentes possibilita tanto uma consistência dos resultados obtidos quanto uma comunicação mais clara com os pacientes e suas famílias e entre os profissionais.

Zorzi e Hage (2004), publicaram o Protocolo de Observação Comportamental (PROC) para a avaliação da linguagem e dos aspectos cognitivos infantis. $O$ protocolo foi elaborado no sentido de propor uma situação planejada na qual se possa observar e registrar, a interação de crianças entre 12 e 48 meses com o examinador, envolvendo brinquedos pré-selecionados. O tempo sugerido por sessão é de 30 a 40 minutos. Para os autores, a observação comportamental é um procedimento pelo qual se analisa o comportamento geral da criança em contextos 
semi-estruturados. É um procedimento útil com crianças pequenas, pois possibilita avaliar a criança considerando todos os seus comportamentos.

Hage et al (2004), referem que alterações no processo de desenvolvimento da linguagem devem ser identificadas precocemente, uma vez que tais alterações podem interferir nos aspectos sociais e escolares da criança. As autoras referem ainda que, os procedimentos de avaliação da linguagem infantil ocorrem por meio de testes padronizados ou protocolos que envolvem amostra de linguagem oral espontânea e dirigida. Tanto os testes de linguagem como os protocolos são úteis na verificação de qual ou quais níveis de linguagem estão comprometidos. Escalas de desenvolvimento também são eficientes na medida em que, podem verificar a existência de discrepância entre o desenvolvimento de linguagem e o de outras áreas do desenvolvimento infantil.

Broggio (2005) refere que no Brasil, faltam instrumentos sensíveis ao diagnóstico de alterações no desenvolvimento da linguagem e por isso, realizou um estudo com crianças com desenvolvimento típico de linguagem com idades entre 4:00 e 8:10 anos, com o objetivo de traduzir e adaptar para o Português Brasileiro o Test of Language Development Primary 3 (TOLD - P:3), de Newcomer e Hammill, 1997. Para isso, foram avaliadas 76 crianças e os resultados indicaram diferenças significantes quanto ao desempenho nos subtestes em função do aumento da idade, isto é, com o aumento da idade, as crianças pontuaram mais no teste. Esta diferença não foi encontrada quanto ao sexo. A autora refere que as crianças tiveram melhor desempenho no subteste vocabulário a partir de figura e pior desempenho no subteste análise fonêmica. Nos demais subtestes houve variação no desempenho entre os grupos. Concluiu-se com o estudo que o TOLD-P:3 adaptado para o Português Brasileiro poderá ser utilizado como instrumento diagnóstico e que os valores encontrados na população estudada servirão de parâmetro para futuros estudos. 


\section{3 - Considerações sobre instrumentos padronizados}

Para McCauley e Swisher (1984) um teste é válido quando mede com exatidão aquilo que pretende avaliar e que a verificação da fidedignidade do teste $\mathrm{e}$ dos examinadores é fundamental.

Os testes são elaborados de tal forma que permitem comparações entre as pontuações de um escala elaborada a partir de dados obtidos numa população normal e as pontuações do examinado. Podem ser aplicados em um número grande de crianças de distintas populações e deve atender a critérios estatísticos de confiabilidade e validade. Podem avaliar um ou vários componentes da linguagem, a saber, semântica, fonologia, sintaxe, morfologia ou pragmática, considerando a recepção, a expressão ou ambas (Hage, 2000; Hage et al, 2004).

Para McCauley e Swisher (1984), existem alguns critérios psicométricos que são determinantes na validade de um teste: uma amostra de normalidade contendo pelo menos 100 sujeitos e que informe as características sócio-econômicas do grupo, a avaliação da fidedignidade do próprio teste, a fidedignidade dos examinadores, o manual de aplicação deve destacar a necessidade de um treinamento antes da utilização do teste e informações necessárias sobre sua metodologia.

Os mesmos autores realizaram um estudo com o objetivo de fazer uma revisão dos critérios psicométricos de trinta testes de linguagem utilizados com crianças pré-escolares. Os resultados indicaram que metade dos testes revisados encontraram não mais que dois critérios e somente quatro encontram quatro critérios psicométricos necessários à padronização. A maioria dos testes analisados não apresentaram evidências empíricas de validade e fidedignidade. Estes resultados indicam a necessidade de clínicos e pesquisadores reconhecerem as limitações no uso de instrumentos que não exibem suas características psicométricas. 
Para Law (1992) um teste para ser válido precisa ser aceito clinicamente, demonstrando que as habilidades a serem examinadas são realmente relevantes. $O$ teste deve ser capaz de refletir o desempenho da criança. Para que isto ocorra algumas medidas devem ser adotadas: cuidados na aplicação e treinamento dos examinadores a fim de se evitar a utilização de pistas que favoreçam a criança e resultem na obtenção de dados que não representem as suas habilidades reais e a não utilização de materiais culturamente inapropriados para eliciar as respostas.

Para Law (op.cit.), o critério de validade, nos testes de avaliação de linguagem, deve ser capaz de refletir as habilidades comunicativas da criança. Então, os seus dados são comparados com outro tipo de avaliação capaz de representar um padrão de referência (gold standard). A relação entre o teste e o padrão de referência são examinados a partir dos conceitos de especificidade e sensitividade. Um teste é considerado específico quando identifica corretamente as crianças que apresentam baixo desempenho e apresenta um número baixo de falsos positivos. A sensitividade está relacionada à detecção, em grande número, de desempenhos normais que realmente não revelam alterações. Neste caso, o número de falsos negativos deve ser baixo.

Um teste apresenta fidedignidade ao apresentar os mesmos resultados quando aplicado por dois examinadores diferentes num curto período de tempo ou quando o mesmo examinador obtém os mesmos resultados. A partir desta definição, Befi-Lopes e Rodrigues (2001) realizaram um estudo para verificar a fidedignidade de um teste de vocabulário proposto por Befi-Lopes (1997, 2000). Participaram do estudo 22 crianças com diagnóstico de Alteração no Desenvolvimento da Linguagem, com idade entre 2:0 a 8:4 anos. Estas crianças foram avaliadas e reavaliadas pelas mesmas examinadoras e o intervalo, entre a primeira e a segunda testagem, foi de 30 a 45 dias. Os resultados demonstraram que não houve diferenças significativas entre os dados das duas avaliações em 100\% dos sujeitos, indicando que o teste é fidedigno. 
Befi-Lopes, 2002, 2004, destaca que ao se utilizar testes padronizados para diagnosticar alterações de linguagem, é necessário comprovar que o procedimento adotado é efetivo, por meio da demonstração de que as crianças que foram diagnosticadas com alteração e aquelas que foram consideradas em desenvolvimento normal, realmente possuem esse padrão de desenvolvimento de linguagem. Para isso, é recomendada a realização de testagens que validem o teste utilizado. Estudos envolvendo a sensibilidade e especificidade do instrumento podem ser úteis à sua validação.

O uso de testes formais e parametrados na prática clínica e no campo da pesquisa possui uma série de vantagens, mas segundo a literatura, o valor destes pode ser sumarizado por um termo: a objetividade. As medidas informais de avaliação da linguagem levam a interpretações subjetivas, que torna a decisão diagnóstica arriscada (Weiner e Hoock, 1973; Boone e Plante, 1994). Os autores destacam as vantagens, mas também alertam quanto à importância dos testes apresentarem informações sobre as normas utilizadas para a interpretação dos resultados.

\section{4 - Tradução e adaptação transcultural de instrumentos estrangeiros para 0 Português Brasileiro (PB)}

O processo de tradução e adaptação de um instrumento é complexo e, em alguns aspectos, assemelha-se ao processo de construção do próprio instrumento, necessitando inclusive que sejam refeitos os estudos de confiabilidade e validade no novo contexto. A busca pelo máximo de equivalência entre o instrumento original e sua versão traduzida deve guiar todo o processo, de maneira a evitar formas, muitas vezes, sutis, de distorção. Além disso, a literatura destaca que a tradução de instrumentos estrangeiros podem permitir a comparação de pesquisas realizadas no Brasil com as pesquisas internacionais (Guillemin et al, 1993; Freitas, et al, 2001).

Duarte e Bordin (2000) referem que a elaboração e a testagem de um instrumento de avaliação na área da saúde mental infantil, por exemplo, é uma tarefa bastante complexa. Assim, segundo os autores, em culturas diferentes, é aconselhável utilizar versões de instrumentos já devidamente testados, ao invés de 
desenvolver um instrumento novo em cada um dos países que realizam o mesmo tipo de investigação. No entanto, uma série de etapas devem ser seguidas para que determinado instrumento possa ser utilizado em um novo contexto cultural.

O primeiro passo é a tradução e a adaptação cultural do instrumento. Trata-se de uma atividade bastante complexa, pois, ao traduzir um instrumento, deve-se buscar diversos tipos de equivalência em relação ao original, como a cultural, a semântica, a técnica, a de conteúdo, a de critério e a conceitual. Uma técnica útil nesse sentido, para os autores, é o da retrotradução ou back translation, por meio da qual a tradução do instrumento é novamente traduzida (ou retrotraduzida) para o idioma original. As duas versões (a original e a retrotraduzida) são, então, comparadas. Além disso, os autores referem que é de especial relevância obter evidências da validade do instrumento no novo contexto cultural. Para isso, é preciso verificar se o instrumento realmente mede aquilo que se propõe a medir (Duarte e Bordin, 2000).

Nascimento (2004) realizou a adaptação e a padronização da Escala de Inteligência Wechsler para Adultos, do autor David Wechsler (WAISS), desenvolvida para investigar habilidades cognitivas. Este trabalho fez parte de uma pesquisa de doutorado da autora (Nascimento, 1997). As etapas e análises conduzidas foram: tradução direta (inglês para o português) dos itens que compunham o teste, tradução inversa (back translation), análise teórica do itens, envolvendo a análise de juízes. A versão traduzida e adaptada foi aplicada em uma amostra de adolescentes e adultos (788 sujeitos, maiores de 16 anos, residentes na região metropolitana de Belo Horizonte). A autora descreve que para realizar a adaptação houve a criação e a revisão de itens: introdução de novos subtestes, modificações dos itens, procedimentos de aplicação e de avaliação de subtestes, alterações na derivação de escores brutos e de escores compostos. Como resultado da pesquisa, a autora concluiu que a versão adaptada revelou-se satisfatória, com evidências empirícas que legitimam a utilização do teste Waiss III adaptado ao contexto brasileiro. 
Freitas, et al, 2001, apresentaram o processo de tradução e adaptação, para a Língua Portuguesa, da Binge Eating Scale (BES) - Escala de Compulsão Alimentar Periódica (ECAP) que avalia a gravidade da compulsão alimentar periódica em indivíduos obesos. O objetivo do estudo foi traduzir, adaptar e avaliar a aplicabilidade da versão da referida escala para o Português. Após a cuidadosa tradução e adaptação, foi realizado um pré-teste com um grupo de 32 pacientes obesos com transtorno de compulsão alimentar e que procuravam tratamento para emagrecer. Como conclusão verificou-se que a versão em Português da escala foi considerada adequada para uso clínico. Os autores destacaram que o estudo realizado foi bastante pertinente, pois a utiilização da referida Escala permitirá a comparação entre pesquisas realizadas no Brasil e os achados de investigações internacionais.

Capovilla e Capovilla (1997) realizaram um estudo, no qual forneceram a tradução brasileira para o Peabody Picture Vocabulary Test (PPVT, Dunn e Dunn, 1981) e para o Language Developmental Survey (LDS, Rescorla, 1989) ou Lista de Avaliação do Vocabulário Expressivo (LAVE). O PPVT é uma prova de vocabulário receptivo e avalia a compreensão do vocabulário e a LDS é uma prova de vocabulário expressivo que avalia o vocabulário em termos de palavras que a criança emite, segundo o relato da mãe ou do cuidador. Não foram encontradas referências no estudo apresentado, sobre o procedimento adotado na tradução e na adaptação dos instrumentos citados. Como conclusão do estudo, os autores referiram que as traduções dos referidos instrumentos mostraram-se úteis para avaliar o desenvolvimento lingüístico de crianças brasileiras entre 2 e 6 anos de idade, em termos de vocabulário expressivo e receptivo.

Capovilla et al, 2001 realizaram uma pesquisa preliminar que teve como objetivo adaptar para o Português Brasileiro, o "Internacional Dyslexia Test", que avalia diferentes habilidades cognitivas relacionadas à aquisição de leitura e escrita, como consciência fonológica, processamento auditivo, processamento visual, velocidade de processamento, seqüenciamento, habilidades motoras, raciocínio e habilidades matemáticas. Segundo os autores, este teste já foi traduzido para diferentes línguas e é usado como instrumento para o diagnóstico da dislexia em uma série de países. Os resultados encontrados indicaram que o estudo demonstrou 
que crianças com baixo desempenho em escrita sob ditado também tendem a obter escores rebaixados numa série de subtestes do Internacional Dyslexia Test e assim, para os autores, pode-se dizer que a adaptação brasileira do referido teste foi eficaz para identificar crianças com dislexia. Com relação aos procedimentos e critérios adotados para a tradução e adaptação do teste, não foram encontradas referências no estudo apresentado.

Andrade e Juste, 2001, realizaram uma pesquisa que teve como objetivo aplicar o Stuttering Severety Instrument (SSI) em crianças fluentes falantes do Português Brasileiro, para avaliar a sua efetividade numa língua estrangeira. Este teste tem como objetivo avaliar a fluência em crianças e adultos e atribuir grau de severidade. Participaram da pesquisa 200 crianças sem qualquer queixa de gagueira, de ambos os sexos, com idades entre 2 e 11 anos. Os resultados obtidos demonstraram que mesmo nas crianças fluentes, 58,5\% foram classificadas com gagueira muito leve, $24,5 \%$ leve e $17 \%$ moderada. Os resultados sugeriram que 0 teste parece não ser sensível às variações normais de fluência, para falantes do Português Brasileiro, podendo levar a diagnósticos indevidos quando utilizado isoladamente.

Figueredo, 2002, em sua pesquisa de mestrado e doutorado apresentou a adaptação e padronização da Escala de Inteligência Wechsler para Crianças terceira edição (WISC III, de David Wechsler, 1991), de uma amostra brasileira. A população-alvo para a pesquisa de adaptação do teste foram 800 escolares entre 6 e 16 anos da cidade de Pelotas (RS). A autora refere que na forma adaptada, foram feitas algumas modificações em relação à forma original do teste, ou seja, alguns itens foram substituídos por serem culturalmente mais adequados, os critérios de início e de interrupção da aplicação dos subtestes, os tempos de execução dos itens e os bônus relativos à pontuação foram revistos e adaptados de acordo com as características da amostra estudada.

Nascimento e Figueredo, 2002, apresentaram as alterações efetuadas nas versões americanas dos testes WISC-III e WAISS-III e as adaptadas para uso no Brasil. As análises empíricas realizadas com base nas amostras de adaptação, validação e normatização dos referidos testes, acarretaram segundo as autoras, em 
alterações nas versões originais dos testes, no que se refere aos conteúdos de alguns ítens dos subtestes verbais, à ordem de apresentação dos itens, aos tempos limites e às normas.

As autoras concluíram que a utilização de um instrumento estrangeiro sem a sua devida adaptação pode colocar em risco a validade e a precisão de avaliações efetuadas quando não se leva em conta as características sócio-econômicas e culturais das amostras em que os testes serão utilizados. As autoras ressaltaram ainda que, embora as diretrizes preconizadas pela Comissão Internacional de Testes relacionadas ao processo de adaptação se constituam em fontes imprescindíveis para o desenvolvimento de pesquisas de adaptação, se depararam com a escassez de referências práticas sobre os procedimentos e análises envolvidas na construção e adaptação de instrumentos psicológicos.

Em um estudo descrito por Araújo e Perissinoto, 2004, quatro subtestes do Test of Language Competence - Expanded (TCL-E), de Wiig e Secord, 1985, foram traduzidos e adaptados para o Português Brasileiro e foram aplicados em 16 estudantes de 16 a 18 anos de idade, sendo 8 com queixas de dificuldade escolar e 8 sem queixas escolares. O referido teste avalia a compreensão de ambiguidades, inferência, linguagem figurada, elaboração sintática e memória. Os resultados obtidos no estudo indicaram que a versão traduzida do teste foi sensível para diferenciar os dois grupos estudados. Para a adaptação do instrumento, as autoras realizaram primeiramente a tradução e em seguida, foi realizado um estudo piloto com 13 estudantes e após a aplicação, foram feitos ajustes na primeira tradução para elaborar a versão utilizada no estudo.

Ferreira et al (2005) propuseram uma pesquisa que teve como objetivo adaptar culturalmente o Tinnitus Handicap Inventory (THI) para aplicação na população brasileira e avaliar sua reprodutibilidade. A adaptação cultural do THI seguiu as etapas indicadas por Guillemin et al (1993), que incluem a tradução do idioma Inglês para o Português, a adaptação lingüística e revisão das equivalências gramatical e idiomática. Os resultados encontrados indicaram que versão brasileira do THI mostrou-se um instrumento confiável para a verificação do prejuízo causado pelo zumbido na qualidade de vida dos pacientes avaliados. 
Scala, Naspitz e Solé, 2005, realizaram uma pesquisa que teve como objetivo traduzir e adaptar para o Português (cultura brasileira) o Pediatric Asthma Quality of Life Questionnaire (PAQLQ) para uso em crianças e adolescentes com asma e validar a versão adaptada. As autoras apresentaram na pesquisa os procedimentos para adaptação do instrumento: inicialmente foi traduzido para o Português, a seguir foi feita a versão para o Inglês (back translation) por um professor de Inglês não conhecedor do instrumento. Não houve discrepâncias entre a versão original e a versão traduzida. Após a tradução, o instrumento foi aplicado de modo experimental a 20 pacientes com asma. Ao final dessa avaliação, foram retiradas cinco atividades que compunham a versão original, porque não faziam parte da cultura brasileira. $\mathrm{Na}$ conclusão da pesquisa, as autoras concluíram que a tradução da PAQLQ para a Língua Portuguesa não modificou estruturalmente o questionário original e mostrouse um instrumento útil para a avaliação da qualidade de vida em crianças e adolescentes com asma.

Mansur et al, 2006, realizaram uma pesquisa com o Teste de Nomeação de Boston que é um teste amplamente utilizado para avaliação de nomeação em indivíduos adultos. Segundo as autoras, os escores usados no Brasil têm sido os mesmos da versão americana do teste. A pesquisa teve como objetivo avaliar a influência da idade e da escolaridade na habilidade de nomeação em uma amostra de 133 individuos normais, da cidade de São Paulo, com idades entre 28 e 70 anos. Como resultados da pesquisa, as autoras concluíram que a escolaridade foi a variável que mais influenciou o desempenho dos indivíduos. Embora o grau de dificuldade de alguns itens possam diferir na Língua Inglesa e Portuguesa, a aplicação da versão traduzida do teste de Nomeação de Boston sem adaptações, para a população brasileira, é possível, desde que o nivel educacional seja considerado na interpretação dos resultados (Mansur et al, 2006). 


\section{5 - Aplicação de testes e instrumentos formais de avaliação}

A padronização das condições de aplicação dos testes tem como preocupação garantir que a coleta dos dados dos sujeitos seja de boa qualidade. Os autores afirmam que uma má aplicação torna os dados obtidos inválidos, mesmo quando obtidos através de um teste de boa qualidade. É necessária uma uniformidade em todos os procedimentos no uso de um teste, desde as precauções a serem tomadas na aplicação, até o desenvolvimento de parâmetros ou critérios para a interpretação dos resultados obtidos. (Anastasi e Urbina, 2000; Pasquali, 2003).

Pasquali, 2003, refere que o aplicador, por exemplo, de testes psicológicos, deve atender aos seguintes requisitos:

1 - conhecimento: o aplicador deve conhecer profundamente o material que será utilizado;

2 - aparência: o aplicador deve usar roupas adequadas, pois deve causar boa impressão, evitando extravagâncias na sua apresentação;

3 - comportamento durante a testagem: o aplicador do teste deve conduzir a testagem, devendo manter a ordem, respeito e orientação, sem fazer interferências e interrupções desnecessárias. Deve transmitir seriedade, segurança e confiança.

A necessidade de um examinador qualificado está evidente em três aspectos principais da situação de testagem: seleção do teste, aplicação e pontuação, e interpretação dos escores. Para que o teste cumpra sua função, é essencial uma avaliação de seus méritos técnicos em termos de características como: validade, fidedignidade, normas. A causa mais freqüente de usos inadequados de testes provavelmente é um conhecimento insuficiente ou falho a respeito da testagem (Anastasi e Urbina, 2000).

Comitês especiais de organizações profissionais, trabalhando em conjunto com editores de testes, têm dado crescente atenção à prevenção do uso inadequado de testes. O projeto conduzido pelo Test User Qualifications Working Group é um exemplo, onde descreveram as qualificações essenciais para os 
usuários de diferentes tipos de testes para que os editores pudessem incorporar aos seus formulários de qualificações necessárias.

As Diretrizes Internacionais para a Utilização de Testes (International Test Commission) abrangem as responsabilidades que os utilizadores competentes de testes devem ter, bem como as necessárias competências pessoais relacionadas à aplicação e à interpretação dos escores dos testes.

A partir da literatura apresentada, esse estudo teve como objetivo traduzir para o Português Brasileiro, um teste americano que avalia a linguagem infantil, habilidades receptivas e expressivas, o Test of Early Language Development Terceira Edição (TELD-3);

Para responder ao objetivo proposto foi formulada a seguinte hipótese de pesquisa: o TELD-3 por ser um instrumento genérico para diagnóstico precoce de alterações de linguagem, será possível realizar a tradução sem necessidade de mudanças significativas no teste. 


\section{II - Método}

\section{1 - Aspectos Éticos}

Este estudo foi aprovado pela Comissão de Ética para Análise de Projetos de Pesquisa - CAPPesq da Diretoria Clínica do Hospital das Clínicas da Faculdade de Medicina da Universidade de São Paulo, com protocolo número 236/04 (Anexo A).

\section{2 - Material}

Neste estudo foi utilizado o Kit Completo do Test of Early Language Development, Terceira Edição (TELD-3).

\section{1 - Descrição do Teste}

\section{Edições do TELD}

O TEST OF EARLY LANGUAGE DEVELOPMENT (TELD) foi desenvolvido por Wayne P. Hresko, D. Kim Reid e Donald D. Hammill e foi publicado pela Editora PRO-ED, An Intenational Publisher.

A primeira edição do teste foi publicada em 1981 e foi indicada para testar crianças de 3 a 7:11 anos. A partir das considerações e sugestões realizadas por revisores a segunda edição foi publicada em 1991 - TELD-2, contendo itens adicionais com novos dados normativos e com ampliação da faixa etária testada, ou seja, passou a ser indicado também para crianças de 2 anos.

Atualmente, o TELD está na terceira edição, que foi publicada em 1999, revisada e com novos itens adicionados. Nesta terceira edição o teste foi subdividido em subtestes, correspondentes às medidas de linguagem receptiva e linguagem expressiva, com nova padronização dos escores, denominados pelos autores de quocientes. Também foi realizada uma revisão de todos os itens que o compunha e novos itens foram acrescentados por serem considerados mais apropriados às faixas etárias testadas. Dados normativos referentes à etnicidade, raça, gênero, região geográfica, nível educacional do pais, condições residenciais (rural ou urbana) e aspectos sócio-econômicos também foram considerados. O álbum de 
figuras necessário para a aplicação do Teste é colorido, e portanto, atrativo às crianças e os brinquedos necessários à sua aplicação também estão inclusos no kit. Na primeira e na segunda edição estes materiais não estavam disponíveis.

Segundo os autores, o teste foi padronizado a partir de uma amostra de 2.217 crianças residentes em 35 estados americanos. A análise dos itens que compõem o teste foi realizada por um grupo de juízes, composto por 22 professores universitários e alunos de pós-graduação das áreas de educação especial, desenvolvimento de linguagem, patologias e prática clínica em linguagem.

\section{Fundamentação Teórica do Teste}

Para Hresko, Reid e Hammill (1999) o diagnóstico de alterações no desenvolvimento da linguagem deve ser feito a partir de instrumentos formais e objetivos e estes devem ser confiáveis e válidos, estatisticamente. Um teste deve: avaliar a habilidade geral de linguagem bem como as habilidades receptivas e expressivas; deve fornecer informações normativas que possibitem comparações entre grupos e entre faixas etárias; deve identificar habilidades e dificuldades; ser útil para profissionais que trabalham com avaliação e não somente para os especialistas em linguagem; deve ser administrado em um curto período de tempo para evitar fadiga da criança e do examinador; deve incluir uma amostra normativa significativa. Segundo os autores, o TELD-3 foi desenvolvido considerando estas especificidades.

Os três componentes lingüísticos incorporados no teste são: semântica, sintaxe e morfologia. Os componentes fonológico e pragmático não estão inclusos no teste.

Os autores referem que a linguagem também pode ser conceitualizada de acordo com os tipos de transmissão da mensagem, que podem ser definidos como sistemas de linguagem, que se subdividem em: recepção e expressão. O TELD-3 foi elaborado visando fornecer dados a respeito destes dois sistemas e por isso, é composto por dois subtestes: receptivo e expressivo. 
Segundo os autores, se o leitor optar pela terminologia proposta por Bloom e Lahey (1978) os componentes lingüísticos incorporados no TELD-3 poderiam ser referidos como: os itens semânticos avaliam o conteúdo e os itens sintáticos e morfológicos avaliam a forma (conteúdo e forma). Aspectos relacionados ao uso da linguagem não estão inclusos no teste.

Os autores optaram por desenvolver um teste breve, mas que pudesse fornecer uma medida acurada de desenvolvimento de linguagem, por isso focaram nos itens essenciais e não em todos os componentes da linguagem. $\mathrm{O}$ aspecto morfológico foi incluído devido à sua relação semiótica com a sintaxe. Embora seja dificil distinguir itens puramente semânticos ou puramente sintáticos, principalmente em crianças jovens, os autores fizeram esta subdivisão por ser mais um dado que poderá ser utilizado na investigação clínica.

Concluindo, os autores descrevem que o TELD-3 é um teste de identificação precoce de alterações no processo de desenvolvimento da linguagem e que efetivamente distingue entre habilidades receptivas e expressivas e que também reflete a natureza integrada do desenvolvimento das habilidades semânticas/sintáticas e morfológicas da criança em desenvolvimento (Hresko, Reid e Hammill, 1999).

\section{Kit Completo do Teste}

O kit completo do Teste inclui:

1. Manual do Examinador;

2. Protocolo de Respostas - Forma A;

3. Protocolo de Respostas - Forma B;

4. Álbum de figuras (para aplicação das Formas A e B);

5. Kit de brinquedos com uma boneca, um sapato de nenê, um carrinho, uma colher, cinco blocos, cinco moedas (americanas) e uma bola pequena. 
Figura 01: Foto ilustrativa do Kit Completo do TELD-3:

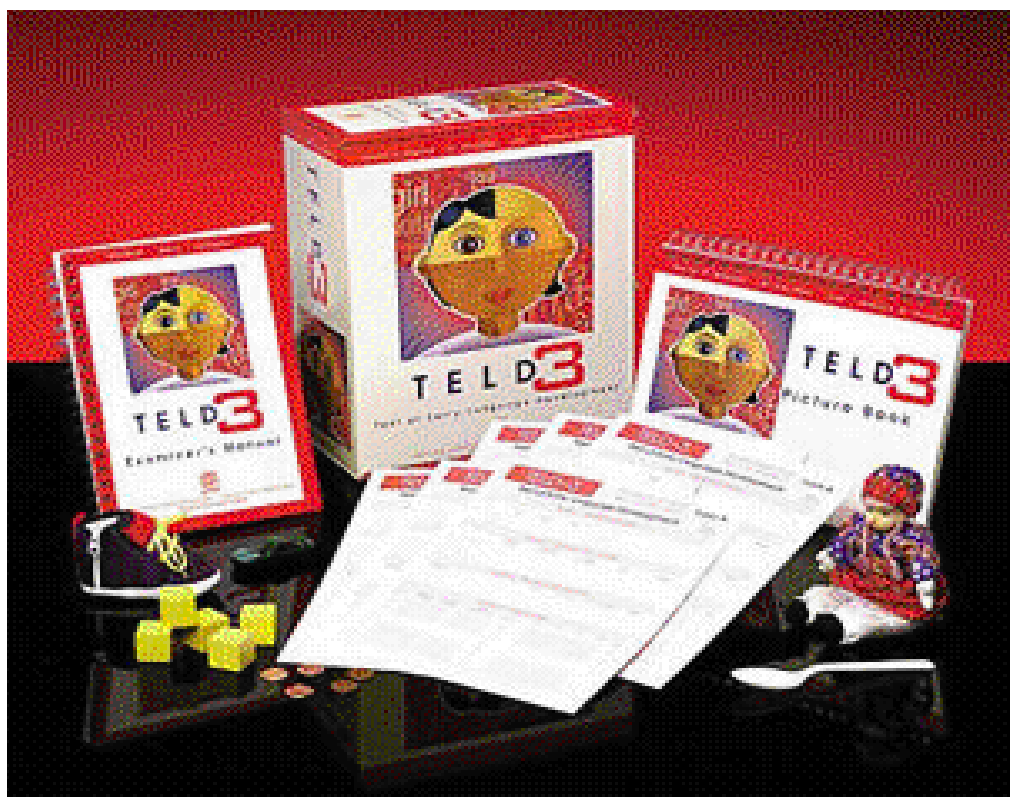

TELD-3

Hresko, Reid, Hammill, (1999)

O TELD-3 é indicado para avaliar as habilidades receptivas e expressivas da linguagem oral em crianças, na faixa etária de 2 a 7:11 anos. O tempo médio de aplicação é de trinta minutos. O teste possui duas formas, que segundo os autores, são equivalentes (forma $A$ e forma B).

\section{Subtestes do TELD-3}

Para cada forma do teste (A e B) existe um subteste de Linguagem Receptiva e um subteste de Linguagem Expressiva. Na construção das duas formas do teste foram selecionados os itens aproxidamente semelhantes para cada uma. Os escores dos subtestes quando combinados, fornecem a medida de Linguagem Falada e esta medida pode ser considerada um eficiente indicador de habilidade geral de linguagem oral. 
Subteste de Linguagem Receptiva: cada subteste receptivo possui 37 itens. $\mathrm{Na}$ forma A são 24 itens semânticos e 13 itens morfossintáticos e na forma B são 25 itens semânticos e 12 itens morfossintáticos. Todos estes itens verificam as habilidades de compreensão de linguagem da criança.

Subteste de Linguagem Expressiva: cada subteste expressivo possui 39 itens. $\mathrm{Na}$ forma A são 22 itens semânticos e 17 itens morfossintáticos e na forma B são 24 itens semânticos e 15 itens morfossintáticos.

\section{Principais Propostas do TELD-3}

O TELD-3 foi elaborado para atingir cinco principais propostas, segundo os autores:

1. Identificar crianças que estão significativamente abaixo dos seus pares, de mesma faixa etária, no desenvolvimento da linguagem e que possivelmente são candidatas a programas de intervenção precoce;

2. Identificar habilidades e dificuldades individuais das crianças testadas. Detectar diferenças nas habilidades de linguagem receptiva e linguagem expressiva;

3. Medir e documentar as evoluções das crianças no decorrer dos programas de intervenção de linguagem;

4. Ser utilizado como instrumento de pesquisas científicas relacionadas ao desenvolvimento de linguagem;

5. Ser utilizado como instrumento complementar de avaliação: acompanhar outras medidas de avaliação. 


\section{Relação dos Subtestes do TELD-3 com outros testes de linguagem}

$\mathrm{Na}$ terceira edição do TELD os autores subdividiram o teste em subteste receptivo e subteste expressivo. Esta subdivisão é bastante comum e pode ser encontrada nos principais testes que avaliam as habilidades precoces de linguagem, conforme ilustra o quadro abaixo* :

Quadro 01: Relação dos Subtestes do TELD-3 com outros testes de linguagem

\begin{tabular}{|c|c|c|c|}
\hline \multirow[b]{2}{*}{ Testes } & \multicolumn{3}{|c|}{ TELD-3 } \\
\hline & $\begin{array}{l}\text { Subteste } \\
\text { Receptivo }\end{array}$ & $\begin{array}{l}\text { Subteste } \\
\text { Expressivo }\end{array}$ & $\begin{array}{c}\text { Linguagem } \\
\text { Falada }\end{array}$ \\
\hline $\begin{array}{l}\text { Clinical Evaluation of } \\
\text { Language } \\
\text { Fundamentals- } \\
\text { Preschool (CELF-P) }\end{array}$ & & & \\
\hline $\begin{array}{l}\text { Linguagem Receptiva } \\
\text { Linguagem Expressiva } \\
\text { Linguagem Total }\end{array}$ & $x$ & $\mathbf{x}$ & $x$ \\
\hline $\begin{array}{l}\text { Fluharty Preschool } \\
\text { Speech and Language } \\
\text { Screening Test }\end{array}$ & & & \\
\hline $\begin{array}{l}\text { Recepção } \\
\text { Expressão }\end{array}$ & $\mathbf{x}$ & $\mathbf{X}$ & \\
\hline $\begin{array}{l}\text { Preschool Language } \\
\text { Scale (PLS-3) }\end{array}$ & & & \\
\hline $\begin{array}{l}\text { Compreensão auditiva } \\
\text { Comun. Expressiva } \\
\text { Linguagem total }\end{array}$ & X & $\mathbf{x}$ & 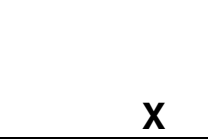 \\
\hline $\begin{array}{l}\text { Receptive-Expressive } \\
\text { Emergent Language } \\
\text { Test }\end{array}$ & & & \\
\hline $\begin{array}{l}\text { Recepção } \\
\text { Expressão } \\
\text { Combinado }\end{array}$ & X & $\mathrm{x}$ & $x$ \\
\hline $\begin{array}{l}\text { Test of Language } \\
\text { Development Primary: } \\
\text { Third Edition } \\
\text { Audição } \\
\text { Fala } \\
\text { Linguagem falada }\end{array}$ & $X$ & $X$ & $x$ \\
\hline
\end{tabular}

* Ref: Manual do Examinador do Test of Early Language Development - TELD-3, Hresko, Reid e Hammill, 1999, pag. 95 


\section{2 - Instruções gerais para a aplicação do Teste:}

O TELD-3 é composto pelo subteste receptivo e pelo subteste expressivo e possui duas formas (A e B), conforme já descrito anteriormente. Os subtestes receptivo e expressivo possuem 37 e 39 itens respectivamente, que testam diferentes habilidades semânticas e morfossintáticas da linguagem oral. Segundo as instruções originais do teste, a ordem de aplicação dos subtestes receptivo e expressivo pode ficar a critério do examinador.

A aplicação do teste deve ser iniciada baseando-se na idade cronológica da criança, como ilustra o quadro abaixo:

\section{Quadro 02: Itens para início do teste}

\begin{tabular}{|l|l|}
\hline \multicolumn{1}{|c|}{ Linguagem Receptiva } & \multicolumn{1}{c|}{ Linguagem Expressiva } \\
\hline 2 anos: começar com item 5 & 2 anos: começar com item 10 \\
\hline 3 anos: começar com item 10 & 3 anos: começar com item 15 \\
\hline 4 anos: começar com item 15 & 4 anos: começar com item 20 \\
\hline 5 anos: começar com item 20 & 5 anos: começar com item 25 \\
\hline 6 anos: começar com item 25 & 6 anos: começar com item 30 \\
\hline 7 anos: começar com item 28 & 7 anos: começar com item 33 \\
\hline
\end{tabular}

Deve-se iniciar o teste pelo item indicado para a idade cronológica da criança. O primeiro passo é encontrar a Base que corresponde ao acerto de três itens na seqüência. Todos os itens que estiverem abaixo da base serão considerados como corretos. Por exemplo, para uma criança de 3 anos, inicia-se a aplicação do subteste receptivo pelo item 10 e se esta criança respondeu corretamente para os itens 10, 11 e 12, ou seja, três itens na seqüência, esta é a Base e isto significa que os itens de 1 a 9 (abaixo do item 10) deverão ser considerados como corretos. É possível, também, encontrar duas bases e nesse caso deve-se considerar a base mais alta. 
O Teste deve ser interrompido quando a criança errar três itens na seqüência. Esse é o Teto. Por exemplo, para uma criança de 3 anos, inicia-se o subteste receptivo pelo item 10 e foram respondidos corretamente os itens 10,11 e 12 e os itens 13, 14 e 15 foram respondidos incorretamente, ou seja, três erros na seqüência, esse é o Teto, portanto, o teste deverá ser interrompido.

Para cada item de cada subteste respondido corretamente a criança recebe um ponto e zero para cada item respondido incorretamente. Para todos os itens existem os critérios de pontuação (o que a criança deve realizar ou responder para obter pontos). A partir da soma dos itens respondidos corretamente, é possível obter a quantidade de escores brutos nos subtestes e assim prosseguir com a interpretação dos resultados para se obter a classificação da performance da criança no teste.

\section{3 - Etapas para interpretação dos resultados do Teste}

O TELD-3 fornece cinco tipos de escores, que serão descritos a seguir:

\section{Escore Bruto Receptivo e Expressivo}

Os escores brutos correspondem ao número de itens respondidos corretamente em cada subteste (número de acertos). Estes possuem valor limitado e não podem ser usados para fazer interpretações clinicas sobre a performance da criança. Os itens de cada subteste se diferem tanto em quantidade quanto em grau de complexidade e em decorrência disso, os escores brutos de diferentes subtestes não são comparáveis.

\section{Quociente de Linguagem Receptiva e de Linguagem Expressiva}

No TELD-3 os escores-padrão são chamados de quocientes, que foram padronizados, segundo uma distribuição normal com média 100 e um desvio padrão de 15 para cada idade. Os quocientes podem ser classificados e a partir desta classificação é possível verificar qual a performance da criança no teste. 


\section{Quociente de Linguagem Falada}

O quociente de linguagem falada (QLF) compreende os quocientes do subteste de linguagem receptiva (LR) e de linguagem expressiva (LE). É o indicador da habilidade geral de linguagem oral de uma criança ( $Q L F=L R+L E)$. O quociente de linguagem falada também pode ser classificado.

\section{Percentil}

O percentil representa um valor relativo numa escala de 1 a 99 que indica o percentual de distribuição de cada faixa etária possível de análise. Ou seja, a performance da crianca em questão receberá um valor (quociente) que quando comparado à tabela referência, indicará o percentual de distribuição de sua performance no teste em relação à população, de sua faixa etária.

\section{Idade Equivalente (idade lingüística)}

Equivalências de idade são derivadas calculando-se a média normativa do escore de um grupo a cada intervalo de idade e indicam a idade lingüística obtida pela criança no teste.

Para se obter os resultados do teste, primeiramente são encontrados os escores brutos nos subtestes de Linguagem Receptiva e de Linguagem Expressiva, somando os pontos obtidos pela criança (cada item respondido corretamente equivale a 1 ponto e para cada item respondido incorretamente, a criança não pontua (zero)). Em seguida, estes escores brutos são convertidos em quocientes de Linguagem Receptiva e de Linguagem Expressiva, por meio da tabela padronizada de conversão.

A soma dos quocientes expressivo e receptivo é convertida para Quociente de Linguagem Falada, também por meio da tabela padronizada de conversão.

Os valores do escore bruto receptivo e escore bruto expressivo também podem ser convertidos para a idade equivalente (idade lingüística) por meio de uma tabela padronizada de conversão. 
Estas tabelas de conversão estão disponíveis no manual do examinador do TELD-3 e devido às questões éticas, ou seja, em respeito à propriedade intelectual dos autores, as mesmas não foram publicadas neste Estudo.

Para se obter a classificação da performance da criança no teste, os quocientes são classificados, conforme ilustra o quadro abaixo:

\section{Quadro 03*: Classificação dos quocientes}

\begin{tabular}{|c|c|}
\hline Quocientes & Classificação \\
\hline $131-165$ & Muito Superior \\
\hline $121-130$ & Superior \\
\hline $111-120$ & Acima da Média \\
\hline $90-110$ & Média \\
\hline $80-89$ & Abaixo da Média \\
\hline $70-79$ & Pobre \\
\hline $35-69$ & Muito Pobre \\
\hline
\end{tabular}

* Referência: TELD-3, Manual do examinador, página 61 


\section{3 - Procedimento}

Anterior à aquisição do Teste, foi realizado um contato com os autores e com a Editora (PRO-ED), que autorizaram a tradução do mesmo para as finalidades desta pesquisa, aspecto fundamental neste tipo de atividade (Anexos B e C). Após a aquisição foi realizada a tradução do instrumento. As etapas e as análises conduzidas foram as seguintes:

\section{Tradução direta do teste (Inglês Americano para o Português Brasileiro)}

A pesquisadora realizou a tradução direta do teste para o Português Brasileiro. As formas A e B do teste foram traduzidas. Todos os itens que o compõe, a ordem de apresentação destes, bem como os procedimentos de aplicação, correção e interpretação dos resultados foram mantidos de acordo com o formato original do teste.

A correção da tradução (Inglês - Português) realizada pela pesquisadora foi revisada por uma professora de Inglês, não conhecedora do teste, com formação em Letras e que possui o domínio dos dois idiomas.

\section{Tradução inversa (back translation)}

A tradução inversa foi realizada por uma professora de Inglês. Em seguida, a pesquisadora juntamente com professora analisou cada item de cada subteste, de ambas as formas do teste, individualmente. Para cada item traduzido foi analisado se a tradução inversa para o Inglês ficou equivalente à da versão original do teste. Os itens em que não foi possível manter a tradução original ou nos quais foram necessários alguns ajustes, a pesquisadora consultou dois juízes, Professoras Doutoras Associadas do Curso de Fonoaudiologia da Faculdade de Medicina da Universidade de São Paulo, para as devidas adaptações. 


\section{Análise da equivalência teórica, semântica e cultural}

A pesquisadora examinou cada item testado em cada subteste em ambas as formas do teste. Nesta análise foram considerados os seguintes critérios: descrição da habilidade testada, faixa etária indicada para a aplicação do item, componente lingüístico testado (semântico ou morfossintático), subteste testado (se receptivo ou expressivo), critérios adotados para pontuar no item. O objetivo da análise de cada item que integra o teste é garantir a maior equivalência possível na tradução do teste com sua versão original. Aspectos culturais também foram analisados.

\section{Análise Operacional}

$\mathrm{Na}$ tradução do teste foram mantidos os mesmos procedimentos de aplicação, bem como foram adotados os mesmos critérios de pontuação, de correção e de interpretação dos resultados contidos no manual de aplicação da versão original do teste. A tradução da classificação dos escores também foi mantida de acordo com o teste original. A tradução das instruções de aplicação do teste realizada pela pesquisadora também foi revisada por uma professora de Inglês.

\section{Análise do álbum de figuras que compõem o teste}

No kit completo do TELD-3 possui um álbum de figuras que são utilizadas na aplicação de alguns itens do subteste receptivo e do subteste expressivo. Estas figuras foram analisadas pela pesquisadora e por três juízes fonoaudiólogos, que estão cursando Pós-Graduação e possuem experiência com a aplicação de testes.

O objetivo desta análise foi verificar se haveriam discrepâncias sócio-culturais nas figuras do álbum. 


\section{IV - Resultados}

A tradução do Test of Early Language Development - 3 (TELD-3), embora trabalhosa, foi realizada sem dificuldades. Todo o formato original do teste foi mantido, ou seja, foram mantidos todos os subtestes e itens testados, assim como todas as instruções de aplicação (início do teste, ordem de apresentação dos itens, critérios de pontuação, etapas de interpretação dos resultados e protocolos de respostas). Os resultados das análises adotadas no processo de tradução serão apresentadas a seguir.

\section{1 - Tradução Direta e Inversa do Teste:}

A tradução realizada pela pesquisadora foi corrigida por uma professora de Inglês. E após a tradução direta foi feita a tradução inversa que foi compatível com a versão original do teste. No entanto, foram necessários alguns ajustes para que fosse mantida a maior equivalência possível entre a versão americana e a versão traduzida do teste.

\section{2 - Tradução dos itens que compõem os subtestes e análise das equivalências}

\section{Tradução da Forma A do Teste}

A forma A do TELD-3, conforme já descrito anteriormente, é composta por um subteste receptivo e um subteste expressivo, compostos por 37 e 39 itens respectivamente. A maioria dos itens foram apenas traduzidos, não sendo necessárias adaptações significativas.

As adaptações realizadas na forma $A$ do teste foram: no item 30 do subteste receptivo, o nome próprio do gato foi modificado de Jerônimo, para Mimi (por ser um nome culturalmente mais comum no Brasil). No item 13 do subteste expressivo é avaliada a habilidade da criança usar pronomes pessoais, que no Inglês são diferentes do Português Brasileiro (PB), por isso, foram adaptados para os pronomes pessoais e pronomes possessivos da Língua Portuguesa. No item 28, 31 e 33 do subteste expressivo é avaliada a capacidade da criança em repetir sentenças. 
Devido às diferenças de língua, não foi possível manter a mesma estrutura que no PB, ou seja, foi feita a tradução literal destas sentenças (a complexidade gramatical de uma sentença no Inglês é diferente do Português). Itens que avaliaram os aspectos sintático-morfológicos, foram mais dificeis de serem mantidos, porque a estrutura sintática e morfológica do Inglês é diferente do Português.

\section{Tradução da Forma B do Teste}

Todos os itens dos subtestes que compõem a forma B do teste foram traduzidos. No subteste receptivo, o item 22 avalia os conceitos "top of, bottom of $e$ middle of " (adjetivos comparativos) e foram traduzidos para "parte mais baixa/meio/ alto" e esta foi a equivalência mais próxima encontrada. No item 31 a criança tem que mostrar a figura que combina com o que a examinadora fala e uma das figuras solicitadas era o "umpire" que significa árbitro (de jogo de beisebol) e esta figura foi trocada pela figura do "policial", por ser culturalmente mais equivalente.

No item 35 do subteste receptivo, a criança também tem que dizer dentre quatro palavras, qual não combina com a demais. Nesse item as palavras do teste original eram: tenda, iglu, traço e celeiro. Estas palavras foram substituídas por tenda, barraca, traço e cabana.

No subteste expressivo, o item 28 verifica a habilidade da criança em repetir sentenças. As sentenças foram traduzidas, porém a estrutura da sentença do Inglês para o PB ficou diferente. Por exemplo, a primeira sentença é "He has been eating" e na tradução ficou "Ele está comendo" (estrutura do verbo, quantidade de palavras na frase, são aspectos que diferem).

Nos itens 27, 30 e 38 também do subteste expressivo os nomes próprios Billy, Sally e Keisha que foram substituídos pelo nome "Maria" (por ser culturalmente mais comum). Demais itens foram apenas traduzidos e mantidos como no teste original.

Assim como na forma $A$, a equivalência dos itens sintático-morfológicos foi mais difícil de ser mantida na tradução devido às diferenças da Língua. 


\section{3 - Tradução do manual de aplicação do Teste}

No manual de aplicação do TELD-3 todas as instruções ao examinador e também à criança, que está sendo testada, estão descritas de forma clara e objetiva. As instruções de aplicação do teste na tradução foram todas mantidas, não houve necessidade de adaptações. As instruções dadas às crianças poderão ser utilizadas, por serem usuais em nosso contexto, por exemplo, instruções como: mostre, aponte, repete para mim, me conte, quantos, o que é isso, etc.

As instruções para correção e interpretação dos resultados também estão descritas de forma clara. $\mathrm{Na}$ tradução do teste, todas as instruções para a interpretação dos resultados, dos critérios de pontuação e da classificação da performance da criança testada, foram mantidas conforme a versão original do teste.

\section{4 - Resultados da análise do álbum de figuras}

As figuras do álbum necessárias à aplicação do teste foram analisadas pela pesquisadora e por três juízes fonoaudiólogos. No subteste receptivo, na forma $A$ são 25 pranchas de figuras, na forma $B$ são 18 pranchas. Nos subtestes expressivos, temos 09 pranchas para a forma A e 10 pranchas para a forma B. Houve $100 \%$ de concordância entre os juízes na análise realizada e foram obtidas as seguintes conclusões: de uma forma geral as figuras são comuns ao contexto brasileiro, com exceção da prancha AR1 na qual é solicitada à criança para mostrar "a cadeira", mas parece um "sofá", também é solicitada a figura do "sapato", mas na prancha parece um "tênis". Na prancha AE 3 na placa está escrito em Inglês "stop" e o desenho da figura do ônibus é característico do contexto americano. Na prancha BR14 temos uma montanha coberta de gelo, o que não faz parte do nosso contexto geral. Portanto, de um total de 62 pranchas de figuras, $03(4,8 \%)$ pranchas apresentaram discrepâncias sócio-culturais, segundo a análise conduzida pelos juízes que participaram da pesquisa. 


\section{5 - Protocolos de Respostas - Formas A e B}

Os protocolos de respostas acompanham o kit completo do TELD-3 e na tradução os seus formatos foram mantidos conforme a versão original do teste. Estes protocolos podem ser utilizados pelo examinador no momento da aplicação do teste para registrar as respostas obtidas.

Os protocolos de respostas são compostos por seis seções: a seção I contém os dados de identificação do sujeito. A seção II corresponde ao resumo dos resultados obtidos no teste. Na seção III poderão ser registrados os escores de outros testes, quando aplicados. Na seção IV um gráfico ilustrará o perfil dos escores obtidos pelo sujeito. A seção $\mathbf{V}$ possui os itens que compõem os subtestes receptivo e expressivo. E para finalizar, na seção VI dos protocolos há um espaço disponível para interpretações e/ou outras observações relevantes verificadas durante a aplicação do teste, como por exemplo, características observadas na criança que está sendo testada, tanto no que diz respeito à performance de linguagem como tambem às questões comportamentais (estava atenta ou não, estava interessada, cansou facilmente, etc).

Os protocolos de respostas encontram-se nos Anexos D e E. 


\section{V- Discussão}

A hipótese levantada no início da realização do presente estudo foi que o TELD-3, por ser um instrumento genérico para diagnóstico precoce de alterações de linguagem, seria possível realizar a sua tradução sem necessidade de mudanças significativas. Hipótese Confirmada.

É consenso na literatura que avaliar o processo de desenvolvimento da linguagem em crianças não é uma tarefa fácil, considerando a complexidade e a diversidade dos fatores envolvidos neste processo. Os procedimentos adotados pelos profissionais no processo de avaliação são determinantes para a precisão e validade do diagnóstico e posteriomente para a efetividade do processo de intervenção.

Os autores referem diferentes procedimentos de avaliação, como o uso de medidas informais, o uso de testes formais, uso de protocolos especifícos e de escalas de desenvolvimento. A necessidade de obter dados em situações espontâneas e naturais de avaliação também é mencionada. Dentre estes diversos procedimentos usuais de avaliação, a indicação de usar testes formais e objetivos, é unânime entre os autores (Bloom e Lahey, 1978; Stark e Tallal, 1981; McCauley e Swisher, 1984; Lahey, 1990; Reed, 1994; Rice, 1997; Paul, 2001; Befi-Lopes, 2003, Correa, Freitas e Lima, 2003; Shipley e McAfee, 2004, Andrade et al, 2004; Broggio, 2005; Mansur et al, 2006).

No Brasil, o uso de testes formais e objetivos na prática fonoaudiológica, ainda é pouco usual, fato este que pode ser comprovado quando levantamos a quantidade de testes comercialmente disponíveis para avaliar e diagnosticar problemas de linguagem nesta área. Atualmente existe o teste de linguagem infantil - ABFW, desenvolvido por Andrade et al (2004) e existe também disponível o PROC - Protocolo de Observação Comportamental, desenvolvido por Zorzi e Hage (2004) e que é indicado para avaliação da linguagem e dos aspectos cognitivos infantis, em crianças de 12 a 48 meses. 
Esta não é uma realidade constatada em outros países, como nos Estados Unidos, onde os profissionais da área de Fonoaudiologia dispõem de um amplo conjunto de testes para estas finalidades. O Directory of Speech-Language Pathology Assessments Instruments da American Speech-Language Hearing Association (ASHA), apresenta uma relação com mais de cem testes comercialmente disponíveis.

No Brasil faltam testes formais para avaliar a linguagem infantil, conforme apontado pelos autores (Capovilla e Capovilla, 1997; Hage, 2000; Befi-Lopes, 2002; Correa, Freitas e Lima, 2003; Andrade et al, 2004; Broggio, 2005, Mansur et al, 2006).

Este aspecto causa um impacto negativo para o aprimoramento da profissão no país. O uso de medidas subjetivas na prática clínica pode trazer conseqüências para o levantamento de hipóteses diagnósticas, para a comunicação com os pacientes, seus familiares e outros profissionais. A definição de conduta também pode ser prejudicada pela ausência de dados objetivos.

Alguns autores sugerem que a tradução e a adaptação de instrumentos já disponíveis em outras Línguas pode amenizar esta carência. Além disso, pesquisas com este objetivo podem propiciar estudos transculturais, que comparem os achados do contexto brasileiro com achados internacionais. Objetos de estudo seriam melhor caracterizados na medida em que vários centros de pesquisas usassem os mesmos instrumentos (Duarte e Bordin, 2000; Freitas, et al, 2001; Scala, Naspitz e Solé, 2005; Ferreira et al, 2005).

Considerando, estes dados, este estudo teve como objetivo apresentar a tradução do Test of Early Language Development - um teste americano utilizado para avaliar a linguagem infantil, para o Português Brasileiro, visando futuramente analisar a sua aplicabilidade com crianças falantes do Português Brasileiro.

Gillemin et al, 1993, Duarte e Bordin, 2000, Freitas et al, 2001, referem que o processo de tradução e adaptação de um instrumento é complexo e, em alguns aspectos, assemelha-se ao processo de construção do próprio instrumento. Nas 
pesquisas relacionadas a tradução e adaptação de instrumentos estrangeiros para o contexto brasileiro, os autores destacam os procedimentos necessários para pesquisas com esta finalidade, como por exemplo, a tradução, a retrotradução, a análise da equivalência dos itens testados nos aspectos semânticos, teóricos e culturais. Tais procedimentos visam assegurar a equivalência entre as versões originais e traduzidas dos testes.

Em algumas pesquisas, existem citações quanto às modificações nos formatos dos testes. Nascimento e Figueredo (2002) ressaltam que na área da Psicologia, por exemplo, embora as diretrizes preconizadas pela Comissão Internacional de Testes relacionadas ao processo de adaptação são imprescindíveis para estas pesquisas, as autoras depararam com a escassez de referências práticas sobre procedimentos e análises envolvidas na construção e adaptação de instrumentos de diagnóstico.

Os procedimentos adotados no presente estudo, tais como a tradução direta, a tradução inversa e a análise das equivalências teórica, operacional e cultural foram compatíveis com as orientações descritas na literatura quanto aos cuidados que o processo de tradução e adaptação de um instrumento estrangeiro exigem. Além disso, todo o formato original do teste, no que diz respeito aos critérios de pontuação e dos itens apresentados foi mantido.

O processo de tradução e de adaptação de instrumentos publicados em outras Línguas deve ser criterioso para não inviabilizar o uso e a aplicabilidade dos mesmos. Não é possível realizar pesquisas transculturais se, primeiramente, não for garantida a equivalência entre a versão original e a versão traduzida do instrumento. No momento do levantamento bibliográfico realizado para este estudo foi possível constatar que alguns instrumentos de diagnósticos que foram traduzidos para 0 Português Brasileiro foram modificados, não apenas os conteúdos dos itens como também os critérios de pontuação. Além disso, também foi observado que em alguns estudos, os autores não descrevem os procedimentos adotados no processo de tradução e adaptação do instrumento. 
Boone e Plante, 1994; Law, 2001; Shipley e McAfee, 2004, referem que existem diferentes tipos de testes: teste de triagem, testes de identificação precoce, que fornecem indicativos da habilidade geral da criança e testes que avaliam aspectos mais específicos da linguagem, como por exemplo, apenas a fonologia ou apenas o vocabulário. Os autores destacam também que, ao selecionar um teste para avaliação, o examinador deve ser criterioso. Considerando a dimensão dos aspectos envolvidos no processo de aquisição e de desenvolvimento da linguagem, dificilmente um teste irá contemplar todos os aspectos.

Discussões feitas por Fonoaudiólogos, em alguns momentos, referem que testes não dão diagnóstico, além de outras criticas. De fato, um profissional competente saberá que a aplicação de um teste é uma parte de um processo bem mais abrangente, que é o diagnóstico. Conhecer a real aplicabilidade do teste é fundamental. Cada teste tem uma finalidade.

O TELD-3 segundo seus autores, é um teste de identificação precoce, é indicado para crianças de 2:00 a 7:11 anos e fornece ao examinador medidas das habilidades receptivas, expressivas e gerais de linguagem. Os autores optaram por desenvolver um teste breve mas que pudesse fornecer uma medida acurada de desenvolvimento de linguagem, por isso focaram nos itens essenciais e não em todos os componentes da linguagem (Hresko, Reid e Hammill, 1999).

No processo de tradução do teste, este dado pode ser confirmado, pois o teste foi praticamente apenas traduzido, sem a necessidade de adaptações significativas. Os itens que o compõem investigam os principais marcos do desenvolvimento da linguagem e, por isso, divergências relacionadas às diferenças de idioma não foram tão significativas.

A pesquisa publicada por Mansur et al, 2006, também corrobora com esta idéia. As autoras avaliaram a influência da idade e da escolaridade na habilidade de nomeação em uma amostra de 133 indivíduos normais, da cidade de São Paulo, com idades entre 28 e 70 anos, no Teste de Boston que foi apenas traduzido. Como resultados concluíram que embora, o grau de dificuldade de alguns itens possa diferir na Língua Inglesa e Portuguesa, a aplicação da versão apenas traduzida do 
teste de Nomeação de Boston sem adaptações, para a população brasileira, é possível, desde que o nivel educacional seja considerado na interpretação dos resultados (Mansur et al, 2006).

Ao analisar a equivalência entre a versão traduzida e a versão original do TELD-3 a pesquisadora deparou com mais dificuldades nos itens que investigam aspectos sintáticos e morfológicos da linguagem oral. Conforme apontado por Correa, Freitas e Lima, 2003, faltam no Brasil testes específicos que investiguem o desempenho da criança na produção/compreensão de estruturas lingüísticas, tais como passivas, relativas, relações de concordância, dentre outras. A tradução de instrumentos estrangeiros pode ser dificultada pelas diferenças lingüísticas entre as línguas.

Essa diferença já era esperada dado que a estrutura morfossintática do Inglês é diferente do Português Brasileiro. Mas mesmo assim, pode-se dizer que estas diferenças não foram tão significativas.

Um outro aspecto importante no processo de tradução de um instrumento é analisar sua efetividade. Ë importante que o instrumento traduzido seja aplicado no novo contexto para que a sua validade possa ser analisada. Andrade e Juste, 2001, concluíram com seus estudos que o teste americano SSI pode gerar diagnósticos indevidos para falantes do Português Brasileiro e por isso deve ser aplicado com cautela.

McCauley e Swisher, 1984; Law, 1992; Boone e Plante, 1994 e Befi-Lopes, 2001, 2002 referem que um teste para ser válido precisa ser aceito clinicamente e medir com exatidão aquilo que pretende avaliar, além de que, estudos envolvendo a sensibilidade e a especificidade do instrumento podem ser úteis a sua validação.

Estudos futuros envolvendo a aplicação do TELD-3 em crianças falantes do Português Brasileiro poderão fornecer parâmetros que serão úteis para analisarmos a sensibilidade e a especificidade do teste no nosso contexto. 
Analisar o manual de aplicação de um teste, também é uma forma de julgar sua qualidade. Com relação a este aspecto, pode-se dizer que o manual de aplicação do TELD-3 é de fácil compreensão. Os exemplos fornecidos pelos autores facilitam a compreensão de como aplicá-lo e interpretá-lo. As instruções de aplicação do teste estão descritas de forma clara e objetiva.

$\mathrm{Na}$ tradução dos procedimentos de aplicação do TELD-3 foram mantidas as mesmas instruções e os mesmos procedimentos de interpretação dos resultados da versão original do teste. Algumas pesquisas citam que o processo de tradução e adaptação utilizado acarretou alteração na versão original do teste, no que se refere aos conteúdos de alguns itens e aos critérios de pontuação e aplicação (Nascimento e Figueredo, 2002), não foi o caso do presente estudo.

Segundo os autores, Watkins, 1994; Plante e Vance, 1994; Rice, 1997; TagerFlusberg e Cooper, 1999; Paul, 2001, a avaliação de crianças com suspeita de alteração no processo de desenvolvimento da linguagem deve determinar os parâmetros de linguagem que estão deficientes, ou seja, há a necessidade de discriminar as habilidades receptivas e expressivas e quais os componentes lingüísticos alterados, para que o diagnóstico possa ser melhor definido. O TELD-3 incorpora itens que investigam aspectos semânticos e morfossintáticos da linguagem, e seus subtestes fornecem medidas receptivas e expressivas da linguagem oral.

A subdivisão em recepção e expressão é bastante importante e auxilia no diagnóstico diferencial e no levantamento de hipóteses diagnósticas. Referências diagnósticas relevantes tais como o DSM-IV (Manual Diagnóstico e Estatístico de Transtornos Mentais), a CID-10 (Classificação Internacional de Doenças), utilizam destas subdivisões para descreverem as categorias diagnósticas na área de linguagem infantil. O TELD-2 não possuía esta subdivisão e houve crítica de vários revisores por isso. Atualmente, os testes de linguagem infantil mais utilizados trazem esta subdivisão. 
Pesquisas realizadas na área de linguagem infantil geralmente enfocam a expressão. No levantamento bibliográfico realizado pela pesquisadora não foram encontrados testes disponíveis no Brasil que avaliem aspectos específicos da linguagem receptiva.

Conforme descrito por Boone e Plante, 1994 e Castro- Rebolledo et al, 2004, ainda não existe uma medida de linguagem que inclua e englobe a diversidade dos fatores envolvidos. E em crianças que estão em processo de desenvolvimento, este aspecto fica ainda mais difícil (Hresko, Reid e Hammill, 1999).

Um outro ponto importante descrito na literatura refere-se à necessidade do treinamento dos examinadores, antes da utilização do teste. Os testes são instrumentos técnicos e seu manejo necessita de pessoas treinadas e conhecedoras das regras de aplicação (McCauley e Swisher, 1984; Pasquali, 2003). Considerando que no Brasil, o uso de testes na prática fonoaudiológica ainda é pouco usual, é necessário não só a elaboração/adaptação de instrumentos de avaliação de linguagem para a população infantil, como também a implementação de programas de treinamento para o uso e aplicação correta de testes formais.

Em alguns sites de venda de testes, o comprador só pode adquirir um teste se primeiramente passar por um treinamento. Nos cursos de Fonoaudiologia, por exemplo, nos Estados Unidos, existem disciplinas na graduação sobre a aplicação e a utilização de testes formais. Esse é um ponto bastante importante porque pode-se ter um instrumento de qualidade, mas se o mesmo não for utilizado para a finalidade determinada ou se não for aplicado adequadamente, pode tornar-se inviável.

Não foram encontradas na literatura específica da área da Fonoaudiologia referências relacionadas a este assunto. Para que a elaboração ou a adaptação de instrumentos de diagnóstico possa se consolidar na área, é necessário que os Fonoaudiólogos busquem um maior embasamento técnico e teórico sobre o assunto. A criação de fóruns e comitês científicos, poderia ser uma forma de promover discussões e ações relacionadas a este tema. 


\section{V - Considerações Finais}

A partir do estudo realizado foi possível apresentar a tradução do Test of Early Language Development - Terceira Edição (TELD-3, Hresko, Reid e Hammill, 1999), um teste de avaliação de linguagem, de origem americana para o Português Brasileiro.

No Brasil, é notável a escassez de instrumentos formais e objetivos disponíveis para avaliar a linguagem infantil. Pesquisas relacionadas à tradução e adaptação de instrumentos já disponíveis em outras Línguas podem ajudar a amenizar este problema. No entanto, os procedimentos adotados no processo de tradução e adaptação devem ser criteriosos e cuidadosos, uma vez que este processo é tão importante quanto à construção de um novo instrumento.

Pesquisas com estas iniciativas têm sido observadas o que resultará em um futuro próximo, na disponibilidade de um maior número de instrumentos de diagnóstico na área da Fonoaudiologia. Além do impacto que tais instrumentos terão na prática clínica e na pesquisa, eles constituirão um passo fundamental para a identificação dos problemas mais freqüentes em nosso meio e de seus fatores de risco, permitindo o melhor planejamento das políticas de saúde na infância e na avaliação das intervenções e tratamentos oferecidos.

A tradução de instrumentos de avaliação já existentes, ao invés da criação de novos instrumentos é válida, na medida que pode viabilizar pesquisas transculutrais, possibilitando a comparação entre os achados nacionais com os internacionais. A implantação de programas de treinamento para aplicadores de testes também é necessária. 
ESTUDO II - Performance de crianças típicas no Test of Early Language Development (TELD-3) traduzido para o Português Brasileiro 


\section{I - Introdução}

\section{1 - Aquisição e Desenvolvimento da Linguagem}

O processo de aquisição e desenvolvimento da linguagem é complexo e é estudado por diferentes áreas do conhecimento, o que resulta em uma série de abordagens que tentam explicá-lo e compreendê-lo. Neste estudo será considerada a influência do aspecto cognitivo, o processo maturacional de desenvolvimento cerebral pelo qual a criança passa durante o período de desenvolvimento e a importância do meio social (Spinelli, 1983; Bishop, 1992; Reed, 1994; Rice, 1997; Limongi, 1998, Tager-Flusberg e Cooper, 1999; Herschkowitz, 2000 , Bishop, 2000).

Para Bates (1976) a linguagem pode ser definida como um conjunto de operações mentais para a construção e uso de sentenças dentro de um contexto. $O$ uso destas sentenças envolve regras tradicionalmente abordadas nas teorias sintática e semântica, bem como estruturas pragmáticas, isto é, o objetivo do falante em usar expressões e regras que relacionem estas expressões a um determinado contexto.

Halliday (1978) considera que primeiro a criança cria sua própria linguagem e depois adquire a língua materna conforme ocorre a interação com seu grupo social. A linguagem seria então, um produto do processo de inserção do sujeito na sociedade. Quando a criança desenvolve linguagem, ela está aprendendo conceitos existentes no mundo por meio da própria linguagem, e dessa forma, construindo sua noção da realidade. Esse desenvolvimento depende de habilidades cognitivas.

A linguagem é uma habilidade ou comportamento que resulta de uma complexa inter-relação de fatores fisiológicos, cognitivos, psicológicos, lingüísticos, ambientais e sociais. É um código no qual símbolos específicos são utilizados para representar, para significar idéias, desejos e pensamentos (Reed, 1994). 
A aquisição da linguagem é uma função da elaboração das estruturas cognitivas, além de depender também de um modelo exterior. É uma das manifestações da capacidade humana de representar eventos, mesmo na sua ausência. Portanto, implica em representação dotada de significação, além de um sistema que combina símbolos de acordo com regras, que devem ser adquiridas e aplicadas na conservação e na compreensão (Limongi, 1998 citando Piaget, 1978).

Alguns estudos tentam fornecer algumas informações sobre as bases neurais do desenvolvimento normal de linguagem. Os autores reconhecem que durante o desenvolvimento cerebral, a transição da infância para a maturidade envolve grande quantidade de reorganização cerebral e que diferentes áreas podem estar envolvidas quando uma função complexa como a linguagem está sendo aprendida, o que se estabiliza quando ela já está automatizada. Bishop (2000), destaca que no início da aquisição de linguagem o cérebro da criança funciona e é estimulado de maneira difusa, não sendo possível observar áreas corticais especializadas e responsáveis por determinada habilidade. Com o passar dos anos, a influência ambiental e o amadurecimento cerebral, pode-se observar que estas manifestações difusas tornam-se específicas e, então, pode-se correlacionar determinadas áreas à funções mais específicas.

Os estudos ainda sugerem que o aprendizado da linguagem envolve mais que a progressão de formas simples para complexas. Além disso, os tipos de processamento cognitivo envolvidos na aprendizagem da linguagem, podem ser diferentes daqueles que ocorrem depois que a linguagem está complemente aprendida. Sabe-se que lesões focais em áreas cerebrais de linguagem levam a uma reorganização funcional de forma que a linguagem é representada em outro lugar. No entanto, tem sido observado que essa plasticidade não se aplica universalmente àquelas crianças que têm grande dificuldade de aprender a linguagem. E os estudos mais recentes sugerem que essas dificuldades não são conseqüências de distúrbios neurológicos adquiridos, mas de anormalidades no desenvolvimento cerebral no período pré-natal, que leva a um cérebro que não está organizado de forma optimal para a linguagem e os genes parecem fortemente implicados nesse processo. Por meio das diferenças individuais observadas na 
aprendizagem da linguagem fica claro que a biologia tanto quanto o ambiente afetam a forma como a linguagem é aprendida (Bishop, 2000).

Além do desenvolvimento cognitivo e neurobiológico, para que a aquisição e o desenvolvimento da linguagem ocorra de maneira satisfatória é importante considerar os aspectos relacionados ao ambiente. Reed (1994) destaca que a influência do meio social exerce um papel importante no aprendizado do código lingüístico e das regras que governam e determinam o uso desse código no contexto social.

\section{2 - Algumas considerações sobre o desenvolvimento normal da linguagem}

Sabe-se que crianças que estão em processo de aquisição de linguagem podem apresentar variações no seu desenvolvimento. Existem variações na velocidade com que as crianças adquirem a linguagem, por exemplo, algumas crianças podem começar a usar palavras distintas aos 10 meses, outras não antes dos 18 meses. Uma possibilidade para explicar essa variação pode ser a influência da hereditariedade, se considerarmos que alguns padrões cerebrais de processamento da linguagem são inatos ou determinados geneticamente, faz sentido pensar que algumas crianças podem herdar um sistema mais eficiente do que outras. Outra possibilidade para explicar essas variações podem ser as influências ambientais, relacionadas aos estímulos que a criança recebe (Bee, 1996, Law, 2001). O ambiente familiar e escolar podem ser destacados como grandes fontes de estímulo para a aquisição e desenvolvimento da linguagem (Befi-Lopes, 1997).

Bishop e Mogford (2002) relatam que as diferenças individuais existem não só no ritmo, mas também no padrão de aquisição. E embora a variação individual seja menos marcante que as similaridades no desenvolvimento, ela é importante pelo que pode nos dizer sobre a natureza da aquisição da linguagem. Variações no padrão ou ritmo do desenvolvimento podem indicar até que 0 ponto 0 
desenvolvimento lingüístico é livre para variar ou está sujeito a fatores como as características da Língua a ser aprendida e, ainda, ao ambiente verbal.

Scheuer et al (2003) referem que as diferenças individuais no desenvolvimento da linguagem, podem existir tanto nos períodos nos quais determinadas características devem aparecer como na velocidade e na qualidade dessa linguagem. Esses fatores, segundo as autoras, estão relacionados às capacidades internas de cada indivíduo e ao ambiente, que deve ser rico em estímulos e possibilitar diversas experiências à criança.

Por outro lado, embora existam variações individuais, é possível observar seqüências no processo de aquisição e desenvolvimento de linguagem comuns às crianças. Bee (1996) menciona que a maioria das crianças já conseguem falar de forma efetiva ("falar bem") por volta dos 5 e 6 anos de idade.

Alguns estudos sobre a aquisição de linguagem indicam que seu aprendizado ocorre, principalmente, durante os cinco primeiros anos de vida da criança (Bishop, 1992; Reed, 1994). Porém, outros estudos (Bates, et al., 1984) revelam que mudanças significativas ainda podem ser observadas depois dos 4 anos.

Para Scheuer et al (2003) mesmo antes dos 2 anos, a maioria das crianças começa a formar sentenças com duas palavras, que na maioria das vezes têm sentido de posse e de lugar. Dessa forma, o desenvolvimento da linguagem, dos gestos às primeiras palavras e sentenças pode ser considerado um processo muito organizado e previsível, que reflete como as crianças pensam sobre o mundo do qual fazem parte, como o reconhecem, além de demonstrar o que é importante para elas. 
Bee (1996) descreve que o desenvolvimento da linguagem pode ser dividido em uma fase pré-lingüística e uma fase lingüística propriamente dita, que se inicia com as primeiras palavras. Os sons e gestos que os bebês fazem durante a fase pré-lingüística estão intimamente relacionados à emergência das primeiras palavras.

Por volta dos 9 ou 10 meses também faz parte do processo de desenvolvimento o uso de gestos. Um bebê de 10 meses que aparentemente quer que você lhe alcance um brinquedo favorito pode esticar-se e estender a mão para ele, abrindo e fechando a mão, indicando um pedido (Boone e Plante,1994).

O uso convencional da linguagem inicia-se ao redor dos 12 meses, quando as crianças normalmente falam suas primeiras palavras reconhecíveis pelo adulto e por responderem apropriadamente a palavras que estão fora do contexto de jogos rotineiros, evidenciando que estão compreendendo palavras simples e relacionadas às suas experiências (Tomasello e Kruger, 1992; Boone e Plante, 1994; Bee, 1996).

No segundo ano de vida, as crianças, gradualmente, expandem o seu vocabulário para combinar duas palavras numa frase. $O$ vocabulário expressivo de uma criança aos 18 meses é de aproximadamente 50 palavras. Entre 18 e 24 meses, as crianças vivenciam uma grande expansão do vocabulário e por volta dos 24 meses têm um léxico de 200 a 300 palavras (Reed, 1994; Bassan et al, 1998).

Com 2 anos de idade, a criança é capaz de apontar para figuras corretas, quando solicitada a apontar objetos, como cachorro, carro. Consegue seguir instruções faladas melhor do que consegue falar, consegue produzir frases de duas a três palavras (Boone e Plante, 1994).

Rice (1997) destaca que a emergência da linguagem é o grande marco do desenvolvimento infantil e ocorre entre um e dois anos de idade. 
As primeiras frases de duas palavras normalmente aparecem entre os 18 e 24 meses e são curtas e gramaticalmente simples, sem as várias inflexões gramaticais. Este período traz importantes mudanças nas habilidades conversacionais da criança. Elas começam a compreender a necessidade de responder com fala à fala do outro, perguntam questões rotineiras, respondem a elas e podem começar a tomar parte de uma troca lingüística entre duas pessoas e compreender o que lhes é dito quando essa linguagem está direcionada para ela. Aos 3 ou 4 anos, as crianças são capazes de formar frases complexas (Bee, 1996, Scheuer et al, 2003).

É possível constatar que, dos 2 aos 5 anos, a linguagem da criança evolui do uso de uma palavra a uma forma gramatical bem estruturada e torna-se mais eficiente, sabendo direcioná-la para vários interlocutores. Neste período o vocabulário se expande e este fato pode estar relacionado em parte, ao desenvolvimento cognitivo, isto é, à capacidade simbólica, à representação e metarepresentação ( Limongi, 1998, Scheuer et al, 2003).

\section{3 - Os componentes da Linguagem}

Para melhor compreender e estudar a linguagem, os pesquisadores realizam uma divisão que possibilita uma abordagem mais específica e objetiva.

Bates (1976) sugere a divisão da linguagem em três áreas, a saber, a sintática - que se refere à relação mantida entre os sinais; a semântica - relações entre os sinais e seus referentes e a pragmática, que se refere às relações entre os sinais e o uso dos falantes. Vale ressaltar que, embora no aspecto conceitual a linguagem possa ser dividida em subsistemas ou componentes, na prática, estes componentes operam de forma harmônica, encontrando-se, intrinsecamente relacionados (Bates, 1976).

Segundo Bloom e Lahey (1978) a linguagem pode ser dividida em três grandes componentes: conteúdo, forma e uso. O conteúdo se refere ao significado das mensagens, ao aspecto semântico da linguagem. A forma se refere aos 
componentes fonológico, sintático e morfológico. E o uso corresponde ao componente pragmático da linguagem.

Segundo Reed (1994) a linguagem é constituída por cinco grandes componentes: semântico, sintático, morfológico, fonológico e pragmático. Cada componente é parte de um sistema e assim, é governado por regularidades e um conjunto de regras que todos os falantes devem aprender para se comunicarem efetivamente. Destaca também, que embora possamos discutir cada componente separadamente, eles estão inter-relacionados no funcionamento da linguagem.

Considerando que o tema do estudo aqui apresentado está relacionado aos componentes semântico, sintático e morfológico da linguagem, estes serão a seguir, discutidos de forma mais específica.

A semântica é o ramo da lingüística que se ocupa com estudo do significado da linguagem. Tem havido muita discussão na lingüística para definir até que ponto a gramática e a semântica podem ser estudadas independentemente. Além de se concentrar na análise do significado das frases, a semântica também analisa o significado de palavras isoladas. Estas podem ser divididas em quatro categorias de acordo com a complexidade das condições de seu uso: o nível mais simples é o dos substantivos próprios, seguidos dos substantivos comuns. O nível seguinte inclui palavras relacionais, como os adjetivos dimensionais e por último estão as expressões dêiticas, nas quais o referente depende da situação do enunciado. $O$ conhecimento específico de uma palavra, o conhecimento de categorias conceituais e a interpretação de significados dentro de contextos variados são elementos importantes deste componente (Reed, 1994; Bishop e Mogford, 2002).

O componente sintático refere-se à ordem e organização das palavras em sentenças ou frases; é a organização das palavras para formar sentenças com significado. $\mathrm{O}$ sistema sintático contém regras que indicam como combinar palavras em frases e em como transformar estas frases em outras frases. Em cada Língua, há um número limitado de estruturas sintáticas aceitáveis (Reed, 1994; Boone e Plante, 1994; Gleason, 1997). 
A morfologia tem sido definida como as regras utilizadas em uma Língua para derivar as formas de palavras e as regras que determinam o uso de marcadores ou inflexões. Estas formas derivadas incluem plural, tempo verbal, advérbios e superlativos. Pelo fato da morfologia ser constituída por uma seqüência de fonemas, ela pode ser discutida, algumas vezes, como parte do sistema fonológico. Algumas vezes, é considerada como parte do sistema semântico devido ao significado de algumas formas derivadas de seqüência de fonemas e em outras vezes, a morfologia pode ser considerada como parte do sistema sintático devido sua relação entre as variadas formas de palavras e suas funções dentro das sentenças. Por outras vezes, a morfologia é considerada um componente separado da linguagem devido às regras únicas que afetam as formas de palavras (Reed, 1994).

À medida que a criança vai se desenvolvendo, a complexidade gramatical do seu discurso aumenta em diferentes maneiras. Ocorre um aumento na utilização de morfemas gramaticais, no tamanho médio da frase, o número de elementos de uma oração aumenta, tanto as locuções quanto as orações são aumentadas pelos processos de coordenação e de subordinação (Bishop e Mogford, 2002).

Vários estudos têm sido realizados, na Lingüistica, Psicoligüística e Fonoaudiologia, enfocando os subsistemas da linguagem. Porém, existem poucas referências de normalidade para Português Brasileiro sobre a morfossintaxe.

Aráujo e Befi-Lopes (2004) realizaram uma pesquisa que teve como objetivo identificar alguns aspectos que determinam o desempenho gramatical de crianças pré-escolares falantes do Português. Participaram do estudo 60 sujeitos com desenvolvimento típico de linguagem e os resultados indicaram aumento das médias, entre todas as faixas etárias, nas variáveis testadas. O desempenho gramatical das crianças caracterizou-se, principalmente, pelo uso de artigos e substantivos no singular e masculino, verbos conjugados na $3^{\text {a }}$ pessoa do presente do indicativo e um aumento do número de palavras por frase nos sujeitos de 4 anos. 
Takiuchi et al (2005) realizaram uma pesquisa com 232 pré-escolares que teve como obejtivo explorar o domínio da morfologia flexional do Português Brasileiro. Os resultados indicaram o domínio precoce das flexões de gênero e de flexões verbais. Para as flexões indicando número, plural, tanto nominais como verbais, foi observado um aumento gradual com a idade, porém a produção destes morfemas foi muito abaixo do observado nos demais morfemas investigados. Para a população estudada, o não-uso das flexões de número plural pareceu indicar uma variação sociolingüística e não uma dificuldade de aquisição.

\section{4 - Linguagem: compreensão e produção}

Uma outra forma de conceitualizar linguagem é considerarmos o tipo de transmissão das informações. Reed (1994) sugere duas formas de transmissão: compreensão e produção da mensagem.

A relação entre compreensão e produção de linguagem é um aspecto importante e diferentes visões têm sido colocadas. A mais popular parece ser a visão de Ingram, 1974, de que a compreensão de linguagem precede a produção. Por outro lado, outros autores argumentam que a relação entre compreensão e produção é variável e está em constante modificação durante o curso do desenvolvimento, a depender de fatores como o contexto e a interação entre o crescimento das habilidades lingüísticas e cognitivas da criança. Portanto, a compreensão e a produção são vistas como modalidades diferentes, mas mutuamente dependentes de outros importantes processos (Hakansson e Hansson, 2000).

Uma criança pode produzir certas formas sintáticas, sentenças apropriadas com sujeito, verbo e objeto, mas pode ser incapaz de demonstrar compreensão das mesmas formas em situação formal de teste. Nestes casos, a visão de que a compreensão precede a produção não procede. Isto significa que não devemos supôr sobre a compreensão de linguagem, baseando-nos apenas na produção e vice-versa (Miller e Paul, 1995). 
Para Harris et al (1995) a compreensão da palavra antecipa a sua produção. Estudos que compararam a compreensão e a produção da palavra encontraram um gap de vários meses na aquisição de um nível similar de números de palavras de acordo com a modalidade de linguagem.

Hirsh-Pasek e Golinkoff (1997) também destacam que a relação entre produção e compreensão tem sido alvo de muito debate. Para as autoras, a compreensão deve preceder a produção e alguns argumentos sustentam esta hipótese: a compreensão envolve a relação sobre o que foi dito em um esquema enquanto que a produção envolve a construção do esquema, o input de compreensão de linguagem é organizado para o ouvinte enquanto que na produção deve ser organizado pelo falante e por fim, o contexto oferece mais suporte e relevância para compreender do que para falar.

A relação entre compreensão e produção em crianças tem sido investigada nos quadros de Distúrbio Específico de Linguagem em diversos estudos.

Bishop (1979) a partir de um estudo com crianças com Distúrbio Específico de Linguagem, refere que a maioria destas crianças incluindo aqueles classificados apenas como distúrbios expressivos, apresentavam também déficits na compreensão de linguagem. Os resultados do estudo ilustraram as inadequadas formas de investigar estes déficits, uma vez que estas crianças mesmo não demonstrando problemas óbvios de compreensão durante as situações informais de conversação, apresentaram desempenho inferior ao seus pares em desenvolvimento normal, em tarefas formais. O estudo então, apontou para a necessidade de se desenvolver medidas formais para avaliar a compreensão de linguagem. (Bishop, 1979).

Os estudos mostram que crianças com desordens de linguagem apresentam um gap entre a sua performance em linguagem expressiva e linguagem receptiva. Geralmente as habilidades expressivas são julgadas como significamente abaixo da média e suas habilidades receptivas, freqüentemente são classificadas como "normais". Estes resultados podem ser baseados em resultados de um teste de linguagem receptiva ou de observações clinicas informais (Rizzo e Stephens, 1981) 
Para Rizzo e Stephens (1981) os clínicos devem escolher testes de compreensão contendo normas populacionais similares às da criança que está sendo avaliada. Além disso, alertam que os clínicos deveriam administrar mais que um teste de compreensão e que os programas de intervenção deveriam incluir as habilidades de compreensão.

Para Dale e Henderson (1987) a distinção entre as habilidades receptivas e expressivas é importante para a prática clinica e para o direcionamento das pesquisas. Crianças que apresentam déficits expressivos acompanhados de déficits receptivos necessitam de tratamento diferenciado daquelas que apresentam apenas déficits expressivos. Os autores referem ainda, que as pesquisas com crianças com desenvolvimento normal de linguagem incluem medidas expressivas e receptivas, entretanto, poucos dados são encontrados sobre uma relação empírica entre as duas habilidades ou sistemas.

A subdivisão da linguagem em recepção e expressão, conforme apontado anteriormente tem implicações para o diagnóstico diferencial. Em referências como o Manual de Diagnóstico e Estatístico de Transtornos Mentais - DSM-IV e na CID-10 - Classificação Internacional de Doenças, a classificação dos distúrbios de linguagem é baseada nesta subdivisão: Transtorno de Linguagem Expressiva, Transtorno Misto de Linguagem Receptivo-Expressiva (DSM-IV); Transtorno Expressivo de Linguagem (F80.1) e Transtorno Receptivo de Linguagem (F80.2), segundo a CID-10.

\section{5 - Avaliação da Linguagem Infantil}

Pesquisadores da área de avaliação e diagnóstico em linguagem infantil referem que avaliar a linguagem infantil não é uma tarefa fácil. Alguns fatores podem justificar este fato: o desenvolvimento da linguagem é influenciado por outros aspectos do desenvolvimento, como cognição, desenvolvimento motor, desenvolvimento social. Condições clínicas como Deficiência Intelectual, Surdez, Autismo também afetam o desenvolvimento da linguagem. Os componentes lingüísticos funcionam de forma harmônica e a avaliação isolada destes não 
promove informação sobre o seu uso integrado. Além disso, as expectativas sobre a performance de linguagem podem variar com o tempo, ou seja, o que é normal em uma idade, pode não ser em outra. E deve-se destacar, ainda, que os falantes não constituem um grupo homogêneo, experiências e variações individuais também podem influenciar a avaliação (Shipley e McAfee, 2004).

A avaliação de crianças com suspeita de alteração no desenvolvimento da linguagem deve determinar os parâmetros de linguagem que podem estar deficientes, ou seja, é necessário discriminar as habilidades receptivas e expressivas e quais os componentes lingüísticos alterados, para que o diagnóstico possa ser melhor definido (Watkins, 1994; Plante e Vance, 1994; Rice, 1997; TagerFlusberg e Cooper, 1999; Paul, 2001).

Para que todos os objetivos do processo de avaliação e diagnóstico possam ser atingidos é necessário utilizar instrumentos e procedimentos adequados para verificar os padrões de linguagem. Estes instrumentos devem atender às reais condições da faixa etária e possibilidade de linguagem, bem como devem propiciar o melhor acesso ao potencial lingüístico da criança testada (Reed, 1994; Befi-Lopes, 2002).

$\mathrm{Na}$ literatura existe referência quanto aos procedimentos usuais de avaliação do desenvolvimento da linguagem infantil. Estes procedimentos variam de acordo com a literatura consultada, alguns autores referem que a avaliação deve ser realizada em situações naturais, utilizando amostras espontâneas de fala, outros referem a necessidade de utilizar procedimentos formais, como a aplicação de protocolos específicos. Embora exista uma diversidade de procedimentos sugeridos, os autores são unânimes em afirmar que o uso de testes formais e objetivos devem sempre integrar o processo de avaliação e diagnóstico (Bloom e Lahey, 1978; Stark e Tallal, 1981; Watkins e DeThorme, 2000; Correa, Freitas e Lima, 2003, Andrade et al, 2004). 


\section{6 - Uso de Testes Formais no Processo de Avaliação da Linguagem Infantil}

$\mathrm{Na}$ literatura internacional, os autores são unânimes em afirmar que para avaliar a linguagem infantil há a necessidade de utilizar vários testes e que a identificação das alterações deve ser realizada por meio de um sistema padronizado. O diagnóstico de possíveis alterações no desenvolvimento da linguagem deve identificar aspectos comprometidos e para isso existe a indicação de testes padronizados (Stark e Tallal, 1981; McCauley e Swisher, 1984; Lahey, 1990; Reed, 1994; Rice, 1995; Rice, 1997; Plante, 1999; Hresko, Reid e Hammill, 1999, Paul, 2001; Hage et al 2004).

Os testes devem identificar habilidades receptivas e expressivas de linguagem, devem promover informações normativas que possibiltem comparações entre as idades com a normalidade. Além disso, devem indicar as habilidades e dificuldades das crianças testadas e serem administrados em um período curto de tempo, de modo a evitar a fadiga da criança ou do examinador (Hresko, Reid e Hammill, 1999).

Os mesmos autores acrescentam que os testes além de indicarem as habilidades e as dificuldades da criança, também podem ser usados como parâmetro de evolução durante o processo de intervenção e também podem ser utilizados como instrumentos de pesquisas científicas.

Nos Estados Unidos, Boone e Plante (1994) referem que os profissionais da área de Fonoaudiologia dispõem de um amplo conjunto de testes e medidas formais para testar as habilidades de linguagem. Esta não é a mesma realidade observada no contexto brasileiro.

No Brasil, o uso de testes para avaliar a linguagem infantil não é uma prática usual. Faltam instrumentos desta categoria e tal afirmação pode ser comprovada, quando levantamos a quantidade de testes comercialmente disponíveis para esta finalidade. Atualmente, existe o teste ABFW - Teste de Linguagem Infantil, destinado à avaliação das áreas de fonologia, vocabulário, fluência e pragmática. 
Segundo as autoras, é um teste inédito no Brasil, inteiramente direcionado ao Português Brasileiro (Andrade et al, 2004).

Zorzi e Hage (2004) publicaram o Protocolo de Observação Comportamental para avaliação da linguagem e dos aspectos cognitivos em crianças de 12 a 48 meses. Os autores acreditam que este procedimento pode permitir uma compreensão mais precisa a respeito do que se considera evolução normal e do relacionamento entre tais aspectos do desenvolvimento. Além disso, a sistematização de observações sobre o comportamento infantil pode contribuir no diagnóstico de crianças com alteração de linguagem.

Sicuro, Freitas e Lima (2003) realizaram uma pesquisa na qual apresentam os resultados de um levantamento conduzido com o intuito de caracterizar o perfil de crianças falantes do Português com queixas de linguagem e de analisar os instrumentos usuais utilizados na avaliação de seu desempenho lingüístico. As autoras referem que em países onde as habilidades lingüísticas de crianças são regularmente avaliadas por volta dos cinco anos de idade, crianças diagnosticadas como Distúrbio Específico de Linguagem, por exemplo, são identificadas por pesquisadores e submetidas a testes que se utilizam de procedimentos experimentais desenvolvidos no estudo da aquisição de linguagem.

No Brasil, a falta de uma avaliação regular do desenvolvimento lingüistico bem como a falta de instrumentos de avaliação teoricamente embasados dificulta a identificação e a caracterização de crianças com Distúrbio Específico de Linguagem falantes do Português Brasileiro (Sicuro, Correa, Freitas, 2003).

Uma forma encontrada pelos pesquisadores de amenizar a falta de instrumentos formais e objetivos para avaliação da linguagem infantil no país, tem sido a tradução e a adaptação de instrumentos estrangeiros já devidamente testados. Alguns autores referem que é aconselhável a utilização de instrumentos já disponiveís entre outros países, ao invés de desenvolver um instrumento novo em cada um dos países que realizam o mesmo tipo de investigação. Os autores destacam que a tradução de instrumentos estrangeiros também pode permitir 
pesquisas transculturais (Guillemin et al, 1993; Duarte e Bordin, 2000; Freitas, et al 2001).

Neste sentido, algumas pesquisas nacionais têm sido realizadas com este propósito. Capovilla e Capovilla (1997) realizaram um estudo no qual forneceram a tradução brasileira para o Peabody Picture Vocabulary Test (PPVT, Dunn e Dunn, 1981) e para o Language Developmental Survey (LDS, Rescorla, 1989) ou Lista de Avaliação do Vocabulário Expressivo (LAVE). O PPVT é uma prova de vocabulário receptivo e avalia a compreensão do vocabulário e a LDS é uma prova de vocabulário expressivo que avalia o vocabulário em termos de palavras que a criança emite, segundo o relato da mãe ou do cuidador.

Os resultados deste estudo mostraram que os escores obtidos nos testes de vocabulário receptivo e expressivo aumentaram em função do nível escolar e da idade dos sujeitos. Como conclusão do estudo, os autores referiram que as traduções dos referidos instrumentos mostraram-se úteis para avaliar o desenvolvimento lingüístico de crianças brasileiras entre 2 e 6 anos de idade, em termos de vocabulário expressivo e receptivo, respectivamente.

Andrade e Juste (2001) realizaram uma pesquisa que teve como objetivo aplicar o Stuttering Severity Instrument (SSI) em crianças fluentes falantes do Português Brasileiro, para avaliar a sua efetividade numa lingua estrangeira. $O$ objetivo do referido teste foi avaliar a fluência em crianças e adultos e atribuir grau de severidade. Participaram da pesquisa 200 crianças sem qualquer queixa de gagueira, de ambos os sexos, com idades entre 2 e 11 anos. Os resultados demonstraram que mesmos nas crianças fluentes, 58,5\% foram classificadas com gagueira muito leve, $24,5 \%$ leve e $17 \%$ moderada. Uma implicação importante apontada a partir desta pesquisa é questionar a validade da transposição direta de escores de testes elaborados e padronizados em outras línguas para o Português. Com base nestes resultados, pode-se sugerir que o SSI, pelo menos para as crianças nas faixas etárias testadas, falantes nativos do Português Brasileiro não seja aplicado isoladamente como único teste diagnóstico para a gagueira e como determinante de seu grau de severidade. 
Em um estudo descrito por Araújo e Perissinoto, 2004, quatro subtestes do Test of Language Competence - Expanded (TCL-E) de Wiig e Secord, 1985, foram traduzidos e adaptados para o Português Brasileiro e foram aplicados em 16 estudantes de 16 a 18 anos de idade, sendo 08 com queixas de dificuldade escolar e 8 sem queixas escolares. Os resultados obtidos no estudo indicaram que a versão traduzida do teste foi sensível para diferenciar os dois grupos estudados. Houve uma diferença estatisticamente significante entre os grupos sem queixa e com queixa no se refere ao desempenho geral nas tarefas metalingüísticas avaliadas.

Broggio, 2005, realizou uma pesquisa que teve como objetivo adaptar o Test of Language Development Primary-3 (TOLD-P:3), de Newcomer e Hammil, 1997, para o Português Brasileiro e estabelecer o desempenho de crianças em desenvolvimento típico de linguagem segundo os subtestes do teste adaptado. As crianças tiveram desempenho melhor em função do aumento da idade, com aumento da complexidade das respostas fornecidas. As crianças de todos os grupos apresentaram melhor desempenho no subteste vocabulário de figuras e pior desempenho no subteste análise fonêmica e nos demais subtestes houve variação no desempenho entre os grupos. Como conclusão, Broggio refere que a adaptação do TOLD-P:3 para o Português Brasileiro poderá ser utilizada como teste diagnóstico para verificar o perfil lingüístico de crianças de 4 a 8 anos de idade.

Mansur et al, 2006, realizaram uma pesquisa com o Teste de Nomeação de Boston que é um teste amplamente utilizado para avaliação de nomeação em indivíduos adultos. Segundo as autoras, os escores usados no Brasil têm sido os mesmos da versão americana do teste. A pesquisa teve como objetivo avaliar a influência da idade e da escolaridade na habilidade de nomeação em uma amostra de 133 individuos normais, da cidade de São Paulo, com idades entre 28 e 70 anos. Como resultados da pesquisa, as autoras concluíram que a escolaridade foi a variável que mais influenciou o desempenho dos indivíduos. Embora o grau de dificuldade de alguns itens possa diferir na Língua Inglesa e Portuguesa, a aplicação da versão traduzida do teste de Nomeação de Boston sem adaptações, para a população brasileira, é possível, desde que o nivel educacional seja considerado na interpretação dos resultados (Mansur et al, 2006). 
Silagi et al (2006) referem que no Brasil são poucos os instrumentos-padrão de medidas quantificáveis para crianças nos primeiros anos de vida. Por isso, realizaram uma pesquisa que teve como objetivo verificar a concordância de itemidade entre crianças, sem queixa de desenvolvimento e a padronização americana do Preschool Language Scale-3 (PLS-3, Zimmerman, Steiner \& Pond, 1992). Participaram do estudo 32 crianças, entre 30 e 47 meses de idade, de ambos os sexos, sem queixa de comunicação. Para avaliação foi utilizado a PLS-3 versão em Português (Perissinoto e Farias, 2002) que avalia a recepção auditiva e a emissão verbal e não-verbal, por meio de duas escalas: Compreensão Auditiva (CA) e Comunicação Expressiva (CE), compostas por quatro tarefas em cada faixa etária por semestre.

Como resultados, não foram verificadas diferenças de desempenho na PLS-3 quanto ao sexo. Em comparação ao padrão americano, 3 crianças apresentaram desempenho abaixo do esperado. Quanto às faixas etárias, observou-se um acréscimo na média de acertos dos itens, em ambas as escalas, mostrando um aumento no grau de complexidade dos itens do teste. Para alguns itens que obtiveram porcentagem de acertos abaixo de $50 \%$ foram propostas reformulações. Como conclusão, as autoras concluíram que a Preschool Language Scale-3 demonstrou ser um instrumento aplicável e sensível para avaliar a linguagem de crianças de 30 a 47 meses, sendo que a pontuação média obtida pelas crianças avaliadas ficou dentro do padrão observado no teste original.

Considerando os dados descritos na literatura, este estudo tem como objetivo verificar a performance de crianças com desenvolvimento típico de linguagem no Test of Early Language Development - Terceira Edição (TELD-3, Hresko, Reid e Hammill, 1999), traduzido para o Português Brasileiro, em todas as possibilidades de análise do referido Teste.

As hipóteses de pesquisa testadas para responder aos objetivos propostos foram: 
Hipótese 1. A performance das crianças testadas será compatível com a média esperada para cada faixa etária, na versão original do Teste.

Hipótese 2. Não haverá diferença estatisticamente significante de performance nas formas A e B, bem como entre os subtestes receptivo e expressivo.

Hipótese 3. Haverá um aumento na pontuação, ou seja, um aumento nos valores dos escores brutos, conforme aumenta a idade cronológica das crianças testadas. 


\section{II - Método}

\section{1 - Aspectos Éticos}

Este estudo foi aprovado pela Comissão de Ética para Análise de Projetos de Pesquisa - CAPPesq da Diretoria Clínica do Hospital das Clínicas da Faculdade de Medicina da Universidade de São Paulo, com protocolo número 236/04 (Anexo A), inclusive o Termo de Consentimento Livre e Esclarecido (Anexo F) que todos os responsáveis pelos sujeitos assinaram antes do início da coleta de dados, autorizando a participação na pesquisa.

\section{2 - Sujeitos}

Participaram deste estudo 120 sujeitos com desenvolvimento típico de linguagem, com faixa etária entre 2:00 a 7:11 anos. Cada faixa etária foi composta por 20 sujeitos, de ambos os sexos, sendo 10 do sexo masculino e 10 do sexo feminino.

Os sujeitos de 2:00 a 6:11 anos estavam matriculados em um Centro Infantil e os sujeitos de 7:11 anos em uma Escola Municipal de Educação Infantil e Fundamental. Todos residentes da cidade de Limeira, interior do Estado de São Paulo.

Os procedimentos de avaliação só foram iniciados após os processos éticos pertinentes: Parecer da Comissão de Ética, autorização dos responsáveis pelos locais de coleta (Centro Infantil e Escola Municipal) e assinatura do Termo de Consentimento Livre e Esclarecido pelos responsáveis pelos sujeitos.

Para que pudessem participar do estudo, os sujeitos passaram por um processo de seleção seguindo critérios de exclusão e de inclusão.

Como critérios de exclusão foram considerados os seguintes aspectos: presença de queixa fonoaudiológica pelas educadoras, encaminhamento e/ou 
tratamento pregresso de fonoaudiologia e outras especialidades sugerindo assim, possíveis alterações desenvolvimentais. Para confirmar os dados a pesquisadora realizou uma breve consulta no prontuário de cada sujeito, para que fosse confirmada a ausência de encaminhamentos e estes dados também foram confirmados com os responsáveis pelos sujeitos.

Como critérios de inclusão foram considerados: a indicação de crianças que as educadoras consideravam que se comunicavam adequadamente para suas respectivas idades. Também foi considerada a faixa etária e data de aniversário dos sujeitos, para que a amostra ficasse equilibrada quanto à variação dos meses. Os sujeitos também tiveram que apresentar desempenho adequado na triagem fonoaudiológica, realizada individualmente pela pesquisadora.

Segundo a caracterização realizada pelas profissionais do Serviço Social do Centro Infantil e da Escola, os sujeitos atendidos nestes locais pertenciam ao nível sócio-econômico médio, médio-baixo e baixo. 


\section{3 - Material}

Para realização deste estudo foi utilzado o Test of Early Language Development - terceira edição (TELD-3), traduzido para o Português Brasileiro. Este teste foi selecionado após um levantamento realizado pela própria pesquisadora sobre os testes disponíveis no mercado internacional para avaliar a linguagem infantil. O TELD-3 foi escolhido porque é um teste que visa a identificação precoce de alterações no processo de desenvolvimento de linguagem e por isso, fornece ao examinador uma medida geral da performance lingüística das crianças. Ou seja, analisando o teste notou-se que o mesmo contempla os principais marcos do desenvolvimento da linguagem e por ser uma medida mais geral, percebemos que as diferenças culturais e de língua iriam interferir menos nos nossos resultados do que outros testes que avaliam aspectos mais específicos, como por exemplo, apenas a morfologia ou a fonologia. Além disso, vale ressaltar que instrumentos desta categoria, são escassos no Brasil.

É importante destacar que anterior à aquisição do teste, foi realizado um contato com os autores e com a editora (PRO-ED), que autorizaram o uso do mesmo para as finalidades desta pesquisa (Anexos B e C). Este procedimento é fundamental em pesquisas com esta finalidade.

Vale salientar também que os procedimentos adotados na tradução e adaptação do TELD-3 para o Português Brasileiro foram descritos no Estudo I desta Tese. 


\section{1 Descrição do Teste}

O TEST OF EARLY LANGUAGE DEVELOPMENT (TELD) foi desenvolvido por Wayne P. Hresko, D. Kim Reid e Donald D. Hammil e sua primeira edição foi publicada em 1981. A segunda edição do Teste foi publicada em 1991, contendo itens adicionais com novos dados normativos e com ampliação da faixa etária. Atualmente, o TELD está na sua terceira edição, publicada em 1999.

O TELD-3 é utilizado para verificar as habilidades receptivas e expressivas da linguagem em crianças, na faixa etária de 2 anos a 7:11 anos. O tempo médio de aplicação é de trinta minutos. O Teste possui duas formas, que segundo os autores, são equivalentes (forma $\mathrm{A}$ e forma $\mathrm{B}$ ) e é composto por dois subtestes: linguagem receptiva e linguagem expressiva, contendo 37 e 39 itens, respectivamente.

\section{4 - Procedimento}

Após a seleção dos sujeitos e a seleção do material, foi iniciada a coleta de dados. Todos os sujeitos foram testados individualmente e tempo de coleta foi em média de trinta minutos. O teste foi aplicado de acordo com as instruções contidas no manual de aplicação do mesmo. As respostas fornecidas pelos sujeitos foram registradas nos protocolos de respostas. Em seguida, a examinadora corrigiu as respostas, calculou a pontuação e classificou a performance de cada sujeito, também de acordo com as instruções originais do Teste e que foram mantidas no seu processo de tradução e adaptação para o Português Brasileiro.

\section{1 - Aplicação do Teste}

O Teste é subdividido em subtestes de Linguagem Receptiva e Linguagem Expressiva e possui, segundo os autores, duas formas equivalentes - forma A e forma B. De acordo com as instruções, os subtestes receptivo e expressivo podem ser aplicados em qualquer ordem. Quanto a este aspecto, neste estudo, foi iniciada a aplicação pelo subteste receptivo, pelo fato de exigir da criança mais respostas gestuais, como por exemplo, apontar figuras. Com isso, a criança tinha um tempo maior para se familiarizar com a situação de teste e também com a pesquisadora, 
favorecendo a interação e o contato. Deste modo, estes aspectos, poderiam interferir menos, no momento da aplicação do subteste expressivo.

Quantos às diferentes formas, por serem equivalentes, de acordo com as instruções contidas no manual de aplicação, o examinador pode aplicar uma ou outra. Neste estudo, optou-se por administrar as duas formas em grupos diferentes de sujeitos, para obter valores de referência para ambas as formas. Ou seja, o grupo de sujeitos de cada faixa etária foi dividido e para cada subgrupo foi utilizada uma forma diferente do Teste (em 50\% da amostra foi utilizada a forma A e nos demais $50 \%$, a forma $B$ ).

\section{5 - Análise dos Dados}

Após a aplicação do teste, foram realizadas as correções das respostas, seguidas das classificações das performances e para isso foram utilizadas as tabelas de conversão dos escores da versão original do teste.

Para cada item de cada subteste está descrito, no manual do examinador, o que a criança deve realizar ou responder para obter pontos. A criança recebeu um ponto para cada item respondido corretamente e zero para cada item respondido incorretamente. A partir da soma dos itens corretos de cada subteste, foi possível encontrar os escores brutos nos subtestes e assim, prosseguir com a interpretação dos resultados, para se obter a classificação da performance da criança e para isso, deve-se considerar os valores dos quocientes que podem ser interpretados do seguinte modo: 


\section{Quadro 01*: Classificação dos quocientes}

\begin{tabular}{|c|c|}
\hline Quocientes & Classificação \\
\hline $131-165$ & Muito Superior \\
\hline $121-130$ & Superior \\
\hline $111-120$ & Acima da Média \\
\hline $90-110$ & Média \\
\hline $80-89$ & Abaixo da Média \\
\hline $70-79$ & Pobre \\
\hline $35-69$ & Muito Pobre \\
\hline
\end{tabular}

* Referência: TELD-3, Manual do examinador, página 61

As correções dos desempenhos dos sujeitos no Teste bem como a interpretação dos resultados foram submetidas a dois juizes fonoaudiólogos, que estão cursando Pós-Graduação e possuem experiência em transcrição e em aplicação de testes com a população infantil. Foram selecionados 06 sujeitos por faixa etária, o que corresponde a $25 \%$ da amostra total dos sujeitos participantes. Foi realizada uma análise comparativa para verificar a fidedignidade dos dados obtidos e houve uma concordância de $100 \%$. 


\section{Análise Estatística}

Após a coleta, os dados foram tabulados e foram enviados para análise estatística pertinente. Foi realizada a análise descritiva e inferencial, sendo que para esta última foi fixado um nível de significância de 5\% em todos os testes e intervalos de confiança.

As técnicas estatísticas utilizadas foram:

- Análise Descritiva Unidimensional

- Análise de Regressão Clássica

- Testes de Hipóteses Paramétricos

- Teste de Hipóteses Não Paramétricos 


\section{V - Resultados}

Os resultados deste estudo serão divididos em 06 partes. Na primeira parte serão apresentadas as medidas descritivas das variáveis Escore Bruto e Quociente. $\mathrm{Na}$ segunda parte serão apresentados os resultados referentes à comparação do desempenho dos sujeitos nas formas A e B do teste. Na terceira parte serão apresentados os dados da comparação de desempenho no subteste receptivo e expressivo. A análise do aumento dos valores do escores brutos em função da idade cronológica será apresentada na quarta parte. E para finalizar na quinta e sexta partes serão apresentados os percentuais de distribuição da classificação dos sujeitos no teste e as curvas de referências obtidas a partir do desempenho dos sujeitos testados.

\section{1 - Medidas descritivas da performance dos sujeitos nas formas A e B do teste:}

As Tabelas (1 a 12) apresentadas abaixo ilustram os valores das medidas descritivas para as seguintes variáveis: Escore Bruto Receptivo, Escore Bruto Expressivo, Quociente Receptivo, Quociente Expressivo e Quociente Falado, para as faixas etárias de 2:00 a 7:11 anos, nas formas $A$ e $B$ do teste.

Os Escores Brutos correspondem ao número de acertos no teste, ou seja, ao número de itens respondidos corretamente em cada subteste. A partir de uma tabela de conversão padronizada os Escores Brutos são convertidos nos Quocientes, que correspondem aos escores-padrão do teste e a partir destes é possível classificarmos a performance da criança. Quando os Quocientes apresentam valores entre 90 e 110 significa que a performance obtida pela criança no Teste está dentro da média esperada para sua idade.

Analisando primeiramente os valores das medidas descritivas na forma $A$ do teste, é possível verificarmos que os valores das médias do Escore Bruto Receptivo e Expressivo aumentam em função das faixas etárias. Quanto aos valores das médias dos Quocientes - Receptivo, Expressivo e Falado nota-se que as médias de todos os quocientes ficaram dentro dos valores esperados (90 a 110). 
Na forma B do teste, a partir das Tabelas apresentadas é possível verificar que as médias dos Escores Brutos também aumentam em função da faixa etária, porém aos observarmos as médias dos Quocientes podemos notar que as médias do Quociente Expressivo nas faixas etárias de 5 e 6 anos ficaram abaixo do valor esperado (87,3 e 86,8, respectivamente).

Tabela 01: Medidas descritivas para a variável Escore Bruto na Faixa Etária 2 anos.

\begin{tabular}{|c|c|c|c|c|c|c|c|c|c|}
\hline & & & média & mínimo & Q1 & mediana & Q3 & máximo & erro padrão \\
\hline \multirow{4}{*}{ Forma } & \multirow{2}{*}{ A } & Receptivo & 9,1 & 6 & 7,0 & 8,5 & 10,5 & 15 & 0,85 \\
\hline & & Expressivo & 12,8 & 11 & 11,0 & 12,5 & 14,3 & 15 & 0,51 \\
\hline & \multirow{2}{*}{ B } & Receptivo & 9,4 & 6 & 7,0 & 10,0 & 10,5 & 13 & 0,70 \\
\hline & & Expressivo & 14,3 & 11 & 12,0 & 12,5 & 17,5 & 19 & 0,99 \\
\hline
\end{tabular}

Tabela 02: Medidas descritivas para a variável Quociente na Faixa Etária 2 anos.

\begin{tabular}{rlrrrrrrr}
\hline & & média & mínimo & Q1 & mediana & Q3 & máximo & erro padrão \\
\hline \multirow{6}{*}{ Forma } & A Receptivo & 98,5 & 89 & 92,0 & 97,0 & 107,0 & 110 & 2,43 \\
& Expressivo & 97,5 & 88 & 95,5 & 97,0 & 101,3 & 105 & 1,49 \\
& Falado & 97,6 & 86 & 94,5 & 96,5 & 102,0 & 109 & 1,95 \\
\cline { 2 - 8 } & Receptivo & 98,9 & 92 & 92,0 & 100,0 & 106,0 & 106 & 1,97 \\
\multirow{2}{*}{ B } & Expressivo & 101,3 & 96 & 96,8 & 98,0 & 109,0 & 112 & 1,97 \\
& Falado & 100,8 & 93 & 94,5 & 101,5 & 105,5 & 111 & 1,89 \\
\hline
\end{tabular}

Tabela 03: Medidas descritivas para a variável Escore Bruto na Faixa Etária 3 anos.

\begin{tabular}{|c|c|c|c|c|c|c|c|c|c|}
\hline & & & média & mínimo & Q1 & mediana & Q3 & máximo & erro padrão \\
\hline \multirow{4}{*}{ Forma } & \multirow{2}{*}{ A } & Receptivo & 19,1 & 12 & 18,8 & 20,0 & 20,0 & 22 & 0,85 \\
\hline & & Expressivo & 22,1 & 17 & 21,5 & 22,5 & 24,0 & 24 & 0,69 \\
\hline & \multirow{2}{*}{ B } & Receptivo & 16,4 & 12 & 12,8 & 16,5 & 19,5 & 21 & 1,10 \\
\hline & & Expressivo & 21,1 & 17 & 18,8 & 21,0 & 23,3 & 25 & 0,81 \\
\hline
\end{tabular}


Tabela 04: Medidas descritivas para a variável Quociente na Faixa Etária 3 anos.

\begin{tabular}{|c|c|c|c|c|c|c|c|c|c|}
\hline & & & média & mínimo & Q1 & mediana & Q3 & máximo & erro padrão \\
\hline \multirow{6}{*}{ Forma } & \multirow{3}{*}{ A } & Receptivo & 104,7 & 92 & 98,0 & 106,0 & 113,0 & 113 & 2,29 \\
\hline & & Expressivo & 100,6 & 83 & 89,8 & 103,0 & 112,0 & 116 & 3,78 \\
\hline & & Falado & 102,9 & 93 & 93,0 & 102,5 & 113,5 & 117 & 3,00 \\
\hline & \multirow{3}{*}{ B } & Receptivo & 96,8 & 86 & 89,0 & 96,5 & 102,0 & 113 & 2,60 \\
\hline & & Expressivo & 97,6 & 91 & 94,0 & 98,5 & 101,0 & 103 & 1,30 \\
\hline & & Falado & 96,7 & 90 & 92,0 & 95,5 & 99,8 & 108 & 1,69 \\
\hline
\end{tabular}

Tabela 05: Medidas descritivas para a variável Escore Bruto na Faixa Etária 4 anos.

\begin{tabular}{|c|c|c|c|c|c|c|c|c|c|}
\hline & & & média & mínimo & Q1 & mediana & Q3 & máximo & erro padrão \\
\hline \multirow{4}{*}{ Forma } & \multirow{2}{*}{ A } & Receptivo & 25,3 & 20 & 22,0 & 25,0 & 30,0 & 30 & 1,16 \\
\hline & & Expressivo & 28,3 & 23 & 26,0 & 29,0 & 31,0 & 32 & 1,00 \\
\hline & \multirow{2}{*}{ B } & Receptivo & 25,2 & 21 & 22,0 & 23,0 & 29,3 & 31 & 1,21 \\
\hline & & Expressivo & 26,6 & 23 & 24,5 & 26,0 & 28,8 & 32 & 0,97 \\
\hline
\end{tabular}

Tabela 06: Medidas descritivas para a variável Quociente na Faixa Etária 4 anos.

\begin{tabular}{|c|c|c|c|c|c|c|c|c|c|}
\hline & & & média & mínimo & Q1 & mediana & Q3 & máximo & erro padrão \\
\hline \multirow{6}{*}{ Forma } & \multirow{3}{*}{ A } & Receptivo & 104,1 & 83 & 91,0 & 100,5 & 122,0 & 125 & 4,66 \\
\hline & & Expressivo & 101,0 & 82 & 91,8 & 102,0 & 112,0 & 112 & 3,68 \\
\hline & & Falado & 103,0 & 96 & 97,0 & 100,5 & 107,8 & 120 & 2,50 \\
\hline & \multirow{3}{*}{ B } & Receptivo & 104,5 & 91 & 95,0 & 96,5 & 119,8 & 122 & 4,06 \\
\hline & & Expressivo & 94,4 & 82 & 87,3 & 92,5 & 99,5 & 115 & 3,16 \\
\hline & & Falado & 99,2 & 86 & 88,8 & 95,0 & 109,0 & 120 & 3,65 \\
\hline
\end{tabular}

Tabela 07: Medidas descritivas para a variável Escore Bruto na Faixa Etária 5 anos.

\begin{tabular}{|c|c|c|c|c|c|c|c|c|c|}
\hline & & & média & mínimo & Q1 & mediana & Q3 & máximo & erro padrão \\
\hline \multirow{4}{*}{ Forma } & \multirow{2}{*}{ A } & Receptivo & 28,2 & 23 & 24,8 & 27,5 & 31,0 & 36 & 1,27 \\
\hline & & Expressivo & 30,8 & 29 & 30,0 & 31,0 & 31,3 & 33 & 0,36 \\
\hline & \multirow{2}{*}{ B } & Receptivo & 29,3 & 23 & 28,8 & 30,0 & 31,0 & 32 & 0,92 \\
\hline & & Expressivo & 28,3 & 23 & 27,5 & 28,0 & 30,0 & 32 & 0,79 \\
\hline
\end{tabular}


Tabela 08: Medidas descritivas para a variável Quociente na Faixa Etária 5 anos.

\begin{tabular}{|c|c|c|c|c|c|c|c|c|c|}
\hline & & & média & mínimo & Q1 & mediana & Q3 & máximo & erro $p$. \\
\hline \multirow{6}{*}{ Forma } & \multirow{3}{*}{ A } & Receptivo & 102,5 & 82 & 91,3 & 101,0 & 115,0 & 127 & 4,60 \\
\hline & & Expressivo & 95,5 & 91 & 91,0 & 94,0 & 97,0 & 112 & 1,96 \\
\hline & & Falado & 98,9 & 86 & 89,5 & 98,0 & 108,5 & 113 & 3,22 \\
\hline & \multirow{3}{*}{ B } & Receptivo & 107,6 & 82 & 104,8 & 110,0 & 115,5 & 118 & 3,85 \\
\hline & & Expressivo & 87,3 & 73 & 85,0 & 85,0 & 91,0 & 102 & 2,33 \\
\hline & & Falado & 97,0 & 84 & 90,8 & 97,0 & 101,8 & 112 & 2,71 \\
\hline
\end{tabular}

Tabela 09: Medidas descritivas para a variável Escore Bruto na Faixa Etária 6 anos.

\begin{tabular}{|c|c|c|c|c|c|c|c|c|c|}
\hline & & & média & mínimo & Q1 & mediana & Q3 & máximo & erro padrão \\
\hline \multirow{4}{*}{ Forma } & \multirow{2}{*}{ A } & Rec & 31,6 & 26 & 28,5 & 32,5 & 34,3 & 35 & 1,01 \\
\hline & & Expressivo & 33,9 & 31 & 32,5 & 34,0 & 35,3 & 37 & 0,62 \\
\hline & \multirow{2}{*}{ B } & Receptivo & 30,8 & 29 & 29,8 & 31,0 & 32,0 & 32 & 0,39 \\
\hline & & Expressivo & 29,9 & 27 & 29,0 & 30.0 & 31,0 & 32 & 0,46 \\
\hline
\end{tabular}

Tabela 10: Medidas descritivas para a variável Quociente na Faixa Etária 6 anos.

\begin{tabular}{rlrrrrrrr}
\hline & & média & mínimo & Q1 & mediana & Q3 & máximo & erro padrão \\
\hline \multirow{6}{*}{ Forma } & Receptivo & 107,0 & 85 & 95,0 & 110,0 & 115,8 & 121 & 3,91 \\
& Expressivo & 100,7 & 88 & 95,3 & 99,5 & 108,3 & 115 & 2,77 \\
& Falado & 104,5 & 96 & 99,5 & 104,5 & 109,5 & 113 & 1,81 \\
\cline { 2 - 8 } & Receptivo & 103,4 & 97 & 99,3 & 105,0 & 106,3 & 110 & 1,50 \\
\multirow{2}{*}{ B } & Expressivo & 86,8 & 79 & 85,0 & 88,0 & 90,0 & 90 & 1,08 \\
& Falado & 94,1 & 89 & 90,8 & 95,0 & 97,0 & 100 & 1,16 \\
\hline
\end{tabular}

Tabela 11: Medidas descritivas para a variável Escore Bruto na Faixa Etária 7 anos.

\begin{tabular}{|c|c|c|c|c|c|c|c|c|c|}
\hline & & & média & mínimo & Q1 & mediana & Q3 & máximo & erro padrão \\
\hline \multirow{4}{*}{ Forma } & \multirow{2}{*}{ A } & Receptivo & 34,8 & 33 & 33,0 & 35,5 & 36,0 & 36 & 0,44 \\
\hline & & Expressivo & 34,7 & 31 & 33,8 & 34,0 & 36,3 & 39 & 0,70 \\
\hline & \multirow{2}{*}{ B } & Receptivo & 32,0 & 29 & 30,5 & 31,5 & 34,0 & 36 & 0,71 \\
\hline & & Expressivo & 33,7 & 32 & 32,0 & 33,0 & 35,3 & 38 & 0,65 \\
\hline
\end{tabular}


Tabela 12: Medidas descritivas para a variável Quociente na Faixa Etária 7 anos.

\begin{tabular}{|c|c|c|c|c|c|c|c|c|c|}
\hline & & & média & mínimo & Q1 & mediana & Q3 & máximo & $\begin{array}{r}\text { erro } \\
\text { padrão }\end{array}$ \\
\hline \multirow{6}{*}{ Forma } & \multirow{3}{*}{ A } & Receptivo & 110,4 & 105 & 105,0 & 112,0 & 114,0 & 114 & 1,31 \\
\hline & & Expressivo & 94,9 & 85 & 90,0 & 92,0 & 99,5 & 112 & 2,67 \\
\hline & & Falado & 103,1 & 97 & 98,5 & 102,0 & 107,0 & 116 & 1,86 \\
\hline & \multirow{3}{*}{ B } & Receptivo & 99,1 & 84 & 91,3 & 98,5 & 106,3 & 118 & 3,29 \\
\hline & & Expressivo & 92,4 & 85 & 87,3 & 89,0 & 97,0 & 112 & 2,59 \\
\hline & & Falado & 94,8 & 83 & 89,0 & 93,0 & 99,3 & 113 & 2,97 \\
\hline
\end{tabular}

\section{2 - Comparação entre os desempenhos nas formas A e B do teste: resultados da análise inferencial}

$\mathrm{Na}$ Tabela abaixo (13) são apresentados os p-valores dos testes utilizados para verificar a igualdade das médias, medianas e variâncias entre as formas $A$ e $B$ para as seguintes variáveis: Escore Bruto (Receptivo e Expressivo) e Quociente (Receptivo, Expressivo e Falado), por faixa etária.

O teste $\mathrm{t}$ foi realizado para verificar a igualdade de médias. $\mathrm{O}$ teste não paramétrico de Kruskall-Wallis foi realizado para verificar a igualdade de medianas. E para verificar a igualdade de variâncias foi utilizado o teste de Levene.

Para efeitos inferenciais foi fixado um nível de significância de 5\% em todos os testes e intervalos de confiança. 
Tabela 13: Níveis descritivos ( $p$-valores) dos testes utilizados para verificar a igualdade entre as formas $\mathrm{A}$ e $\mathrm{B}$.

\begin{tabular}{|c|c|c|c|c|c|}
\hline \multirow{2}{*}{$\begin{array}{l}\text { Faixa } \\
\text { Etária }\end{array}$} & \multirow[b]{2}{*}{ variável } & \multirow{2}{*}{$\begin{array}{l}\text { Teste de } \\
\text { Levenne }\end{array}$} & \multicolumn{2}{|c|}{ teste $t$} & \multirow{2}{*}{$\begin{array}{c}\text { teste de } \\
\text { Kruskal- } \\
\text { Wallis }\end{array}$} \\
\hline & & & $\begin{array}{c}\text { variâncias } \\
\text { iguais }\end{array}$ & $\begin{array}{l}\text { variâncias } \\
\text { diferentes }\end{array}$ & \\
\hline \multirow{6}{*}{$\begin{array}{l}2 \\
\text { anos }\end{array}$} & Escore Bruto Receptivo & 0,751 & 0,789 & - & 0,540 \\
\hline & Escore Bruto & & & & \\
\hline & Expressivo & 0,005 & - & 0,200 & 0,317 \\
\hline & Quociente Receptivo & 0,640 & 0,900 & - & 0,909 \\
\hline & Quociente Expressivo & 0,191 & 0,141 & - & 0,251 \\
\hline & Quociente Falado & 0,943 & 0,254 & - & 0,342 \\
\hline \multirow{5}{*}{$\begin{array}{l}3 \\
\text { anos }\end{array}$} & $\begin{array}{l}\text { Escore Bruto Receptivo } \\
\text { Escore Bruto }\end{array}$ & 0,106 & 0,067 & - & 0,083 \\
\hline & Expressivo & 0,548 & 0,360 & - & 0,302 \\
\hline & Quociente Receptivo & 0,657 & 0,035 & - & 0,035 \\
\hline & Quociente Expressivo & 0,001 & - & 0,469 & 0,477 \\
\hline & Quociente Falado & 0,065 & 0,089 & - & 0,139 \\
\hline \multirow{5}{*}{$\begin{array}{l}4 \\
\text { anos }\end{array}$} & $\begin{array}{l}\text { Escore Bruto Receptivo } \\
\text { Escore Bruto }\end{array}$ & 0,518 & 0,953 & - & 0,878 \\
\hline & Expressivo & 0,961 & 0,238 & - & 0,222 \\
\hline & Quociente Receptivo & 0,846 & 0,949 & - & 0,879 \\
\hline & Quociente Expressivo & 0,287 & 0,190 & - & 0,182 \\
\hline & Quociente Falado & 0,096 & 0,401 & - & 0,198 \\
\hline \multirow{5}{*}{$\begin{array}{l}5 \\
\text { anos }\end{array}$} & $\begin{array}{l}\text { Escore Bruto Receptivo } \\
\text { Escore Bruto }\end{array}$ & 0,226 & 0,492 & - & 0,513 \\
\hline & Expressivo & 0,126 & 0,010 & - & 0,009 \\
\hline & Quociente Receptivo & 0,223 & 0,406 & - & 0,358 \\
\hline & Quociente Expressivo & 0,565 & 0,015 & - & 0,005 \\
\hline & Quociente Falado & 0,208 & 0,657 & - & 0,622 \\
\hline \multirow{6}{*}{$\begin{array}{l}6 \\
\text { anos }\end{array}$} & Escore Bruto Receptivo & 0,016 & - & 0,476 & 0,191 \\
\hline & Escore Bruto & & & & \\
\hline & Expressivo & 0,385 & 0,000 & - & 0,001 \\
\hline & Quociente Receptivo & 0,012 & - & 0,408 & 0,168 \\
\hline & Quociente Expressivo & 0,020 & - & 0,001 & 0,001 \\
\hline & Quociente Falado & 0,071 & 0,000 & - & 0,001 \\
\hline \multirow{5}{*}{$\begin{array}{l}7 \\
\text { anos }\end{array}$} & $\begin{array}{l}\text { Escore Bruto Receptivo } \\
\text { Escore Bruto }\end{array}$ & 0,198 & 0,004 & - & 0,009 \\
\hline & Expressivo & 1,000 & 0,309 & - & 0,220 \\
\hline & Quociente Receptivo & 0,020 & - & 0,008 & 0,009 \\
\hline & Quociente Expressivo & 0,939 & 0,509 & - & 0,338 \\
\hline & Quociente Falado & 0,339 & 0,029 & - & 0,015 \\
\hline
\end{tabular}

Estatisticamente significante a $5 \%$ 
A partir da Tabela 13 podemos verificar:

- Para a Faixa Etária de 2 anos: as médias e variâncias das duas formas são equivalentes, em todas as variáveis, exceto no Escore Bruto Expressivo que houve uma diferença de variância. E observando novamente a Tabela 01 pode-se concluir que a Forma $B$ apresenta uma maior variabilidade que a Forma $A$ (valor mínimo do Escore Bruto Expressivo na Forma B é 11 e o valor máximo é 19, ao passo que na Forma A o valor mínimo é 11 e o máximo é 15).

- Para a Faixa Etária de 3 anos: as médias e as variâncias para as duas formas do teste são equivalentes, exceto para variância do Quociente Expressivo (onde a variabilidade da forma $A$ é maior do que a forma $B$, conforme ilustra a Tabela 04) e para a média do Quociente Receptivo (a média da Forma A é maior do que a forma B, conforme podemos observar na Tabela 04).

- Para a Faixa Etária de $\mathbf{4}$ anos: as formas são equivalentes em todas as variáveis testadas.

- Para a Faixa Etária de 5 anos: há diferença de médias para o Escore Bruto Expressivo e para o Quociente Expressivo. Observando novamente as Tabelas $07 \mathrm{e}$ 08 vemos que a média obtida na forma $A$ é maior do que a Forma $B$.

- Para a Faixa Etária de 6 anos: há diferença entre as variâncias para o Escore Bruto Expressivo e Quociente Falado (a forma A apresenta maior variabilidade do que a Forma $B$, conforme podemos visualizar nas Tabelas 09 e 10 ). E também há diferença entre as médias para o Escore Bruto Receptivo e Quociente Receptivo ( as médias da Forma $\mathrm{A}$ são maiores que as da Forma B)

- Para a Faixa Etária de 7 anos: há diferença entre as médias do Escore Bruto Receptivo e Quociente Falado (na forma A os valores são maiores, conforme ilustra as Tabelas 11 e 12. O Quociente Receptivo apresenta diferença entre as formas para as médias e variâncias (também a forma A com maiores valores). 


\section{3 - Comparação entre a performance no Subteste Receptivo e o Subteste Expressivo}

Para comparar o desempenho dos sujeitos no subteste receptivo e no subteste expressivo foram realizados testes t-pareados para a variável Quociente e foram encontrados os respectivos intervalos de confiança para esta diferença. Foi realizado simultaneamente o teste não paramétrico, teste de Wilcoxon para diferença de mediana. Todos os resultados inferenciais foram os mesmos nos testes paramétrico e não-paramétrico. Na Tabela abaixo encontram-se os intervalos de confiança e os p-valores correspondentes aos testes utilizados.

Tabela 14: Comparação entre o Subteste Receptivo e o Subteste Expressivo

\begin{tabular}{|c|c|c|c|c|c|c|c|}
\hline \multirow{3}{*}{$\begin{array}{l}\text { Faixa } \\
\text { Etária }\end{array}$} & & & \multicolumn{3}{|c|}{ Diferenças Pareadas } & \multirow{3}{*}{$\begin{array}{c}\text { teste } t \\
\text { pareado } \\
\text { p-valor }\end{array}$} & \multirow{3}{*}{$\begin{array}{c}\text { teste de } \\
\text { Wilcoxon } \\
\text { p-valor }\end{array}$} \\
\hline & & & \multirow{2}{*}{ média } & \multicolumn{2}{|c|}{$\begin{array}{c}\text { intervalo de } 95 \% \text { de } \\
\text { confiança }\end{array}$} & & \\
\hline & & & & $\begin{array}{c}\text { limite } \\
\text { inferior }\end{array}$ & $\begin{array}{l}\text { limite } \\
\text { superior }\end{array}$ & & \\
\hline \multirow{2}{*}{2 anos } & \multirow{2}{*}{$\begin{array}{l}\text { Quociente Receptivo - } \\
\text { Quociente Expressivo }\end{array}$} & Forma A & 1,000 & $-4,427$ & 6,427 & 0,687 & 0,838 \\
\hline & & Forma B & $-2,400$ & $-8,174$ & 3,374 & 0,372 & 0,507 \\
\hline \multirow{2}{*}{3 anos } & \multirow{2}{*}{$\begin{array}{l}\text { Quociente Receptivo - } \\
\text { Quociente Expressivo }\end{array}$} & Forma A & 4,100 & $-4,481$ & 12,681 & 0,308 & 0,153 \\
\hline & & Forma B & $-0,800$ & $-7,466$ & 5,866 & 0,792 & 0,574 \\
\hline \multirow{2}{*}{4 anos } & \multirow{2}{*}{$\begin{array}{l}\text { Quociente Receptivo - } \\
\text { Quociente Expressivo }\end{array}$} & Forma A & 3,100 & $-13,305$ & 19,505 & 0,679 & 0,721 \\
\hline & & Forma B & 10,100 & 1,055 & 19,145 & $0,032^{*}$ & $0,015^{\star}$ \\
\hline \multirow{2}{*}{5 anos } & \multirow{2}{*}{$\begin{array}{l}\text { Quociente Receptivo - } \\
\text { Quociente Expressivo }\end{array}$} & Forma A & 7,000 & $-3,492$ & 17,492 & 0,166 & 0,385 \\
\hline & & Forma B & 20,300 & 10,094 & 30,506 & $0,001^{*}$ & $0,009^{*}$ \\
\hline \multirow{2}{*}{6 anos } & \multirow{2}{*}{$\begin{array}{l}\text { Quociente Receptivo - } \\
\text { Quociente Expressivo }\end{array}$} & Forma A & 6,300 & $-7,493$ & 20,093 & 0,328 & 0,405 \\
\hline & & Forma B & 16,600 & 12,481 & 20,719 & $0,000^{*}$ & $0,005^{\star}$ \\
\hline \multirow{2}{*}{7 anos } & \multirow{2}{*}{$\begin{array}{l}\text { Quociente Receptivo - } \\
\text { Quociente Expressivo }\end{array}$} & Forma A & 15,500 & 8,847 & 22,153 & $0,001^{*}$ & $0,008^{*}$ \\
\hline & & Forma B & 6,700 & $-0,619$ & 14,019 & 0,068 & 0,074 \\
\hline
\end{tabular}

* Estatisticamente significante a $5 \%$

$\mathrm{Na}$ Tabela 14 podemos verificar que, na forma $\mathrm{A}$ do teste apenas para a faixa etária de 7 anos rejeita-se a hipótese de igualdade entre as médias do Quociente Receptivo e do Quociente Expressivo. Na forma B a hipótese de igualdade foi rejeitada para as faixas etárias de 4, 5 e 6 anos. Em todos os casos em que existe diferença entre as médias, nota-se pelos intervalos de confiança, que a média do Quociente Receptivo é maior que do Quociente Expressivo. 


\section{4 - Análise do aumento dos valores da Variável Escore Bruto em função do aumento da Idade Cronológica}

Os gráficos de dispersão que serão apresentados a seguir (Gráficos 1 e 2) ilustram o aumento dos valores dos Escores Brutos em função do aumento da Idade Cronológica. A reta contínua de cor preta corresponde à referência americana, os quadrados em vermelho correspondem aos valores obtidos na forma $A$ e os losangos azuis correspondem à forma $\mathrm{B}$ do teste.

Gráfico 01: Dispersão de Escore Bruto Receptivo x Idade com a curva de referência americana.

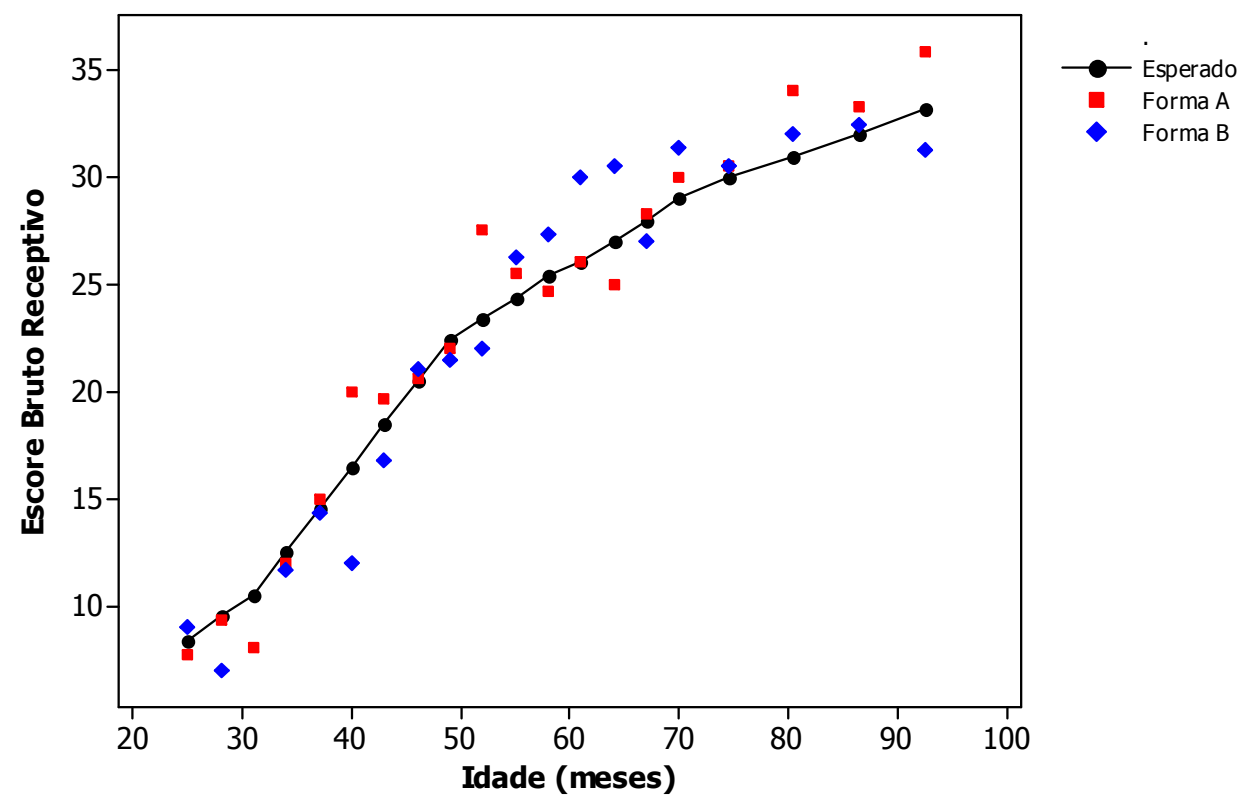

No Gráfico acima, nota-se que o crescimento da média do Escore Bruto Receptivo por intervalos de idade, apresenta um padrão próximo ao esperado. Contudo, para os maiores valores da Variável Idade, aparecem mais pontos acima da curva esperada, principalmente para a Forma A do teste. Observando-se novamente as Tabelas 9 e 11 podemos verificar que para as Faixas Etárias de 6 e 7 anos, as médias do Escore Bruto Receptivo apresentam valores maiores para a Forma A do teste. E obsevando-se as medidas descritivas das Faixas Etárias de 2, 3 , e 4 anos (Tabelas 1, 3 e 5) observam-se poucas diferenças entre as formas. 
Gráfico 02: Dispersão de Escore Bruto Expressivo x Idade com a curva de referência americana.

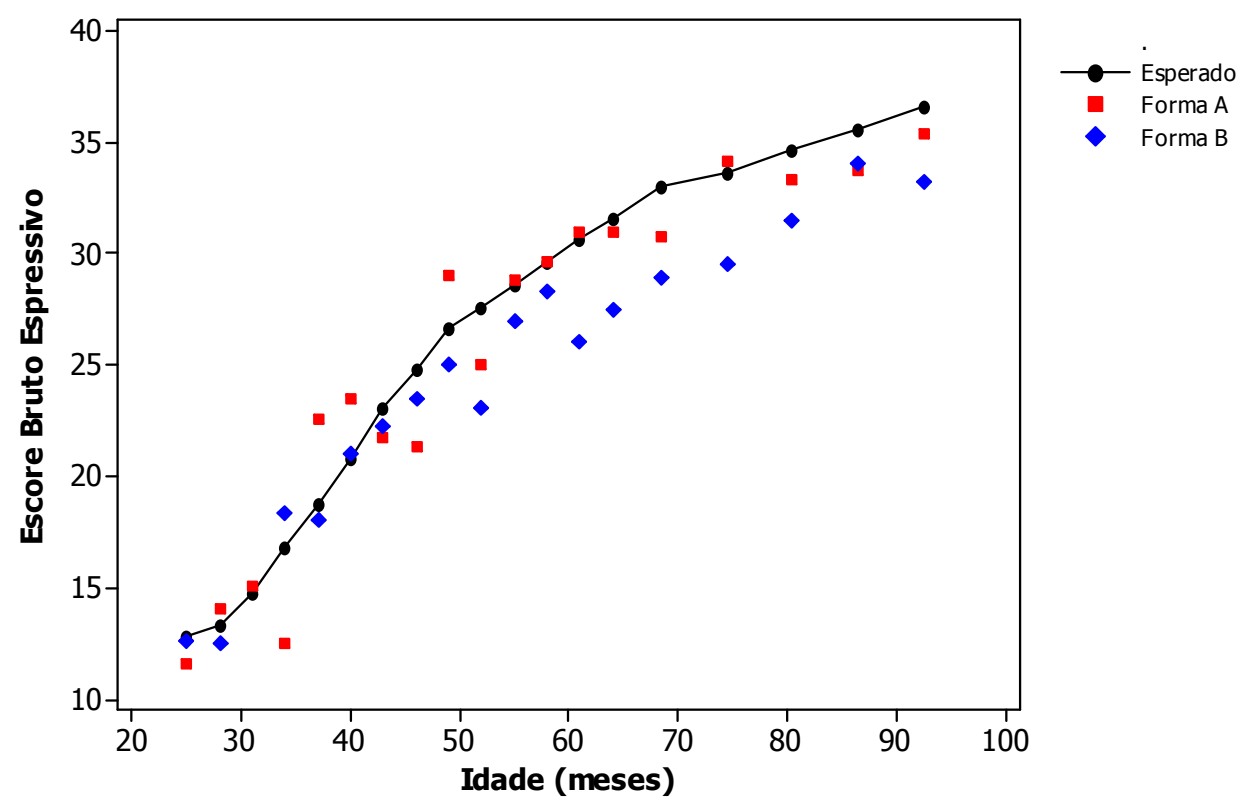

No Gráfico 02 nota-se que o crescimento da média do Escore Bruto Expressivo por intervalos de idade, também apresenta um padrão próximo ao esperado. Porém, na Forma B, para as idades superiores a 60 meses, aparecem muitos pontos abaixo do esperado. Observando- se as Tabelas descritivas 07, $09 \mathrm{e}$ 11 nota-se que para as faixas etárias 5, 6 e 7 anos, os valores da média e dos quartis do Escore Bruto Expressivo referentes à Forma $\mathrm{A}$ estão acima dos valores referentes à Forma $\mathrm{B}$ do teste. 


\section{5 - Distribuição da classificação da performance dos sujeitos}

A partir dos valores dos Quocientes é possível obtermos a classificação do sujeito testado. Os gráficos apresentados a seguir ilustram a distribuição percentual das classificações obtidas.

Gráfico 03: Distribuição percentual da variável Classificação do Quociente Receptivo para as Formas A e B do teste.
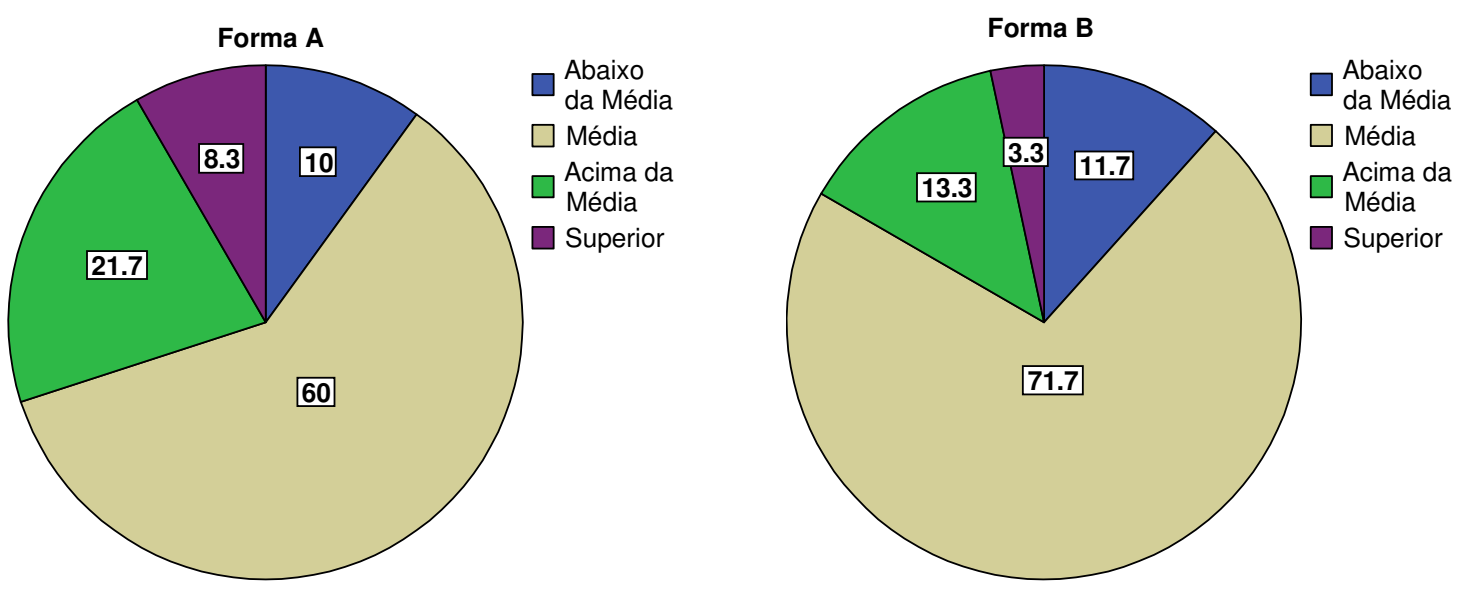

O Gráfico 03 ilustra que a Forma A do teste apresentou um percentual maior de sujeitos com classificação do Quociente Receptivo superior à média, pois temos $30 \%$ dos sujeitos com classificação Acima da Média ou Superior e apenas 10\% Abaixo da Média. Já, a Forma B, apresentou porcentagens próximas, com 16,6\% dos sujeitos com classificação Acima da Média ou Superior e 11,7\% com classificação Abaixo da Média. Nota-se, também, que a proporção de sujeitos com classificação Média foi maior para a Forma $B$ do teste, $71,7 \%$ contra $60 \%$ para a Forma A. Nenhum sujeito recebeu as classificações Muito Pobre, Pobre ou Muito Superior no subteste receptivo. 
Gráfico 04: Distribuição percentual da variável Classificação do Quociente Expressivo para as Formas A e B do teste
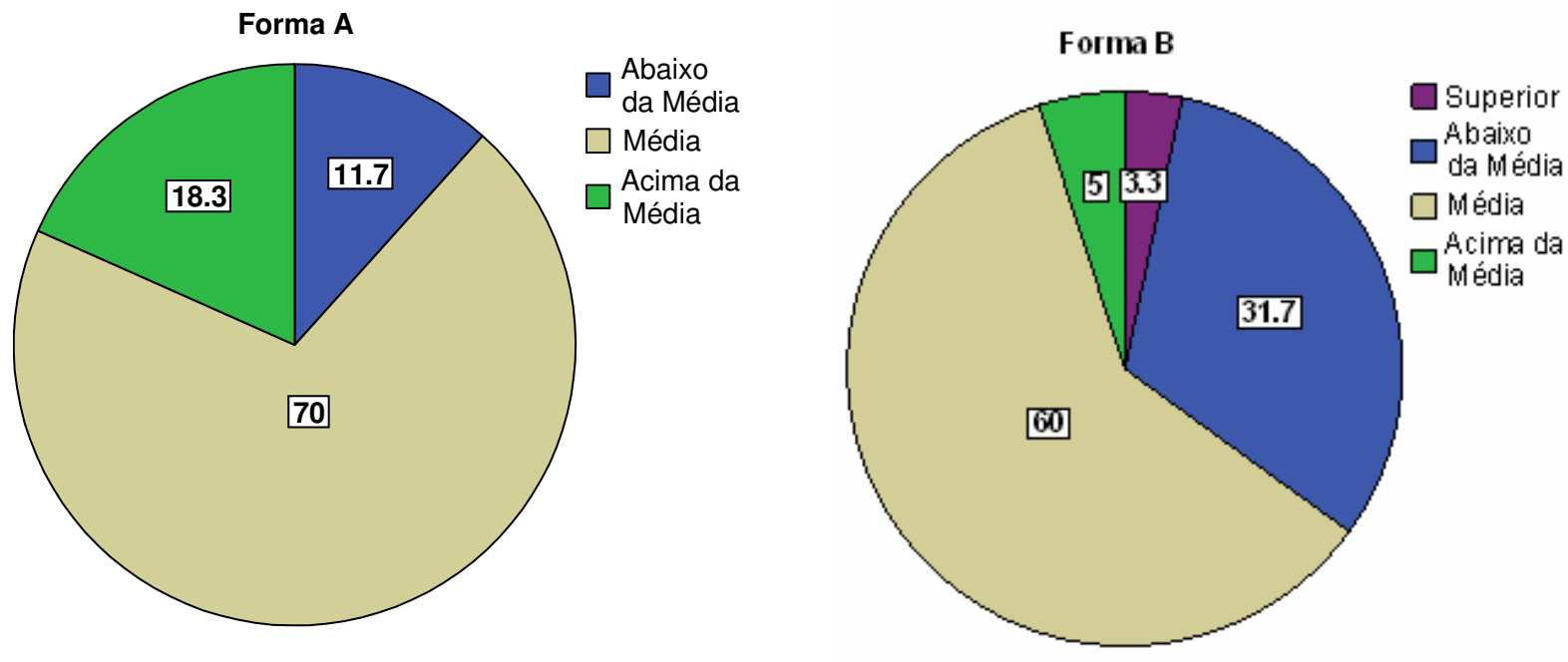

No Gráfico 04, vemos que a Forma B apresentou um maior número de sujeitos com Classificação Expressiva inferior à classificação Média, tendo 31,7\% dos sujeitos com classificação Abaixo da Média contra 8,3\% Acima da Média ou Superior. Já, na Forma $A$, as porcentagens foram mais próximas, apresentando 11,7\% Abaixo da Média e 18,3\% Acima da Média. Para o subteste expressivo obteve-se uma maior proporção de sujeitos com classificação Média na Forma A, $70 \%$, contra $60 \%$ para a Forma B. Nenhum sujeito recebeu a classificação Muito Pobre, Superior ou Muito Superior no subteste expressivo. 
Gráfico 05: Distribuição percentual da variável Classificação do Quociente de Linguagem Falada para as Formas A e B do teste.
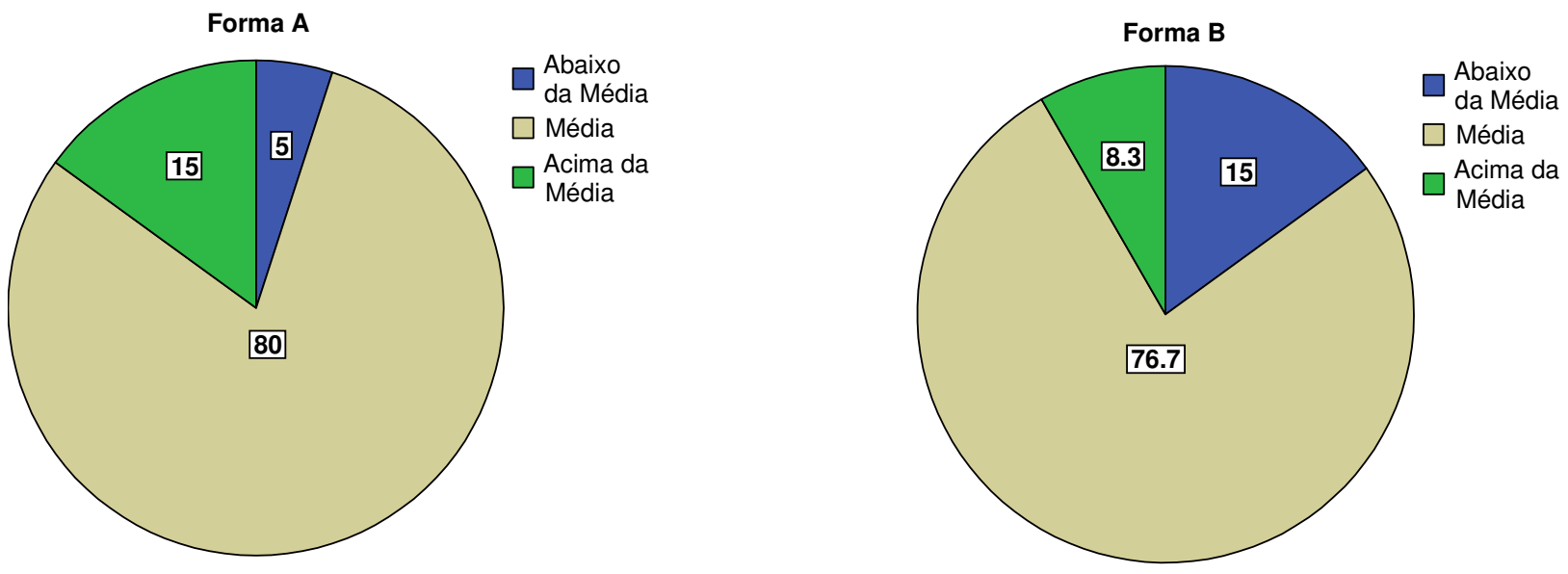

No Gráfico acima verificamos que, na Forma A do teste, a proporção de sujeitos com classificação do Quociente Falado Acima da Média (15\%) foi maior do que com Abaixo da Média (5\%). Já, a Forma B, apresentou 15\% dos sujeitos com classificação Abaixo da Média e 8,3\% Acima da Média. Obteve-se uma maior proporção de sujeitos com classificação Média para a Forma A do que para a Forma B, $80 \%$ contra $76,7 \%$. Nenhum sujeito recebeu classificação Muito Pobre, Pobre, Superior ou Muito Superior. 


\section{6 - Apresentação das Curvas de Referência}

A partir da performance apresentada pelos sujeitos da pesquisa foram construídas curvas de referência. Para que estas curvas pudessem ser construídas foi realizada uma análise de regressão. Foram ajustados modelos de regressão, separadamente para cada Forma do teste, para as variáveis Escore Bruto em função da Idade Cronológica, expressa em meses.

A análise de regressão realizada encontra-se no Anexo G.

A partir dos percentis estimados de ordem 5, 25, 50, 75 e 95, foram construídas as curvas de referência, conforme ilustram os gráficos que serão apresentados a seguir (Gráficos 6, 7, 8 e 9).

Gráfico 6: Curva de referência para o Escore Bruto Receptivo na Forma A.

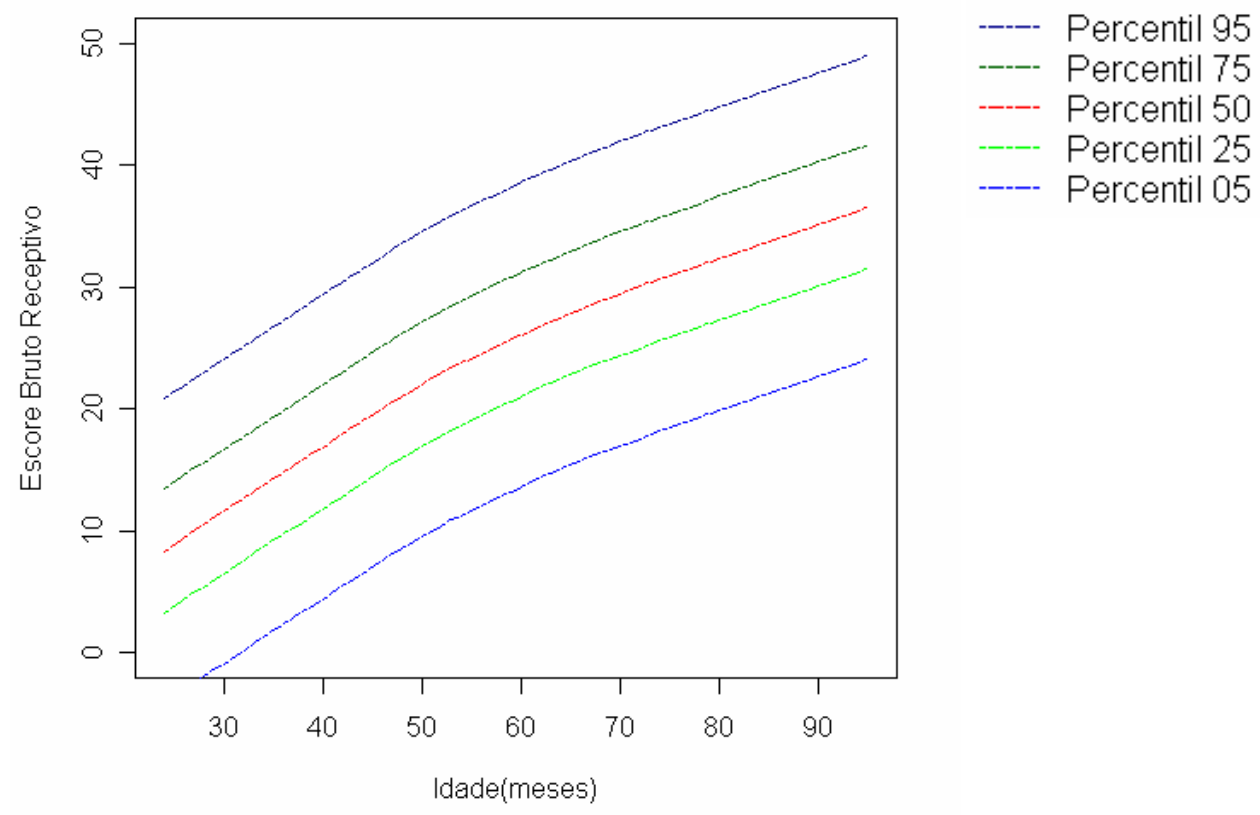


Gráfico 7: Curva de referência para o Escore Bruto Receptivo na Forma B.

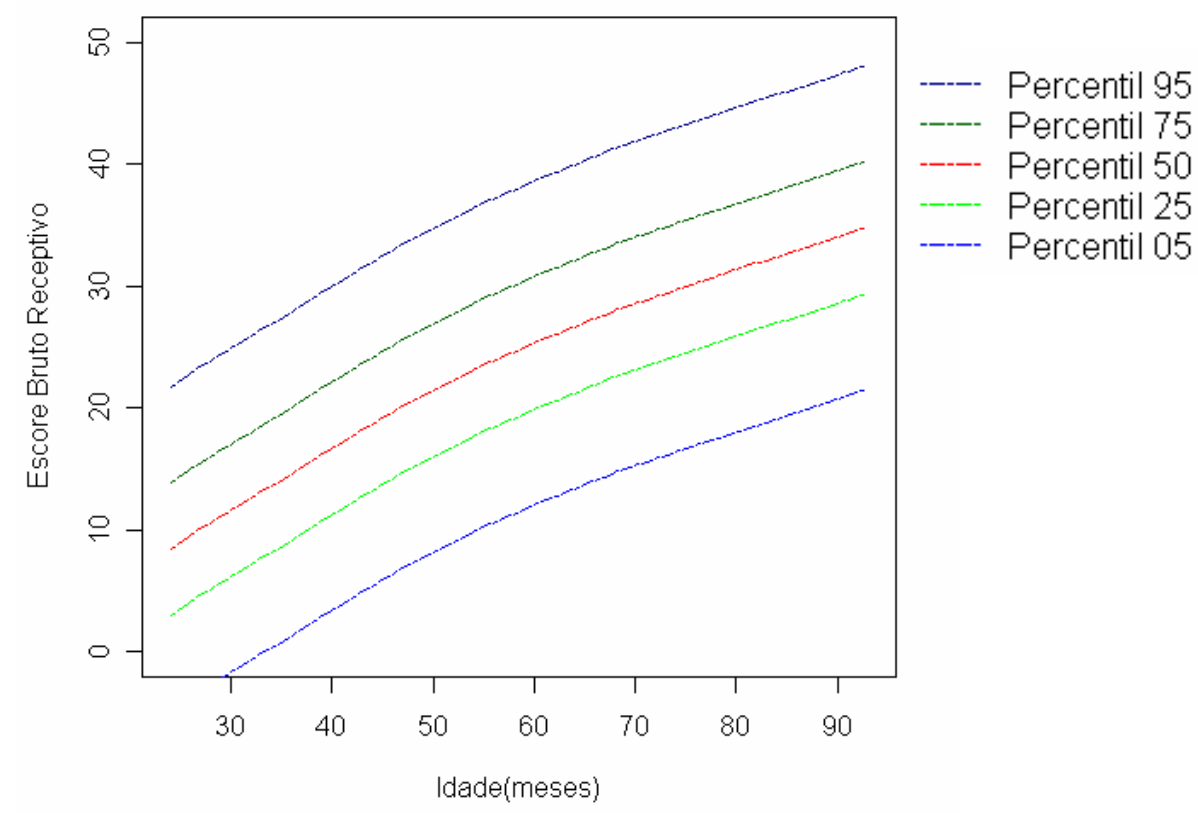

Gráfico 8: Curva de referência para o Escore Bruto Expressivo na Forma A.

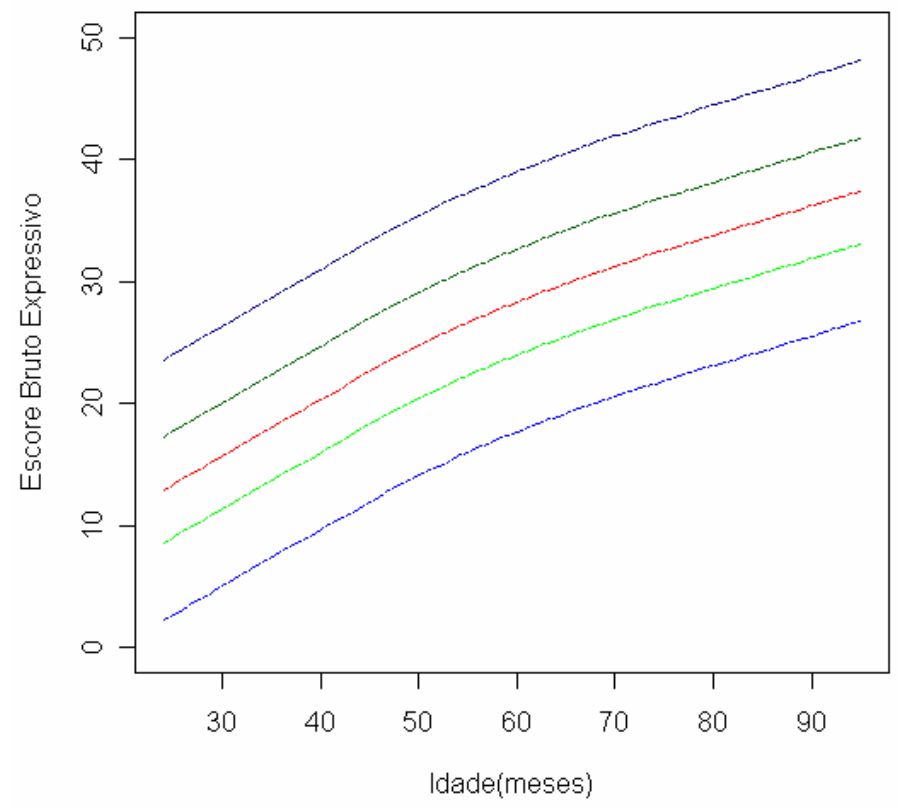

----- Percentil 95

---- Percentil 75

---- Percentil 50

-- Percentil 25

----- Percentil 05 
Gráfico 9: Curva de referência para o Escore Bruto Expressivo na Forma B.

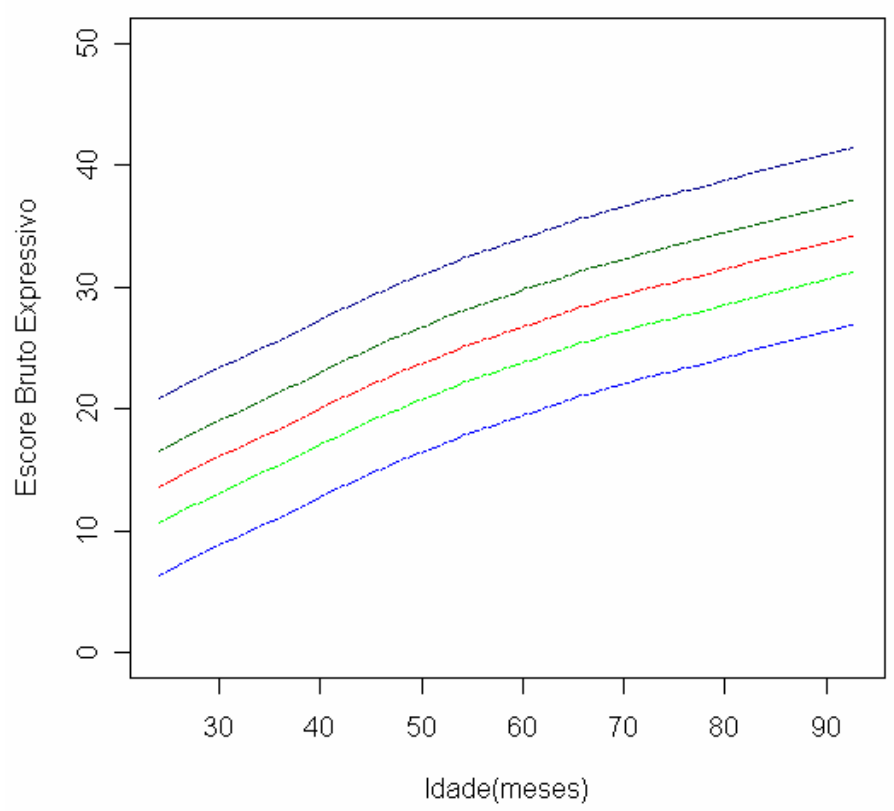

---- Percentil 95

--- Percentil 75

---- Percentil 50

--- Percentil 25

---- Percentil 05 


\section{V - Discussão}

A aquisição e desenvolvimento da linguagem é um dos grandes marcos do desenvolvimento infantil (Rice, 1997). Vários fatores correlacionam-se com este desenvolvimento, tornando-o complexo e abrangente. Reed (1994) refere que o desenvolvimento da linguagem resulta de uma complexa inter-relação de fatores fisiológicos, cognitivos, psicológicos, lingüísticos, ambientais e sociais.

Apesar de ser um dos grandes marcos do desenvolvimento infantil, no Brasil, faltam programas de identificação e intervenção precoce de alterações no desenvolvimento da linguagem. A falta de uma avaliação regular do desenvolvimento lingüístico bem como a falta de instrumentos de avaliação de identificação precoce dificulta a detecção de crianças que seriam candidatas a programas de intervenção.

O processo de diagnosticar alterações na aquisição e desenvolvimento da linguagem, não é uma tarefa fácil. Em países da América do Norte e Europa, profissionais da área de Fonoaudiologia dispõem de um amplo conjunto de procedimentos formais e objetivos para este processo (Boone e Plante, 1994; Law, 2001; Paul, 2001).

Apesar da variedade e da divergência entre os estudiosos sobre qual ou quais procedimentos devam ser utilizados, é possível encontrarmos uma unanimidade entre eles quanto à necessidade de usar testes formais e objetivos (Stark e Tallal, 1981; McCauley e Swisher, 1984; Lahey, 1990; Reed, 1994; Rice, 1995; Rice, 1997; Plante, 1999; Hresko, Reid e Hammill, 1999, Paul, 2001; Shipley e McAfee, 2004).

Apesar destas questões já estarem consolidadas no cenário internacional, no contexto brasileiro não é bem isso que ocorre. A prática fonoaudiológica com uso de testes de linguagem infantil, ainda é pouco usual. Os profissionais aqui não dispõem de muitos instrumentos voltados para o diagnóstico de alterações no processo de desenvolvimento da linguagem. 
Sicuro, Freitas e Lima (2003) referem que a falta de instrumentos de avaliação teoricamente embasados dificulta não só a identificação de crianças com alterações no processo de aquisição e desenvolvimento da linguagem, como também a realização de pesquisas científicas relacionadas à caracterização do perfil de falantes do Português Brasileiro com queixas de linguagem.

Uma forma que alguns pesquisadores têm encontrado para amenizar este problema é traduzir e adaptar para a Língua do país, instrumentos estrangeiros comercialmente disponíveis. No entanto, os autores destacam que o processo de tradução e adaptação deve ser cuidadoso e criterioso e deve se tomar o cuidado para preservar as equivalências entre a versão original e a versão traduzida do teste (Guillemin et al , 1993; Duarte e Bordin, 2000, Freitas et al, 2001).

A utilização de instrumentos já disponíveis em outros países pode permitir a realização de estudos transculturais, possibilitando a comparação das pesquisas realizadas no Brasil com as pesquisas internacionais. Além disso, o tempo necessário à criação de um novo instrumento pode ser maior do que o tempo necessário à tradução e adaptação de um já existente.

Considerando a relevância téorica-prática e cientifíca dos aspectos apresentados, este estudo teve como objetivo aplicar o Test of Early Language Development- Terceira Edição (TELD-3, de Hresko, Reid e Hammill, 1999) traduzido para o Português Brasileiro, em 120 sujeitos com desenvolvimento típico de linguagem, na faixa etária de 2:00 a 7:11 anos, de ambos os sexos.

Hipótese 1. A performance das crianças testadas será compatível com a média esperada para cada faixa etária, na versão original do teste. Parcialmente confirmada

A performance das crianças testadas foi compatível com a média esperada na forma $A$ do Teste. Na forma $B$, as crianças das faixas etárias de 5 e 6 anos no subteste expressivo, foram classificadas como "abaixo da média". 
O TELD-3 (Hresko, Reid e Hammill, 1999) é um teste de identificação precoce que avalia a linguagem de crianças de 2 a 7:11anos. $O$ teste possui duas formas (A e B) e subdivide-se em subteste receptivo e subteste expressivo.

A classificação da performance da criança no teste é obtida a partir dos valores dos escores-padrão, denominados pelos autores de quociente. Quando os valores dos quocientes estão entre 90 e 110, indica que a classificação obtida pelos sujeitos no teste se refere à média esperada para a idade. No TELD-3 é possível classificar a partir dos subtestes receptivo e expressivo, três tipos de quocientes: o receptivo, o expressivo e o falado (indicador da habilidade geral de linguagem). Os quocientes podem ser classificados, de acordo com os valores obtidos, conforme ilustrado no quadro 01, página 90 deste estudo.

$\mathrm{Na}$ forma $\mathrm{A}$ do teste, os sujeitos de todas as faixas etárias estudadas, obtiveram as médias dos Quocientes Receptivo, Expressivo e Falado dentro dos valores esperados, de 90 a 110.

$\mathrm{Na}$ distribuição percentual da classificação geral (Gráficos 3, 4 e 5) obtida pelos sujeitos, no Quociente Receptivo, apenas $10 \%$ foram classificados como abaixo da média e os demais como na média, acima da média e superior. No Quociente Expressivo, 11, 7\% foram classificados como abaixo da média e no Quociente Falado, apenas 5\% foram classificados como abaixo da média e os demais foram classificados como na média ou acima dela.

Portanto, analisando estes resultados, nota-se que para a Forma A do teste, a hipótese do estudo foi confirmada, ou seja, os valores médios das perfomances dos sujeitos testados receberam classificação "média", segundo a referência americana. Considerando que foram selecionados para participar deste estudo, sujeitos com desenvolvimento típico de linguagem, os resultados obtidos indicaram que a forma A do TELD-3 traduzido para o Português Brasileiro mostrou ser sensível para caracterizar a performance de linguagem destes sujeitos. 
Na forma B, a performance dos sujeitos das faixas etárias de 5 e 6 anos no subteste expressivo do teste foi classificada como abaixo da média. Nas demais faixas etárias, as médias obtidas pelos sujeitos, nos Quocientes Receptivo, Expressivo e Falado foram classificadas como estando na média, acima da média e superior.

Nos Gráficos (03, 04 e 05) que ilustram a distribuição percentual da classificação geral obtida pelos sujeitos na Forma B do teste, nota-se que quanto ao Quociente Receptivo, 11,7\% foram classificados como abaixo da média e os demais como na média, acima da média e superior. No Quociente Expressivo, 31,7\% foram classificados como abaixo da média e os demais como na média, acima da média e superior. E no Quociente Falado, 15\% foram classificados como abaixo da média e os demais na média ou acima da média.

Os resultados obtidos indicaram que para a forma B do TELD-3, subteste expressivo para as faixas etárias 5 e 6 anos, o teste parece não ser sensível para caracterizar a performance de linguagem, indicando um rebaixamento.

Na pesquisa apresentada por Andrade e Juste (2001) 58,5\% das crianças foram classificadas com gagueira muito leve, $24,5 \%$ com gagueira leve e $17 \%$ com gagueira moderada, no Stuttering Severity of Stuttering (SSI), que é um teste utilizado para avaliar a fluência. Silagi et al, 2006 em um estudo realizado com 32 crianças, entre 30 e 47 meses que foram avaliadas com o Preschool Language Scale-3 (Zimmerman, Steiner e Pond, 1992) versão traduzida para o Português Brasileiro referiram que em comparação ao padrão americano, 3 crianças apresentaram desempenho abaixo do esperado.

Analisando especificamente os itens do teste indicados às faixas etárias que foram classificadas como abaixo da média, notamos que na forma $B$ do teste, no subteste expressivo, $90 \%$ dos sujeitos não pontuaram no item 26 , esperado para 5 anos. A habilidade testada neste item é a capacidade da criança em produzir nomes no plural. A criança deve completar uma sentença iniciada pela examinadora, baseando- se em estímulos visuais. Por exemplo: é mostrado o desenho de uma faca e depois é mostrado um conjunto com três facas e a criança deve completar a 
frase - "Esta é uma faca" - Estas são as facas" . Os sujeitos não pontuaram no item porque completaram as frases utilizando singular.

Este achado pode estar relacionado ao nível sócio-econômico dos sujeitos que participaram deste estudo, que segundo a caracterização social realizada, pertencem ao nível sócio econômico médio, médio-baixo e baixo. Alguns estudos têm indicado que o uso de morfemas de número no plural não têm sido usados regularmente por pré-escolares, sugerindo uma variação sociolingüística.

Takiuchi et al, (2005) realizaram uma pesquisa com 232 pré-escolares que teve como objetivo explorar o domínio da morfologia flexional do Português Brasileiro. Os resultados indicaram que para as flexões de número no plural, a produção dos morfemas foi muito abaixo dos demais morfemas investigados. O estudo revelou que o não-uso de flexões de número no plural pareceu indicar uma variação sociolingüística e não uma dificuldade de aquisição.

Em um outro estudo, em que foram analisados os dados de triagens realizadas com pré-escolares com o objetivo de comparar a compreensão e a produção de morfemas flexionados no plural, os resultados também indicaram que para todas as faixas etárias a relação predominante foi compreensão correta e produção incorreta, com menor ocorrência de concordância nominal para o plural (Takiuchi e Navas, 2005).

Já para a idade de 6 anos, 100\% dos sujeitos não conseguiram pontuar no item 31 que verifica a habilidade da criança em definir palavras. São dadas quatro palavras e a criança tem que responder corretamente a pelo menos três para pontuar no teste. As palavras que a criança deve definir são: remo, desenhar, coruja e martelar. Para pontuar a criança tem definir a palavra, descrições não são aceitas.

O desenvolvimento da habilidade de definir é um processo gradual, que geralmente se inicia nos primeiros anos escolares e se aprimora até a adolescência. Geralmente existe uma progressão de definições concretas, funcionais, que evoluem para uma forma mais abstrata e formal (Marinellie e Johnson, 2002). Definir é uma habilidade que requer conhecimento linguïstico e metalingüístico (Nippold, 1998). 
Os resultados deste estudo indicaram que as crianças apresentaram dificuldades quanto à tarefa de definir as palavras. Isto pode estar relacionado a complexidade de tal habilidade para as crianças da faixa etária de 6 anos. Além disso, as palavras selecionadas na tarefa (exceto a palavra "desenhar") são não tão comuns.

Além disso, um outro aspecto que pode ser discutido com relação a estes achados é que no Brasil, aspectos formais da Língua, como por exemplo, regras de plural, concordância, habilidades metalingüísticas, tais como falar sinônimos, definir palavras, são trabalhados no Ensino Fundamental e Ensino Médio. Isso pode justificar a dificuldade apresentada pelos sujeitos falantes do Português Brasileiro, que foram selecionados de um Centro Infantil e da $1^{\text {a }}$ série e $2^{\mathrm{a}}$ séries de uma Escola Municipal. Por isso, o contato dos sujeitos com habilidades deste tipo ocorre ainda informalmente, e sabemos que, no Brasil, principalmente, para classes de nível sócio-econômico baixo, a formalidade da Língua nem sempre é praticada.

Estes resultados podem sugerir que seria importante analisar o conteúdo das grades curriculares dos centros infantis e séries escolares iniciais, ou seja, habilidades relacionadas aos aspectos formais da Língua poderiam ser trabalhados mais precocemente. Tal aspecto poderia favorecer não apenas a aquisição e o desenvolvimento lingüístico como também poderia predizer melhores desempenhos acadêmicos.

Hipótese 2. Não haverá diferença estatisticamente significante de performance nas formas A e B bem como entre os subtestes receptivo e expressivo. Parcialmente confirmada

A performance nas formas $A$ e $B$ do teste não foram equivalentes para todas as faixas etárias e também houve diferença estatisticamente significamente, para algumas faixas etárias, nos subtestes receptivo e expressivo.

O TELD-3 possui duas formas que, segundo os autores, são equivalentes. Neste estudo, o subteste receptivo mostrou ser equivalente nas formas A e B para 
as faixas etárias de 2, 4 e 5 anos, ou seja, para estas faixas etárias a média e a variância do subteste receptivo são iguais nas duas formas do teste. Para a faixa etária de 3 e de 7 anos, a análise do quociente receptivo mostrou que a média na forma A é significantemente maior do que na forma B. E para a faixa etária de 6 anos a variância da forma $A$ é maior que na forma $B$.

Para o subteste expressivo, pode se concluir que as médias nas formas $A$ e $B$ do teste são equivalentes nas faixas etárias de 2, 3, 4 e 7 anos. Para 5 e 6 anos, as médias são maiores na forma $A$ do que na forma $B$ do teste. $E$, com relação às variâncias, aparece diferença na faixa etária de 2 anos, na qual a variância do escore bruto expressivo é maior na forma $B$ e nas faixas etárias de 3 e 6 anos, nas quais a variância do quociente expressivo é maior na forma $A$.

$\mathrm{Na}$ análise do quociente falado, pode-se concluir que a forma $\mathrm{A}$ é equivalente à forma $B$ para as faixas etárias 2, 3, 4 e 5 anos. Para as faixas etárias de 6 e 7 anos, a média na forma $A$ é maior do que na forma $B$.

Os resultados obtidos neste estudo parecem indicar que para crianças falantes do Português Brasileiro, as formas A e B do TELD-3 não são equivalentes, uma vez que na forma $A$ foi observada uma maior variabilidade de desempenho entre os sujeitos do que na forma $B$ e também as médias encontradas na forma $A$ do teste foram mais altas e estas diferenças foram estastisticamente significantes para algumas faixas etárias do teste. Este dado é discordante com os dados fornecidos pelos autores do teste, Hresko, Reid e Hammill, 1999, para os falantes do Inglês.

Comparando o desempenho das crianças nos subtestes receptivo e expressivo, é possível concluir a partir dos resultados deste estudo que na forma $A$ do teste existe diferença apenas para a faixa etária de 7 anos. Já para a forma $B$, a diferença existe para as faixas etárias de 4, 5 e 6 anos. Nestas faixas etárias onde existe diferença entre os dois subtestes, notou-se que o desempenho no subteste receptivo é superior ao do subteste expressivo. 
Os resultados parecem sugerir que para a faixa etária de 3 e 7 anos, 0 subteste receptivo da forma $A$ do teste, parece ser "fácil" para as crianças falantes do Português Brasileiro e este dado também é confirmado quando observamos o Gráfico 03 que ilustra o percentual de distribuição da classificação dos sujeitos no teste, sendo que na forma A quanto ao Quociente Receptivo, 30\% dos sujeitos obtiveram classificação acima da média e superior, ao passo que na forma $B$ do teste, $16,6 \%$ dos sujeitos obtiveram esta classificação.

O Gráfico 1 também ilustra esta diferença, mostrando a dispersão do Escore Bruto Receptivo em função da idade cronológica e no qual podemos observar que aparecem mais pontos acima da curva esperada, indicando que as crianças deste estudo obtiveram pontuação mais alta do que a referência americana.

Já com relação ao subteste expressivo, os resultados sugerem que na forma $B$, os sujeitos tiveram pontuação abaixo do esperado para as suas idades, quanto aos aspectos expressivos. Observando o Gráfico 04 vemos que na forma $A$ 11,7\% sujeitos tiveram performance classificada como abaixo da média, já na forma $B$, $31,7 \%$ dos sujeitos foram classificados como "abaixo da média". No Gráfico 02 também vemos esta diferença, até 60 meses nota-se que o crescimento da média do escore bruto expressivo por intervalos de idade, apresenta um padrão próximo ao esperado, no entanto, após esta idade aparecem muitos pontos abaixo do esperado.

Morselli (2003) refere em seu estudo que crianças com desenvolvimento típico de linguagem geralmente apresentam pontuações mais altas em testes de vocabuário receptivo quando comparado ao expressivo. Broggio (2005) também refere como achados de sua pesquisa que nas tarefas envolvendo recepção os sujeitos pontuaram mais do que nas tarefas de expressão.

A relação entre compreensão e produção tem sido debatida por alguns pesquisadores e diferentes visões têm sido colocadas. Alguns referem que compreensão precede a produção (Ingram, 1974, Miller e Paul, 1995, Harris et al, 1995). Outros argumentam que esta relação é variável e está em constante modificação durante o curso de desenvolvimento (Bishop, 1979; Hakansson e Hansson, 2000). 
A relação entre compreensão e produção tem sido investigada a partir dos quadros de alteração de linguagem. E os resultados indicam que crianças com desordens de linguagem apresentam um gap entre a performance em linguagem receptiva e expressiva (Bishop, 1979; Rizzo e Stephens, 1981).

A distinção entre o desempenho em habilidades receptivas e expressivas é importante para a prática clínica e para o direcionamento das pesquisas. Em referências como o Manual de Diagnóstico e Estatístico de Transtornos Mentais DSM-IV e na Classificação Internacional de Doenças - CID-10 a classificação dos distúrbios de linguagem baseia-se nesta subdivisão.

No estudo aqui apresentado, os dados obtidos indicaram que o desempenho dos sujeitos testados no subteste receptivo do TELD-3 foi superior ao desempenho no subteste expressivo. Este dado pode estar relacionado ao fato, de que, no subteste expressivo, as diferenças de Língua podem ser mais marcantes, ou seja, considerando que o TELD é um teste americano e que investiga além do aspecto semântico da linguagem, os aspectos morfossintáticos, isso pode justificar a pontuação mais baixa no subteste expressivo.

De todos os aspectos da linguagem, a morfossintaxe é um dos que mais se difere nas diferentes Línguas. Cada Língua possui uma gramática específica e isso pode ter sido refletido nos resultados deste estudo.

Hipótese 3. Haverá um aumento na pontuação, ou seja, um aumento nos valores dos escores brutos, conforme aumenta a idade cronológica das crianças testadas. Confirmada.

Em ambas as formas do teste houve um aumento nos valores dos escores brutos, ou seja, houve um aumento no número de acertos no teste em função do aumento da idade cronológica. Conforme apontado por Bishop, 1992, Reed, 1994, Bee, 1996, sabemos que ocorre uma evolução significativa na aquisição e no desenvolvimento da linguagem, com o passar dos anos, principalmente no período entre 2 e 5 anos de idade. $O$ aprendizado da linguagem envolve a progressão de 
formas simples para complexas, que se justificam pela maturidade cerebral, pelo desenvolvimento cognitivo e pelas influências ambientais (Bishop, 2000).

No estudo realizado por Capovilla e Capovilla (1997) no qual forneceram a tradução para o Português Brasileiro para o Peabody Picture Vocabulary Test (PPVT, Dunn e Dunn, 1881) e para o Language Developmental Survey (LDS, Rescorla, 1989), os resultados mostraram que os escores do vocabulário receptivo e expressivo aumentaram em função do nível escolar e da idade da criança.

Segundo Bishop (2000) a aquisição de um nível mais abstrato de representação no processo da linguagem, leva a um armazenamento e recuperação mais eficiente da informação lingüística e por conseguinte a uma aprendizagem mais rápida de novas formas lingüísticas. A consciência dessas regras abstratas desenvolve-se gradativamente e o conhecimento adquirido ocorre de forma parelela à aquisição desse conhecimento lingüístico.

Para Scheuer et al, (2003) o desenvolvimento da linguagem, dos gestos às primeiras palavras e sentenças, pode ser considerado um processo muito organizado e previsível, que reflete como as crianças pensam sobre o mundo do qual fazem parte, como o reconhecem.

É possível constatar que dos 2 aos 5 anos de idade, a linguagem da criança evolui do uso de uma palavra para formas gramaticais bem estruturadas e torna-se mais eficiente, sabendo direcioná-la para vários interlocutores. Neste período o vocabulário se expande e este fato pode estar relacionado em parte, ao desenvolvimento cognitivo, isto é, à capacidade simbólica, à representação e metarepresentação (Limongi, 1998; Scheuer et al 2003).

Araújo e Befi-Lopes (2004) referem em seu estudo com 60 crianças com desenvolvimento típico de linguagem, que aos 2 anos de idade as crianças apresentararam valores de extensão média dos enunciados menores do que os sujeitos de 4 anos, evidenciando que ocorre um aumento da extensão média das frases ao longo do desenvolvimento infantil, ou seja, o desenvolvimento propicia a 
passagem de um estágio mais primitivo e restrito para outro mais desenvolvido e complexo.

Estes dados também são condizentes com os achados da pesquisa realizada por Broggio 2005, cujos resultados indicaram diferenças significantes quanto ao desempenho nos subtestes do TOLD-P:3 adaptado para o Português Brasileiro, em função do aumento da idade. Silagi et al (2006) também encontrou em sua pesquisa com crianças sem queixas de desenvolvimento de linguagem, de 30 a 47 meses, um aumento no desempenho das mesmas no Preschool Language Scale-3 em função da idade.

O crescimento das médias dos valores dos escores brutos em função do aumento da idade cronológica também confirma a afirmação do autores do TELD-3 quanto aos aspectos relacionados à complexidade dos itens que compõem o teste. Ou seja, o teste foi elaborado com itens que devem ir aumentando de complexidade conforme as faixas etárias. Os resultados encontrados no estudo aqui apresentado confirmam esta afirmação, quanto mais velhos os sujeitos, mais pontuaram nos itens do teste e o aumento dos pontos foi gradual e crescente nas faixas etárias. 


\section{VI - Considerações Finais}

No Brasil faltam testes formais e objetivos para avaliar a linguagem na infância. Traduzir e adaptar para Língua do país, instrumentos estrangeiros já disponíveis em outras Línguas para esta finalidade, é uma forma de amenizar este problema.

O objetivo deste estudo foi verificar a performance de crianças com desenvolvimento típico de linguagem no Test of Early Language Development - 3 (TELD-3, de Hresko, Reid, Hammill), traduzido para o Português Brasileiro.

Em relação à primeira hipótese, os resultados indicaram que a performance dos sujeitos testados foi compatível com a média esperada, para todas as faixas etárias estudadas na forma $A$ do teste. Já na forma $B$, a média obtida pelos sujeitos das faixas etárias de 5 e 6 anos no subteste expressivo foi compatível com a classificação "abaixo da média".

Quanto à segunda hipótese, os resultados indicaram que as formas $A$ e $B$ dos testes para os sujeitos falantes do Português Brasileiro e que participaram do estudo, não foram equivalentes para todas as faixas etárias. Houve uma diferença estatisticamente significante, para as faixas etárias de 4, 5 e 6 anos, nos subtestes receptivo e expressivo, sendo que neste último, os sujeitos obtiveram pontuação menor.

A terceira hipótese indicou que houve um aumento na pontuação, nos valores dos escores brutos, com o aumento da idade cronológica. Sabe-se que o desenvolvimento lingüístico envolve a progressão de formas simples para complexas e todo esse processo é muito organizado e previsível e pode ser justificado pela maturidade cerebral, pelo desenvolvimento cognitivo e pelas influências ambientais, as quais as crianças estão expostas. 
De um modo geral, os resultados obtidos neste estudo sugerem que o Test of Early Language Development - Terceira Edição (TELD-3, Hresko, Reid e Hammill, 1999) - versão traduzida para o Português Brasileiro pode ser um instrumento sensível para a identificação precoce de alterações no processo de aquisição e desenvolvimento da linguagem.

Os resultados indicaram que para a população estudada, os subtestes receptivos da Forma $A$ e $B$ do teste mostraram-se sensíveis para caracterizar a performance de linguagem dos sujeitos. Já os subtestes expressivos, também mostraram-se sensíveis, porém a forma A do teste, mostrou ser mais efetiva.

No entanto, estudos complementares relacionados à sensibilidade e à especificidade do Teste, são necessários. Além disso, a aplicação do instrumento em uma amostra maior de sujeitos também contribuirá para a generalização dos resultados aqui encontrados. Os resultados deste estudo também poderão futuramente contribuir para pesquisas transculturais, possibiltando a comparação entre pesquisas nacionais e internacionais. 
ESTUDO III - Análise comparativa da performance de sujeitos falantes do Português (Brasil) e sujeitos falantes do Inglês (EUA) no

Test of Early Language Development (TELD-3) 


\section{I - Introdução}

$\mathrm{Na}$ literatura sobre avaliação da linguagem infantil os autores referem a necessidade de utilizar testes formais e objetivos no processo de diagnóstico de alterações de desenvolvimento da linguagem (Bloom e Lahey, 1978; Stark e Tallal, 1981; Reed, 1994, Boone e Plante, 1994; Law, 2001; Paul, 2001, Shipley e MacAfee, 2004).

Para Hresko, Reid e Hammill (1999) o diagnóstico de alterações no desenvolvimento da linguagem deve ser feito a partir de testes formais e estes devem ser confiáveis e válidos, estatisticamente. Um teste deve: avaliar a habilidade geral de linguagem bem como as habilidades receptivas e expressivas; deve fornecer informações normativas que possibilitem comparações entre grupos e entre faixas etárias; deve identifcar habilidades e dificuldades; ser útil para profissionais que trabalham com avaliação e não somente para os especialistas em linguagem; deve ser administrado em um curto período de tempo para evitar fadiga da criança e do examinador e deve incluir uma amostra normativa significativa.

Baseados nestes fundamentos, Hresko, Reid e Hammill (1981) publicaram a primeira edição do Test of Early Language Development (TELD), um teste de identificação precoce de alterações no desenvolvimento da linguagem, indicado para crianças de 2 a 7:11 anos e que investiga habilidades expressivas e receptivas de linguagem. Os componentes lingüísticos avaliados e incorporados no teste são: semântico, sintático e morfológico. O teste está na sua terceira edição, publicada em 1999, pela Editora Pro-Ed.

Segundo os autores o TELD-3 foi padronizado a partir de uma amostra de 2.217 crianças residentes em 35 estados americanos. A análise dos seus itens foi realizada por um grupo de juízes, composto por 22 professores universitários e alunos de pós-graduação.

Dale e Henderson (1987) realizaram uma pesquisa com 85 pré-escolares, com idade entre 3 e 6:11 anos, com diagnóstico de Distúrbio Específico de Linguagem, com o objetivo de verificar a validade do TELD, comparando-o com 
outras medidas de linguagem e para verificar sua utilidade na identificação de déficits de linguagem em crianças. Todas os participantes foram avaliados com o TELD, com o Peabody Picture Vocabulary Test, com o McCarthy Scales of Children Abilities - Verbal Scale, com a medida de MLU (Mean Length of Utterance, Brown, 1973) e também foi coletada uma amostra de conversa espontânea.

Os escores obtidos no TELD indicaram um déficit de linguagem e foram correlacionados com as outras medidas utillizadas. Neste estudo, os autores também fizeram algumas críticas quanto à estrutura do teste, como por exemplo, a falta da subdivisão em subteste receptivo e expressivo. Além disso, referiram que poucos estudos sobre o TELD tem sido relatados (Dale e Henderson, 1987).

Essary (1993) realizou uma revisão do TELD-2 e referiu que o teste demonstrou ser útil para identificar crianças pré-escolares com atraso ou distúrbio de linguagem. As características psicométricas da segunda edição estão mais embasadas do que na primeira edição. Essary referiu que os materiais necessários à aplicação deveriam acompanhar o kit do teste (no TELD-3 estão materiais foram incorporados no kit). Shapiro (1995) sugeriu que mais exemplos deveriam ser colocados nos critérios de pontuação de cada item, para maior clareza dos mesmos.

Essary (1993) também questionou o grau de dificuldade de cada item que compõe o teste. O autor notou que no TELD-2, alguns itens foram fáceis para algumas idades e mais complexos para outras. Também foram feitas críticas quanto aos dados de validade do teste, argumentando que faltaram evidências suficientes para sua validação.

Segundo Hresko, Reid e Hammill (1999) a terceira edição do TELD foi publicada considerando todas as sugestões que foram feitas pelos revisores na edição anterior do teste. E especificamente as seguintes melhorias foram feitas: o teste foi subvidido em subteste receptivo e expressivo; os escores-padrão foram revistos; alguns itens foram adicionados por serem considerados mais adequados às faixas etárias testadas; foram refeitos estudos de validade e de confiabilidade; foram acrescentados dados normativos da amostra do teste; as figuras do álbum 
necessário à aplicação passaram a ser coloridas para serem mais atrativas às crianças, foi feita uma análise do conteúdo do item e sua relação com a figura. Os materiais necessários à aplicação do teste foram incorporados no seu kit. As instruções de aplicação foram reescritas de forma mais clara.

Breeyear et al (2001) realizaram um estudo analisando as características do TELD-3. E a partir desta análise concluíram que os materiais disponibilizados no teste são apropriados e convidativos para as crianças, é um teste de fácil aplicação, o examinador pode saber o que é testado em cada item. É um teste, segundo os autores, que pode detectar atrasos no processo de desenvolvimento da linguagem e seus resultados podem ser utilizados para indicação de programas de intervenção. Com relação às fraquezas do teste, o vocabulário utilizado nem sempre é apropriado para as idades dos grupos, a pontuação é difícil de ser compreendida, as tabelas de escores não são explicadas dificultando a compreensão das mesmas.

Suen (2002) publicou uma revisão do TELD-3 e referiu que é um teste de fácil aplicação, os materiais disponíveis podem ser facilmente utilizados, os autores do teste descrevem recomendações relacionadas ao cuidado que se deve ter na interpretação dos resultados, afirmando que o diagnóstico de uma alteração de linguagem não pode ser baseado apenas no resultado do teste. As características psicométricas do teste estão descritas detalhadamente. Com relação às criticas ao teste, Suen (2002) refere que no manual do examinador aparece a afirmação de que "o teste é um preditor de futuras habilidades de linguagem e de habilidades escolares". Segundo o autor, o teste não fornece evidências suficientes para comprovar esta afirmação.

Suen (2002) refere que considerando que o uso apropriado de um teste é uma responsabilidade dividida entre o criador do teste e o seu usuário, espera-se que clínicos e pesquisadores que utilizarem o TELD-3 devam analisar estas evidências, relatando suas próprias experiências. 
Kulick (2002) comentou uma revisão sobre o teste e referiu que um ponto relevante na terceira edição é que os autores do teste consideraram todas as criticas e sugestões feitas por revisores a respeito do TELD-2 e as incorporaram no TELD-3.

Kulick refere que o teste pode ser considerado um indicador válido para investigar habilidades receptivas, expressivas e gerais de linguagem. Pode ser utilizado como instrumento de pesquisa na área de desenvolvimento da linguagem, conforme descrito por seus autores. É um teste de fácil aplicação e suas instruções são também facilmente compreendidas. Os criérios de pontuação são claros e qualquer examinador, com treinamento adequado, poderá compreendê-los. O TELD3 é um teste que pode ser aplicado rapidamente, em média em trinta minutos.

Uma critica ao teste é que consta em sua descrição que "é um teste que pode ser preditor de habilidades futuras de linguagem e habilidades acadêmicas" e no entanto, não existem evidências significativas que comprovem tal afirmação (Kulick, 2002).

Martinez (2005) um pesquisador do Curso de Fonoaudiologia da Faculdade de Ciências da Saúde da Universidade de Talca - Chile, realizou a tradução e adaptação do TELD-3 para o espanhol do Chile. O autor descreve que foi necessária a adaptação de alguns termos relacionados ao vocabulário. Participaram deste estudo 204 sujeitos, sendo 34 por faixas etária, 17 do sexo masculino e 17 do sexo feminino. Os resultados indicaram que houve um crescimento dos valores dos escores brutos com aumento da idade. Como conclusão do estudo, o autor destaca que o teste pode ser considerado altamente confiável para os seus propósitos. A versão traduzida mostrou-se efetiva para ser utilizada na identificação precoce de alterações no desenvolvimento da linguagem.

No final de 2006 foi publicado e passou a ser comercialmente disponível o TELD-3-Spanish, publicado pelos autores Margarita Ramos, Jorge Ramos em parceria com Hresko, Reid e Hammill. O TELD-3:S é uma versão traduzida e adaptada do TELD-3 em Inglês. A versão em espanhol do TELD-3 manteve todo o formato original do teste. A amostra normativa foi constituída por 1441 sujeitos, 
residentes no Chile, Costa Rica, México e Espanha. Os dados foram coletados no período de janeiro de 2002 a maio de 2005.

No manual do examinador do TELD-3 os autores do teste convidam clinicos e pesquisadores que usarem o TELD-3 a enviarem uma cópia de suas pesquisas, colocando sugestões de mehorias para o teste (Hresko, Reid e Hammill, 1999, manual do examinador).

Não foram encontradas referências nacionais relacionadas à pesquisa com o Test of Early Language Development - 3 (TELD-3) com sujeitos falantes do Português Brasileiro.

A partir da literatura apresentada, este estudo tem como objetivos:

1 - Comparar a performance de sujeitos típicos falantes do Português (Brasil) com os sujeitos falantes do Inglês (EUA) no Test of Early Language Development Terceira Edição (TELD-3, Hresko, Reid e Hammill, 1999);

2 - Realizar uma análise individual da performance dos sujeitos falantes do Português Brasileiro nos itens do teste;

Para responder aos objetivos propostos, foram formuladas e testadas as seguintes hipóteses de pesquisa:

Hipótese 1. Os escores obtidos pelos sujeitos falantes do Português Brasileiro serão equivalentes às referências originais do teste.

Hipótese 2. A análise individual da performance dos sujeitos falantes do Português Brasileiro no teste indicará que não haverá necessidade de significativas adaptações na versão traduzida do TELD-3. 


\section{II - Método}

\section{1 - Sujeitos}

Participaram deste estudo 120 sujeitos falantes nativos do Português Brasileiro com desenvolvimento típico de linguagem, com faixa etária entre 2:00 a 7:11 anos. Cada faixa etária foi composta por 20 sujeitos, de ambos os sexos, sendo 10 do sexo masculino e 10 do sexo feminino.

Os sujeitos de 2:00 a 6:11 anos estavam matriculados em um Centro Infantil e os sujeitos de 7:11 anos em uma Escola Municipal de Educação Infantil e Fundamental. Todos residentes na cidade de Limeira, interior do Estado de São Paulo.

Os procedimentos de avaliação só foram iniciados após os processos éticos pertinentes: Parecer da Comissão de Ética (CAPPesq HCFMUSP - número 236/04 Anexo A) e assinatura do Termo de Consentimento Livre e Esclarecido, pelos responsáveis pelos sujeitos (Anexo F).

Para que pudessem participar do estudo, os sujeitos passaram por um processo de seleção seguindo critérios de exclusão e de inclusão.

Como critérios de exclusão foram considerados os seguintes aspectos: presença de queixa fonoaudiológica pelas educadoras, encaminhamento e/ou tratamento pregresso de fonoaudiologia e outras especialidades sugerindo assim, possíveis alterações desenvolvimentais. Para confirmar os dados a pesquisadora realizou uma breve consulta no prontuário de cada sujeito, para que fosse confirmada a ausência de encaminhamentos e estes dados também foram confirmados com os responsáveis pelos sujeitos.

Como critérios de inclusão foram considerados: a indicação de crianças que as educadoras consideravam que se comunicavam adequadamente para suas respectivas idades. Também foi considerada a faixa etária e data de aniversário dos sujeitos, para que a amostra ficasse equilibrada quanto à variação dos meses. Os 
sujeitos também tiveram que apresentar desempenho adequado na triagem fonoaudiológica, realizada individualmente pela pesquisadora.

Segundo a caracterização realizada pelas profissionais de Serviço Social do Centro Infantil e da Escola, os sujeitos atendidos nestes locais pertenciam ao nível sócio-econômico médio, médio-baixo e baixo.

\section{2 - Material}

Neste estudo foi utilizado o kit completo do Test of Early Language Development - Terceira Edição (TELD-3, Hresko, Reid e Hammill, 1999) versão original (em Inglês) e a versão traduzida para o Português Brasileiro.

É importante destacar que anterior à aquisição do teste, foi realizado um contato com os autores e com a editora (PRO-ED), que autorizaram o uso do mesmo para as finalidades desta pesquisa (Anexos B e C), aspecto fundamental para pesquisa deste tipo.

Os procedimentos adotados na tradução do teste para o Português Brasileiro foram descritos no Estudo I desta Tese. 


\section{3 - Procedimento de coleta de dados com os sujeitos falantes do Português Brasileiro}

Após a seleção dos sujeitos que participariam da pesquisa e a seleção do material foi iniciada a coleta de dados com os sujeitos falantes do Português Brasileiro.

Todos os sujeitos foram avaliados individualmente e tempo da aplicação do teste foi em média de trinta minutos. O teste foi aplicado de acordo com as instruções contidas no manual de aplicação do TELD-3. As respostas fornecidas pelos sujeitos foram registradas nos protocolos de respostas. Em seguida, a examinadora corrigiu as respostas, calculou a pontuação e classificou a performance de cada sujeito, também de acordo com as instruções originais do Teste. Os dados foram tabulados e posteriormente enviados para análise e tratamento estatístico.

\section{4 - Análise dos Dados}

\section{1 - Comparação entre a performance dos sujeitos falantes do Inglês (EUA) com os sujeitos falantes do Português (Brasil)}

Após o tratamento estatístico pertinente, foi realizada uma análise comparativa entre a performance obtida com os sujeitos típicos falantes do Português Brasileiro (sujeitos-pesquisa) e os sujeitos falantes do Inglês (EUA). Com relação à performance dos sujeitos falantes do Inglês foram considerados os dados disponíveis no TELD-3, mais especificamente, no Manual do Examinador que faz parte do kit completo do Teste.

$\mathrm{Na}$ análise comparativa realizada os seguintes aspectos foram considerados:

1 - Se os valores das variáveis Escore Bruto Receptivo e Escore Bruto Expressivo (que correspondem ao número de acertos no teste) se relacionam com a variável Idade Cronológica, ou seja, se os valores dos escores brutos aumentam em função da idade e se este aumento é proporcional ao observado nos sujeitos falantes do Inglês; 
2 - Se os valores do variável Idade Equivalente (que corresponde à idade lingüística obtida no teste) se equipara às Idades Cronológicas dos sujeitos testados e estes aos valores obtidos pelos sujeitos falantes do Inglês;

3 - A distribuição percentual da classificação obtida pelos sujeitos falantes do Português no teste foi comparada à distribuição obtida pelos sujeitos falantes do Inglês.

\section{2 - Análise Individual da performance dos sujeitos falantes do Português Brasileiro}

A pesquisadora realizou uma análise individual da performance dos sujeitos em cada item do teste, nos subtestes receptivo e expressivo de ambas as formas ( $A$ e B).

Nesta análise foram considerados os números de acertos e erros apresentados pelos sujeitos testados. Após esta análise os dados foram tabulados pela pesquisadora. Para cada faixa etária e para cada forma do teste foi possível levantar a porcentagem de erros e de acertos em cada item testado. Serão apresentados os itens, cujo índice de erro foi igual ou superior a $70 \%$, ou seja, quando $70 \%$ ou mais dos sujeitos não pontuaram o item foi registrado.

Vale salientar que o índice de $70 \%$ foi definido após assessoria com um Estatístico, que calculou este valor tendo por base o tamanho da amostra estudada. 


\section{III - Resultados}

A apresentação dos resultados deste estudo será dividida em 04 partes. $\mathrm{Na}$ primeira parte serão apresentados os resultados referentes ao aumento dos valores dos Escores Brutos em função da idade cronológica, expressa em meses. Na segunda parte serão apresentados os resultados da comparação entre a idade cronológica e a idade equivalente (lingüística), em relação à curva de referência dos sujeitos falantes do Inglês (EUA). Na terceira parte será apresentada a comparação entre a distribuição percentual da classificação obtida pelos sujeitos falantes do Inglês e pelos sujeitos falantes do Português e para finalizar na quarta parte serão apresentados os resultados da análise individual da performance dos sujeitos falantes do Português nos itens do teste. 


\section{1 - Resultados da análise da variável Escore Bruto em função da Idade Cronológica}

Gráfico 01: Dispersão de Escore Bruto Receptivo x Idade com a curva de referência americana.

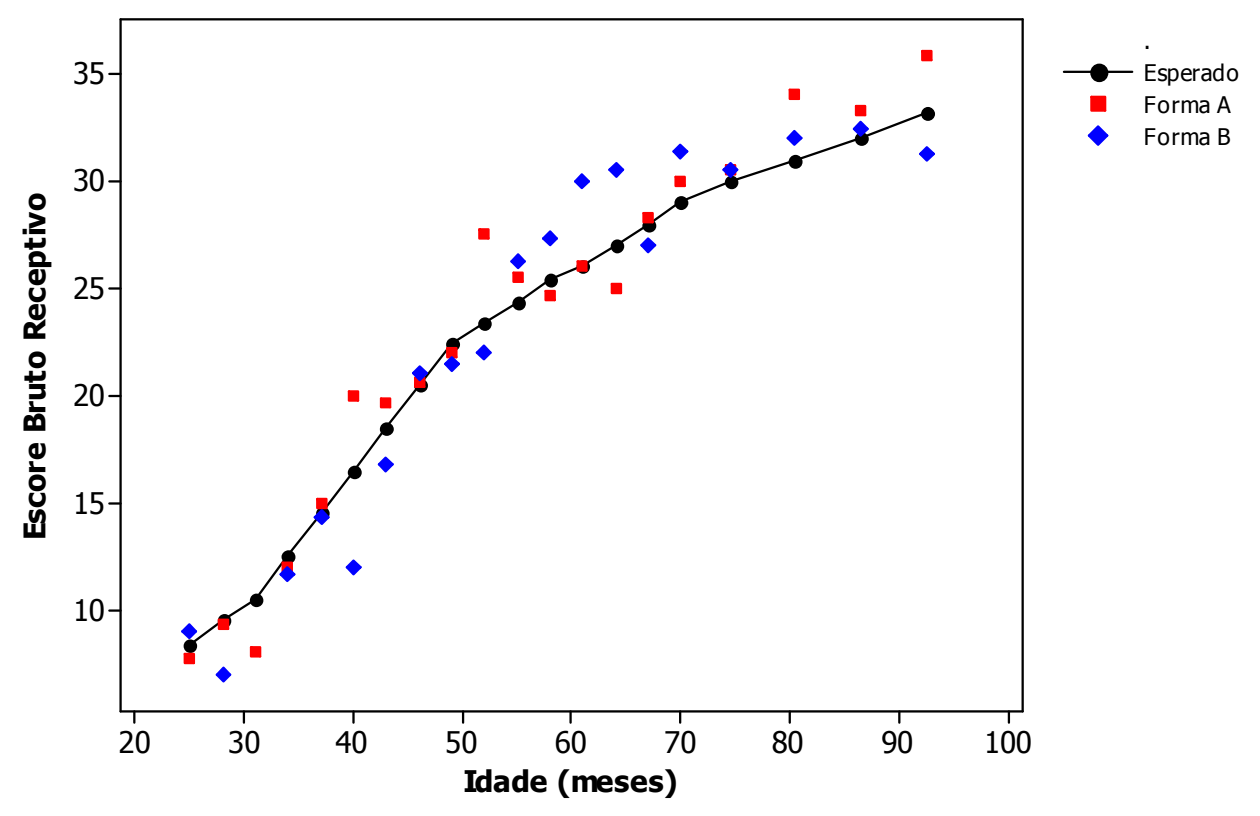

O Gráfico 01 ilustra os valores da variável Escore Bruto Receptivo em função da Idade Cronológica. A linha contínua de cor preta refere-se à curva de referência dos sujeitos falantes do Inglês, os quadrados vermelhos referem-se à distribuição dos escores brutos dos sujeitos falantes do Português Brasileiro na forma $\mathrm{A}$ do teste e os losangos azuis à distribuição dos escores brutos dos sujeitospesquisa na forma B. A partir deste Gráfico, nota-se que o crescimento da média do Escore Bruto Receptivo dos sujeitos-pesquisa, por intervalos de idade (expressos em meses) apresenta um padrão próximo ao obtido pelos sujeitos falantes do Inglês. Para as faixas etárias de 6 e 7 anos as médias dos escores brutos na forma $A$ são maiores que os obtidos no TELD original (padrão americano). Já os valores das faixas etárias de 2, 3 e 4 anos são muito próximos as do TELD original. 
Este dado pode ser confirmado no quadro abaixo que ilustra os valores descritivos da variável Escore Bruto Receptivo na forma A e B do teste (sujeitospesquisa e sujeitos americanos) por faixa etária.

\section{Quadro 01: Média dos Valores do Escore Bruto Receptivo por faixa etária}

\begin{tabular}{|l|c|c|c|c|}
\hline $\begin{array}{c}\text { Faixa } \\
\text { Etária }\end{array}$ & $\begin{array}{c}\text { Sujeitos-pesquisa } \\
\text { Forma A }\end{array}$ & $\begin{array}{c}\text { Sujeitos-Pesquisa } \\
\text { Forma B }\end{array}$ & $\begin{array}{c}\text { Sujeitos Americanos } \\
\text { Forma A* }\end{array}$ & $\begin{array}{c}\text { Sujeitos Americanos } \\
\text { Forma B* }^{*}\end{array}$ \\
\hline 2 anos & 9,1 & 9,4 & 9 & 9 \\
\hline 3 anos & 19,1 & 16,4 & 17 & 17 \\
\hline 4 anos & 25,3 & 25,2 & 24 & 27 \\
\hline 5 anos & 28,2 & 29,3 & 26 & 30 \\
\hline 6 anos & 31,6 & 30,8 & 29 & 32 \\
\hline 7 anos & 34,8 & 32,0 & 32 & 27 \\
\hline
\end{tabular}

* Referência: Manual do Examinador do TELD-3, página 106

No Quadro acima é possível verificar que os valores do Escore Bruto Receptivo para as faixas etárias de 2, 3 e 4 anos são muito próximos aos valores dos sujeitos americanos. Já para as faixas etárias de 6 e 7 anos, os sujeitos falantes do Português obtiveram valores mais altos do que os sujeitos falantes do Inglês, na forma A do teste. 
Gráfico 02: Dispersão de Escore Bruto Expressivo x Idade com a curva de referência americana.

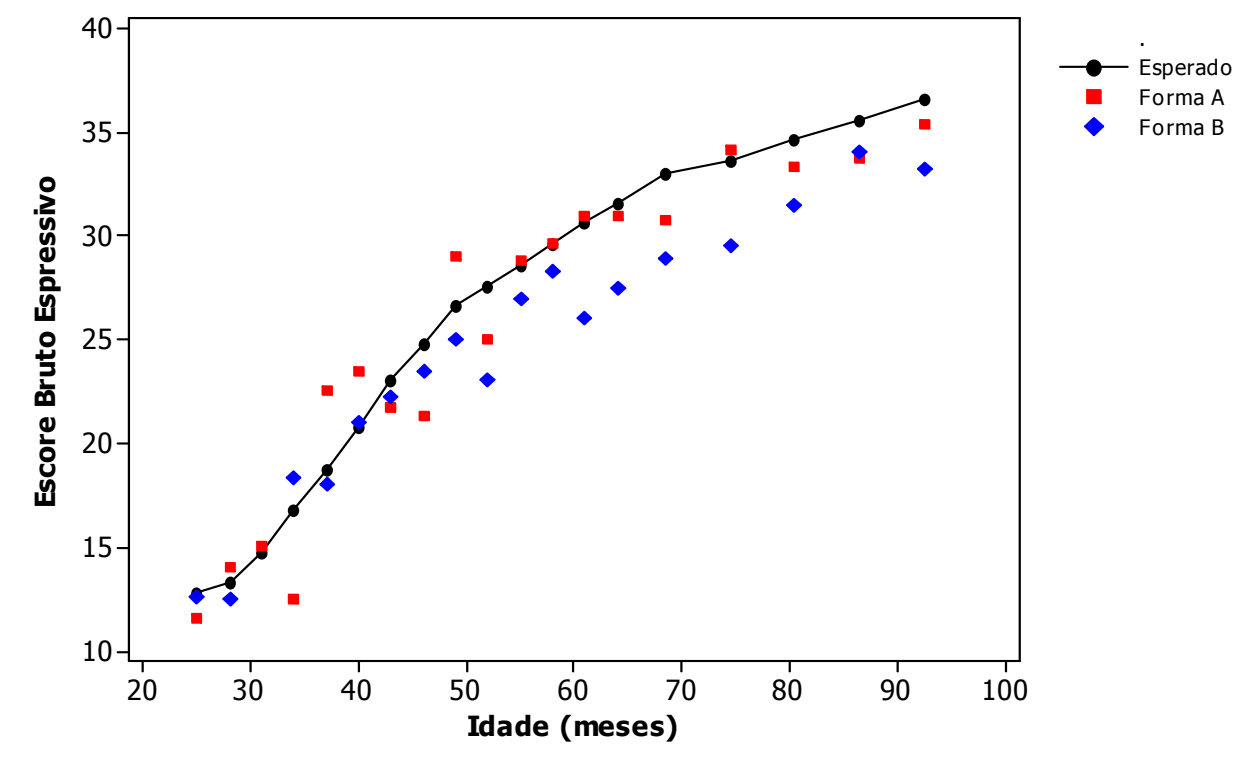

No Gráfico 02 é possível verificar que o crescimento da média do Escore Bruto Expressivo por intervalos de idade, também apresenta um padrão próximo ao obtido pelos sujeitos falantes do Inglês. Porém, como é possível visualizar, na forma B (em azul) para as idades acima de 60 meses, aparecem pontos abaixo do esperado. Nota-se que para as faixas etárias de 5, 6 e 7 anos os valores das médias referentes à forma $\mathrm{A}$ estão acima dos valores da forma $\mathrm{B}$. 


\section{Quadro 02: Média dos Valores do Escore Bruto Expressivo por faixa etária}

\begin{tabular}{|l|c|c|c|c|}
\hline $\begin{array}{c}\text { Faixa } \\
\text { Etária }\end{array}$ & $\begin{array}{c}\text { Sujeitos-Pesquisa } \\
\text { Forma A }\end{array}$ & $\begin{array}{c}\text { Sujeitos-Pesquisa } \\
\text { Forma B }\end{array}$ & $\begin{array}{c}\text { Sujeitos Americanos* } \\
\text { Forma A }\end{array}$ & $\begin{array}{c}\text { Sujeitos Americanos* } \\
\text { Forma B }\end{array}$ \\
\hline 2 anos & 12,8 & 14,3 & 12 & 12 \\
\hline 3 anos & 22,1 & 21,1 & 21 & 21 \\
\hline 4 anos & 28,3 & 26,6 & 29 & 31 \\
\hline 5 anos & 30,8 & 28,3 & 31 & 32 \\
\hline 6 anos & 33,9 & 29,9 & 33 & 35 \\
\hline 7 anos & 34,7 & 33,7 & 35 & 29 \\
\hline
\end{tabular}

* Referência: Manual do Examinador do TELD-3, página 106

No Quadro acima é possível verificar que para as faixas etárias de 2, 3 e 4 anos os valores obtidos com os sujeitos-pesquisa (falantes do Português) estão próximos aos valores obtidos pelos sujeitos falantes do Inglês. Já para as faixas etárias, de 5 e 6 anos principalmente, os valores da forma $B$ do teste estão abaixo dos valores da forma $A$ do teste.

Para confirmar os resultados descritos anteriormente foi realizada uma análise de regressão. Foram ajustados modelos de regressão, separadamente, para cada forma do teste, para as variáveis Escore Bruto Receptivo e Escore Bruto Expressivo em função da Idade (Modelo 1: Escore Bruto Receptivo na Forma A; Modelo 2: Escore Bruto Receptivo na Forma B; Modelo 3: Escore Bruto Expressivo na Forma A; Modelo 4: Escore Bruto Expressivo na Forma B).

Os dados da análise de regressão realizada encontra-se no Anexo G. 
Os Gráficos apresentados a seguir ilustram as curvas de regressão ajustadas.

Gráfico 03: Curva de regressão ajustada com intervalo de confiança de 95\% para a média do Escore Bruto Receptivo na forma A e curva de referência americana

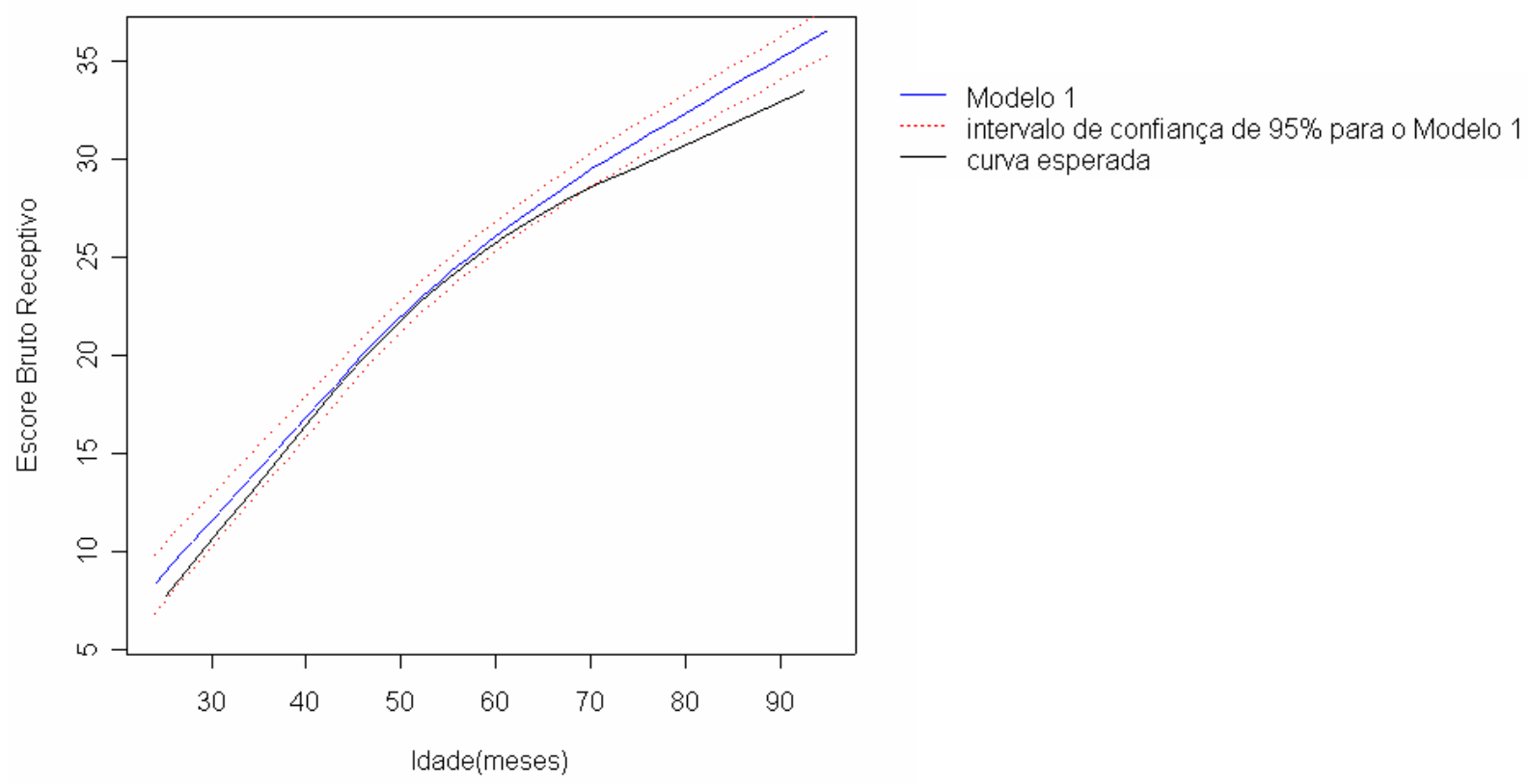

No Gráfico acima podemos verificar que a curva ajustada para o Escore Bruto Receptivo para a Forma A do teste não é significantemente diferente da curva esperada (que refere-se aos sujeitos falantes do Inglês) até aproximadamente 70 meses. A partir desta idade a curva ajustada fica significantemente acima da curva de referência do padrão americano. 
Gráfico 04: Curva de regressão ajustada com intervalo de confiança de 95\% para a média do Escore Bruto Receptivo na forma B e curva de referência americana.

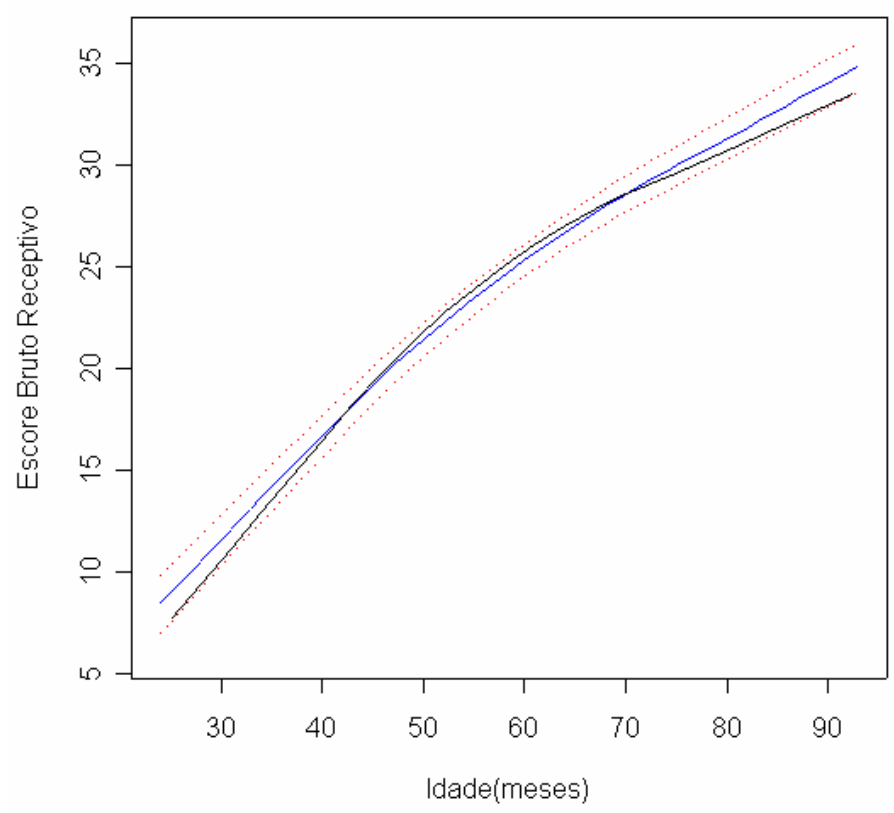

- Modelo 2

..... intervalo de confiança de $95 \%$ para o Modelo 2

- curva esperada

No Gráfico 04 verifica-se que a curva de regressão ajustada para a média do Escore Bruto Receptivo na forma $B$ quando comparada à curva de referência do padrão americano (linha contínua que está em preto) não apresenta evidências de que a curva ajustada seja diferente da curva esperada. 
Gráfico 05: Curva de regressão ajustada com intervalo de confiança de 95\% para a média do Escore Bruto Expressivo na forma A e curva de referência americana.

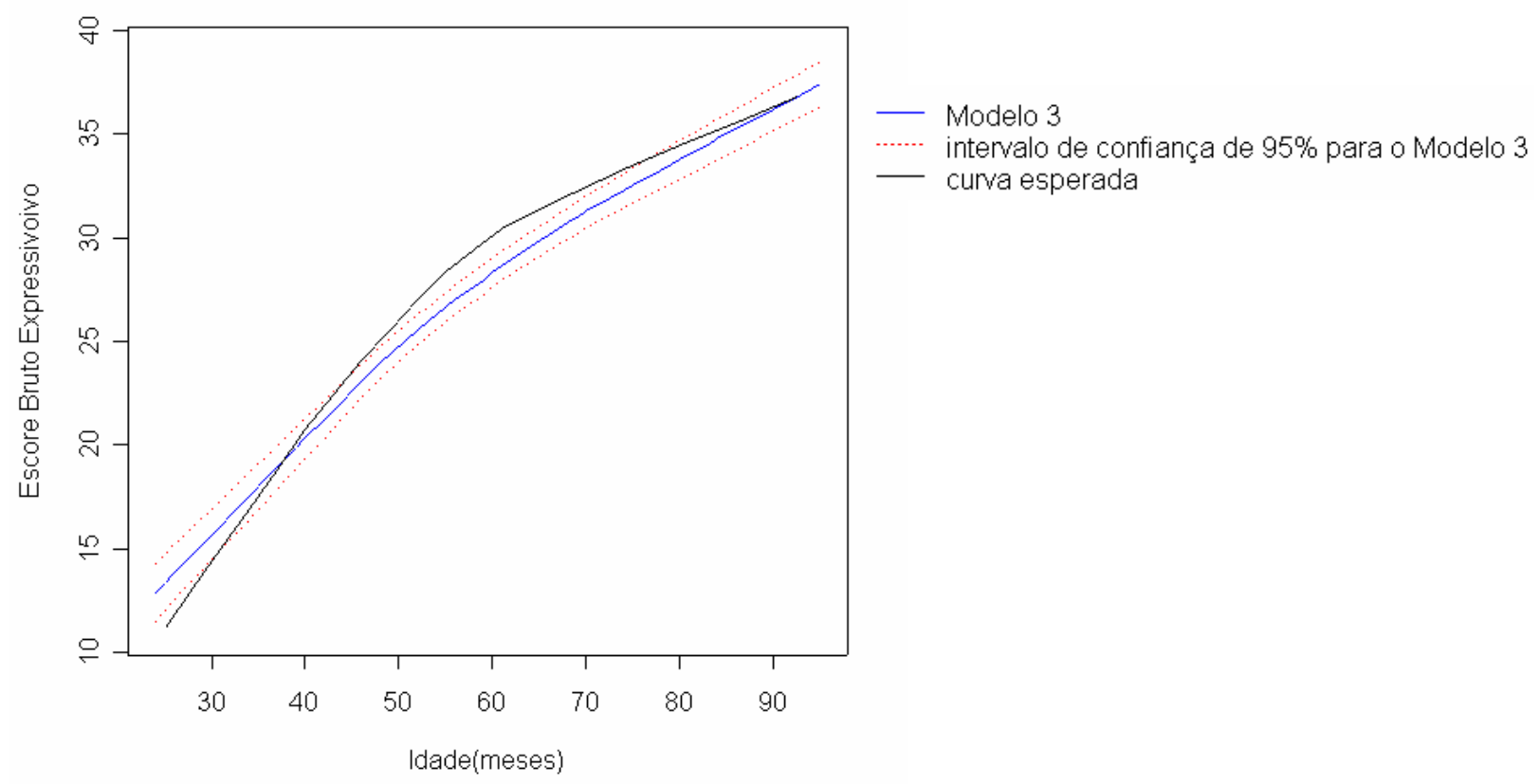

No Gráfico 05 observamos que entre aproximadamente 50 e 70 meses a curva ajustada (linha contínua em azul) está significantemente abaixo da curva esperada (padrão americano). 
Gráfico 06: Curva de regressão ajustada com intervalo de confiança de $95 \%$ para a média do Escore Bruto Expressivo na forma B e curva de referência americana.

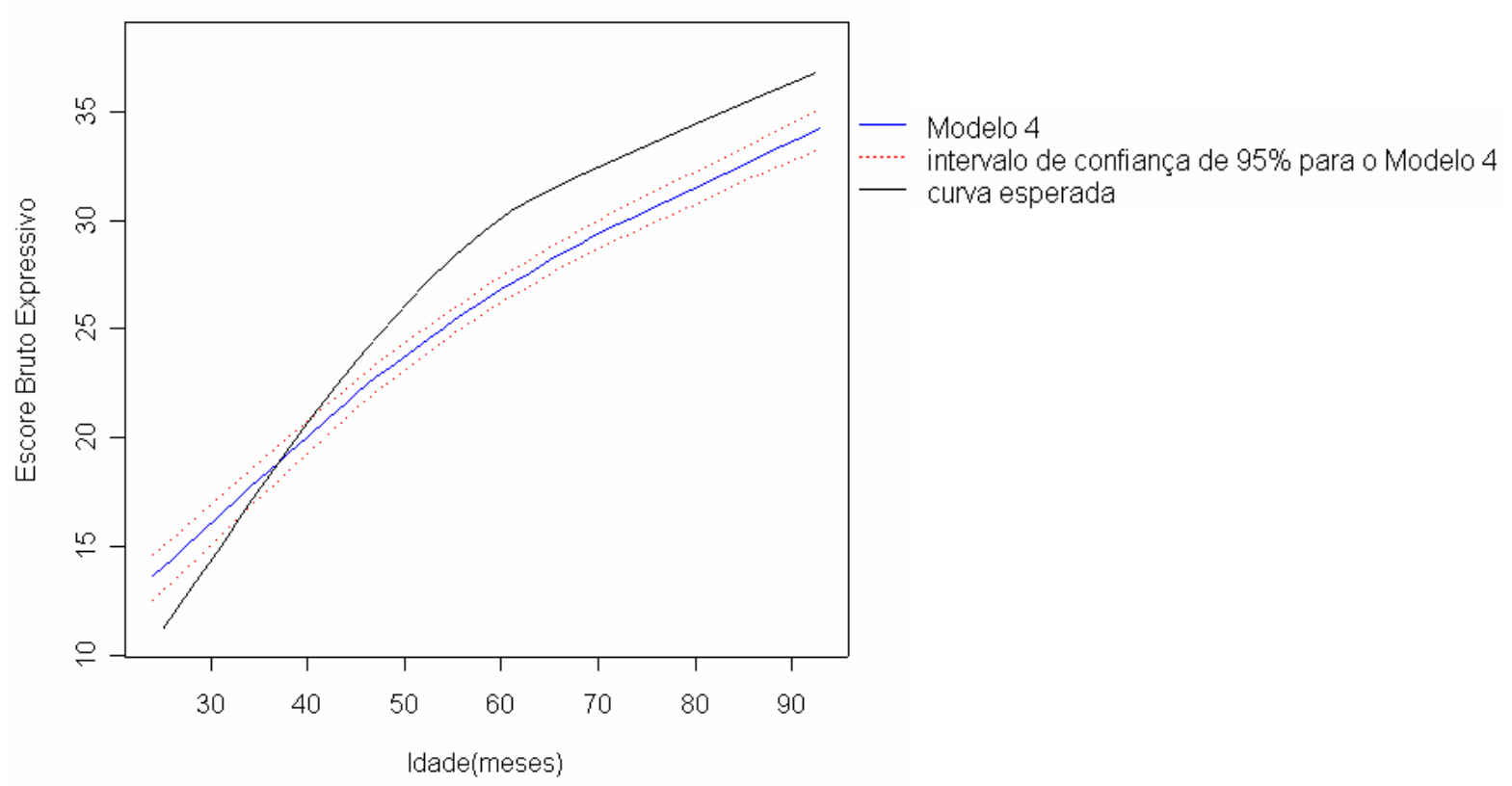

No Gráfico 06 é possível observarmos que a curva ajustada para o Escore Bruto Expressivo para a forma B do teste (linha contínua em azul) é significantemente diferente da curva esperada em quase sua totalidade, e em geral abaixo da curva esperada.

\section{2 - Resultados da comparação da Idade Cronológica e a Idade Equivalente (lingüística)}

A variável Idade Equivalente refere-se à idade lingüística da criança (expressa em meses). 
Gráfico 07: Dispersão de Idade x Idade Equivalente Receptiva com a reta de referência americana.

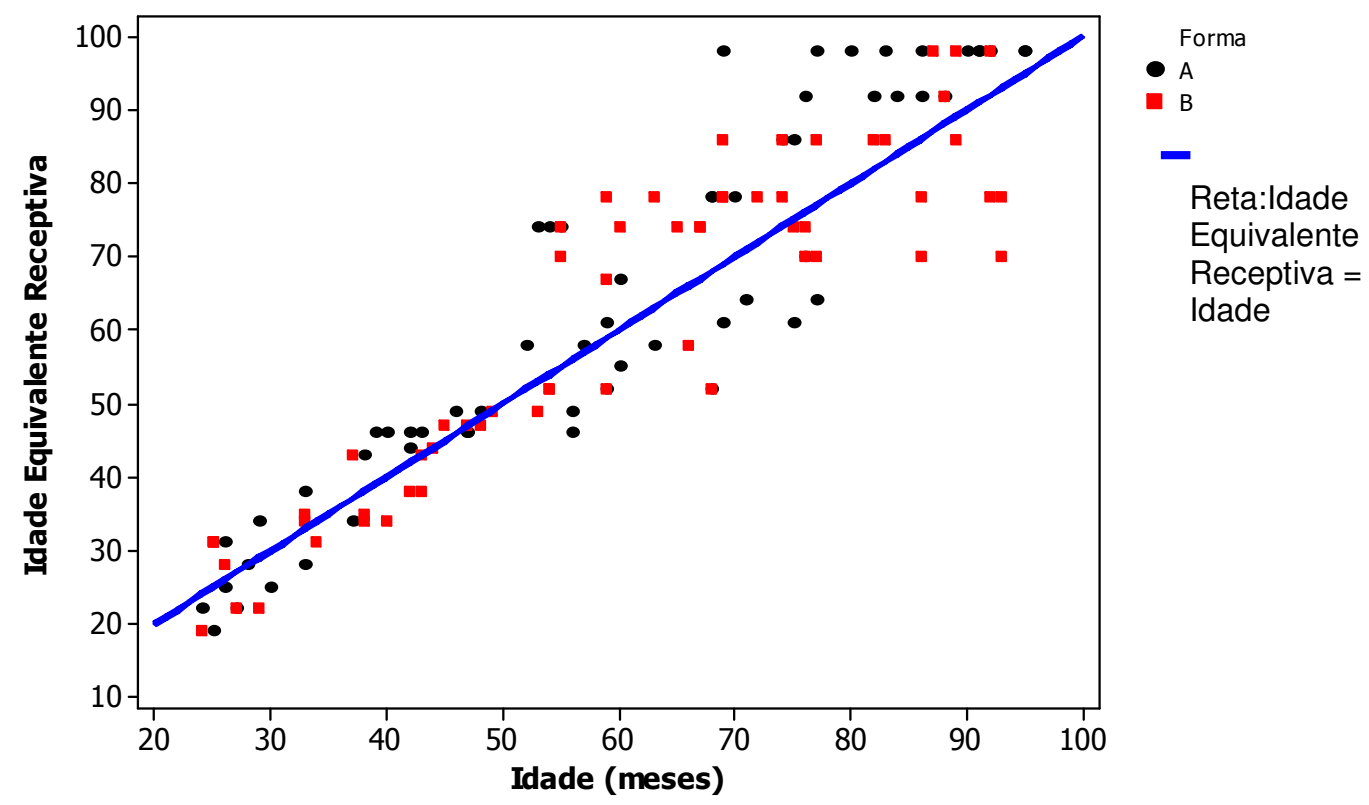

O Gráfico 07 ilustra a variável Idade Cronológica versus a Idade Equivalente Receptiva. A reta diagonal azul refere-se à referência dos sujeitos falantes do Inglês. Os pontos pretos são os sujeitos-pesquisa que foram testados com a forma $A$ do teste e os pontos vermelhos os que foram testados com a forma $B$ do teste.

Ë possível notar que, até 60 meses (4:11 anos) a Idade Equivalente Receptiva equipara-se à idade cronológica das crianças para as duas formas do teste, ou seja, os pontos estão próximos à reta diagonal (Idade Equivalente Receptiva $=$ Idade Cronológica). Já a partir dos 5 anos, nota-se que os pontos referentes à forma $\mathrm{B}$, apesar de apresentarem uma maior variabilidade, continuam se equiparando à idade cronológica. Por outro lado, na forma $A$ do subteste, a idade equivalente receptiva parece ser maior do que a idade cronológica, a maioria dos pontos encontra-se acima da reta diagonal. 
Gráfico 08: Dispersão de Idade x Idade Equivalente Expressiva com a reta de referência americana.

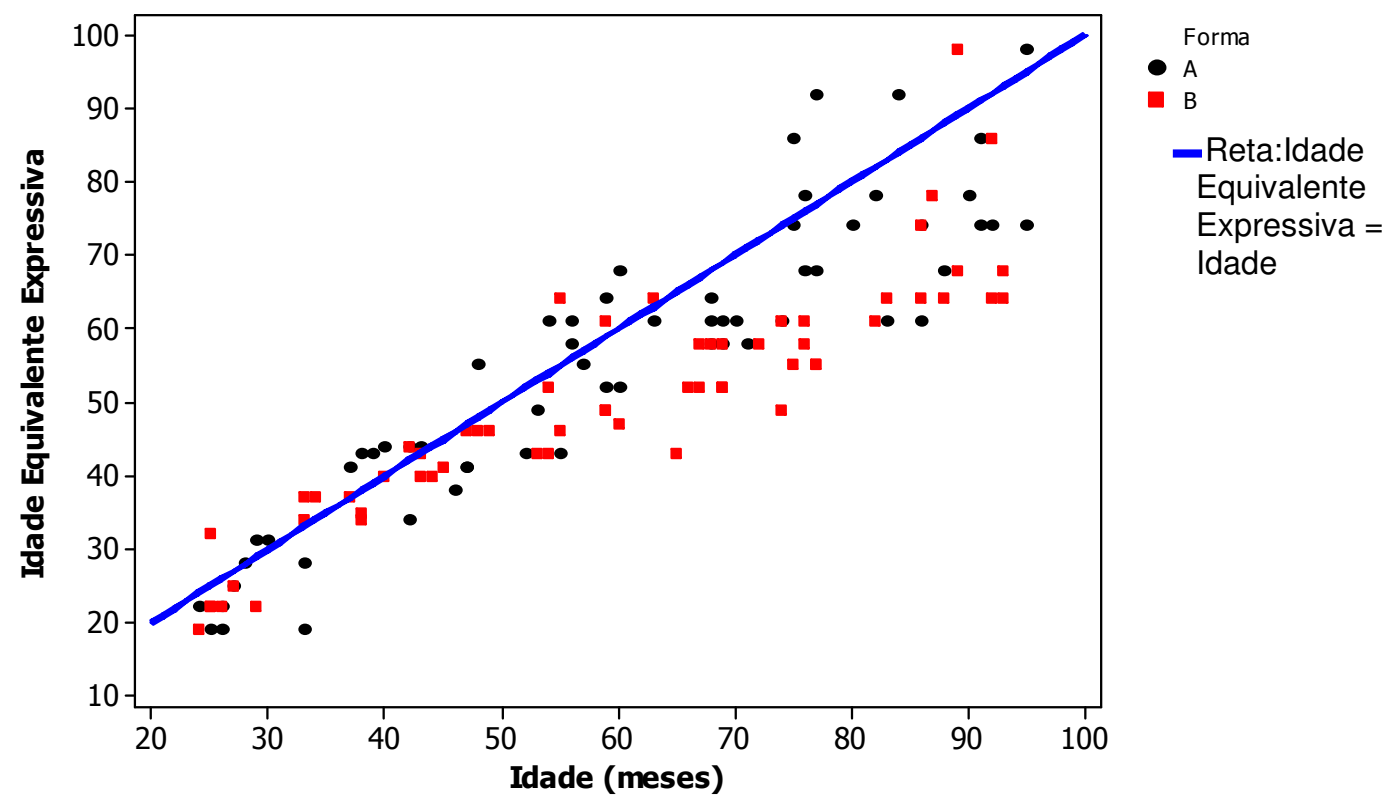

No Gráfico 08 verifica-se que para a forma A do teste, até 60 meses (4:11anos), a Idade Equivalente Expressiva equipara-se à idade cronológica das crianças, sendo que para as idades superiores a 60 meses está abaixo da idade cronológica. Os valores da Idade Equivalente Expressiva para a forma B estão abaixo da idade cronológica, sendo que esta diferença parece aumentar com a idade cronológica, ou seja, para maiores valores da variável idade os pontos ficam mais abaixo da reta diagonal.

\section{3 - Distribuição do Percentual de Classificação Geral obtida pelos sujeitos no teste}

Os escores-padrão do TELD-3 são denominados de quocientes. Os escores brutos, que correspondem ao número de acertos obtidos em cada subteste do teste podem ser convertidos em quocientes por meio de uma tabela de conversão padronizada. A partir dos valores dos quocientes, é possivel classificar a performance do sujeito no teste. 


\section{Quadro 03: Distribuição da Classificação Geral obtida pelos sujeitos no Teste}

\begin{tabular}{|c|c|c|c|}
\hline Quocientes* & Classificação * & $\begin{array}{c}\text { Sujeitos } \\
\text { americanos* }\end{array}$ & Sujeitos-pesquisa \\
\hline $131-165$ & Muito superior & $2.34 \%$ & $0 \%$ \\
\hline $121-130$ & Superior & $6.87 \%$ & $2.51 \%$ \\
\hline $111-120$ & Acima da média & $16.12 \%$ & $13.58 \%$ \\
\hline $90-110$ & Média & $49.51 \%$ & $69.73 \%$ \\
\hline $80-89$ & Abaixo da média & $16.12 \%$ & $14.18 \%$ \\
\hline $70-79$ & Pobre & 6.87 & $0 \%$ \\
\hline $35-69$ & Muito pobre & $2.34 \%$ & $0 \%$ \\
\hline
\end{tabular}

* Referência: manual do examinador do TELD-3 página 61

No Quadro acima é possível observar que a distribuição da classificação geral da performance dos sujeitos no teste indica que $49.51 \%$ dos sujeitos falantes do Inglês tiveram classificação "média" no teste, enquanto $69.73 \%$ dos sujeitos falantes do Português Brasileiro tiveram esta classificação. Os sujeitos falantes do Português Brasileiro não apresentaram classificação compatível a "muito superior", "superior", "pobre" e "muito pobre", conforme ilustra o Quadro acima.

\section{4 - Resultado da análise individual da performance dos sujeitos no teste}

A pesquisadora realizou uma análise da peformance de cada sujeito em cada item do teste, em ambos os subtestes. Foram registrados, conforme ilustram os Quadros abaixo, os itens cuja porcentagem de erro foi igual ou superior a $70 \%$. 


\section{Quadro 04: Itens com índice de $70 \%$ ou mais de Erros - Forma A}

\begin{tabular}{|c|c|}
\hline Subteste Receptivo & Subteste Expressivo \\
\hline Item 8 & Item 14 \\
\hline Item 12 & Item 32 \\
\hline Item 24 & Item 33 \\
\hline Item 35 & Item 39 \\
\hline
\end{tabular}

Conforme ilustra o Quadro 04, no subteste receptivo dos 37 itens que compõem este subteste, em 04 (11\%) destes os sujeitos obtiveram $70 \%$ ou mais de erros, os sujeitos não responderam ou suas respostas foram incorretas. No subteste expressivo, dos 39 itens que o compõem, em apenas 04 (10\%) houve o índice de erro estabelecido No Quadro 05 apresentado a seguir consta uma descrição das habilidades testadas nos respectivos itens.

Quadro 05: Descrição dos Itens - Forma A

\begin{tabular}{|c|c|l|c|}
\hline Item & $\begin{array}{c}\text { Faixa Etária } \\
\text { indicada }\end{array}$ & \multicolumn{1}{|c|}{ Descrição da habilidade testada } & $\begin{array}{c}\text { Componente } \\
\text { lingüístico }\end{array}$ \\
\hline 8 & 2 anos & $\begin{array}{l}\text { Demonstrar uma atividade após o pedido (mostrar } \\
\text { como escova os dentes) }\end{array}$ & Semântico \\
\hline 12 & 3 anos & Compreensão de superlativo - maior e menor & Morfossintaxe \\
\hline 24 & 5 anos & Compreender conceitos metalingüísticos & Morfossintaxe \\
\hline 35 & 7 anos & Identificar sinônimos & Morfossintaxe \\
\hline 14 & 2 anos & Repetir sentenças & Morfossintaxe \\
\hline 32 & 6 anos & $\begin{array}{l}\text { Capacidade de expressar concordância sujeito-verbo } \\
\text { (plural) }\end{array}$ & \begin{tabular}{l} 
Morfossintaxe \\
\hline 33
\end{tabular} \\
\hline 39 anos & 7 anos & Faluralidade de expressar concordância sujeito-verbo & Morfossintaxe \\
\hline
\end{tabular}




\section{Quadro 06 : Itens com índice de 70\% ou mais de Erros - Forma B}

\begin{tabular}{|c|c|}
\hline Subteste Receptivo & Subteste Expressivo \\
\hline Item 09 (3 anos) & Item 13 ( 2 anos $)$ \\
\hline Item 14 (3 anos) & Item 26 (5 anos) \\
\hline Item 30 (7 anos) & Item 31 (6 anos) \\
\hline Item 32 (7 anos) & Item 33 (7 anos $)$ \\
\hline Item 33 (7 anos) & Item 37 (7 anos $)$ \\
\hline Item 37 (7 anos) & Item 38 ( 7 anos $)$ \\
\hline & Item 39 (7 anos $)$ \\
\hline
\end{tabular}

Conforme pode-se verificar no Quadro 06, dos 37 itens que compõem o subteste receptivo da Forma B do teste, em 06 itens (16\%) os sujeitos apresentaram um índice de erro igual ou superior a $70 \%$. Já no subteste expressivo, o número de itens com o percentual de erro estabelecido foi 07 (18\%). No Quadro apresentado a seguir, estão descritas as habilidades testadas nesses itens. 
Quadro 07: Descrição do Itens - Forma B

\begin{tabular}{|c|c|l|c|}
\hline Item & $\begin{array}{c}\text { Faixa Etária } \\
\text { indicada }\end{array}$ & \multicolumn{1}{|c|}{ Descrição da habilidade testada } & $\begin{array}{c}\text { Componente } \\
\text { lingüístico }\end{array}$ \\
\hline 9 & 2 anos & $\begin{array}{l}\text { Capacidade de compreender superlativo - maior e } \\
\text { menor }\end{array}$ & Morfossintaxe \\
\hline 14 & 3 anos & $\begin{array}{l}\text { Capacidade de compreender conceito de } \\
\text { comprimento }\end{array}$ & Semântico \\
\hline 30 & 6 anos & $\begin{array}{l}\text { Capacidade de identificar partes específicas do } \\
\text { corpo }\end{array}$ & Semântico \\
\hline 32 & 6 anos & Compreensão de conceitos metalingüísticos & Morfossintaxe \\
\hline 33 & 6 anos & Compreensão de conceitos metalingüísticos & Morfossintaxe \\
\hline 37 & 7 anos & Compreensão de sinônimos & Morfossintaxe \\
\hline 13 & 2 anos & Usar nomes no plural & Morfossintaxe \\
\hline 26 & 5 anos & Produzir nomes no plural & Semântico \\
\hline 31 & 6 anos & Habilidade de definir palavras & Semântico \\
\hline 33 & 7 anos & Falar elementos que faltam de uma sentença & Semântico \\
\hline 37 & 7 anos & Capacidade de expressar sinônimos & Morfossintaxe \\
\hline 38 & 7 anos & Combinar sentenças & Formar frases com pares de palavras \\
\hline 39 & 7 anos & \multicolumn{1}{|c|}{ Sorfaxe } \\
\hline
\end{tabular}




\section{IV - Discussão}

Hipótese 1. Os escores obtidos pelos sujeitos falantes do Português Brasileiro serão equivalentes às referências originais do teste. Parcialmente Confirmada.

Houve diferença entre a performance dos sujeitos para algumas faixas etárias. Para comparar a performance dos falantes do Português e falantes do Inglês no Test of Early Language Development -3 (TELD-3) alguns parâmetros foram considerados. Primeiramente foi analisado se os valores dos escores brutos receptivo e expressivo obtidos pelos sujeitos falantes do Português Brasileiro aumentariam em função da idade e se este aumento seria proporcional ao observado nos falantes do Inglês.

Com relação a estes aspectos, os resultados obtidos indicaram que o crescimento dos valores do Escore Bruto Receptivo apresentou um padrão muito próximo nos dois grupos de sujeitos, até 4:11 anos. Já para as faixas etárias de 5, 6 e 7 anos os valores do Escore Bruto Receptivo na Forma A do teste foram mais altos do que os observados na referência americana.

No Gráfico 02 que ilustra os valores do crescimento das médias do Escore Bruto Expressivo, observa-se que também até 4:11 anos, os valores dos grupos de sujeitos não apresentaram diferenças significantes. Para as faixas etárias de 5 e 6 anos, os valores do Escore Bruto Expressivo na forma $B$ do teste foram menores quando comparados à referência americana.

Os resultados da análise de regressão clássica confirmaram estes achados ou seja, até 4:11 anos, em ambas as formas do teste, os desempenhos foram semelhantes nos dois grupos de sujeitos, em ambos os subtestes - receptivo e expressivo. A partir desta idade, vimos que quanto ao Escore Bruto Receptivo na forma $A$ do teste, os sujeitos falantes do Português Brasileiro obtiveram pontuação mais alta quando comparados à referência americana. $E$ quanto ao Escore Bruto Expressivo na forma $A$ e $B$, predominantemente das faixas etárias de 5 e 6 anos os valores obtidos pelos sujeitos falantes do Português Brasileiro foram menores 
quando comparados à referência americana, sendo que na forma $\mathrm{B}$ esta diferença foi mais acentuada.

Um outro aspecto considerado na análise comparativa foi se os valores da Idade Equivalente (Idade Lingüística) se equiparavam à Idade Cronológica dos sujeitos falantes do Português Brasileiro que participaram deste estudo e estes aos valores apresentados na referência americana. Considerando que foram selecionados sujeitos com desenvolvimento típico de linguagem, esperava-se que a Idade Equivalente fosse equiparada à Idade Cronológica.

No subteste receptivo, a Idade Equivalente Receptiva se equiparou à Idade Cronológica e à referência americana nas formas $A$ e $B$ do teste até 60 meses (4:11 anos). Já a partir de 5 anos, a Idade Equivalente Receptiva na forma $A$ do teste mostrou ser maior que a Idade Cronológica e do que a referência americana.

No subteste expressivo, os resultados indicaram também que até 60 meses (4:11 anos) a Idade Equivalente Expressiva se equiparou à Idade Cronológica e à referência americana. Já a partir de 5 anos, na forma $B$ do teste, a Idade Equivalente Expressiva ficou abaixo da Idade Cronológica e da referência americana.

O TELD-3 é um teste de identificação precoce de alterações no desenvolvimento da linguagem. Segundo seus autores, o teste foi elaborado com itens que investigam aspectos genéricos da linguagem infantil. Os resultados deste estudo indicaram que até $4: 11$ anos, a performance dos sujeitos falantes do Português e dos falantes do Inglês foram muito parecidas e partir desta idade, os sujeitos falantes do Português obtiveram mais pontos no subteste receptivo e menos pontos no subteste expressivo, principalmente na forma B do teste. Este achado pode indicar que a partir de 4:11 anos, as diferenças entre as Línguas podem ser mais marcantes, principalmente e possivelmente pela gramaticalização da Língua, justificando desta forma a diferença encontrada nas performances dos grupos estudados (Hadley, 2006; Crain et al, 2006). 
O terceito critério adotado na comparação entre a performance dos sujeitos falantes do Português e os falantes do Inglês foi analisar a distribuição percentual da classificação geral obtida pelos sujeitos no teste. A partir do Quadro 03 foi possível observar que a grande maioria dos sujeitos ficou concentrada na classificação "média" - 49.51\% no caso dos falantes do Inglês e $69.73 \%$ dos falantes do Português Brasileiro. O percentual referente à classificação "abaixo da média" e "acima da média" também foi muito parecido nos dois grupos de sujeitos. Os falantes do Português não obtiveram classificação "muito superior', "pobre" e "muito pobre".

$\mathrm{Na}$ amostra dos falantes do Inglês foram incluídos grupos distintos de sujeitos: americanos nativos, americanos anglo-europeus, afro-americanos, híspanoamericanos, crianças com Distúrbio de Aprendizagem, crianças com Distúrbio de Linguagem, crianças com Déficit de Atenção/Hiperatividade e crianças com distúrbios cognitivos. Já na amostra dos falantes do Português Brasileiro foram incluídos apenas sujeitos com desenvolvimento típico de linguagem. Esta diferença nos grupos que compuseram as amostras podem justificar o porquê que os sujeitos falantes do Português não obtiveram classificação "pobre"e "muito pobre".

Estes resultados indicam que o teste mostrou-se sensível para caracterizar a performance de linguagem dos sujeitos falantes do Português Brasileiro. Estes achados corroboram com o estudo desenvolvido por Martinez (2005) que aplicou o TELD-3 em crianças falantes do Espanhol e que indicou que o teste pode ser considerado confiável para os seus propósitos.

Hipótese 2. A análise individual da performance dos sujeitos falantes do Português Brasileiro no teste indicará que não haverá necessidade de significativas adaptações na versão traduzida do TELD-3. Confirmada.

A pesquisadora realizou um levantamento considerando a performance individual dos sujeitos falantes do Português Brasileiro em cada item do teste, nos subtestes receptivo e expressivo, em ambas as formas. 
Os itens nos quais $70 \%$ ou mais dos sujeitos não pontuaram foram registrados. Na forma A conforme ilustrou o Quadro 04, dos 37 itens do subteste receptivo, em apenas $04(11 \%)$ os sujeitos tiveram $70 \%$ ou mais de erros e no subteste expressivo foram $04(10 \%)$ itens. Já na forma B, no subteste receptivo foram registrados 06 (16\%) itens com $70 \%$ ou mais de erros e no subste expressivo foram $07(18 \%)$ itens.

$\mathrm{Na}$ descrição dos itens registrados com a porcentagem de erros estabelecida, é possível verificar que na forma $A, 75 \%$ dos itens registrados são indicados para avaliar o componente morfossintático da linguagem oral. $\mathrm{E}$ na forma $\mathrm{B}, 55 \%$ dos itens tinham este objetivo. Tais resultados podem se relacionar com as diferenças nos aspectos morfossintáticos dos dois idiomas e que ficaram marcadas principalmente a partir de 5 anos de idade.

Comparando as duas formas do Teste é possível verificar que a Forma $B$ apresentou uma quantidade maior de itens cuja porcentagem de erros apresentados pelos sujeitos foi igual ou superior a $70 \%$. O rebaixamento apresentado pelos sujeitos de 5 e 6 anos na forma $B$ do teste pode estar relacionado a este dado.

Apesar de ter havido estas diferenças, os resultados estatísticos referentes ao desempenho geral dos sujeitos falantes do Português Brasileiro no teste indicam que elas não foram tão significantes ao ponto de rebaixar de forma expressiva a performance dos sujeitos. Apenas 14. 18\% dos sujeitos na amostra geral foram classificados como "abaixo da média", enquanto que o restante dos sujeitos receberam classificação "média", "acima da média" e "superior".

Assim sendo, apesar do resultado da análise individual da performance dos sujeitos falantes do Português Brasileiro ter indicado que numericamente alguns itens, tanto da forma $A$ quanto da forma $B$, deveriam ser revistos, visto que nestes itens $70 \%$ ou mais dos sujeitos testados não pontuaram, indicando que podem não estar adequados para este grupo, os resultados estatísticos revelam que apesar destas diferenças, o teste foi sensível para caracterizar a performance de linguagem da população estudada, isto é, apesar dos índices de erros registrados, na classificação geral os sujeitos não apresentaram classificação "pobre" e "muito 
pobre". O resultado da análise individual da performance dos sujeitos nos itens do teste tornou-se não significante frente ao resultado da análise estatística.

Parece possível concluir então que a versão traduzida do teste poderá ser utilizada sem a necessidade de adaptações significativas. Além disso, a modificação dos itens que compõem o teste ou a retirada de algum item poderia comprometer as propriedades do teste, bem como as suas características psicométricas. A alteração no formato original do teste poderia inviabilizar pesquisas transculturais, visto que não seriam mantidas as equivalências entre a versão original e a versão traduzida do teste.

Conforme apontado por Dale e Henderson (1987) poucos estudos sobre o TELD têm sido relatados. Essary (1993) e Suen (2002) referem que pesquisadores que utilizaram o TELD devem relatar os resultados de suas pesquisas e esta sugestão também é feita pelos autores do teste (Hresko, Reid e Hammill, 1999).

Tendo em vista estas considerações e as experiências obtidas com o estudo aqui proposto é possível apontar algumas análises referentes à aplicação do TELD-3 com os sujeitos falantes do Português Brasileiro e que participaram deste estudo.

Com relação aos pontos positivos, foi observado que o TELD-3 é de fácil aplicação, todas as instruções estão descritas com clareza no manual do examinador. Os materiais necessários à aplicação (brinquedos e álbum de figuras) acompanham seu kit completo, o que facilita e agiliza sua aplicação. A fundamentação teórica do teste bem como as suas finalidades estão descritas de forma clara no manual do examinador. A divisão em subeste receptivo e subteste expressivo é um outro ponto positivo e que pode auxiliar no diagnóstico diferencial. As propriedades psicométricas estão disponibilizadas no manual do examinador e demonstram que o TELD-3 pode ser considerado estatisticamente confiável. Um outro ponto positivo que pode ser destacado é que os autores descrevem com clareza os cuidados necessários, desde sua aplicação até o cuidado que se deve ter na interpretação dos resultados e como passar estas informações aos responsáveis pelo paciente. Estas considerações também foram encontradas em algumas 
revisões do teste (Dale e Henderson, 1987; Essary, 1993; Breeyear et al, 2001; Kulick, 2002).

A sugestão de enviar uma cópia de pesquisas com o Teste aos autores também é um ponto favorável e que pode a partir disso, viabilizar pesquisas transculturais envolvendo o referido TELD-3.

Com relação às fraquezas do teste, pode-se apontar, a partir do estudo realizado, que as tabelas padronizadas utilizadas para conversão dos escores brutos em quocientes não são claramente explicadas, o que acaba dificultando a compreensão das mesmas. Na descrição dos critérios utilizados para corrigir a pontuação obtida no teste, existem alguns exemplos. Porém, em alguns itens, os exemplos foram poucos o que gerou dúvidas na correção, ou seja, faltaram algumas opções de respostas, visto que o exemplo dado ficou vago.

O tempo gasto na aplicação do TELD-3 é, em média, trinta minutos. Um ponto que poderia ser discutido seria a complementação de alguns itens para algumas faixas etárias, tornando-o mais completo e menos artificial em alguns aspectos. Para isso, poderia ser analisada a possibilidade de se ter apenas uma forma do teste ao invés de duas formas como está organizado. Em outros testes de avaliação de linguagem infantil comumente utilizados na prática clínica e em pesquisas, não encontramos esta mesma organização de duas formas, como é o TELD-3.

Para finalizar, podemos supôr que da mesma forma que foi possível publicar a versão do teste em Espanhol, acreditamos que a partir dos resultados aqui obtidos também seria possível sua publicação em Português Brasileiro. 


\section{V - Considerações Finais}

Os objetivos deste estudo foram comparar a performance de sujeitos típicos falantes do Português (Brasil) com sujeitos falantes do Inglês (EUA) no Test of Early Language Development - 3 (TELD-3) e analisar a performance individual dos sujeitos falantes do Português nos itens do teste.

Em relação à primeira hipótese, os resultados indicaram que a performance dos sujeitos foram equivalentes para a idade até 4:11 anos. Para 5, 6 e 7 anos no subteste receptivo da forma $A$, os sujeitos falantes do Português obtiveram pontuação mais alta do que a apresentada na referência americana. $E$ para as faixas etárias de 5 e 6 anos no subteste expressivo, na forma $B$, a pontuação dos sujeitos falantes do Português foi menor do que a observada na referência americana.

A analise individual da performance dos sujeitos falantes do Português Brasileiro no teste, indicou que apesar de ter ocorrido $70 \%$ ou mais de erros em alguns itens, isto não interferiu estatisticamente, na pontuação e classificação geral dos sujeitos no teste. Além disso, esta análise também indicou que não há necessidade de adaptações significativas a serem feitas no teste.

A partir dos resultados apresentados, pode-se concluir que o TELD-3 versão traduzida para o Português Brasileiro, mostrou-se sensível para caracterizar a performance de linguagem dos sujeitos que participaram deste estudo. Os resultados obtidos sugerem que, quanto aos subtestes receptivos, ambos se mostraram sensíveis para caracterizar a performance de linguagem da amostra estudada. Já quanto ao subteste expressivo, a forma $A$ do teste mostrou-se mais efetiva.

Estudos complementares com um número maior de sujeitos e estudos comparando diferentes grupos são necessários, visando analisar a sensibilidade e a especificidade do teste. Além disso, outros estudos poderão além de complementarem os resultados aqui encontrados, poderão também contribuir para maior generalização dos mesmos. 
O objetivo geral desta Tese foi verificar a performance de crianças típicas falantes do Português Brasileiro no Test of Early Language Development - Terceira Edição, (TELD-3, de Hresko, Reid e Hammill, 1999).

Primeiramente foi apresentada a tradução do TELD-3 para o Português Brasileiro. Os procedimentos adotados pela pesquisadora no processo de tradução contribuíram para que fosse mantida a maior equivalência possível entre a versão original e a versão traduzida do teste. E os resultados indicaram que não houve mudanças significativas no conteúdo e formato do teste, aspecto importante em pesquisas com esta finalidade.

No Brasil, Fonoaudiólogos não dispõem de muitos instrumentos para avaliação da linguagem na infância, diferentemente do que ocorre em outros países. Por isso, a tradução e adaptação de testes publicados e comercializados em outras Línguas pode amenizar esta carência. No entanto, em pesquisas sobre o assunto, os autores referem que este processo deve ser cuidadoso e criterioso. Esta orientação é preconizada pela Comissão Internacional de Testes (International Test Commission) que tem notado, que nos últimos anos, muitos estudos sobre o assunto têm sido realizados.

Os resultados obtidos indicaram que é necessário que Fonoaudiólogos busquem maior embasamento técnico e teórico sobre o assunto, uma vez que praticamente não foram encontradas referências sobre este tema na literatura pesquisada. Seria importante que discussões pudessem ser apresentadas em fóruns e comitês científicos e este seria um importante passo para que pesquisas transculturais pudesem ser feitas. Objetos de estudo seriam melhor caracterizados à medida que vários centros de pesquisa usassem os mesmos instrumentos de diagnóstico, por exemplo. 
Além disso, tais estudos poderiam contribuir para uma maior compreensão e caracterização das especificidades das alterações na aquisição e desenvolvimento da linguagem, nas diferentes Línguas.

Os resultados também indicaram a necessidade de implantar programas de treinamento sobre testes, desde a elaboração, a tradução, adaptação até a aplicação e interpretação correta dos mesmos. Em cursos de Fonoaudiologia, por exemplo, nos Estados Unidos, alunos da graduação têm disciplinas específicas sobre o assunto e no Brasil é necessária uma maior preocupação com este aspecto.

A análise da perfomance dos sujeitos falantes do Português Brasileiro na versão traduzida do TELD-3 indicou que nos subtestes receptivos das Formas A e B sua classificação foi "média". Já com relação aos subtestes expressivos, os grupos de sujeitos de 5 e 6 anos foram classificados como "abaixo da média", na Forma B do teste. Tais resultados indicaram que para a amostra estudada, os subtestes receptivos das Formas A e B mostraram-se sensíveis para caracterizar a performance de linguagem dos sujeitos. Já os subtestes expressivos, também mostraram-se sensíveis, porém a forma A mostrou ser mais efetiva.

Para os sujeitos falantes do Português Brasileiro as formas A e B do teste não foram equivalentes em todas as faixas etárias, assim como os subtestes receptivo e expressivo que tiveram uma diferença estatisticamente significante para as faixas de 4, 5, e 6 anos, sendo que nos subtestes expressivos os sujeitos obtiveram menos pontos. Apesar destas diferenças foi observado um aumento crescente nos valores dos escores brutos em função do aumento da idade cronológica, ou seja, quanto maior a idade cronológica maior foi a pontuação, sugerindo uma evolução quanto aos parâmetros de linguagem contemplados no teste.

A análise comparativa entre a performande dos sujeitos falantes do Português (Brasil) e os sujeitos falantes do Inglês (EUA), indicou que até 4:11 anos as performances foram muito parecidas, ou seja, não houve diferenças 
estatíticamente significantementes. Já a partir desta idade, no subteste receptivo da forma $A$ os sujeitos falantes do Português obtiveram pontuação mais alta quando comparados à referência americana e no subteste expressivo da Forma $B$, a pontuação obtida foi inferior à observada na referência americana, para o grupo de sujeitos de 5 e 6 anos de idade.

Embora tenham sido observadas estas diferenças, na distribuição percentual da classificação geral obtida pelos sujeitos no teste, foi verificado que com relação às classificações - Média, Acima da Média e Abaixo da Média, os valores apresentados pelos dois grupos foram próximos.

Analisando individualmente a performance dos sujeitos falantes do Português em cada item do teste, verificou-se que a porcentagem de itens nos quais $70 \%$ ou mais dos sujeitos não pontuaram não foi significante a ponto de rebaixar a performance no teste, dado confirmado pelos resultados da análise estatística. Estudos futuros relacionados a uma análise mais aprofundada destes itens poderão realizados.

De uma forma geral, os resultados obtidos nesta Tese indicaram que a versão traduzida para o Português Brasileiro do Test of Early Language Development Terceira Edição (TELD-3) mostrou-se sensível para caracterizar a performande de linguagem da população estudada.

Futuras pesquisas relacionadas à sensibilidade e à especificidade do teste são necessárias. Além disso, a aplicação do teste em uma amostra maior de sujeitos poderá contribuir para uma maior generalização dos resultados aqui encontrados.

Uma cópia dos resultados aqui apresentados será enviada aos autores do teste que colocam esta sugestão no manual do examinador. Além disso, a pesquisadora pretende manter futuros contatos com os autores, a fim de viabilizar pesquisas transculturais, que poderiam fortalecer a Fonoaudiologia Brasileira como Ciência e a Tese aqui apresentada pode ser um passo inicial para isto. 
Os resultados aqui obtidos parecem indicar que seria possível editar o TELD3 para o Português Brasileiro, da mesma forma que foi editado para o Espanhol e publicado no final de 2006. 
REFERÊNCIAS BIBLIOGRÁFICAS 


\section{INTRODUCCÃO GERAL}

ANDRADE, Claúdia Regina Furquim de. Prevenção em Fonoaudiologia: eficácia dos tratamentos e programas terapêuticos. In: I Jornada Internacional de Otorrinolaringologia, 1998. Ribeirão Preto. Collectanea Symposium: Série Medicina e Saúde. São Paulo: Frontis Editorial, p. 113 -118, 1998.

ANDRADE, Claúdia Regina Furquim de. A fonoaudiologia baseada em evidências. Einstein, v. 2, p. $59-60,2004$.

ANDRADE, Claúdia Regina Furquim de et al. ABFW: Teste de Linguagem Infantil nas áreas de fonologia, vocabulário, fluência e pragmática. 2. ed. Barueri: Pró Fono, 2004.

ANDRADE, Claúdia Regina Furquim de; JUSTE, Fabíola. Proposta de análise de performance e de evolução em crianças com gagueira desenvolvimental. Revista Cefac, v. 7, nº 2, p. 158-170, 2005.

BEFI-LOPES, Débora Maria. Alterações no desenvolvimento da linguagem princípios de avaliação, diagnóstico e intervenção. In: LIMONGI, S.C.O. (Org.), Ed. Guanabara Koogan. Fonoaudiologia Informação para a Formação: Procedimentos Terapêuticos em Linguagem. Rio de Janeiro: Editora Guanabara koogan, 2003, p.112.

PERISSINOTO, Jacy; CHIARI, Brasília M. A avaliação como ação precursora do diagnóstico. In: Andrade, C.R.F., Marcondes, E. (Coords.). Fonoaudiologia em Pediatria. São Paulo: Sarvier, 1 ed., 2003, p. 135 - 140.

REED, Vicki. A. An introduction to Children With Language Disorders. $2^{\text {nd }}$ Edition. New York: McMillan, 1994. 
SHIPLEY, Kenneth G; McAFEE, Julie G. Assessment in Speech-Language Patholoy: a Resource Manual. $3^{\text {rd }}$ Edition. New York: Delmar Learning, 2004. 518p. 


\section{ESTUDO I}

ANASTASI, Anne.; URBINA, Susana. Natureza e uso dos testes psicológicos. In: . Testagem Psicológica, 7. ed. Porto Alegre: Artmed, 2000, p. 17 - 37.

ANDRADE, Claúdia Regina Furquim de et al. ABFW: Teste de Linguagem Infantil nas áreas de fonologia, vocabulário, fluência e pragmática. 2. ed. Barueri: Pró Fono, 2004.

ANDRADE, Claúdia Regina Furquim de.; JUSTE, Fabíola. Aplicação de um teste americano de severidade da gagueira (SSI) em crianças fluentes falantes do Português Brasileiro. Pró-Fono Revista de Atualização Científica, v. 13, nº 2, p. 177 180, 2001.

ANDRADE, Claúdia Regina Furquim de; JUSTE, Fabíola. Proposta de análise de performance e de evolução em crianças com gagueira desenvolvimental. Revista Cefac, v. 7, nº 2, p. 158-170, 2005.

ARAÚJO, Alessandra Amaral; PERISSINOTO, Jacy. Desenvolvimento da linguagem na adolescência: competências semânticas, sintáticas e pragmáticas. Pró-Fono Revista de Atualização Científica, v. 16, n 3, p. 251-260, 2004.

BEFI-LOPES, Débora Maria. Aspectos da Competência e do Desempenho Lexicais em Crianças entre 4:0 e 6:6 anos, com padrões de desenvolvimento normal e com alterações articulatórias. 1997. 285f. Tese (Doutorado em Semiótica e Lingüística Geral) - Faculdade de Filosofia, Letras e Ciências Humanas, Universidade de São Paulo. São Paulo.

BEFI-LOPES, Débora Maria.; GALEA, Daniela Evaristo. dos S. Análise do desempenho lexical em crianças com alteração no desenvolvimento da linguagem. Pró-Fono Revista de Atualização Científica, v. 12, n², p, 31-38 , 2000. 
BEFI-LOPES, Débora Maria, RODRIGUES, Amália. Avaliação do vocabulário nas alterações de desenvolvimento de linguagem. Jornal Brasileiro Fonoaudiologia, v.2, nº 8, p.183-190, 2001.

BEFI-LOPES, Débora Maria. Prova de Verificação do Vocabulário: Aspectos da Efetividade como Instrumento de Diagnóstico. 2002. Tese (Livre Docência) Faculdade de Medicina, Universidade de SãoPaulo. São Paulo.

BEFI-LOPES, Débora Maria. Alterações no desenvolvimento da linguagem princípios de avaliação, diagnóstico e intervenção. In: LIMONGI, S.C.O. (Org.), Ed. Guanabara Koogan. Fonoaudiologia Informação para a Formação: Procedimentos Terapêuticos em Linguagem. Rio de Janeiro: Editora Guanabara koogan, 2003, p. 112.

BEFI-LOPES, Débora Maria. Avaliação, diagnóstico e aspectos terapêuticos nos distúrbios específicos de linguagem. In: FERREIRA, L.P; BEFI-LOPES, D. M; LIMONGI, S.C. O. (Org(s). Tratado de Fonoaudiologia, 1 ed., São Paulo: Roca, v.1, 2004, p. $987-1000$.

BISHOP, Dorothy V.M. The underlying nature of specific impairment. Journal of Child Psycology and Psychiatry, v. 33, , nº p. p. 3-66, 1992.

BOONE, Daniel R; PLANTE, Elena. Comunicação humana e seus Distúrbios. Trad. Sandra Costa. 2ed. Porto Alegre: Artes Médicas, 1994.

BLOOM, Lois; LAHEY, Margaret. Language Development and Language Disorders. New York: McMillan, 1978, 689 p.

BROGGIO. Francine T. O. Desempenho de crianças típicas de 4 a 8 anos de idade no Test of Language Development Primary-3 Adaptado para o Português Brasileiro. 
2005. 281f. Dissertação (Mestrado em Semiótica e Lingüística Geral) - Faculdade de Filosofia, Letras e Ciências Humanas da Universidade de São Paulo, São Paulo.

CAPOVILLA, Fernando C.; CAPOVILLA, Alessandra G. Seabra. Desenvolvimento lingüístico na criança dos dois aos seis anos: tradução e estandardização do Peabody Picture Vocabulary Test de Dunn \& Dunn, e da Language Development Survey de Rescorla. Ciência Cognitiva: Teoria, pesquisa e aplicação, v.1:1, p. 353 380, 1997.

CAPOVILLA, Alessandra G. Seabra. et al. Adaptação brasileira do "International Dyslexia Test": perfil cognitivo de crianças com escrita pobre. Temas sobre desenvolvimento, v.10, $n^{0}$ 57, p. 30-37, 2001.

CORREA, Letícia Maria Sicuro; FREITAS, M.C, LIMA, C. M. C. Crianças com queixas de linguagem e procedimentos usuais de avaliação de habilidades lingüísticas. Calidoscópio, v.1, nº 1, p. 43-68, 2003.

CASTRO-REBOLLEDO, R. et al. Specific development language disorder: a theoritical aproach to its diagnosis, etiology and clinical symptoms. Rev. Neurology, v. 39 (12), p. $1173-1181,2004$.

DIRECTORY OF SPEECH-LANGUAGE PATHOLOGY ASSESSMENT INSTRUMENTS. American Speech-Language-Hearing Association. 2006 Edition. In: www. Asha.org.

DIRECTRIZES INTERNACIONAIS para a utilização de Testes. Versão Portuguesa da International Test Commission (ITC).

DUARTE, Cristiane S.; BORDIN, Isabel A. S. Instrumentos de avaliação. Revista Brasileira de Psiquiatria, v. 22, nº 2, p. $55-58,2000$. 
FERREIRA, P. E. A. et al. Tinnitus handicap inventory: adaptação cultural para o Português brasileiro. Pró-Fono Revista de Atualização Científica, v. $17, n^{0} 3$, p. 303310, set-dez, 2005.

FREITAS, Silvia. et al. Tradução e adaptação para o português da Escala de Compulsão Alimentar Periódica. Revista Brasileira de Psiquiatria, v. 23, n 4, p. 215 $-220,2001$.

FIGUEIREDO, Vera Lúcia M. WISC-III: Escala de Inteligência Wechsler para crianças: manual/ David Wechsler, $3^{a}$ ed: Adaptação e Padronização de uma amostra brasileira, $1^{\text {a }}$ ed. São Paulo: Casa do Psicólogo, 2002.

GUILLEMIN, F.; BOMBARDIER, C.; BEATON, D. Cross-cultural adaptation of healthy-related quality of life measures: literature review and proposed guidelines. Journal Clinical Epidemiol.. v.46, n.12, p. 1417-1432, 1993.

GRASSI-OLIVEIRA, R.; STEIN, L. M.; PEZZI, J. C. Tradução e validação de conteúdo da versão em português do Childhood Trauma Questionnaire. Rev. Saúde Pública, v.40, nº 2, p. 249-255, abr. 2006.

HAGE, Simone Rocha de Vasconcelos. Distúrbio Específico do Desenvolvimento da Linguagem: subtipos e correlações neuroanatômicas. Tese (Doutorado em Ciências Médicas) - 2000. - Faculdade de Ciências Médicas da Universidade de Campinas, Unicamp. Campinas. São Paulo.

HAGE, Simone Rocha de Vasconcelos. et al. Diagnóstico de crianças com alterações específicas de linguagem por meio de escala de desenvolvimento. Arquivos de Neuropsiquiatria, v. 62, nº 3-A, p. 649-653, 2004. 
HRESKO, Wayne P. REID, D. Kim.; HAMMILL, Donald D. Test of Early Language Developmental (TELD) Third Edition. Austin, TX: PRO-ED., 1999.

LAHEY, Margaret. Who shall be called language disordered? Some reflections and one perspective. Journal of Speech and Hearing Disorders, v. 55, p. $612-620$, 1990.

LAW, James. The process of early identification. In: The early of identification of language impairment in children. Ed. Chapman \& Hall, 1992, cap.6, p. 109-133.

LAW, James. Identificação precoce dos distúrbios de linguagem na criança. Trad. Maria Ines Corrêa Nascimento. Rio de Janeiro: Revinter, 2001. 210 p.

MANSUR, Letícia L. et al. Teste de nomeação de Boston: desempenho de uma população de São Paulo. Pró-Fono Revista de Atualização Científica. v.18, n 1, p. 13-20, jan-abr, 2006.

MERREL, A.; PLANTE, E. Norm- referenced test interpretation in the diagnosis process. Language Speech and Hearing Services in Schools, v. 28, $n^{0} 1$, p. 50-58, 1997.

McCAULEY, Rebeca. J.; SWISHER, Linda. Psycometric review of language and articulation tests for preschool children. Journal of Speech and Hearing Disorders, v $49, n^{0} 1,34-42,1984$.

MILLER, J. F. Evaluación de la conducta lingüística de los ninõs. In: . Bases de la intervención en el lenguaje. Madrid: Alhambra, 1986, p. 217-259. 
NASCIMENTO, Elizabeth. WAIS-III: Escala de Inteligência Wechsler para adultos: manual/ David Wechsler; adaptação e padronização de uma amostra brasileira. Elizabeth do Nascimento; [Tradução Maria Cecília de Vilhena Moraes Silva]. $1^{\mathrm{a} e d .}$ São Paulo: Casa do Psicólogo, 2004.

NASCIMENTO, Elizabeth; FIGUEIREDO, Vera Lúcia. M. WISC-III e WAIS-III: alterações nas versões originais americanas decorrentes das adaptações para uso no Brasil. Psicologia: Reflexão e Crítica, v.15, nº 3, p. 603-612, 2002.

PASQUALI, Luiz. Normatização dos testes. In: . Psicometria: Teoria dos testes na psicologia e na educação. Petrópolis: Editora Vozes, 2003, p. 226 - 260.

PAUL, Rhea. Principles of Assessment. In: PAUL, Rhea., Second Edition. Language Disorders From Infancy Through Adolescence. St Louis, MO. 2001, p. 20-52.

PLANTE, Elena.; VANCE, R. Selection of preschool language tests: a date-based approach. Language, Speech and Hearing Services in Schools. v. 28: 15-24, 1994.

REED, Vicki. A. An introduction to Children With Language Disorders. $2^{\text {nd }}$ Edition. New York: McMillan, 1994.

RICE, Mabel L. Specific Language Impairments: In Search of diagnostic markers and genetic contributions. Mental Retardation and Developmental Disabilities Research, v. 03 , p. $350-57,1997$.

SCALA, Cintia S. K.; NASPITZ, Charles K.; SOLÉ, Dirceu. Adaptação e validação do Pediatric Asthma Quality of Life Questionnaire em crianças e adolescentes com asma. Jornal de Pediatria, v. 81, n 1, p. $54-60,2005$. 
SCHEUER, Claúdia. Et al. Estudo piloto para validação do Children Communication Checklist. In: XIV Congresso Brasileiro de Fonoaudiologia. Salvador, 2006. Revista da Sociedade Brasileira de Fonoaudiologia - Suplemento Especial. São Paulo: Copypress, 2006.

SHIPLEY, Kenneth G; McAFEE, Julie G. Assessment in Speech-Language Patholoy: a Resource Manual. $3^{\text {rd }}$ Edition. New York: Delmar Learning, 2004. 518p.

STARK, Rachel.; TALLAL, Paula. Selection of children with specific language deficits. Journal of Speech and Hearing Disorders, vol. 46, p.114-122, 1981.

TAGER-FLUSBER, Helen; COOPER, Judith. Present and future possibilities for defining a phenotype for specific language impairment. Journal of Speech, Language and Hearing Research, v. 42, p.1275-78, 1999.

WATKINS, Ruth V. Specific Language Impairments in Children - an introduction. In: Rice, M. L. (Org.). Specific language impairments in children. Baltimore: Paul H. Brooks Publishing Co, 1994, cap. 1. , p. 1-34.

WATKINS, Ruth V. , De THORNE, L.S. Assessing children's vocabulary skills: from word knowledg to word - learning potencial. Semin Speech Lang, 2000; 21 (3): 235 -46 .

Watkins, Ruth, et al. Measuring Children's lexical diversity: differentiating typical and impaired language learners. Journal of Speech and Hearing Research, 1995, v. 38, p. $1349-55$.

WEINER, P. S.; HOOCK, W. C. The Standardization of Tests: criteria and criticisms. Journal of Speech and Hearing Research, v. 16, p. 616-626, 1973. 
ZORZI, Jaime; HAGE, Simone Rocha de Vasconcelos. PROC: Protocolo de Observação Comportamental: Avaliação de linguagem e aspectos cognitivos infantis. São José dos Campos: Pulso, 2004, 93 p. 


\section{ESTUDO II}

ANDRADE, Claúdia Regina Furquim de et al. ABFW: Teste de Linguagem Infantil nas áreas de fonologia, vocabulário, fluência e pragmática. 2. ed. Barueri: Pró Fono, 2004.

ANDRADE, Claúdia Regina Furquim de.; JUSTE, Fabíola. Aplicação de um teste americano de severidade da gagueira (SSI) em crianças fluentes falantes do Português Brasileiro. Pró-Fono Revista de Atualização Científica, v. 13, n 2, p. 177180, 2001.

ARAÚJO, Karina; BEFI-LOPES, Débora Maria. Extensão média do enunciado de crianças entre 2 e 4 anos de idade: diferenças no uso de palavras e morfemas. Revista da Sociedade Brasileira de Fonoaudiologia, São Paulo, v.9. n.3, p. 156- 163, 2004.

ARAÚJO, Alessandra Amaral; PERISSINOTO, Jacy. Desenvolvimento da linguagem na adolescência: competências semânticas, sintáticas e pragmáticas. Pró-Fono Revista de Atualização Científica, v. 16, n 3, p. 251-260, 2004.

BATES, E. Language e Context. In: BATES, E. (Org.). The acquisition of pragmatics. Colorado: Academic Press, 1976, p. 1- 41.

BATES, E. et al. A cross-linguistic study of the development of sentence interpretation strategies. Child Development, 1984, 55, p. $341-354$.

BEE, Helen. A criança em desenvolvimento. Trad. Maria Aparecida Verissímo Veronese. 7 ed. Porto Alegre: Artes Médicas, 1996.

BASSAN, S. et al. Developmental changes and variability in the early lexicon: a study of french children's naturalistic productions. Journal of Child Language, v. 25, p. 493 -531, 1998. 
BEFI-LOPES, Débora Maria. Aspectos da Competência e do Desempenho Lexicais em Crianças entre 4:0 e 6:6 anos, com padrões de desenvolvimento normal e com alterações articulatórias. 1997. 285f. Tese (Doutorado em Semiótica e Lingüística Geral) - Faculdade de Filosofia, Letras e Ciências Humanas, Universidade de São Paulo. São Paulo.

BEFI-LOPES, Débora Maria. Prova de Verificação do Vocabulário: Aspectos da Efetividade como Instrumento de Diagnóstico. 2002. Tese (Livre Docência) Faculdade de Medicina, Universidade de SãoPaulo. São Paulo.

BEFI-LOPES, Débora Maria. Avaliação, diagnóstico e aspectos terapêuticos nos distúrbios específicos de linguagem. In: FERREIRA, L.P; BEFI-LOPES, D. M; LIMONGI, S.C. O. (Org(s). Tratado de Fonoaudiologia. 1 ed. São Paulo: Roca, 2004, p. $987-1000$.

BISHOP, Dorothy V.M. Comprehension in developmental language disorders. Developmental Medicine and Child Neurology, v.21, p. 225 - 238, 1979.

BISHOP, Dorothy V.M. The underlying nature of specific impairment. Journal of Child Psycology and Psychiatry, v. 33, , n¹, p. 3-66, 1992.

BISHOP, Dorothy V.M. How does the brain learn language? Insights from the study of children with and without language impairment. Developmental Medicine \& Child Neurology, 2000, 42: 133 - 142.

BISHOP, Dorothy V. M.; MOGFORD, Kay. Desenvolvimento da linguagem em circunstâncias especiais. Rio de Janeiro: Revinter, 2002.

BOONE, Daniel R; PLANTE, Elena. Comunicação humana e seus Distúrbios. Trad. Sandra Costa. 2ed. Porto Alegre: Artes Médicas, 1994. 
BLOOM, Lois; LAHEY, Margaret. Language Development and Language Disorders. New York: McMillan, 1978, 689 p.

BROGGIO. Francine T. O. Desempenho de crianças típicas de 4 a 8 anos de idade no Test of Language Development Primary-3 Adaptado para o Português Brasileiro. 2005. 281f. Dissertação (Mestrado em Semiótica e Lingüística Geral) - Faculdade de Filosofia, Letras e Ciências Humanas da Universidade de São Paulo, São Paulo.

CAPOVILLA, Fernando C.; CAPOVILLA, Alessandra G. Seabra. Desenvolvimento lingüístico na criança dos dois aos seis anos: tradução e estandardização do Peabody Picture Vocabulary Test de Dunn \& Dunn, e da Language Development Survey de Rescorla. Ciência Cognitiva: Teoria, pesquisa e aplicação, v.1:1, p. 353 380, 1997.

CORREA, Letícia Maria Sicuro; FREITAS, M.C, LIMA, C. M. C. Crianças com queixas de linguagem e procedimentos usuais de avaliação de habilidades lingüísticas. Calidoscópio, v.1, nº 1, p. 43-68, 2003.

DALE, Philip S., HENDERSON, Vallane L. An evaluation of the Test of Early Language Development as a Measure of Receptive and Expressive Language. Language, Speech and Hearing Services in Schools, v.18, p. 179 - 187, 1987.

DUARTE, Cristiane S.; BORDIN, Isabel AS. Instrumentos de avaliação. Revista Brasileira de Psiquiatria, v. 22, nº 2, p. $55-58,2000$.

FREITAS, Silvia. et al. Tradução e adaptação para o português da Escala de Compulsão Alimentar Periódica. Revista Brasileira de Psiquiatria, v. 23, nº 4, p. 215 $-220,2001$. 
GUILLEMIN, F.; BOMBARDIER, C.; BEATON, D. Cross-cultural adaptation of healthy-related quality of life measures: literature review and proposed guidelines. Journal Clinical Epidemiol.. v.46, n.12, p. 1417-1432, 1993.

GLEASON, J. B. The development of language. Needham Heights, MA: Ally \& Bacon, 1997.

HALLIDAY, M.A.K. Language as social semiotic, the social interpretation of language and meaning. Maryland, University Park Press, 1978.

HAKANSSON, G; HANSSON, K. Comprehension and production relatives sentences. Journal of Child and Language, v. 27, p. 313-333, 2000.

HARRIS, M. et al. Symmetries and asymmetries en early lexical comprehension and production. Journal of Child Language, v.22, p. 1-18, 1995.

Hershkoviks, N. Neurological bases of behavioural development in infancy. Brain Devel, V. 22: $411-416,2000$.

HIRSH-PASEK, K. GOLINKOFF, R.M. The origins of grammar: evidence from early language. Comprehension. Cambridge: MA: MIT Press, 1997, 230p.

HAGE, Simone Rocha de Vasconcelos. et al. Diagnóstico de crianças com alterações específicas de linguagem por meio de escala de desenvolvimento. Arquivos de Neuropsiquiatria, v. 62, nº 3-A, p. 649-653, 2004.

HRESKO, Wayne P. REID, D. Kim.; HAMMILL, Donald D. Test of Early Language Developmental (TELD) Third Edition. Austin, TX: PRO-ED., 1999. 
LAHEY, Margaret. Who shall be called language disordered? Some reflections and one perspective. Journal of Speech and Hearing Disorders, v. 55, p. $612-620$, 1990.

LAW, James. Identificação precoce dos distúrbios de linguagem na criança. Trad. Maria Ines Corrêa Nascimento. Rio de Janeiro: Revinter, 2001. 210 p.

LIMONGI, Suely, C. Paralisia Cerebral: Linguagem e Cognição. 2 ed. Carapicuiba. São Paulo, Pró-Fono, 1998.

MANSUR, Letícia L. et al. Teste de nomeação de Boston: desempenho de uma população de São Paulo. Pró-Fono Revista de Atualização Científica. v.18, n 1, p. 13-20, jan-abr, 2006.

MARINELLIE, Sally, A., JOHNSON, Cyntia. J. Definitional skill in school-age children with specific language impairment. Journal of Communication Disorders, v. 35, p. 241- 259, 2002.

McCAULEY, Rebeca. J.; SWISHER, Linda. Psycometric review of language and articulation tests for preschool children. Journal of Speech and Hearing Disorders, $v$ $49, n^{\circ} 1,34-42,1984$.

MILLER, J. F.; PAUL, Rhea. The clinical assessment of language comprehension. Paul H. Brookes Publishing Co. Baltimore, 185 p., 1995

MORSELLI, Andréa A. Identificação de figures: comparação entre crianças em desenvolvimento normal e com alteração de desenvolvimento de linguagem. Dissertação (Mestrado em Lingüística). 2003. Faculdade de Filosofia, Letras e Ciências Humanas, Universidade de São Paulo, SP. 
NIPPOLD, M. A. et al. Defining abstract entities: development in preadolescents, adolescents and young adults. Journal of Speech, Language and Hearing Research, v. 42, p. 473- 481, 1998.

PAUL, Rhea. Principles of Assessment. In: PAUL, Rhea., Second Edition. Language Disorders From Infancy Through Adolescence. St Louis, MO. 2001, p. 20-52.

PLANTE, Elena. Infant toddler development: an introduction. Journal of Communication Disorders, v. 32, p. 191 - 193, 1999.

PLANTE, Elena.; VANCE, R. Selection of preschool language tests: a date-based approach. Language, Speech and Hearing Services in Schools. v. 28: 15-24, 1994.

REED, Vicki. A. An introduction to Children With Language Disorders. $2^{\text {nd }}$ Edition. New York: McMillan, 1994.

RICE, Mabel L. Specific Language Impairments: In Search of diagnostic markers and genetic contributions. Mental Retardation and Developmental Disabilities Research, v. 03 , p. $350-57,1997$.

RIZZO, J.M.; STEPHENS, M.I. Performance of children with normal and impaired oral language production on a set of auditory comprehension tests. Journal of Speech and Hearing Disorders, v.46, p. 150 - 159, 1981.

SILAGI, M.L; et al. A linguagem de crianças de 30 a 47 meses do município de Osasco por meio do "Preschool Language Scale-3". In: XIV Congresso Brasileiro de Fonoaudiologia, 2006, Salvador. Revista da Sociedade Brasileira de Fonoaudiologia - Suplemento Especial. São Paulo: Copypress, 2006. 
SCHEUER, Claúdia; BEFI-LOPES, Débora Maria; WERTZNER, H. F. Desenvolvimento da linguagem: uma introdução. In: LIMONGI, S. C. O. (Org.), Ed. Guanabara Koogan. Fonoaudiologia Informação para a Formação: Linguagem: Desenvolvimento Normal, Alterações e Distúrbios. Rio de Janeiro: Editora Guanabara koogan, 2003, p. 1-18.

SPINELLI, Mauro. Foniatria: Introdução aos Distúrbios da Comunicação, Audição e Linguagem. 2 ed. São Paulo: Editora Moraes, 1983.

SHIPLEY, Kenneth G; McAFEE, Julie G. Assessment in Speech-Language Patholoy: a Resource Manual. $3^{\text {rd }}$ Edition. New York: Delmar Learning, 2004.

$518 \mathrm{p}$.

STARK, Rachel E.; TALLAL, Paula. Selection of children with specific language deficits. Journal of Speech and Hearing Disorders, vol. 46, p.114-122, 1981.

TAGER-FLUSBER, Helen; COOPER, Judith. Present and future possibilities for defining a phenotype for specific language impairment. Journal of Speech, Language and Hearing Research, v. 42, p.1275-78, 1999.

TAKIUCHI, Noemi; NAVAS, Ana Luiza G. P. Comparação entre comprensão e produção de morfemas flexionais de plural em crianças pré-escolares. In: XIII Congresso Brasileiro de Fonoaudiologia, Santos, 2005.

TAKIUCHI, Noemi. et al. Produção de morfemas de plural em crianças préescolares. In: XIV Congresso Brasileiro de Fonoaudiologia, 15, 2006, Salvador Revista da Sociedade Brasileira de Fonoaudiologia - Suplemento Especial. São Paulo: Copypress, 2006. 
TOMASELLO, M. KRUGER, A.C. Joint attention on actions: acquiring verbs in ostensive and non ostensives contests. Journal of Child Language, n.19, 1992, p. 311- 333.

WATKINS, Ruth V. Specific Language Impairments in Children - an introduction. In: Rice, M. L. (Org.). Specific language impairments in children. Baltimore: Paul H. Brooks Publishing Co, 1994, cap. 1. , p. 1-34.

WATKINS, Ruth V. , De THORNE, L.S. Assessing children's vocabulary skills: from word knowledg to word - learning potencial. Semin Speech Lang, 2000; 21 (3): 235 -46 .

ZORZI, Jaime; HAGE, Simone Rocha de Vasconcelos. PROC: Protocolo de Observação Comportamental: Avaliação de linguagem e aspectos cognitivos infantis. São José dos Campos: Pulso, 2004, 93 p. 


\section{ESTUDO III}

BOONE, Daniel R; PLANTE, Elena. Comunicação humana e seus distúrbios. Trad. Sandra Costa. 2ed. Porto Alegre: Artes Médicas, 1994.

BLOOM, Lois; LAHEY, Margaret. Language development and language disorders. New York: Macmillan, 1978, 689 p.

BREEYEAR, Tom. et al. Review of the Test of Early Language Development -3 . (2001). Disponível em: <http://www. student. plattsburgh.ed/teld3.ppt

CRAIN, S. et al. Language acquisition is language change. Journal Psycholing., n. 35 (1), p. $31-49,2006$.

DALE, P. S.; HENDERSON, V. L. An evaluation of the Test of Early Language Development as a measure of receptive and expressive language. Language, Speech, and Hearing Services in Schools, v. 18, p. 179 - 187, 1987.

ESSARY, C. Review of the Test of Early Language Development -2. Journal of Psychoeducational Assessment, v.11, p. 375 - 380, 1993.

HADLEY, P. A. Assessing the emergence of grammar in toddlers at risk for specific language impairment. Semin Speech Lang. n. 27 (3), p. 173 - 186, 2006.

HRESKO, Wayne P.; REID, D. Kim; HAMMILL, Donald D. Test of Early Language Developmental (TELD) Third Edition . Austin, TX: PRO-ED., 1999.

KULICK, Abby. Test Evalution: Test of Early Language Development-3. (2002). Disponível em: <http://www. vwsp. edu/education/Reference/kathy/ evalution.htm

LAW, James. Identificação precoce dos distúrbios de linguagem na criança. Trad. Maria Ines Corrêa Nascimento. Rio de Janeiro: Revinter, 2001. 210 p. 
MARTINEZ, Luiz. Presentacion del PDIL (Prueba Del Desarrolo Inicial Del Lenguaje): Datos Normativos en Chile. In: Seminario Internacional Evaluações en Transtornos del Lenguaje. Santiago Chile, 2005.

PAUL, Rhea. Principles of Assessment. In: PAUL, R., Second Edition. Language Disorders from infancy through adolescence. St Louis, MO. 2001, p. 20-52.

REED, Vicki. A. An introduction to children with language disorders. $2^{\text {nd }}$ edition. New York: McMillan, 1994.

SUEN, Hoi K. Review of the Test of Early Language Development, Third Edition. Disponível em: www. edu/education/Reference/suen/teld-3.

SHAPIRO, D.A. Review of Test of Early Language Development, Second Edition. In J. C. Conoley \& J.C. Impara (Eds.) The twelfth mental measurements yearbook. Lincoln: University of Nebraska Press, p. 1046 - 1048, 1995.

SHIPLEY, Kenneth G; McAFEE, Julie G. Assessment in Speech-Language Patholoy: a Resource Manual. $3^{\text {rd }}$ Edition. New York: Delmar Learning, 2004. $518 \mathrm{p}$.

STARK, Rachel.; TALLAL, Paula. Selection of children with specific language deficits. Journal of Speech and Hearing Disorders, vol. 46, p.114-122, 1981. 
----- Original Message -----

From: Wayne P. Hresko

To: rlgiusti@widesoft.com.br

Sent: Wednesday, April 28, 2004 5:15 PM

Subject: TELD-3

Ms. Elisabete Giusti

Conego Manual Alves, Avenue, 782

Limeira - San Paulo - Breazil

Zip Code: 13 484-420

Dear Ms. Elisabete Giusti,

I received your email dated Feburary 21, 2004 regarding the TELD-3. I would like to thank you for your kind words regarding our work.

At the present time, the TELD-3 has been translated and adapted for use by Spanish speaking children and is currently finishing standardization. We have sample populations from Mexico, Chili, the southwestern United States, Spain, several Central and South American countries, and several Caribbean countries. We are currently beginning data analysis and final editing changes in the TELD-3S. When we are finished, I will forward you a copy.

Since you are using the TELD-3 Portuguese translation for your own use, PRO-ED will have no problem granting you translation rights for that purpose. I suggest that you email Ms. Loretta Scott with a message indicating that you are working on your Master's and would like to use a Portuguese translation of the TELD-3. Indicate that you have corresponded with me.

For your information, we have just published the Test of Phonological Awareness in Spanish and will soon be publishing the Spanish Photo Articulation Test.

Best regards in your work. I look forward to hearing from you in the future.

Cordially,

Wayne P. Hresko, PhD

hresko@flash.net 
--- Original Message -----

From: Kelly Ligon

To: rlgiusti@widesoft.com.br

Cc: 'Loretta Scott'

Sent: Wednesday, July 14, 2004 1:57 PM

Subject: RE: Portuguese TELD-3

RE: TELD-3 Portuguese - OWN USE

Ms. Elisabete Giusti

Conego Manual Alves, Avenue, 782

Limeira - San Paulo

Zip Code 13 484-420

BRAZIL

Dear Ms. Giusti,

Loretta forwarded me your email regarding the TELD-3. Permission is granted to translate the Test of Early Language Development (TELD-3) into Portuguese for your research only with the understanding that the translated version is only for your own use and is not for commercial use or resale. Also, this permission in no way restricts our right to grant translation rights to others.

Good luck with your endeavor,

Kelly Ligon, Foreign Translations

PRO-ED, Inc.

8700 Shoal Creek Blvd.

Austin, TX 78757

(512) $451-3246(x 682)$

(512) 302-9128 (FAX)

kligon@proedinc.com 


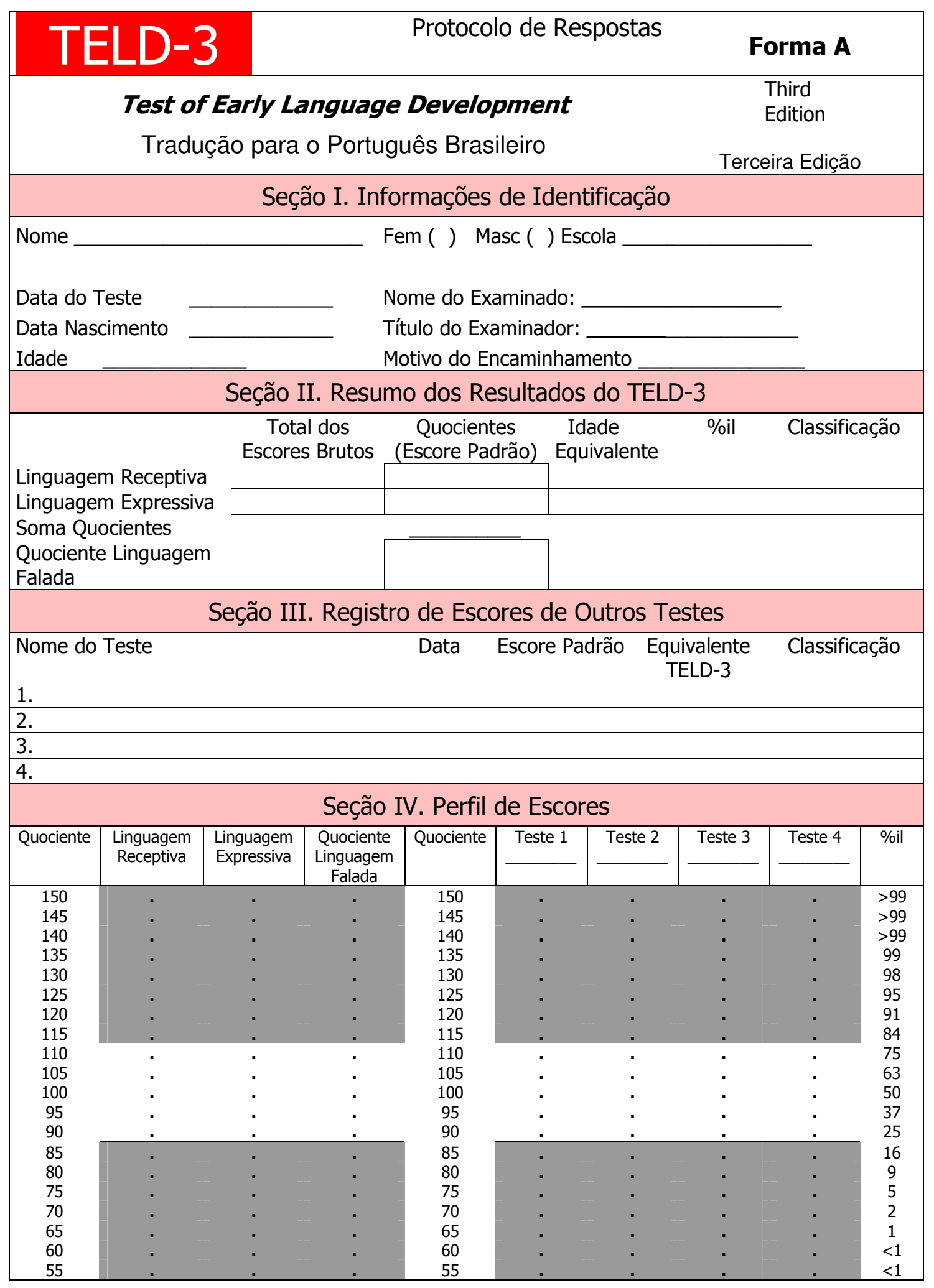




\begin{tabular}{|c|c|c|}
\hline \multicolumn{3}{|c|}{$\begin{array}{l}\text { Seção V. Registro de Respostas } \\
\text { Subteste de Linguagem Receptiva }\end{array}$} \\
\hline Estímulos & Resposta Correta & Escore \\
\hline 1. A criança pára a sua atividade e atende a vozes de adultos ou crianças. & Observação/Relato de Confirmação. & \\
\hline 2. A criança olha ou vem quando seu nome é chamado. & Observação/Relato de Confirmação. & \\
\hline $\begin{array}{l}\text { 3. A criança responde apropriadamente a pelo menos três comandos de } \\
\text { ação como: "sente-se", "venha aqui" e "pare com isso". }\end{array}$ & Observação/Relato de Confirmação. & \\
\hline $\begin{array}{l}\text { 4. Coloque a bola, sapato, colher, cubo e boneca na mesa ou no chão e } \\
\text { peça à criança para apontar para cada objeto. Mostre-me a } \\
\\
\text { corretamente para dois objetos. } \\
\text { 1. Mostre-me a bola. } \\
\text { 2. Mostre-me o sapato. } \\
\text { 3. Mostre-me a colher. } \\
\text { 4. Mostre-me o cubo. } \\
\text { 5. Mostre-me a boneca. }\end{array}$ & $\begin{array}{l}\text { Criança responde corretamente a } \\
2 / 5 \text {. }\end{array}$ & \\
\hline $\begin{array}{l}\text { Idade: } \mathbf{2} \text { anos } \\
\text { 5. Peça a criança para mostrar a sua boca, nariz e olhos. } \\
\text { 1. Mostre-me sua boca. } \\
\text { 2. Mostre-me seu nariz. } \\
\text { 3. Mostre-me seus olhos. }\end{array}$ & $\begin{array}{l}\text { Criança responde corretamente a } \\
3 / 3 \text {. }\end{array}$ & \\
\hline $\begin{array}{l}\text { 6. Mostre o cartão de figuras AR1. } \\
\text { 1. Mostre-me (ou aponte) o cachorro. } \\
\text { 2. Mostre-me (ou aponte) o bebê. } \\
\text { 3. Mostre-me (ou aponte) o sapato. } \\
\text { 4. Mostre-me (ou aponte) a cadeira. } \\
\text { 5. Mostre-me (ou aponte) a xícara. } \\
\text { 6. Mostre-me (ou aponte) o carro. }\end{array}$ & $\begin{array}{l}\text { Criança responde corretamente a } \\
3 / 5 \text {. }\end{array}$ & \\
\hline $\begin{array}{l}\text { 7. Coloque os cinco cubos na frente da criança. Dê-me um cubo. } \\
\text { (Pergunta Reforço: dê um cubo.) }\end{array}$ & Criança responde corretamente. & \\
\hline 8. Mostre-me como você escova os seus dentes. & Criança responde corretamente. & \\
\hline $\begin{array}{l}\text { 9. Mostre o cartão de figuras AR2. } \\
\text { 1. Mostre-me (ou aponte) o sapato dentro da caixa. } \\
\text { 2. Mostre-me (ou aponte) o sapato em cima da caixa. }\end{array}$ & $\begin{array}{l}\text { Criança responde corretamente a } \\
2 / 2 \text {. }\end{array}$ & \\
\hline $\begin{array}{l}\text { Idade: } 3 \text { anos } \\
\text { 10. 1. Levante e põe a mão no dedo do seu pé. } \\
\text { 2. Levante, dê uma volta e sente de novo. }\end{array}$ & $\begin{array}{l}\text { Criança responde corretamente a } \\
2 / 2 \text {. }\end{array}$ & \\
\hline $\begin{array}{l}\text { 11. 1. Levante e põe a mão no nariz. } \\
\text { 2. Levante, põe a mão na cabeça e pule. }\end{array}$ & $\begin{array}{l}\text { Criança responde corretamente a } \\
2 / 2 \text {. }\end{array}$ & \\
\hline $\begin{array}{l}\text { 12. Mostre o cartão de figuras AR3. } \\
\text { 1. Mostre-me a bola maior. } \\
\text { 2. Mostre-me a casa menor. }\end{array}$ & $\begin{array}{l}\text { Criança responde corretamente a } \\
2 / 2 \text {. }\end{array}$ & \\
\hline $\begin{array}{l}\text { 13. Mostre o cartão de figuras AR4. Mostre-me o menino com mais } \\
\text { balões. }\end{array}$ & Criança responde corretamente. & \\
\hline & Total da Página 2 & \\
\hline
\end{tabular}




\begin{tabular}{|c|c|c|}
\hline \multicolumn{3}{|c|}{ Subteste de Linguagem Receptiva (continuação) } \\
\hline Estímulos & Resposta Correta & Escore \\
\hline $\begin{array}{l}\text { 14. 1. Preste muita atenção. Mostre-me seus olhos. Se a criança falhar a } \\
\text { responder, pergunte novamente dizendo, Use seus dedos para me mostrar } \\
\text { seus olhos. Se a criança responde ao "Me mostre" melhor do que "Aponte } \\
\text { para", continue com "Mostre-me". } \\
\text { 2. Mostre-me suas orelhas. } \\
\text { 3. Mostre-me seu cotovelo. } \\
\text { 4. Mostre-me seu ombro. } \\
\text { 5. Mostre-me seu umbigo. }\end{array}$ & $\begin{array}{l}\text { Criança responde corretamente a } \\
4 / 5 \text {. }\end{array}$ & \\
\hline $\begin{array}{l}\text { Idade: } 4 \text { anos } \\
\text { 15. Coloque os cinco cubos na frente da criança, espaçados } \\
\text { aproximadamente } 5 \mathrm{~cm} \text { um do outro. Dê as cinco moedas à criança. } \\
\text { Coloque uma moeda em cima de cada cubo. }\end{array}$ & Criança responde corretamente. & \\
\hline $\begin{array}{l}\text { 16. 1. Mostre cartão de figuras AR5. Mostre-me o menino passando pelo } \\
\text { túnel. } \\
\text { 2. Mostre cartão de figuras AR6. Mostre-me a corda ao redor da árvore. } \\
\text { 3. Mostre cartão de figuras AR7. Mostre-me a menina atrás da cerca. } \\
\text { 4. Mostre cartão de figuras AR8. Mostre-me o menino ao lado da casa. } \\
\text { 5. Mostre cartão de figuras AR9. Mostre-me o sol em cima das nuvens. }\end{array}$ & $\begin{array}{l}\text { Criança responde corretamente a } \\
4 / 5 \text {. }\end{array}$ & \\
\hline $\begin{array}{l}\text { 17. Mostre cartão de figuras AR10. } \\
\text { 1. Aponte para a criança subindo a escada. } \\
\text { 2. Agora aponte para a criança descendo a escada. }\end{array}$ & $\begin{array}{l}\text { Criança responde corretamente a } \\
2 / 2 \text {. }\end{array}$ & \\
\hline $\begin{array}{l}\text { 18. Mostre cartão de figuras AR11. } \\
\text { 1. Mostre-me o menino em cima da mesa. } \\
\text { 2. Mostre-me o menino embaixo da mesa. }\end{array}$ & $\begin{array}{l}\text { Criança responde corretamente a } \\
2 / 2 \text {. }\end{array}$ & \\
\hline $\begin{array}{l}\text { 19. 1. Mostre cartão de figuras AR12. Me mostre "O carro bate no } \\
\text { caminhão". Depois que a criança responder, } \\
\text { 2. Mostre cartão de figuras AR13. Me mostre "Ela está mais perto da } \\
\text { cadeira". } \\
\text { 3. Mostre cartão de figuras AR14. Me mostre "As crianças não estão } \\
\text { correndo". }\end{array}$ & $\begin{array}{l}\text { Criança responde corretamente a } \\
2 / 3 \text {. }\end{array}$ & \\
\hline $\begin{array}{l}\text { Idade: } \mathbf{5} \text { anos } \\
\text { 20. Mostre cartão de figuras AR15. } \\
\text { 1. De quem é o aniversário ? } \\
\text { 2. Onde está o bolo? } \\
\text { 3. Qual presente que você mais gosta? }\end{array}$ & $\begin{array}{l}\text { Criança responde corretamente a } \\
3 / 3 \text {. }\end{array}$ & \\
\hline $\begin{array}{l}\text { 21. 1. Você toma café da manhã de manhã ou à tarde? } \\
\text { 2. Você tira uma soneca de manhã ou à tarde? }\end{array}$ & $\begin{array}{l}\text { Criança responde corretamente a } \\
2 / 2 \text {. }\end{array}$ & \\
\hline $\begin{array}{l}\text { 22. Mostre cartão de figuras AR16. } \\
\text { 1. Mostre-me a primeira criança da fila. } \\
\text { 2. Mostre-me a última criança da fila. }\end{array}$ & $\begin{array}{l}\text { Criança responde corretamente a } \\
2 / 2 \text {. }\end{array}$ & \\
\hline $\begin{array}{l}\text { 23. Mostre cartão de figuras AR17. Olhe para estas figuras. Aponte para } \\
\text { as figuras das palavras que eu falar. Pronto(a)? } \\
\text { 1. Mostre-me óculos. } \\
\text { 2. Mostre-me sombra. } \\
\text { 3. Mostre-me inseto. } \\
\text { 4. Mostre-me correr. }\end{array}$ & $\begin{array}{l}\text { Criança responde corretamente a } \\
4 / 4 \text {. }\end{array}$ & \\
\hline $\begin{array}{l}\text { 24. Eu quero que você me fale qual a frase que você acha que está certa. } \\
\text { 1. Eu nado naquela poça ou eu nado naquele lago. } \\
\text { 2. Qual você acha que está certa? Eu vou àquela fé ou eu vou àquela } \\
\text { igreja? } \\
\text { 3. O vaqueiro dormiu no sofá ou o vaqueiro dormiu na beliche? }\end{array}$ & $\begin{array}{l}\text { Criança responde corretamente a } \\
2 / 3 \text {. }\end{array}$ & \\
\hline & Total da Página 3 & \\
\hline
\end{tabular}




\begin{tabular}{|c|c|c|}
\hline \multicolumn{3}{|c|}{ Subteste de Linguagem Receptiva (continuação) } \\
\hline Estímulos & Resposta Correta & Escore \\
\hline $\begin{array}{l}\text { Idade: } \mathbf{6} \text { anos } \\
\text { 25. Mostre cartão de figuras AR18. Olhe para estas figuras. Aponte para } \\
\text { as figuras das palavras que eu falar. Pronto(a)? } \\
\text { 1. chapéu } \\
\text { 2. planta } \\
\text { 3. fonte } \\
\text { 4. mansão } \\
\text { 5. pensando }\end{array}$ & $\begin{array}{l}\text { Criança responde corretamente a } \\
4 / 5 \text {. }\end{array}$ & \\
\hline $\begin{array}{l}\text { 26. Eu vou falar algumas palavras e você vai me falar qual combina. } \\
\text { 1. O que combina com mãe (pausa), bebê ou árvore? } \\
\text { 2. O que combina com feliz (pausa), bravo ou alegre ? } \\
\text { 3. O que combina com sobre (pausa), em cima ou embaixo? } \\
\text { 4. O que combina com correr (pausa), pular ou parar? }\end{array}$ & $\begin{array}{l}\text { Criança responde corretamente a } \\
3 / 4 \text {. }\end{array}$ & \\
\hline $\begin{array}{l}\text { 27. Eu vou falar umas frases, depois de cada uma, me fale se está certa } \\
\text { ou se tem alguma coisa errada com ela. } \\
\text { 1. Mim vou casa. } \\
\text { 2. O menino não está aqui. } \\
\text { 3. Gato não sentando. }\end{array}$ & $\begin{array}{l}\text { Criança responde corretamente a } \\
2 / 3 \text {. }\end{array}$ & \\
\hline 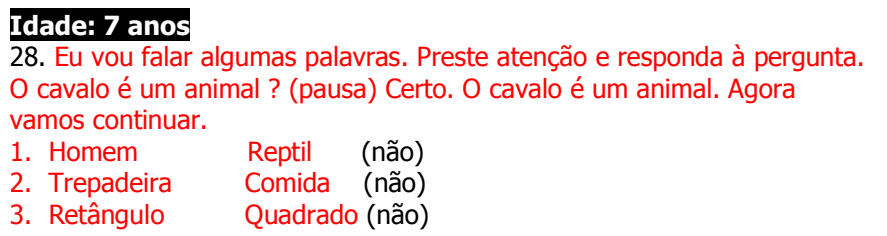 & $\begin{array}{l}\text { Criança responde corretamente a } \\
2 / 3 \text {. }\end{array}$ & \\
\hline $\begin{array}{l}\text { 29. Eu vou falar umas palavras e você vai me falar qual combina. } \\
\text { 1. O que combina com rapidamente (pausa), lentamente ou } \\
\text { depressa? } \\
\text { 2. O que combina com menina (pausa), ele ou ela ? } \\
\text { 3. O que combina com porque (pausa), já que ou mas? }\end{array}$ & $\begin{array}{l}\text { Criança responde corretamente a } \\
2 / 3 \text {. }\end{array}$ & \\
\hline $\begin{array}{l}\text { 30. Olhe para estas figuras. Mostre aquelas que combinam com o que eu } \\
\text { falar. } \\
\text { 1. Mostre cartão de figuras AR19. O menininho triste estava chorando. } \\
\text { 2. Mostre cartão de figuras AR20. Mimi, o gato, lambeu o leite. } \\
\text { 3. Mostre cartão de figuras AR21. O menino que estava seguindo o gato } \\
\text { estava sendo seguido pelo cachorro. } \\
\text { 4. Mostre cartão de figuras AR22. O menino que a mulher olhava estava } \\
\text { rindo. }\end{array}$ & $\begin{array}{l}\text { Criança responde corretamente a } \\
3 / 4 \text {. }\end{array}$ & \\
\hline 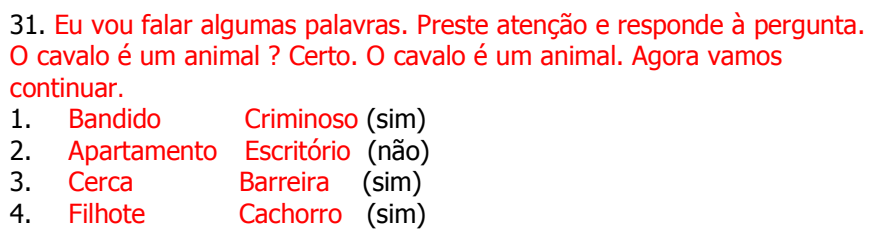 & $\begin{array}{l}\text { Criança responde corretamente a } \\
3 / 4 \text {. }\end{array}$ & \\
\hline $\begin{array}{l}\text { 32. Preste atenção. Eu vou falar algumas palavras. Me fale qual das palavras não } \\
\text { combina com as outras. } \\
\text { 1. Lago, ilha, oceano } \\
\text { 2. Tesouro, lixo, lixeira } \\
\text { 3. Cova, buraco, montanha }\end{array}$ & $\begin{array}{l}\text { Criança responde corretamente a } \\
2 / 3 \text {. }\end{array}$ & \\
\hline $\begin{array}{l}\text { 33. Preste atenção. Eu vou falar algumas palavras. Me fale qual das palavras não } \\
\text { combina com as outras. } \\
\text { 1. Bola, bicicleta, pipa, gato. Qual das palavras não combina com as } \\
\text { outras? } \\
\text { 2. Cama, mesa, pai, cadeira. Qual palavras não combina c/ as outras ? } \\
\text { 3. Dormir, correr, pular, saltar. Qual palavras não combina c/ outras? }\end{array}$ & $\begin{array}{l}\text { Criança responde corretamente a } \\
2 / 3 .\end{array}$ & \\
\hline & Tota & \\
\hline
\end{tabular}




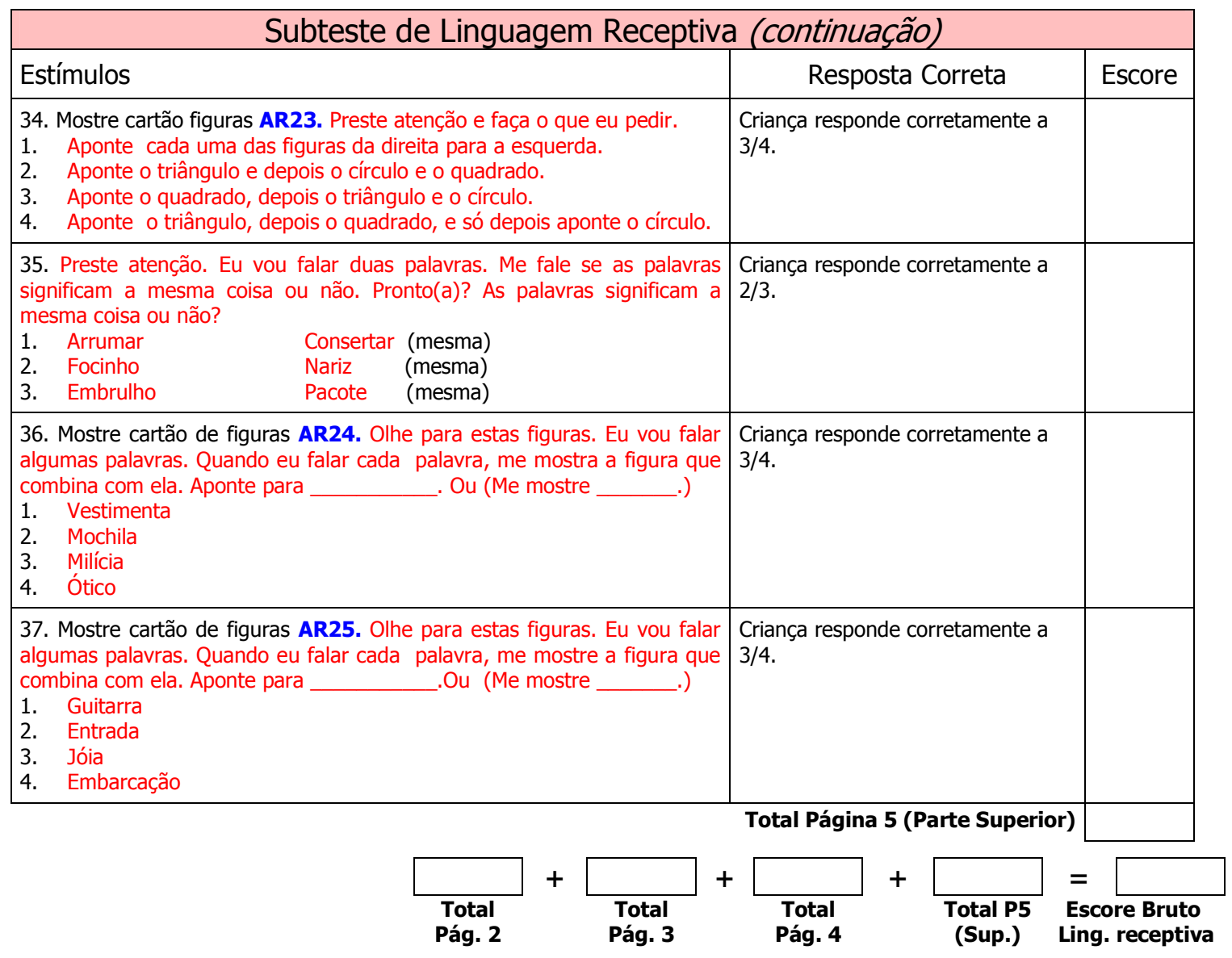

\begin{tabular}{|c|c|c|}
\hline \multicolumn{3}{|c|}{ Subteste de Linguagem Expressiva } \\
\hline Estímulos & Resposta Correta & Escore \\
\hline 1. A criança expressa raiva e prazer. & Observação/Relato de Confirmação. & \\
\hline $\begin{array}{l}\text { 2. A criança pára de balbuciar quando ela percebe que outras pessoas } \\
\text { estão falando. }\end{array}$ & Observação/Relato de Confirmação. & \\
\hline 3. A criança inicia vocalização e balbucios. & Observação/Relato de Confirmação. & \\
\hline 4. A criança responde apropriadamente a palavras como: "Oi" e "Tchau". & Observação/Relato de Confirmação. & \\
\hline 5. A criança usa expressão de espanto e admiração, como "Uh-Oh". & Observação/Relato de Confirmação. & \\
\hline $\begin{array}{l}\text { 6. A criança pode usar duas ou mais palavras de ação com alguma } \\
\text { consistência. }\end{array}$ & Observação/Relato de Confirmação. & \\
\hline 7. A criança diz 10 ou mais palavras reais apropriadamente. & Observação/Relato de Confirmação. & \\
\hline 8. Criança repete palavras ouvidas em conversas de forma significativa. & Observação/Relato de Confirmação. & \\
\hline $\begin{array}{l}\text { 9. Mostre cartão de figuras AE1. Aponte para cada figura. O que é isto ? } \\
\text { 1. Carro } \\
\text { 2. Pássaro (Periquito, Canário). } \\
\text { 3. Árvore } \\
\text { 4. Bola (bola de boliche) } \\
\text { 5. Homem (menino) }\end{array}$ & $\begin{array}{l}\text { Criança responde corretamente a } \\
3 / 5 \text {. }\end{array}$ & \\
\hline & Total Página 5 (Parte Inferior) & \\
\hline
\end{tabular}




\begin{tabular}{|c|c|c|}
\hline \multicolumn{3}{|c|}{ Subteste de Linguagem Expressiva (continuação) } \\
\hline Estímulos & Resposta Correta & Escore \\
\hline $\begin{array}{l}\text { Idade: } 2 \text { anos } \\
10 . \text { A criança usa entre } 10 \text { e } 20 \text { palavras com o propósito comunicativo. }\end{array}$ & Observação/Relato de Confirmação. & \\
\hline 11. A criança usa frases de duas ou três palavras. & Observação/Relato de Confirmação. & \\
\hline 12. Você é um menino ou uma menina? & Criança responde corretamente. & \\
\hline $\begin{array}{l}\text { 13. A criança consistentemente usa os pronomes pessoais: "ele", "ela", } \\
\text { "dele", "dela" e "eu". }\end{array}$ & Observação/Relato de Confirmação. & \\
\hline $\begin{array}{l}\text { 14. Repete o que eu falar. } \\
\text { 1. Ele está cantando. Pausa e continua. } \\
\text { 2. Venha aqui. Pausa e continua. } \\
\text { 3. Olhe o gato. }\end{array}$ & $\begin{array}{l}\text { Criança responde corretamente a } \\
2 / 3 \text {. }\end{array}$ & \\
\hline $\begin{array}{l}\text { Idade: } 3 \text { anos } \\
\text { 15. Conte pra mim o seu jogo favorito. Pergunte a criança se não tiver } \\
\text { resposta ou se a criança disser somente o nome do jogo, fale: me conte a } \\
\text { coisa que você mais gosta de fazer. Pergunte novamente se for } \\
\text { necessário. }\end{array}$ & Criança responde corretamente. & \\
\hline 16. A criança usa sentenças de três a cinco palavras na comunicação oral. & Observação/Relato de Confirmação. & \\
\hline $\begin{array}{l}\text { 17. Mostre o cartão de figuras } \mathbf{A E} \mathbf{2} \text {. } \\
\text { 1. O que o menino está fazendo? } \\
\text { 2. O que a menina está fazendo? }\end{array}$ & $\begin{array}{l}\text { Criança responde corretamente a } \\
2 / 2 \text {. }\end{array}$ & \\
\hline $\begin{array}{l}\text { 18. 1. Por que ..................( preencher com um membro apropriado da } \\
\text { família) trabalha? } \\
\text { 2. Por que ...............( preencher com um membro da família } \\
\text { apropriadamente) estuda? }\end{array}$ & $\begin{array}{l}\text { Criança responde corretamente a } \\
1 / 2 \text {. }\end{array}$ & \\
\hline $\begin{array}{l}\text { 19. Qual é o seu nome? Se a criança responder com somente o primeiro } \\
\text { nome dele ou dela, dizer: Muito bem!, mas qual é o seu nome completo? } \\
\text { Me fale seu primeiro nome e seu último nome. }\end{array}$ & Criança responde corretamente. & \\
\hline $\begin{array}{l}\text { Idade: } 4 \text { anos } \\
\text { 20. Quantos anos você tem? Conte-me quantos anos você tem? Se a } \\
\text { criança responder apenas com os dedos, dizer: Isso, muito bem, mas me } \\
\text { fale quantos anos você tem? Ou quanto é isso? }\end{array}$ & Criança responde corretamente. & \\
\hline $\begin{array}{l}\text { 21. Mostrar a figura AE3. Olhe para estas figuras. Eu vou apontar } \\
\text { algumas destas figuras. Eu quero que você me fale o nome do que eu } \\
\text { apontar. ( Pergunta reforço: me fale o que eu estou apontando...) } \\
\text { 1. borboleta } \\
\text { 2. cowboy/boiadeiro/peão } \\
\text { 3. ônibus da escola } \\
\text { 4. } \quad \text { sinal de pare }\end{array}$ & $\begin{array}{l}\text { Criança responde corretamente a } \\
3 / 4 .\end{array}$ & \\
\hline 22. A criança usa pronomes no plural: "nós", "eles" ou "deles" quando fala. & Observação/Relato de Confirmação. & \\
\hline $\begin{array}{l}\text { 23. Quem é sua família? Se a criança der um nome próprio, dizer: Quem é } \\
\text { ele? }\end{array}$ & Criança responde corretamente. & \\
\hline $\begin{array}{l}\text { 24. 1. Mostrar a figura AE 4: Olhe essa bola, essa boneca, esse caminhão } \\
\text { e essa corda de pular. Estes todos são......Se a criança disser, " coisas } \\
\text { que nós brincamos", dizer: Sim, mas como nós chamamos essas coisas } \\
\text { que brincamos com elas? } \\
\text { 2. Mostrar a figura AE 5: Olhe o cachorro, o gato, o urso e o cavalo. Estes } \\
\text { todos são..... } \\
\text { 3. Mostrar a figura AE 6: Olhe o sapato, o casaco, as calças e a camiseta. } \\
\text { Estes todos são..... }\end{array}$ & $\begin{array}{l}\text { Criança responde corretamente a } \\
2 / 3 .\end{array}$ & \\
\hline & Total Página 6 & \\
\hline
\end{tabular}




\begin{tabular}{|c|c|c|}
\hline \multicolumn{3}{|c|}{ Subteste de Linguagem Expressiva (continuação) } \\
\hline Estímulos & Resposta Correta & Escore \\
\hline $\begin{array}{l}\text { Idade: } 5 \text { anos } \\
\text { 25. Qual é o nome da história que você mais gosta? Se a criança começar } \\
\text { a contar a história para você, dizer: Você pode me falar o nome da } \\
\text { história? }\end{array}$ & Criança responde corretamente. & \\
\hline $\begin{array}{l}\text { 26. Procedimento: Mostrar a figura AE } 7 \text {. Olhe para essa figura e preste } \\
\text { atenção no que eu vou falar. Me fale a palavra que termina a frase. } \\
\text { 1. Este menino é um jogador de futebol. } \\
\text { Eles todos são............ } \\
\text { 2. Ele lava carros. } \\
\text { Ele é um .................. }\end{array}$ & $\begin{array}{l}\text { Criança responde corretamente a } \\
1 / 2 .\end{array}$ & \\
\hline $\begin{array}{l}\text { 27. Preste atenção. Eu vou contar uma história para você. João está triste. } \\
\text { Seu irmão ficou doente } 3 \text { dias. A professora perguntou: "João, por que seu } \\
\text { irmão não veio a escola? O que você acha que o João falou? Se a criança } \\
\text { falhar na resposta, dizer: O que você falaria? }\end{array}$ & Criança responde corretamente. & \\
\hline $\begin{array}{l}\text { 28. Eu vou falar algumas frases. Repete do mesmo jeito que eu falar. Está } \\
\text { pronto? } \\
\text { 1. A menina gosta de andar sozinha. } \\
\text { 2. Maria deu um presente aos meninos. } \\
\text { 3. Mamãe está brincando porque é legal. }\end{array}$ & $\begin{array}{l}\text { Criança responde corretamente a } \\
2 / 3 .\end{array}$ & \\
\hline $\begin{array}{l}\text { 29. Mostre a figura AE8 . Olhe para esta figura. Preste atenção enquanto } \\
\text { eu conto sobre ela para você. Aponte para o centro da figura. Este é um } \\
\text { palhaço, ele está fazendo malabarismo. Ele trabalha em um circo. Ele é } \\
\text { engraçado. } \\
\text { 1. Aponte para a figura do bombeiro. Olhe para esta figura. Você pode } \\
\text { me falar sobre ela? Indução: você pode me falar mais? } \\
\text { 2. Aponte para a figura da mulher fazendo compras. Agora olhe para } \\
\text { esta figura. Você pode me falar sobre ela? }\end{array}$ & $\begin{array}{l}\text { Criança responde corretamente a } \\
2 / 2 . \\
\text { Deve mencionar a pessoa e o } \\
\text { evento. }\end{array}$ & \\
\hline $\begin{array}{l}\text { Idade: } 6 \text { anos } \\
\text { 30. Preste bastante atenção. Eu vou te contar uma história: O avô da Maria disse, } \\
\text { "Maria, venha se sentar comigo. Você trouxe o seu livro de histórias com você". } \\
\text { Maria respondeu, "sim". O que você acha que Maria pediu para o avô dela fazer? Se } \\
\text { a criança falhar na resposta, diga, "O que você falaria? }\end{array}$ & Criança responde corretamente. & \\
\hline $\begin{array}{l}\text { 31. Eu vou falar alguma frases. Repete do mesmo jeito que eu falar. } \\
\text { Pronto? } \\
\text { 1. Diga para todos o que você quer fazer. } \\
\text { 2. A grama foi comida pela cabra. } \\
\text { 3. Eles mesmos dobraram as roupas. }\end{array}$ & $\begin{array}{l}\text { Criança responde corretamente a } \\
2 / 3 \text {. }\end{array}$ & \\
\hline $\begin{array}{l}\text { 32. Preste bastante atenção. Eu vou falar algumas frases. Parte das frases } \\
\text { está faltando. Quando eu apontar para você, você fala o resto da frase. } \\
1 . \quad \text { O menino está pulando. Os meninos ...............(estão pulando) } \\
\text { 2. Ela está comendo. Elas............ ( estão comendo) } \\
\text { 3. Ele corre. Ela ............. ( corre) }\end{array}$ & $\begin{array}{l}\text { Criança responde corretamente a } \\
3 / 3 .\end{array}$ & \\
\hline $\begin{array}{l}\text { Idade: } 7 \text { anos } \\
\text { 33. Preste bastante atenção. Eu vou falar algumas frases. Parte das frases } \\
\text { está faltando. Quando eu apontar para você, você fala o resto da frase. } \\
\text { 1. O menino está brincando. Os meninos .........( estão brincando) } \\
\text { 2. Ela está correndo. Elas ........... ( estão correndo) } \\
\text { 3. Ele anda. Ela ........ ( anda ) }\end{array}$ & $\begin{array}{l}\text { Criança responde corretamente a } \\
3 / 3 .\end{array}$ & \\
\hline $\begin{array}{l}\text { 34. Preste bastante atenção. Eu vou te contar uma história. Quando eu } \\
\text { terminar eu quero que você me conte o que você lembrar sobre a história. } \\
\text { Leia o seguinte para a criança O João foi pescar com o pai dele. Eles } \\
\text { pescaram por muito tempo. O João finalmente pegou um peixe grande, } \\
\text { bem legal!! Ele está muito feliz. Seu pai o ajudou a tirar o peixe do anzol. } \\
\text { João colocou o peixe de volta no rio. Agora você me conta a história. }\end{array}$ & $\begin{array}{l}\text { Criança responde corretamente } \\
\text { relatando três idéias importantes: } \\
\text { foi pescar, pegou um peixe e soltou } \\
\text { o peixe. }\end{array}$ & \\
\hline
\end{tabular}




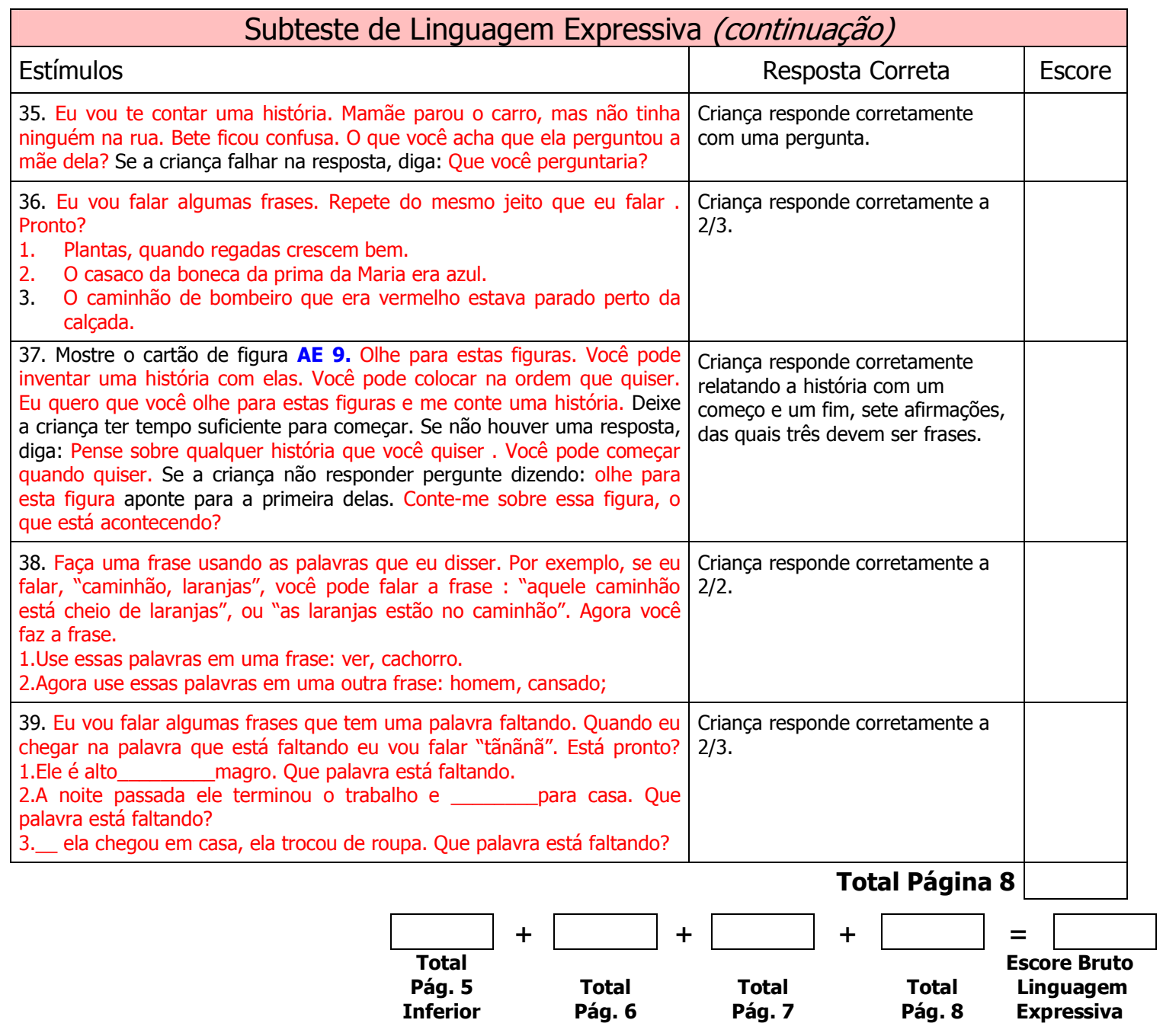

\begin{tabular}{|l|}
\hline Seção VI. Interpretações e Recomendações \\
\hline \\
\hline \\
\hline \\
\hline \\
\hline \\
\hline \\
\hline
\end{tabular}




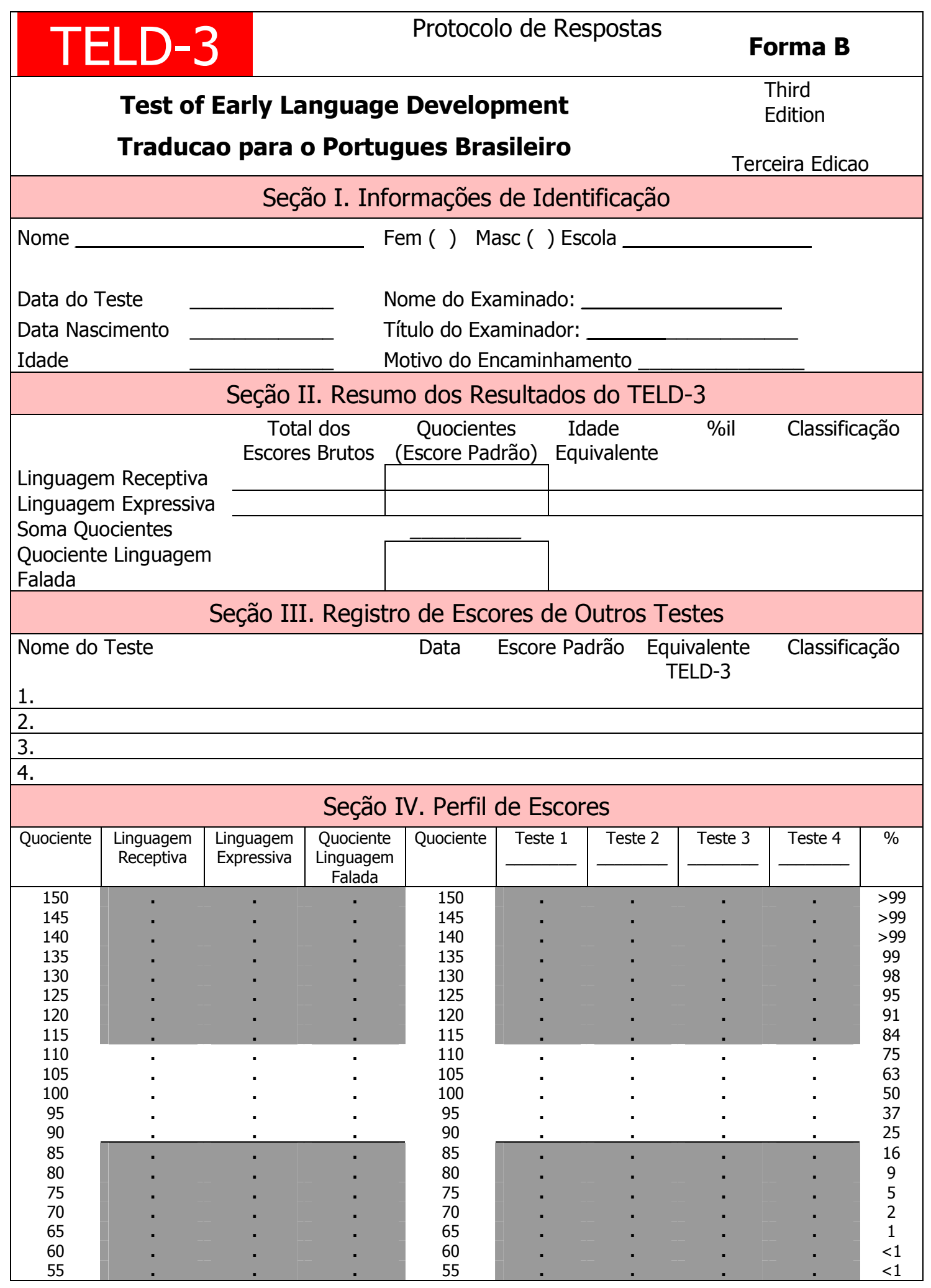




\begin{tabular}{|c|c|c|}
\hline \multicolumn{3}{|c|}{$\begin{array}{l}\text { Seção V. Registro de Respostas } \\
\text { Subteste de Linguagem Receptiva }\end{array}$} \\
\hline Estímulos & Resposta Correta & Escore \\
\hline 1. A criança pára a atividade em resposta ao "não". & Observação/Relato de Confirmação. & \\
\hline 2. A criança identifica membros imediatos da família. & Observação/Relato de Confirmação. & \\
\hline $\begin{array}{l}\text { 3. A criança pegará um objeto que será pedido. Se houver dúvida, permita } \\
\text { a criança tocar nos objetos e brinquedos, então estenda sua mão e diga: } \\
\text { Dê-me } 0 . . . \ldots \ldots \ldots . . . .\end{array}$ & Observação/Relato de Confirmação. & \\
\hline $\begin{array}{l}\text { 4. A criança olha para cima ou olha ao redor quando ele ou ela ouve o } \\
\text { nome de membros da família em uma conversa se eles estão ou não } \\
\text { presentes. }\end{array}$ & Observação/Relato de Confirmação. & \\
\hline $\begin{array}{l}\text { Idade: } 2 \text { anos } \\
\text { 5. Colocar o sapato, bola, carrinho de brinquedo, boneca e colher em uma } \\
\text { mesa ou no chão e peça a criança para apontar cada objeto dizendo: } \\
\text { "Mostre me o ...." } \\
\text { Repita até a criança indicar com sucesso dois objetos. NÃO INCLUIR } \\
\text { objetos usados no item } 3 .\end{array}$ & $\begin{array}{l}\text { Criança responde corretamente a } \\
2 / 4 \text {. }\end{array}$ & \\
\hline 6. A criança segue comandos verbais simples apropriadamente. & Observação/Relato de Confirmação. & \\
\hline $\begin{array}{l}\text { 7. A criança aponta para a sua própria perna, braço, pé, cabeça e } \\
\text { barriga após pedido. }\end{array}$ & $\begin{array}{l}\text { Observação/Relato de Confirmação } \\
\text { de } 3 / 5 \text {. }\end{array}$ & \\
\hline 8. Colocar cinco moedas em frente à criança. Dê-me uma moeda. & Criança responde corretamente. & \\
\hline $\begin{array}{l}\text { 9. Mostre a figura BR1. } \\
\text { 1. Mostre-me (ou aponte) o urso maior. } \\
\text { 2. Mostre-me (ou aponte) o urso menor. }\end{array}$ & $\begin{array}{l}\text { Criança responde corretamente a } \\
2 / 2 \text {. }\end{array}$ & \\
\hline $\begin{array}{l}\text { Idade: } 3 \text { anos } \\
\text { 10. Distribuir as cinco moedas em frente da criança. A ordem não é } \\
\text { importante. Fazer gesto de pedido com as mãos e dizer: De-me todas as } \\
\text { moedas. }\end{array}$ & Criança responde corretamente. & \\
\hline $\begin{array}{l}\text { 11. Mostrar a figura BR } \mathbf{2} \text {. } \\
\text { 1. Mostre-me a figura da noite. } \\
\text { 2. Mostre-me a figura do dia. }\end{array}$ & $\begin{array}{l}\text { Criança responde corretamente a } \\
2 / 2 \text {. }\end{array}$ & \\
\hline $\begin{array}{l}\text { 12. Mostrar a figura BR } 3 \text {. } \\
\text { 1. Mostre-me o prato que está vazio. } \\
\text { 2. Mostre-me o prato que está cheio. }\end{array}$ & $\begin{array}{l}\text { Criança responde corretamente a } \\
2 / 2 \text {. }\end{array}$ & \\
\hline $\begin{array}{l}\text { 13. Mostre o cartão de figuras BR4. Olhe para estas figuras. } \\
\text { 1. Mostre o peixe. } \\
\text { 2. } \text { Agora mostre a bicicleta. }\end{array}$ & $\begin{array}{l}\text { Criança responde corretamente a } \\
2 / 2 \text {. }\end{array}$ & \\
\hline $\begin{array}{l}\text { 14. Mostrar a figura BR } \mathbf{5} \text {. } \\
\text { 1. Mostre-me o pau curto. } \\
\text { 2. Mostre-me o pau comprido. }\end{array}$ & $\begin{array}{l}\text { Criança responde corretamente a } \\
2 / 2 \text {. }\end{array}$ & \\
\hline $\begin{array}{l}\text { Idade: } 4 \text { anos } \\
\text { 15. O que eu falo? Preste atenção. } \\
\text { 1. Coloque sua mão em cima da mesa. } \\
\text { 2. Coloque sua mão embaixo da mesa. } \\
\text { 3. Fique em pé em frente de sua cadeira. } \\
\text { 4. Fique em pé atrás de sua cadeira. } \\
\text { 5. Fique perto da sua cadeira. }\end{array}$ & $\begin{array}{l}\text { Criança responde corretamente a } \\
4 / 5 \text {. }\end{array}$ & \\
\hline $\begin{array}{l}\text { 16. Mostre a figura BR } \mathbf{6} \text {. Mostre-me as coisas que são iguais. ( pergunta } \\
\text { reforço: aponte para coisas que são parecidas). }\end{array}$ & $\begin{array}{l}\text { Criança responde corretamente } \\
\text { apontando para as estrelas. }\end{array}$ & \\
\hline & Total da Página 2 & \\
\hline
\end{tabular}




\begin{tabular}{|c|c|c|}
\hline \multicolumn{3}{|c|}{ Subteste de Linguagem Receptiva } \\
\hline Estímulos & Resposta Correta & Escore \\
\hline 17. Mostre a figura BR 7. Mostre-me a flor que é diferente. & Criança responde corretamente. & \\
\hline $\begin{array}{l}\text { 18. O que eu falo. Preste atenção: } \\
\text { 1. Mostre-me seu joelho. } \\
\text { 2. Mostre-me seu queixo. } \\
\text { 3. Mostre-me seu dedo do pé. } \\
\text { 4. Mostre-me seu dedão da mão/polegar. }\end{array}$ & $\begin{array}{l}\text { Criança responde corretamente a } \\
3 / 4 \text {. }\end{array}$ & \\
\hline $\begin{array}{l}\text { 19. 1. Mostre a figura BR 8: Mostre-me: o menino com chapéu. } \\
\text { 2. Mostre a figura BR 9: Mostre-me: o cachorro que está fora da casinha. } \\
\text { 3. Mostre a figura BR 10: Mostre-me: a pipa que está em cima. }\end{array}$ & $\begin{array}{l}\text { Criança responde corretamente a } \\
3 / 3 \text {. }\end{array}$ & \\
\hline $\begin{array}{l}\text { Idade: } \mathbf{5} \text { anos } \\
\text { 20. 1. Mostre a figura BR 11. Mostre-me: a menina que está no alto da } \\
\text { escada. } \\
\text { 2. Mostre a figura BR 12. Mostre-me: a criança que está entre as árvores. } \\
\text { 3. Mostre a figura BR 13. Mostre-me: o menino de frente. }\end{array}$ & $\begin{array}{l}\text { Criança responde corretamente a } \\
2 / 3 \text {. }\end{array}$ & \\
\hline $\begin{array}{l}\text { 21. 1. Quando o Papai Noel vem? ( se a criança for de uma cultura ou } \\
\text { etnia que não celebra o Natal, você pode substituir por feriado diferente, } \\
\text { como Quando é Kwanza? Ou Quando é Hanukkah? } \\
\text { 2. Quando você toma seu café da manhã? }\end{array}$ & $\begin{array}{l}\text { Criança responde corretamente a } \\
1 / 2 \text {. }\end{array}$ & \\
\hline $\begin{array}{l}\text { 22. Mostre a figura BR 14. Com um gesto manual, diga: Isto é uma } \\
\text { montanha. } \\
\text { 1. Mostre-me o alto da montanha. } \\
\text { 2. Mostre-me o pé da montanha. } \\
\text { 3. Mostre-me o meio da montanha. }\end{array}$ & $\begin{array}{l}\text { Criança responde corretamente a } \\
3 / 3 \text {. }\end{array}$ & \\
\hline $\begin{array}{l}\text { 23. Mostre-me como a árvore faz quando o vento está batendo muito forte } \\
\text { nela. ( reforço: finja que você é uma árvore com seu corpo). }\end{array}$ & Criança responde corretamente. & \\
\hline $\begin{array}{l}\text { 24. 1. Você vai para cama antes do jantar ou depois do jantar? } \\
2 \text {. Você coloca sua blusa ( substituir por sweater ou jaqueta ) antes de } \\
\text { você sair ou depois de sair? }\end{array}$ & $\begin{array}{l}\text { Criança responde corretamente a } \\
2 / 2 \text {. }\end{array}$ & \\
\hline $\begin{array}{l}\text { Idade: } 6 \text { anos } \\
\text { 25. Mostre-me que gesto um policial faz para parar os carros. Reforço: } \\
\text { mostre-me }\end{array}$ & Criança responde corretamente. & \\
\hline $\begin{array}{l}\text { 26. Eu vou falar umas frases. Depois de cada uma, me fale se está certa } \\
\text { ou errada. } \\
\text { 1. Mim come bolacha. } \\
\text { 2. A menina está em casa. } \\
\text { 3. O cachorro não comendo. }\end{array}$ & $\begin{array}{l}\text { Criança responde corretamente a } \\
2 / 3 \text {. }\end{array}$ & \\
\hline $\begin{array}{l}\text { 27. Mostre a figura BR 15. Olhe para estas figuras. Eu vou falar algumas } \\
\text { palavras. Quando eu falar a palavra, aponte para a figura que combina } \\
\text { com ela. Aponte para............ (ou mostre-me........) } \\
\text { 1. amizade } \\
\text { 2. castelo } \\
\text { 3. lanterna }\end{array}$ & $\begin{array}{l}\text { Criança responde corretamente a } \\
2 / 3 \text {. }\end{array}$ & \\
\hline $\begin{array}{ll}\text { Idade: } \mathbf{7} \text { anos } & \\
\text { 28. Preste atenção. } & \text { Você vai ter que falar o que a palavra significa. } \\
\text { 1. abajur } & \text { claro ou escuro } \\
\text { 2. instantâneo } & \underline{\text { rápido ou devagar }} \\
\text { 3. Perpendicular } & \underline{\text { reto ou curvado }} \\
\end{array}$ & $\begin{array}{l}\text { Criança responde corretamente a } \\
2 / 3 \text {. }\end{array}$ & \\
\hline $\begin{array}{l}\text { 29. Mostre a figura BR16. } \\
\text { 1. Olhe para estas figuras. Aponte para a criança que tem mais flores. } \\
\text { 2. Agora aponte para a criança que tem menos flores. }\end{array}$ & $\begin{array}{l}\text { Criança responde corretamente a } \\
2 / 2 \text {. }\end{array}$ & \\
\hline & Total da Página & \\
\hline
\end{tabular}




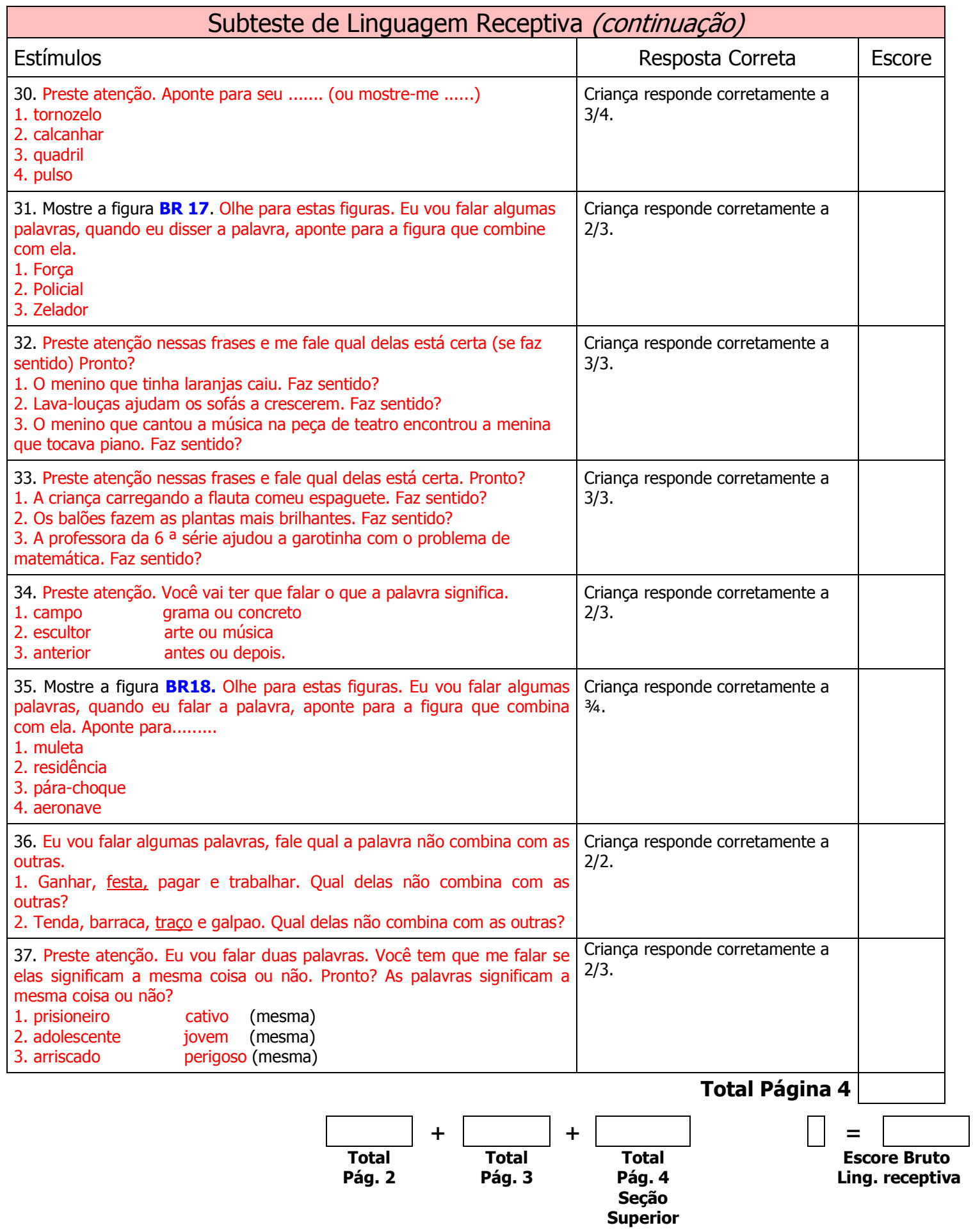




\begin{tabular}{|c|c|c|}
\hline \multicolumn{3}{|c|}{ Subteste de Linguagem Expressiva } \\
\hline Estímulos & Resposta Correta & Escore \\
\hline 1. A criança chora diferente por fome, dor, desconforto e assim por diante. & Observação/Relato de Confirmação. & \\
\hline 2. A criança vocaliza quando ela ouve sons ou conversas. & Observação/Relato de Confirmação. & \\
\hline 3. A criança freqüentemente balbucia quando está sozinha. & Observação/Relato de Confirmação. & \\
\hline $\begin{array}{l}\text { 4. Quando objetos estão fora do alcance da criança, mas num lugar visível, } \\
\text { ela pede por eles através de gestos ou sons. }\end{array}$ & Observação/Relato de Confirmação. & \\
\hline 5. A criança conversa com brinquedos e/ou pessoas combinando sons. & Observação/Relato de Confirmação. & \\
\hline 6. A criança consegue nomear cinco ou mais objetos com consistência. & Observação/Relato de Confirmação. & \\
\hline $\begin{array}{l}\text { 7. A criança tenta recitar versos de ninar ou cantar músicas familiares sem } \\
\text { usar palavras reais (jogo vocal) }\end{array}$ & Observação/Relato de Confirmação. & \\
\hline 8. A criança usa duas ou mais palavras distintas em frases. & Observação/Relato de Confirmação. & \\
\hline 9. A criança usa sim ou não para responder a questões simples. & Observação/Relato de Confirmação. & \\
\hline $\begin{array}{l}\text { Idade: } \mathbf{2} \text { anos } \\
\text { 10. A criança consegue identificar membros de família por "t'itulos" }\end{array}$ & Observação/Relato de Confirmação. & \\
\hline $\begin{array}{l}\text { 11. A criança consegue usar três ou mais palavras em sentenças na } \\
\text { comunicação oral. }\end{array}$ & Observação/Relato de Confirmação. & \\
\hline 12. A criança refere a si própria usando um pronome apropriado. & Observação/Relato de Confirmação. & \\
\hline $\begin{array}{l}\text { 13. Mostre a figura BE1 para a criança. } \\
\text { 1. O que é isto? (aponte para os sapatos). } \\
\text { 2. O que é isto? (aponte para os cachorrinhos). }\end{array}$ & $\begin{array}{l}\text { Criança responde corretamente a } \\
2 / 2 \text {. }\end{array}$ & \\
\hline $\begin{array}{l}\text { 14. 1. O que você gosta de beber? } \\
\text { 2. O que você gosta de comer? }\end{array}$ & $\begin{array}{l}\text { Criança responde corretamente a } \\
1 / 2 \text {. }\end{array}$ & \\
\hline $\begin{array}{l}\text { Idade: } 3 \text { anos } \\
15 . \text { A criança é capaz de relatar experiências sem ser questionada. }\end{array}$ & Observação/Relato de Confirmação. & \\
\hline 16. A criança usa sentenças com adjetivos e advérbios. & Observação/Relato de Confirmação. & \\
\hline $\begin{array}{l}\text { 17. Mostre a figura BE2. Olhe para estas figuras. Passe rapidamente pelas } \\
\text { figuras. Então aponte para a colher e diga, } O \text { que é isto? Fale o nome } \\
\text { disso. Em seguida, faça o mesmo para } \\
\text { 1. menina } \\
\text { 2. porco } \\
\text { 3. trem }\end{array}$ & $\begin{array}{l}\text { Criança responde corretamente a } \\
2 / 3 \text {. }\end{array}$ & \\
\hline $\begin{array}{l}\text { 18. A criança usa pronomes pessoais "Eu", "Você", "Ele" e "Ela" em } \\
\text { comunicação oral. }\end{array}$ & Criança responde corretamente. & \\
\hline $\begin{array}{l}\text { 19. Qual é o seu nome? Se a criança responder com somente o primeiro } \\
\text { nome, dizer: Ok, bom!, mas qual é o seu nome completo? Fale seu } \\
\text { primeiro e seu último nome. }\end{array}$ & Criança responde corretamente. & \\
\hline $\begin{array}{l}\text { Idade: } 4 \text { anos } \\
\text { 20. Quantos anos você tem? Me fale quantos anos você tem? Se a criança } \\
\text { responder apenas com os dedos, dizer: Isso, muito bem, mas me fale } \\
\text { quantos anos você tem? Ou quanto é isso? }\end{array}$ & Criança responde corretamente. & \\
\hline $\begin{array}{l}\text { 21. Mostre a figura BE3. Preste atenção nessas figuras. Eu vou apontar para algumas } \\
\text { e eu quero que você me fale o que cada pessoa está fazendo. Aponte para um de } \\
\text { cada vez. Se a criança descrever a figura, então diga: Bom, agora fale o que a } \\
\text { criança está fazendo. } \\
\text { 1. Lendo (ou estudando) } \\
\text { 2. Dormindo (ou cochilando) } \\
\text { 3. Chorando } \\
\text { 4. Brincando (ou jogando) }\end{array}$ & $\begin{array}{l}\text { Criança responde corretamente a } \\
3 / 4 .\end{array}$ & \\
\hline & Total Pági & \\
\hline
\end{tabular}




\begin{tabular}{|c|c|c|}
\hline \multicolumn{3}{|c|}{ Subteste de Linguagem Expressiva (continuação) } \\
\hline Estímulos & Resposta Correta & Escore \\
\hline $\begin{array}{l}\text { 22. Preste bastante atenção. Eu vou te contar uma história. Quando eu } \\
\text { terminar, eu quero que você repita pra mim o máximo que lembrar sobre } \\
\text { ela. Leia o seguinte para a criança: Maria teve uma festa de aniversário. } \\
\text { Sua mãe, seu pai e todos os seus amigos estavam lá. Sua mãe e seu pai } \\
\text { Ihe deram um cachorrinho de presente de aniversário. Ela estava muito } \\
\text { feliz. Agora repete a história pra mim. }\end{array}$ & $\begin{array}{l}\text { A criança responde corretamente } \\
\text { relatando pelo menos dois detalhes } \\
\text { importantes sobre a história. }\end{array}$ & \\
\hline $\begin{array}{l}\text { 23. A criança usa sentenças de quatro a seis palavras com gramática } \\
\text { correta a maioria das vezes. }\end{array}$ & Observação/Relato de Confirmação. & \\
\hline $\begin{array}{l}\text { 24. Qual é o seu programa de TV preferido? Fale o nome do seu programa } \\
\text { de TV preferido. Se a criança permanecer em silêncio, então diga: Você } \\
\text { assiste televisao? Me fale o nome do programa que você mais gosta. }\end{array}$ & Criança responde corretamente. & \\
\hline $\begin{array}{l}\text { Idade: } \mathbf{5} \text { anos } \\
\text { 25. 1. Me fale o que você faz com um lápis. } \\
\text { 2. O que você faz com uma faca? } \\
\text { 3. O que você faz com um ônibus? } \\
\text { 4. O que você faz com um relógio? } \\
\text { 5. O que você faz com um abajur? }\end{array}$ & $\begin{array}{l}\text { Criança responde corretamente a } \\
4 / 5 . \\
\text { Deve falar a função. Ajudar com Você } \\
\text { pode me falar mais sobre isso? }\end{array}$ & \\
\hline $\begin{array}{l}\text { 26. 1. Mostre figura BE4. Este é um sapato. Estes são os__ } \\
\text { (sapatos). } \\
\text { 2. Mostre figura BE5. Esta é uma faca. Estas são as } \\
\text { 3. Mostre figura BE6. Este é um homem. Estes são os_ (facas). } \\
\text { (homens). } \\
\text { 4. Mostre figura BE7. Este é um número. Estes são os_- } \\
\text { (números). }\end{array}$ & $\begin{array}{l}\text { Criança responde corretamente a } \\
3 / 4 \text {. }\end{array}$ & \\
\hline $\begin{array}{l}\text { 27. Preste atenção. Eu vou te contar uma história. Leia o seguinte para a } \\
\text { criança. João estava cansado. Ele não tirou uma soneca durante o dia } \\
\text { todo. O que você acha que ele disse à mãe dele? Se a criança não } \\
\text { responder, pergunte: O que você falaria? }\end{array}$ & Criança responde corretamente. & \\
\hline $\begin{array}{l}\text { 28. Eu vou falar algumas frases. Repita exatamente como eu falar. } \\
\text { Pronto(a)? } \\
\text { 1. Ele está comendo. } \\
\text { 2. Cachorros querem ser amados. } \\
\text { 3. João não está vindo à escola. } \\
\text { 4. A casa era marrom, não branca. }\end{array}$ & $\begin{array}{l}\text { Criança responde corretamente a } \\
3 / 4 . \\
\text { Ordenação das palavras e erros } \\
\text { gramaticais. Subst. de palavra é } \\
\text { incorreta. }\end{array}$ & \\
\hline $\begin{array}{l}\text { 29. Mostre figura BE8. Estes são todos brinquedos. Aponte para os cubos. } \\
\text { Estes brinquedos são iguais. Aponte para os outros brinquedos. Estes } \\
\text { brinquedos são }\end{array}$ & Criança responde corretamente. & \\
\hline $\begin{array}{l}\text { Idade: } \mathbf{6} \text { anos } \\
\text { 30. Preste atenção. Maria trouxe o avião dela para a escola, para falar } \\
\text { sobre ele. O que você acha que Maria falou à classe? }\end{array}$ & Criança responde corretamente. & \\
\hline $\begin{array}{l}\text { 31. 1. O que significa "remo" ? A criança deve dar uma descrição verbal. } \\
\text { Se a criança usar gestos, diga: Conte pra mim. } \\
\text { 2. O que significa "desenhar" ? } \\
\text { 3. O que significa "coruja" ? Se todas as três estão corretas ou duas ou } \\
\text { mais estão erradas, prossiga para o item } 32 \text {. Se duas estão corretas, } \\
\text { continue com a questão 4. } \\
\text { 4. O que significa "martelar" ? }\end{array}$ & $\begin{array}{l}\text { Criança responde corretamente a } \\
3 / 4 . \\
\text { Deve definir e não descrever. }\end{array}$ & \\
\hline $\begin{array}{l}\text { 32. Mostre a figura BE9 para a criança. Aponte para uma cena de cada } \\
\text { vez. Olhe para esta figura e me fale onde o cachorro está. } \\
\text { 1. sobre, no topo de, } \\
\text { 2. atrás, atrás de, perto } \\
\text { 3. embaixo }\end{array}$ & $\begin{array}{l}\text { Criança responde corretamente a } \\
3 / 3 .\end{array}$ & \\
\hline & Total Página 6 & \\
\hline
\end{tabular}




\begin{tabular}{|c|c|c|}
\hline \multicolumn{3}{|c|}{ Subteste de Linguagem Expressiva (continuação) } \\
\hline Estímulos & Resposta Correta & Escore \\
\hline $\begin{array}{l}\text { Idade: } \mathbf{7} \text { anos } \\
\text { 33. Preste atenção. Eu vou falar algumas frases com algumas palavras } \\
\text { faltando. Quando eu apontar para você, me fale o resto da frase. } \\
\text { Pronto(a)? } \\
\text { 1. Eu fui à sua festa. Você vai vir a minha } \\
\text { 2. Ele pesa muito. Ele é muito }\end{array}$ & $\begin{array}{l}\text { Criança responde corretamente a } \\
2 / 2 .\end{array}$ & \\
\hline $\begin{array}{l}\text { 34. Preste atenção na palavra que eu falar e faça uma frase com ela. Por } \\
\text { exemplo, se eu disser "cachorro", você poderia falar "aquele cachorro } \\
\text { morde" ou "o cachorro é bravo". Agora você faz uma frase: } \\
\text { 1. vulcão } \\
\text { 2. pensamento } \\
\text { 3. musical }\end{array}$ & $\begin{array}{l}\text { Criança responde corretamente a } \\
2 / 3 .\end{array}$ & \\
\hline $\begin{array}{l}\text { 35. Preste atenção. Eu vou falar algumas palavras. Depois que eu falar } \\
\text { cada palavra, me fale uma palavra que significa o contrário. } \\
\text { 1. Qual é o contrário de grande? } \\
\text { 2. Pesado? } \\
\text { 3. Mais? } \\
\text { 4. Menina? }\end{array}$ & $\begin{array}{l}\text { Criança responde corretamente a } \\
3 / 4 \text {. }\end{array}$ & \\
\hline $\begin{array}{l}\text { 36. Mostre figura BE10. Olhe para esta figura e preste atenção no que eu } \\
\text { falar. Você tem que me falar qual é a palavra que termina a frase: } \\
\text { 1. Ele toca um violino. } \\
\text { Ele é um (violinista). } \\
\text { 2. Esta pessoa é um construtor. } \\
\text { Ela está _ (construindo). }\end{array}$ & $\begin{array}{l}\text { Criança responde corretamente a } \\
2 / 2 \text {. }\end{array}$ & \\
\hline $\begin{array}{l}\text { 37. 1. Qual é uma outra palavra para carro? } \\
\text { 2. Qual é uma outra palavra para rapidamente? } \\
\text { 3. Qual é uma outra palavra para sofá? } \\
\text { 4. Qual é uma outra palavra para carpete? } \\
\text { 5. Qual é uma outra palavra para prato? }\end{array}$ & $\begin{array}{l}\text { Criança responde corretamente a } \\
4 / 5 \text {. }\end{array}$ & \\
\hline $\begin{array}{l}\text { 38. O carro é pequeno. O carro é rápido. Eu poderia dizer de outra forma. } \\
\text { Eu poderia colocar as duas frases juntas e fazer uma só. Eu poderia falar, } \\
\text { O carro é pequeno e rápido. Agora é você, vamos tentar. Pronto? } \\
\text { 1. Maria é bonita. Maria é alta. } \\
\text { 2. A casa é vermelha. A casa é grande. }\end{array}$ & $\begin{array}{l}\text { Criança responde corretamente a } \\
2 / 2 \text {. }\end{array}$ & \\
\hline $\begin{array}{l}\text { 39. Forme uma frase com as palavras que eu vou dar para você. } \\
\text { 1. desde, setembro } \\
\text { 2. como, triste }\end{array}$ & $\begin{array}{l}\text { Criança responde corretamente a } \\
2 / 2 \text {. }\end{array}$ & \\
\hline
\end{tabular}

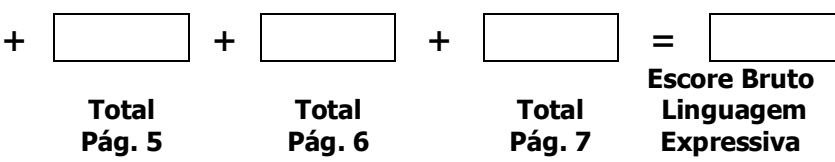


Seção VI. Interpretações e Recomendações 
HOSPITAL DAS CLÍNICAS

DA

FACULDADE DE MEDICINA DA UNIVERSIDADE DE SÃO PAULO

TERMO DE CONSENTIMENTO LIVRE E ESCLARECIDO

(Instruções para preenchimento no verso

\section{I - DADOS DE IDENTIFICAÇÃO DO SUJEITO DA PESQUISA OU RESPONSÁVEL LEGAL}

1 NOME DO PACIENTE

DOCUMENTO DE IDENTIDADE № : SEXO:.$M \square \quad F \square$

DATA NASCIMENTO: ........................

ENDEREÇO

№

APTO:

BAIRRO:

CEP:.

TELEFONE: DDD CIDADE

2.RESPONSÁVEL LEGAL

NATUREZA (grau de parentesco, tutor, curador etc.)

DOCUMENTO DE IDENTIDADE :

SEXO: $M \square \quad F \square$

DATA NASCIMENTO.: ....................

ENDEREÇO

№ …................ APTO:

BAIRRO: CIDADE:

CEP:

TELEFONE: DDD ..).

\section{II - DADOS SOBRE A PESQUISA CIENTÍFICA}

1. TÍTULO DO PROTOCOLO DE PESQUISA "Desempenho de crianças brasileiras em um Teste de Linguagem Infantil".

PESQUISADOR: Elisabete

CARGO/FUNÇÃO: Fonoaudióloga $\quad$ INSCRIÇÃO CONSELHO REGIONAL № CRFa - 9473 - SP.

UNIDADE DO HCFMUSP: Departamento de Fisioterapia, Fonoaudiologia e Terapia Ocupacional.

3. AVALIAÇÃO DO RISCO DA PESQUISA:

$\begin{array}{llll}\text { SEM RISCO } & X & \text { RISCO MÍNIMO } \\ \text { RISCO BAIXO } & \square & \text { RISCO MAIOR } \quad \square & \text { RISCO MÉDIO }\end{array}$

(probabilidade de que o indivíduo sofra algum dano como consequência imediata ou tardia do estudo)

4.DURAÇÃO DA PESQUISA : 3 anos ou 6 semestres 


\section{III - REGISTRO DAS EXPLICAÇÕES DO PESQUISADOR AO PACIENTE OU SEU REPRESENTANTE LEGAL SOBRE A PESQUISA CONSIGNANDO:}

O número de crianças que apresentam alguma dificuldade na fala é muito grande. Assim, estamos realizando uma pesquisa relacionada a avaliação de linguagem porque no Brasil faltam instrumentos (materiais) para avaliar e identificar crianças com estas dificuldades. Nossa pesquisa tem como objetivo verificar o desempenho de crianças normais em um Teste que avalia a linguagem. Com esses dados, poderemos comparar posteriormente o desempenho de crianças normais com crianças que possuem alguma dificuldade de linguagem, o que poderá nos ajudar no diagnóstico e tratamento destas. Participarão deste estudo crianças normais, ou seja, sem dificuldade de fala, de 2 anos a 7 anos e 11 meses. As crianças serão avaliadas na próprio Centro Infantil ou Escola. A criança será retirada da sala de aula e seguirá junto com a pesquisadora até a sala de avaliação ( sala da diretora ou da Assistente Social). No caminho a pesquisadora irá conversar com a criança para explicar que elas irão para uma outra sala para brincar com alguns brinquedos, para ver alguns desenhos e para responder perguntas. Chegando na sala, a pesquisadora convidará a criança para sentar em uma mesinha (igual a da sala de aula) para elas começarem a brincar. O tempo de avaliação dura em média trinta minutos e nesta avaliação a criança precisará apenas responder algumas pergunrtas que serão feitas pela pesquisadora e brincar com alguns brinquedos. Esta pesquisa não apresenta nunhum desconforto ou risco para as crianças participantes, ao contrário, será uma situação prazerosa, pois a criança poderá participar de um momento de atividades divertidas com vários brinqeudos e figuras. Vale ressaltar, que se a criança não quiser participar no dia proposto, a mesma poderá ser avaliada em uma outra data. Esta pesquisa é muito impoortante porque a partir dela poderemos elbaorar um material que nos ajude a identificar mais facilmente crianças com problemas de fala e de linguagem e assim estas crianças poderão ser encaminhadas para atendimentos especializados.

\section{IV - ESCLARECIMENTOS DADOS PELO PESQUISADOR SOBRE GARANTIAS DO SUJEITO DA PESQUISA CONSIGNANDO:}

1. acesso, a qualquer tempo, às informações sobre procedimentos, riscos e benefícios relacionados à pesquisa, inclusive para dirimir eventuais dúvidas.

Sim, todos os responsáveis pelas crianças participantes poderão, a qualquer momento, ter acesso aos procedimentos, riscos e benefícios relacionados à pesquisa, bem como esclarecimento sobre qualquer dúvida.

2. liberdade de retirar seu consentimento a qualquer momento e de deixar de participar do estudo, sem que isto traga prejuízo à continuidade da assistência.

Todos os responsáveis deverão assinar o termo de consentimento, porém o consentimento poderá ser retirado a qualquer momento pelos responsáveis, sem que isso possa interferir na assistência dada à criança.

3. salvaguarda da confidencialidade, sigilo e privacidade.

Os dados obtidos nesta pesquisa serão estritamente confidenciais, sendo que apenas a pesquisadora terá acesso a estes dados para realizar a análise e discussão dos mesmos.

4. disponibilidade de assistência no HCFMUSP, por eventuais danos à saúde, decorrentes da pesquisa. 
Esta pesquisa não oferece risco algum para a saúde dos participantes.

5. viabilidade de indenização por eventuais danos à saúde decorrentes da pesquisa.

Não se aplica.

\section{INFORMACÕES DE NOMES, ENDERECOS E TELEFONES DOS RESPONSÁVEIS PELO ACOMPANHAMENTO DA PESQUISA, PARA CONTATO EM CASO DE INTERCORRÊNCIAS CLÍNICAS E REAÇÕES ADVERSAS.}

* Pesquisador Responsável: Profa. Dra. Débora Maria Befi - Lopes

* Laboratório de Investigação Fonoaudiológica em Desenvolvimento da Linguagem e suas Alterações. Departamento de Fonoaudiologia, Fisioterapia e Terapia Ocupacional da Universidade de São Paulo. (FMUSP).

* Rua Cipotânea, № 51 - Cidade Universitária - Telefone: 3091 - 7453

* Butantã - São Paulo.

\section{OBSERVAÇÕES COMPLEMENTARES:}

\section{VII - CONSENTIMENTO PÓS-ESCLARECIDO}

Declaro que, após convenientemente esclarecido pelo pesquisador e ter entendido o que me foi explicado, consinto em participar do presente Protocolo de Pesquisa

São Paulo, de de 2003. 


\section{Análise Estatística: Análise de Regressão Clássica}

Foram ajustados modelos de regressão, separadamente, para cada Forma do teste, para as variáveis Escore Bruto Receptivo e Escore Bruto Expressivo em função da Idade (em meses) (Modelo 1: Escore Bruto Receptivo na Forma A; Modelo 2: Escore Bruto Receptivo na Forma B; Modelo 3: Escore Bruto Expressivo na Forma A; Modelo 4: Escore Bruto Expressivo na Forma B).

Em todos os casos o modelo que melhor ajustou-se foi um modelo de regressão linear simples, onde foi utilizado o logaritmo neperiano da variável explicativa (Idade). Os quatro modelos de regressão seguem a seguinte forma:

$$
\text { escore }_{i}=\alpha+\beta \ln \left(\text { idade }_{i}\right)+\varepsilon_{i}
$$

em que,

$\alpha$ : intercepto;

$\beta:$ variação média no escore quando o In (idade) aumenta em uma unidade;

idade $_{\text {: }}$ Idade (meses) da i-ésima criança;

escore: : escore obtido pela i-ésima criança, segundo o modelo considerado;

$\varepsilon_{i}$ : erro associado à i-ésima criança, $\varepsilon_{i} \sim N\left(0, \sigma^{2}\right), i=1, \ldots, n$, independentes.

Os gráficos a seguir ilustram os modelos ajustados.

Gráfico 1: Gráfico de Dispersão de Escore Bruto Receptivo na Forma A x Idade (meses), com a curva ajustada do Modelo 1.

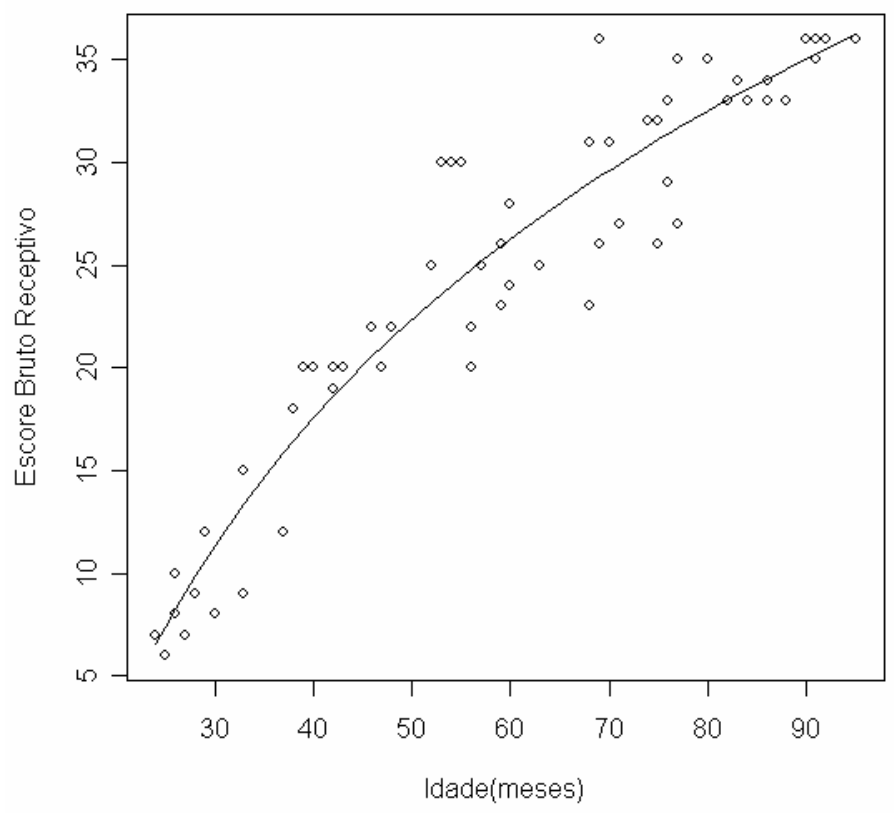


Gráfico 2: Gráfico de Dispersão de Escore Bruto Receptivo na Forma B x Idade (meses), com a curva ajustada do Modelo 2.

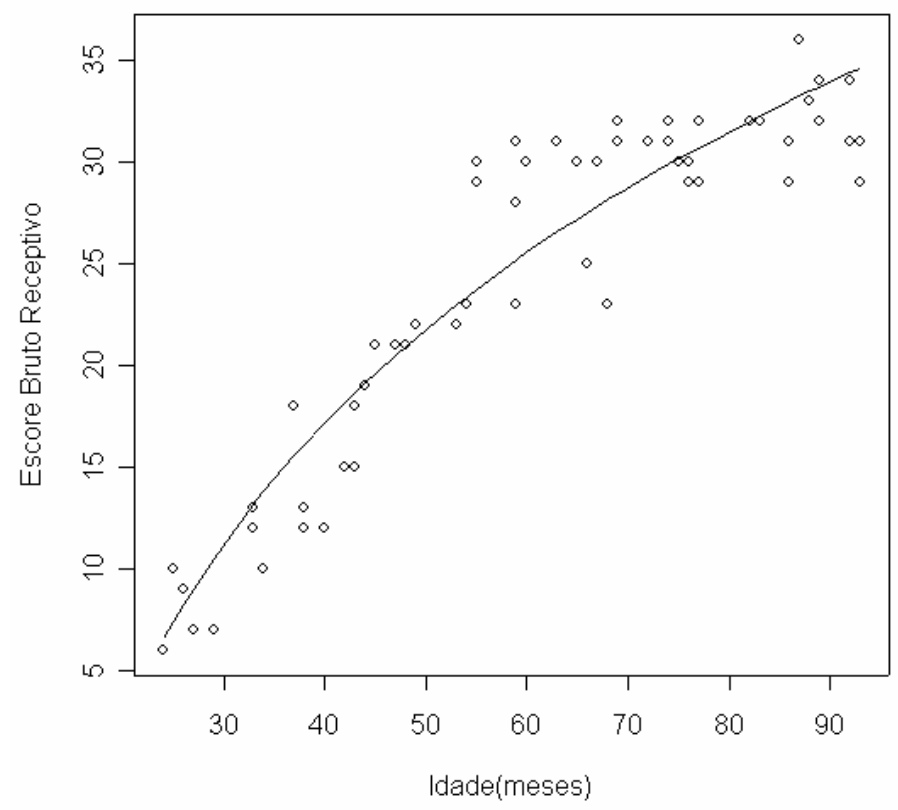

Gráfico 3: Gráfico de Dispersão de Escore Bruto Expressivo na Forma A x Idade (meses), com a curva ajustada do Modelo 3.

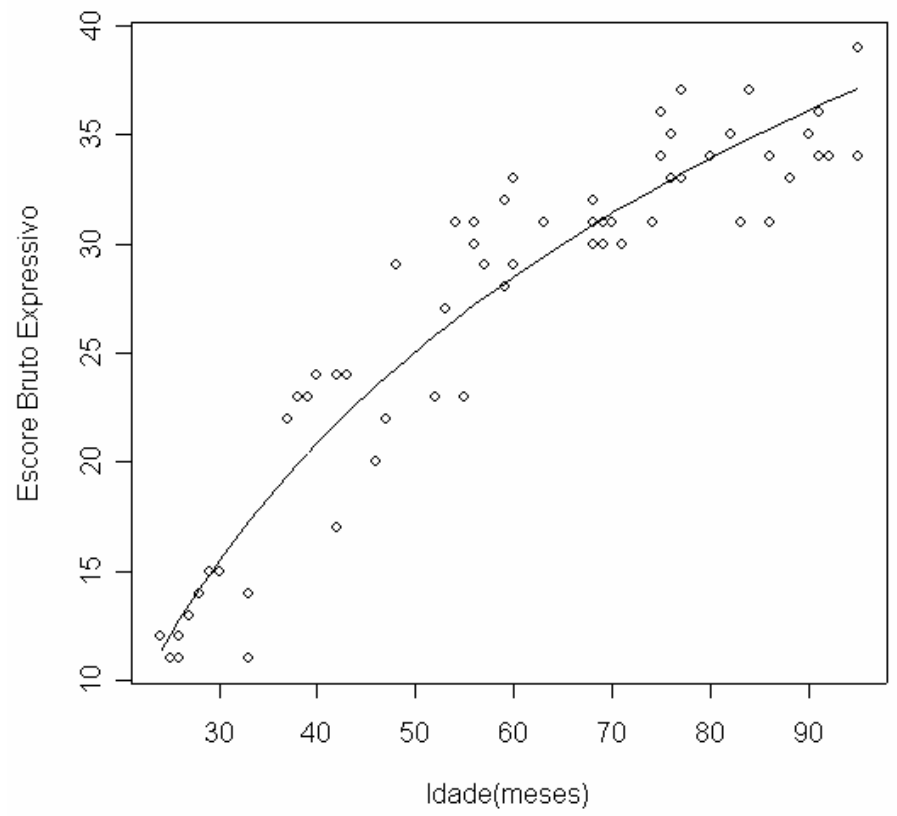


Gráfico 4: Gráfico de Dispersão de Escore Bruto Expressivo na Forma B x Idade (meses) com a curva ajustada do Modelo 4.

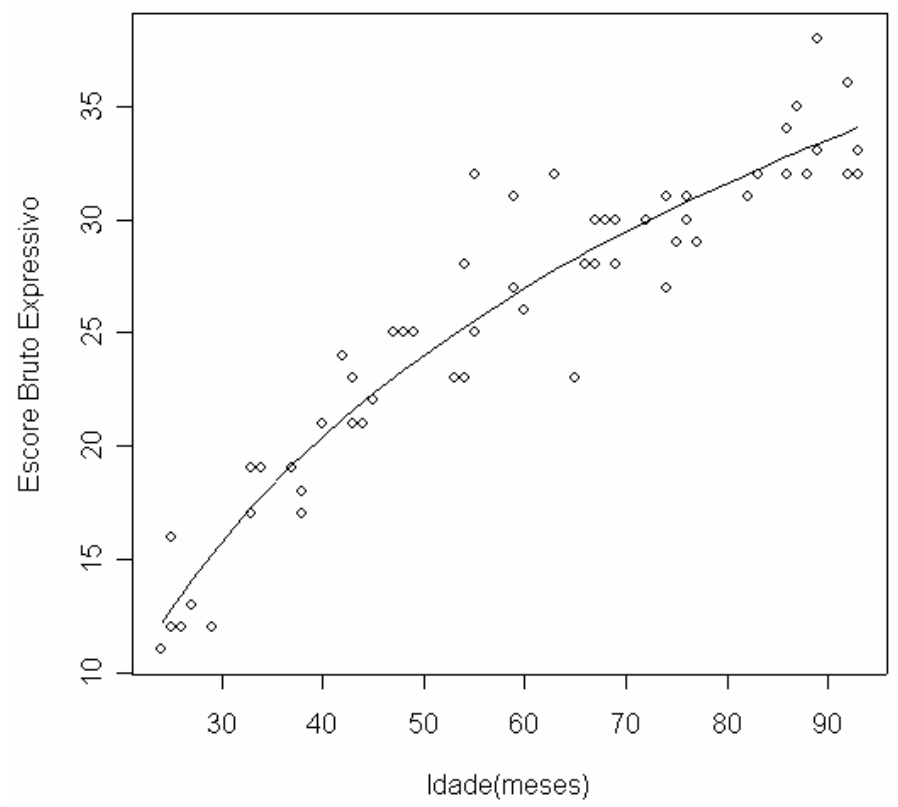

Em todos os casos, o teste de Shapiro-Wilks indicou que não existe evidências de que os resíduos dos modelos não apresentem distribuição normal, conforme mostra a Tabela 01. Por meio dos gráficos de envelope dos modelos, que serão apresentados a seguir, é possível verificar que todos os modelos estão bem ajustados.

Tabela 01: Níveis descritivos ( $p$-valores) do teste de Shapiro-Wilks para normalidade dos resíduos dos modelos ajustados.

\begin{tabular}{lc}
\hline modelo & p-valor \\
\hline Modelo 1 & 0,157 \\
Modelo 2 & 0,513 \\
Modelo 3 & 0,762 \\
Modelo 4 & 0,058 \\
\hline
\end{tabular}


Gráfico 5: Envelope para o Modelo 1.

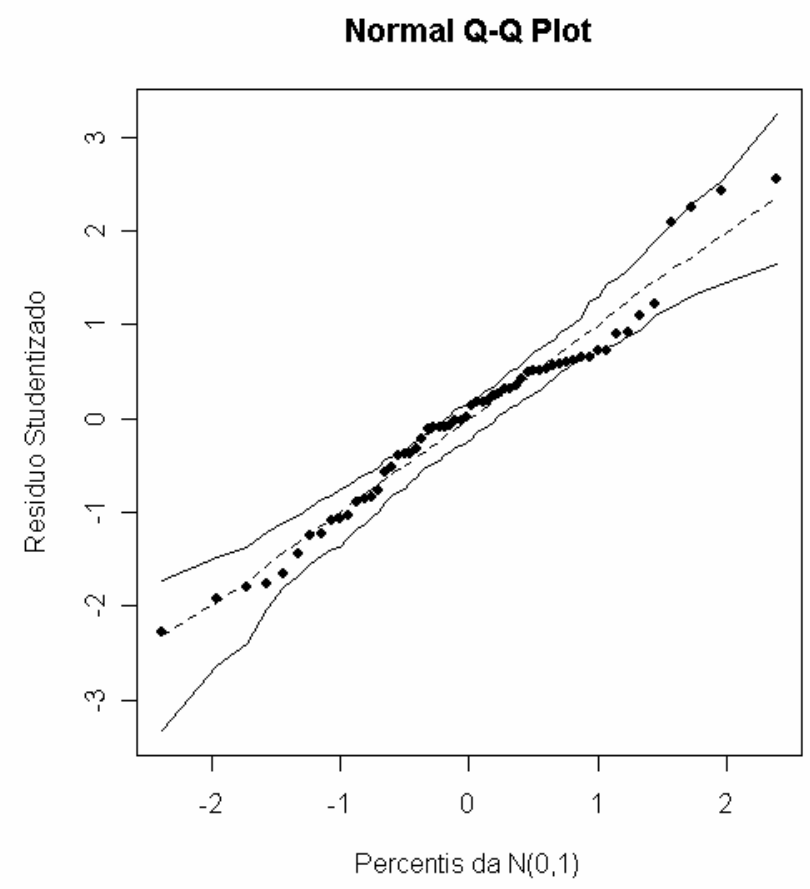

Gráfico 7: Envelope para o Modelo 3.

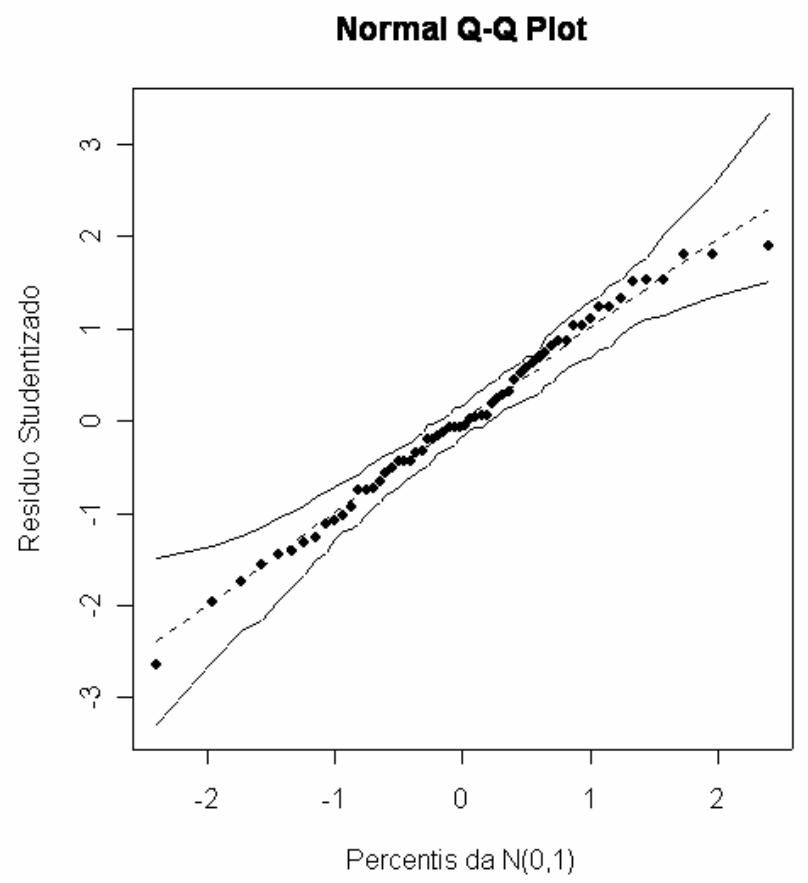

Gráfico 6: Envelope para o Modelo 2.

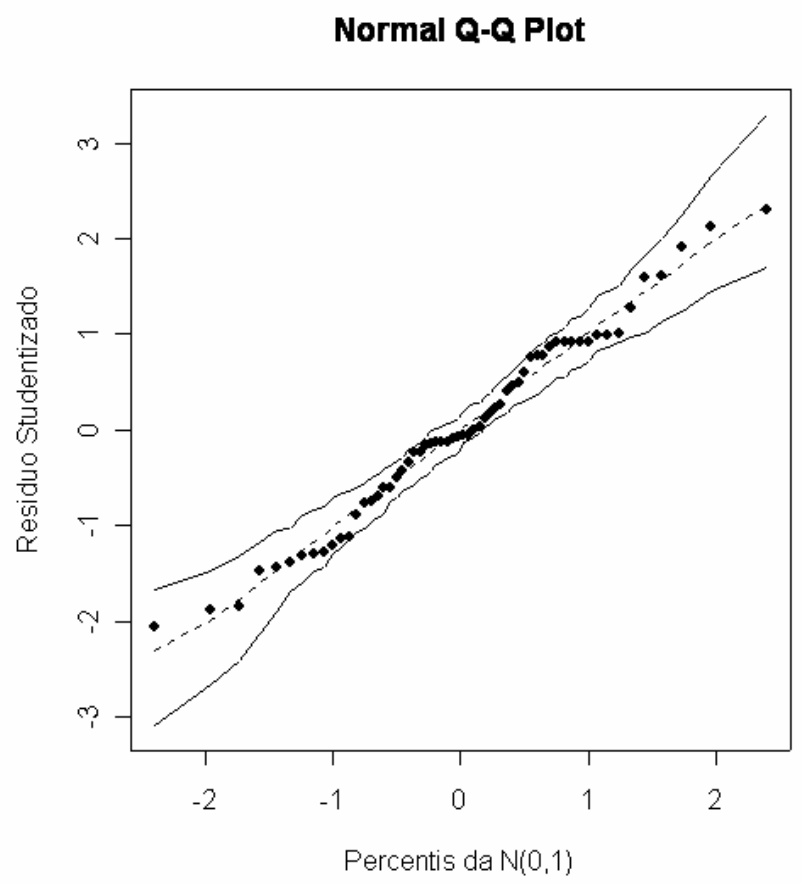

Gráfico 8: Envelope para o Modelo 4.

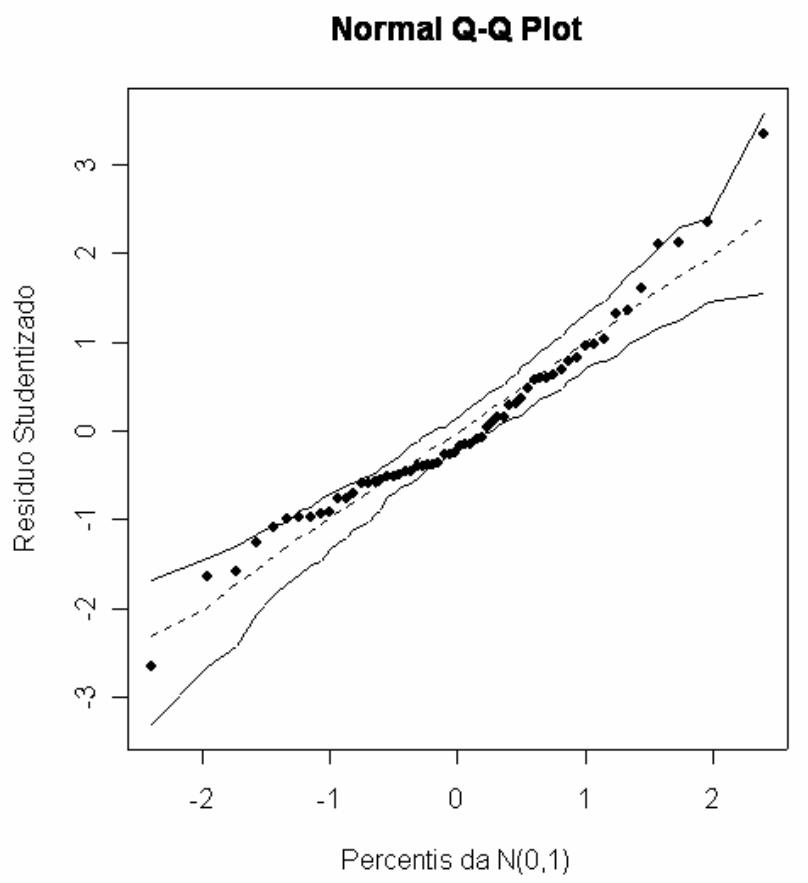


Os Gráficos 5, 6, 7 e 8 são gráficos de envelope dos modelos ajustados e podemos visualizar que todos estão bem ajustados, ou seja, os gráficos encontram-se dentro do intrevalo de confiança que foi estabelecido. Para confirmar que os modelos foram bem ajustados também foi realizada a análise de diagnóstico de modelos e esta análise também confirmou que os modelos foram bem ajustados. A partir desta análise todos os modelos foram reajustados, excluindo os pontos que eram aparentemente influentes. Em nenhum dos casos houve mudanças inferenciais ou grandes variações percentuais nas estimativas dos parâmetros, conforme podemos verificar na Tabela 2 (que será apresentada a seguir) desta forma, nenhum ponto foi excluído.

A seguir serão apresentados os Gráficos $(9,10,11$ e 12) que ilustram os resultados desta análise de diagnóstico dos modelos.

Após a adequação dos modelos escolhidos para realizar os ajustes, foram construídos os gráficos que ilustram as curvas de regressão ajustadas (apresentadas no Estudo III desta Tese).

Gráfico 9: Análise de Diagnóstico do Modelo 1.

Pontos de Alavanca

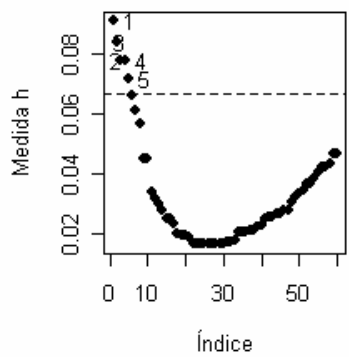

Pontos Aberrantes

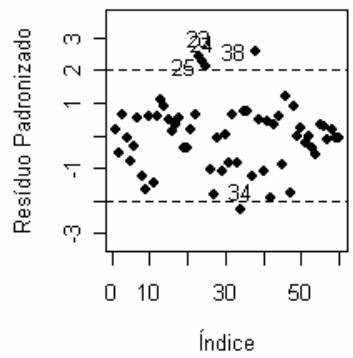

Pontos Influentes

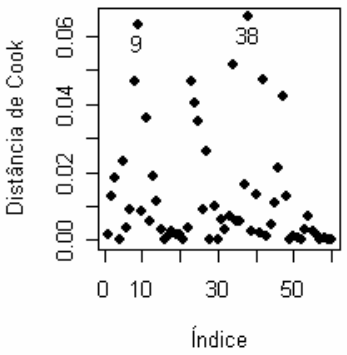

Homocedasticidade

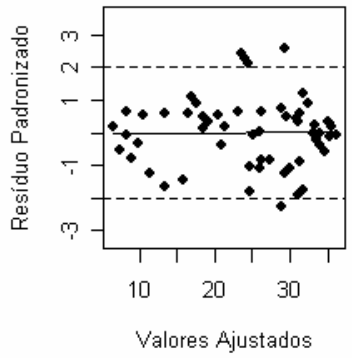


Gráfico 10: Análise de Diagnóstico do Modelo 2.
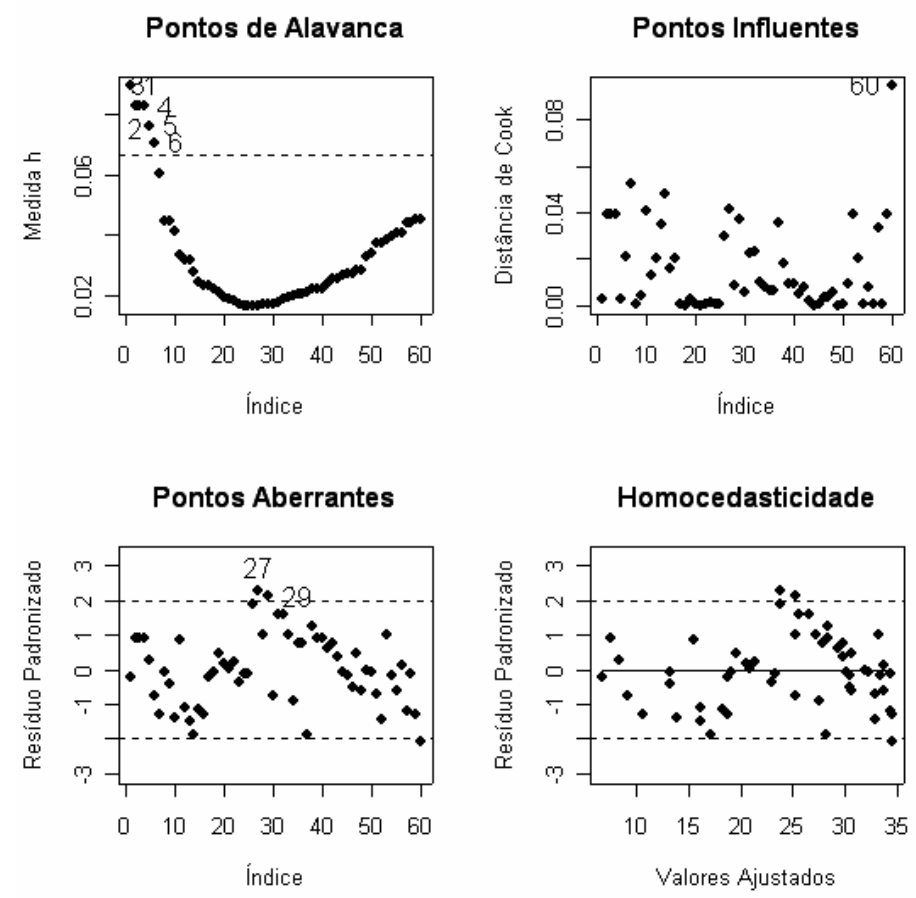

Gráfico 11: Análise de Diagnóstico do Modelo 3.
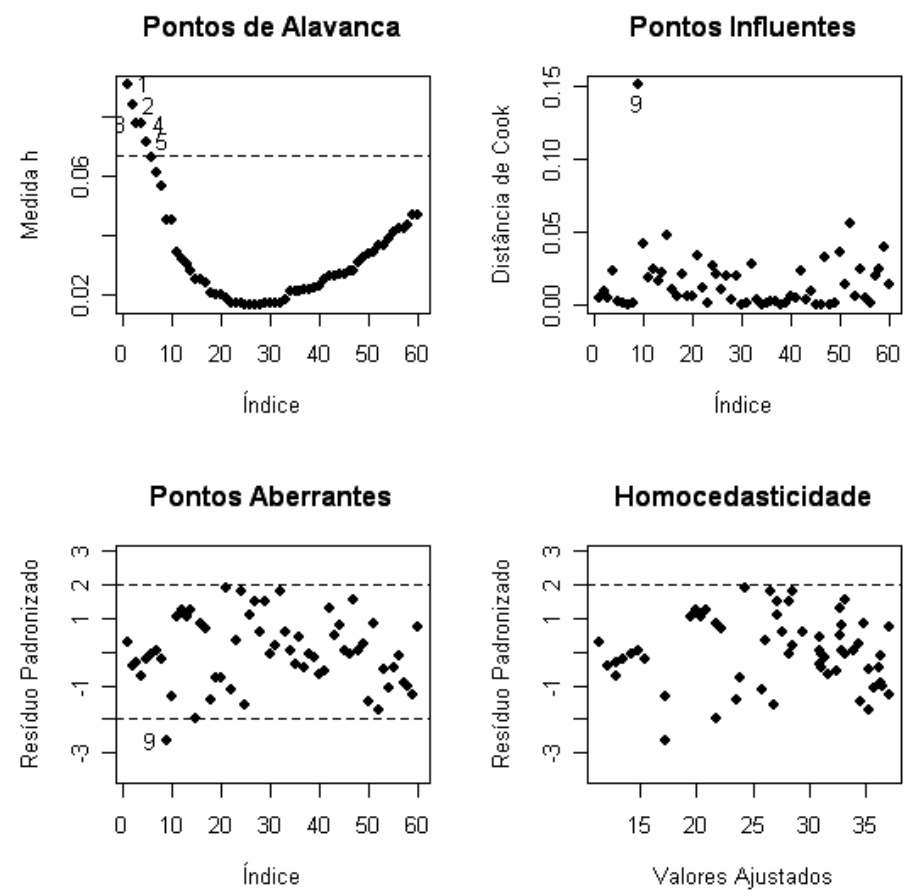
Gráfico 12: Análise de Diagnóstico do Modelo 4.
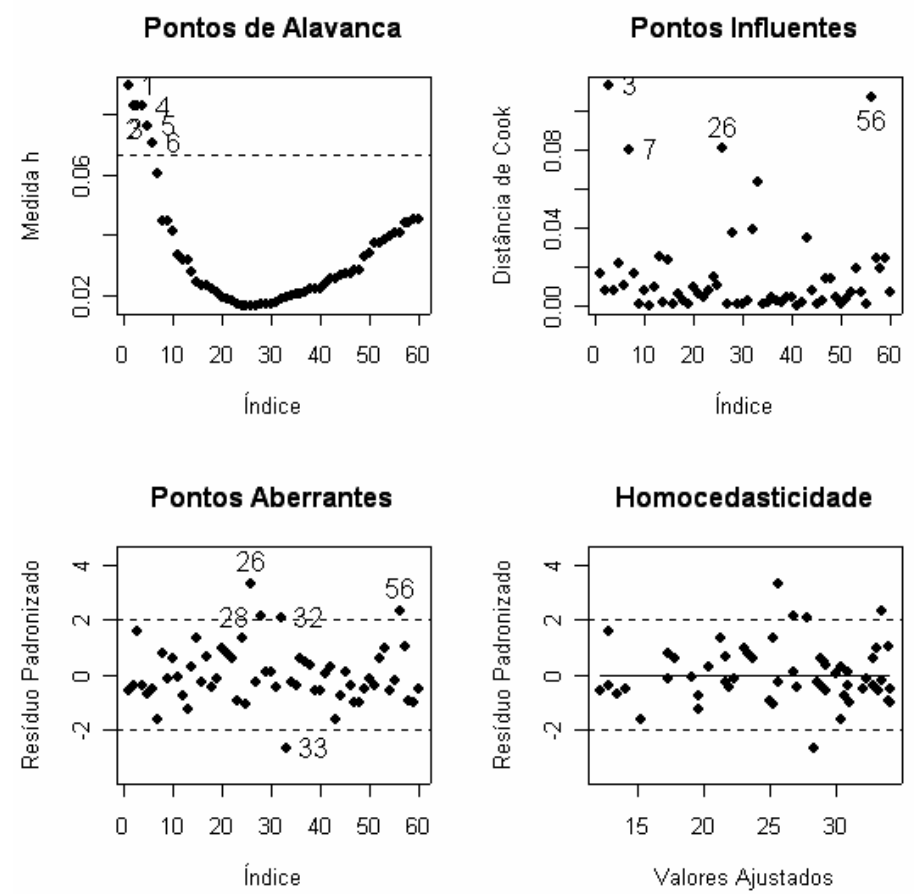
Tabela 2: Estimativas dos coeficientes dos modelos ajustados, níveis descritivos (p-valores) dos coeficientes e variações nas estimativas dos coeficientes após retirada dos pontos aparentemente influentes.

Modelo 1

\begin{tabular}{lrrrrrrr}
\hline & $\begin{array}{c}\text { estimativa } \\
\text { de } \boldsymbol{\alpha}\end{array}$ & p-valor & $\begin{array}{c}\text { variação na } \\
\text { estimativa }\end{array}$ & $\begin{array}{c}\text { estimativa de } \\
\boldsymbol{\beta}\end{array}$ & p-valor & $\begin{array}{c}\text { variação na } \\
\text { estimativa }\end{array}$ \\
\hline todas as observações & $-62,103$ & 0,000 & - & 21,594 & 0,000 & - \\
retirando a observação 38 & $-61,597$ & 0,000 & $-0,8 \%$ & 21,440 & 0,000 & $-0,7 \%$ \\
retirando a observação 9 & $-61,597$ & 0,000 & $-0,8 \%$ & 21,341 & 0,000 & $-1,2 \%$ \\
retirando as observações 9 e 38 & $-60,512$ & 0,000 & $-2,6 \%$ & 21,189 & 0,000 & $-1,9 \%$ \\
\hline
\end{tabular}

Modelo 2

\begin{tabular}{lrrrrrrr}
\hline & constante & p-valor & $\begin{array}{c}\text { variação na } \\
\text { estimativa }\end{array}$ & log(idade) & p-valor & $\begin{array}{c}\text { variação na } \\
\text { estimativa }\end{array}$ \\
\hline todas as observações & $-58,967$ & 0,000 & - & 20,639 & 0,000 & - \\
retirando a observação 60 & $-60,151$ & 0,000 & $2,0 \%$ & 20,959 & 0,000 & $1,5 \%$ \\
\hline
\end{tabular}

Modelo 3

\begin{tabular}{lrrrrrrr}
\hline & constante & p-valor & $\begin{array}{c}\text { variação na } \\
\text { estimativa }\end{array}$ & log(idade) & p-valor & $\begin{array}{c}\text { variação na } \\
\text { estimativa }\end{array}$ \\
\hline todas as observações & $-48,380$ & 0,000 & - & 18,781 & 0,000 & - \\
retirando a observação 9 & $-46,817$ & 0,000 & $-3,2 \%$ & 18,419 & 0,000 & $-1,9 \%$ \\
\hline
\end{tabular}

Modelo 4

\begin{tabular}{lrrrrrr}
\hline & constante & p-valor & $\begin{array}{c}\text { variação na } \\
\text { estimativa }\end{array}$ & log(idade) & $\begin{array}{c}\text { p-valor } \\
\text { estimativa }\end{array}$ & $\begin{array}{c}\text { variac̃o na } \\
\text { estimaçacs }\end{array}$ \\
todas as observações & $-39,253$ & 0,000 & - & 16,175 & 0,000 & - \\
retirando a observação 3 & $-40,474$ & 0,000 & $3,1 \%$ & 16,465 & 0,000 & $1,8 \%$ \\
retirando a observação 7 & $-38,266$ & 0,000 & $-2,5 \%$ & 15,943 & 0,000 & $-1,4 \%$ \\
retirando a observação 26 & $-39,377$ & 0,000 & $0,3 \%$ & 16,178 & 0,000 & $0,0 \%$ \\
retirando a observação 56 & $-38,362$ & 0,000 & $-2,3 \%$ & 15,932 & 0,000 & $-1,5 \%$ \\
retirando as observações 3 e 7 & $-39,472$ & 0,000 & $0,6 \%$ & 16,229 & 0,000 & $0,3 \%$ \\
retirando as observações 3 e 26 & $-40,643$ & 0,000 & $3,5 \%$ & 16,479 & 0,000 & $1,9 \%$ \\
retirando as observações 3 e 56 & $-39,555$ & 0,000 & $0,8 \%$ & 16,216 & 0,000 & $0,3 \%$ \\
retirando as observações 7 e 26 & $-38,423$ & 0,000 & $-2,1 \%$ & 15,955 & 0,000 & $-1,4 \%$ \\
retirando as observações 7 e 56 & $-37,341$ & 0,000 & $-4,9 \%$ & 15,692 & 0,000 & $-3,0 \%$ \\
retirando as observações 26 e 56 & $-38,466$ & 0,000 & $-2,0 \%$ & 15,930 & 0,000 & $-1,5 \%$ \\
retirando as observações 3,7 e 26 & $-39,679$ & 0,000 & $1,1 \%$ & 16,252 & 0,000 & $0,5 \%$ \\
retirando as observações 3,7 e 56 & $-38,513$ & 0,000 & $-1,9 \%$ & 15,971 & 0,000 & $-1,3 \%$ \\
retirando as observações 3,26 e 56 & $-39,704$ & 0,000 & $1,1 \%$ & 16,225 & 0,000 & $0,3 \%$ \\
retirando as observações 7,26 e 56 & $-37,478$ & 0,000 & $-4,5 \%$ & 15,698 & 0,000 & $-2,9 \%$ \\
retirando as observações 3,7,26 e 56 & $-38,702$ & 0,000 & $-1,4 \%$ & 15,988 & 0,000 & $-1,2 \%$ \\
\hline
\end{tabular}


APRESENTAÇÃO 
Ingressei no Curso de Fonoaudiologia da Universidade Estadual Paulista (Unesp) - Campus de Marília em 1995. Desde as primeiras disciplinas tive mais interesse por aquelas relacionadas à Linguagem. No $4^{\circ}$ ano tive a oportunidade de ser monitora no estágio supersionado da disciplina de Avaliação da Linguagem e pude confirmar meu interesse pela área de Linguagem e também foi muito prazeroso e gratificante o contato que tive com os alunos, nos momentos de orientação e supervisão, e isso já sinalizava meu interesse na área acadêmica.

Quando terminei a graduação, cursei algumas disciplinas como aluna especial no Instituto de Estudos de Linguagem da Unicamp - Campinas. Durante esse período pude conhecer uma outra abordagem teórica, porém percebi que para a minha atuação prática, aquela abordagem não estava sendo suficiente para responder às dúvidas que surgiam no dia-a-dia.

Então decidi conhecer uma outra perspectiva teórica e desta forma, optei em fazer o curso de Especialização na Universidade de São Paulo (Núcleo Específico: Alterações no Desenvolvimento da Linguagem). Foi, nesse momento, que comecei a encontrar algumas respostas teóricas e práticas para as minhas dúvidas e isso me motivou a continuar meus estudos e mais ainda, pude confirmar, a cada aula, a cada discussão, que deveria continuar na área acadêmica e por isso resolvi me inscrever para o processo de seleção para o Mestrado.

O tema escolhido para a realização deste trabalho também foi fruto das angústias vivenciadas na minha prática profissional. Em julho de 1999 fui contratada como Fonoaudióloga na APAE de Limeira e em março de 2000 passei a ser coordenadora da equipe interdisciplinar responsável pelos atendimentos aos préescolares. Após algum tempo, também assumi a coordenação da equipe de diagnóstico da entidade. Atuando na área de diagnóstico pude acompanhar, praticamente, todos os dias (e ainda, acompanho) as conseqüências e a gravidade de diagnósticos imprecisos, subjetivos, inadequados e até os danos causados pela falta deles. O prejuízo não mensurável aos pacientes também é estendido aos seus famliares, professores e para a própria entidade. 
O diagnóstico preciso e correto é fundamental para a eficácia dos passos posteriores, como o tratamento. A avaliação fonoaudiológica baseada em métodos subjetivos acaba resultando em diferentes formas de interpretação dos dados, o que compromete sobremaneira, a precisão diagnóstica. $E$ isso afeta diretamente 0 estabelecimento da Fonoaudiologia como uma Profissão séria e necessária.

Diante de todo este contexto, o tema referente à tradução de um instrumento de avaliação foi escolhido. Assim, foi feito um levantamento dos testes existentes no cenário internacional e o Test of Early Language Development - TELD - 3 foi escolhido.

A seleção de sujeitos normais surgiu da necessidade de encontrar valores de referência sobre o desempenho destes no Teste selecionado. Os dados obtidos, futuramente, poderão auxiliar no processo de diagnóstico, avaliação e acompanhamento de crianças que apresentem patologias da comunicação.

Inicialmente este trabalho foi tema da minha dissertação de Mestrado. Em junho de 2004, realizei o exame de qualificação e na ocasião, a banca examinadora, composta pela Prof ${ }^{a}$ Dra. Claúdia Regina Andrade Furquim e pela Prof $^{a}$ Dra. Suelly Limongi, sugeriram, tendo em vista, as perspectivas futuras deste projeto, verificarmos a viabilidade de uma transferência para o Doutorado Direto. Com isso, após discussão e análise desta possibilidade com a minha orientadora, entramos com a solicitação de transferência na Comissão de Pós-Graduação da Faculdade de Filosofia, Letras e Ciências Humanas - USP e a mesma foi autorizada.

Com a transferência e seguindo as recomendações da banca examinadora o projeto foi reestruturado, de modo que, no final deste trabalho, pudessémos concluir que o teste esteja apto ao uso, isso, se os nossos resultados fossem favoráveis à sua aplicação com crianças falantes do Português Brasileiro, como instrumento de avaliação. 
Para melhor análise e discussão dos dados coletados durante este processo (2002 a 2006) e maior agilidade no processo de publicação, a Tese aqui apresentada foi dividida em três estudos, sendo eles:

Estudo I - Tradução do Test of Early Language Development - Terceira Edição (TELD-3) para o Português Brasileiro.

Estudo II - Performance de crianças típicas falantes do Português Brasileiro no Test of Early Language Development (TELD-3) traduzido para o Português Brasileiro.

Estudo III - Análise comparativa da performance de sujeitos falantes do Português (Brasil) e sujeitos falantes do Inglês (EUA) no Test of Early Language Development - Terceira Edição (TELD-3).

A tradução de instrumentos de diagnóstico precoce na área de linguagem infantil poderá amenizar a carência destes no contexto da Fonoaudiologia Brasileira e também poderá propiciar, em um futuro próximo, a realização de pesquisas transculturais, podendo, desta forma, fornecer maiores esclarecimentos diagnósticos e terapêuticos das patologias da linguagem na infância. 
INTRODUÇÃO GERAL 
A Fonoaudiologia é a Ciência que tem como objeto de estudo a Comunicação Humana e seus distúrbios, englobando aspectos relacionados à promoção, habilitação, aperfeiçoamento e recuperação dos padrões comunicativos.

Andrade (1998) refere que a preocupação com a avaliação dos resultados dos tratamentos fonoaudiológicos têm sido uma tendência mundial, porque com a globalização, a saúde tornou-se uma questão fundamentalmente econômica.

Tal preocupação remete à necessidade de um constante questionamento por parte dos profissionais sobre a prática clínica e qual o ganho real do indíviduo submetido a um tratamento fonoaudiológico, quer em termos de sua eficácia (funcionalidade do tratamento), quer em termos de sua eficiência (comparação entre tratamentos), quer em termos de seu efeito - que forma o tratamento modifica a criança e seu padrão comunicativo (Andrade, 2004; Andrade e Juste, 2005).

Sistematizar medidas para analisar os resultados dos tratamentos é uma ação que pode trazer benefícios para os usuários e para os profissionais. Tais medidas poderão ampliar as possibilidades de promoção de novos serviços e avanços terapêuticos, tratamentos diferenciados poderão ser adotados segundo as características dos clientes e quanto maior o volume de dados mais refinada será a comparação, estimulando avanços e mudanças na ciência e na prática profissional (Andrade, 1998; Andrade 2004).

O primeiro ponto a ser destacado nestas discussões é a sistematização da avaliação pelo uso de provas específicas, objetivas e parametradas. Essa sistematização é valiosa uma vez as provas perceptuais de julgamento individual tendem à indução ao erro por serem fortemente dependentes da experiência e maturidade do profisisonal que conduzirá o procedimento de avaliação (Andrade e Juste, 2005).

A obtenção de dados objetivos representa um aspecto fundamental para a precisão diagnóstica. Além disso, a utilização de dados objetivos na avaliação inicial e nas reavaliações subseqüentes possibilita tanto uma consistência dos resultados 
obtidos quanto uma comunicação mais clara com os clientes e suas famílias e entre os profissionais (Andrade et al, 2004).

Avaliar é o processo de coletar informações válidas e confiáveis, integrandoas e interpretando-as para fazer um julgamento ou tomar uma decisão (Shipley e McAfee, 2004). A avaliação prevê o desenvolvimento e a aplicação de recursos e procedimentos que permitam descrever atributos selecionados para compor uma hipótese inicial de forma precisa e confiável (Perissinoto e Chiari, 2003).

Conforme apontado por Befi-Lopes (2003) e Reed (2004), por meio do processo de avaliação e diagnóstico, questões devem ser respondidas ou hipóteses devem ser testadas e formuladas, procedimentos específicos para isso devem ser selecionados, os dados coletados devem estar de acordo com estes procedimentos e os resultados devem ser utilizados na elaboração do plano de intervenção. Se questões certas ou suficientes não forem levantadas, as respostas corretas também não serão descobertas.

Para que reais objetivos do processo de avaliação e diagnóstico possam ser atingidos é necessária a utilização de instrumentos e procedimentos adequados.

No Brasil, diferentemente de outros países, existe uma escassez de instrumentos de diagnósticos direcionados à avaliação da linguagem na infância.

A falta de instrumentos formais e objetivos certamente reflete na definição de condutas terapêuticas e na elaboração de planos de intervenção. Conforme já descrito anteriormente, o primeiro passo para medir a eficácia de um tratamento oferecido é a sistematização dos procedimentos de avaliação.

Uma forma que alguns pesquisadores têm encontrado para amenizar este problema é traduzir instrumentos diagnósticos já disponíveis em outras Línguas ao invés de criar novos instrumentos. Além de amenizar esta carência, tal procedimento pode contribuir para um outro aspecto que também possui grande relevância científica, que se refere a realização de estudos cross-lingüísticos ou transculturais. 
Pesquisas transculturais na área de linguagem infantil podem trazer maiores esclarecimentos e compreensão acerca dos quadros de alterações e de suas especificidades nas diferentes Línguas.

Tendo em vista essas considerações, o objetivo geral desta Tese foi verificar a performance de crianças típicas falantes do Português Brasileiro no Test of Early Language Development - Terceira Edição (TELD-3).

Os resultados obtidos poderão ser utilizados como parâmetros para futuras pequisas com o referido teste, contribuindo para um maior aprimoramento do diagnóstico na área de linguagem infantil. 